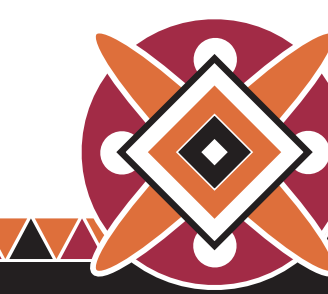

\title{
Journal of Student Affairs in Africa
}

The impact of Covid-19 on Student Affairs in Africa

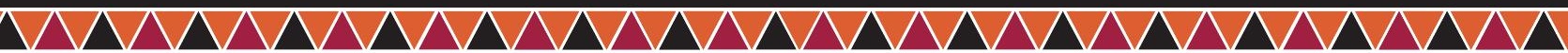

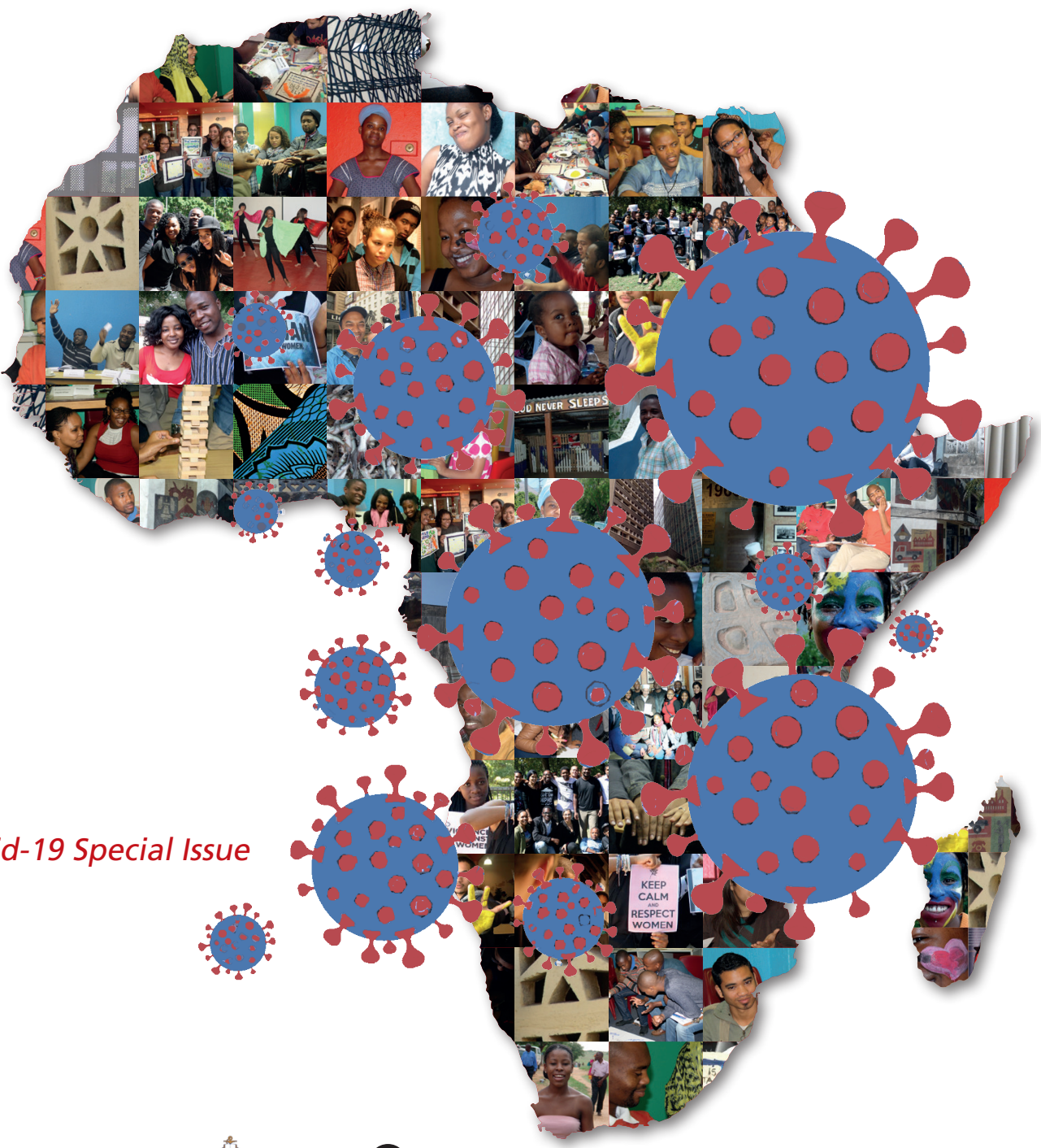

AFrICANM@DIA OPEN 


\section{Journal of Student Affairs in Africa}

The Journal of Student Affairs in Africa (JSAA) is an independent, peer-reviewed, multi-disciplinary, openaccess academic journal that publishes scholarly research and reflective discussions about the theory and practice of student affairs in Africa.

\section{Vision and mission}

The JSAA aims to contribute to the professionalisation of student affairs in African higher education by publishing high-quality scholarly articles, research and reflective discussions by academics, professionals, researchers and students about student affairs and services in African higher education.

The JSAA strives to be the foremost academic journal dealing with the theory and practice of the student affairs domain in universities on the African continent, and an indispensable resource for national policy makers, the executive leadership of universities and colleges dealing with student affairs, deans of students and other senior student affairs professionals, as well as institutional researchers and academics and students focused on the field of higher education studies and student affairs.

\section{Focus and scope}

The JSAA considers theoretical, practice-relevant and reflective contributions from across the scholarly field of student affairs and professional domains of student development/student affairs, taking due cognisance that the scope is broad, fluid and context-dependent.

The scope of JSAA is indicated by keywords such as: student affairs, student career development, student counselling, student development theory and research, student discipline, student engagement, student experience, student finances and financial aid, student housing, disability/disabled students, student leadership and governance, student life cycle, student living and learning, student movement, student organisations, student orientation, student policy, student politics and activism, student sport, student support, academic development (and its intersection with the student affairs co-curriculum), graduate attributes, and teaching and learning support. This list of keywords is not exhaustive. Our key focus area is the core functions of student affairs and services in Africa.

Submissions are encouraged from scholars and reflective practitioners from across the globe. Submissions must be original and relevant to the mission, scope and focus of the journal. Especially encouraged are submissions from African scholars and professionals working in higher education on the African continent. Submissions dealing with student affairs issues from other contexts (e.g. the African diaspora; other emerging economies; developed countries) that are transferable to the African context are also considered for publication. Submissions must be made on the JSAA online submission website. Please register, $\log$ in and submit your manuscript at: https://upjournals.up.ac. za/index.php/jsaa

www.jsaa.ac.za

(c) 2021 Journal of Student Affairs in Africa

ISSN 2311-1771 (print)

ISSN 2307-6267 (electronic)

$J S A A$ is available open access at: www.jsaa.ac.za

This work is licensed under the Creative Commons Attribution Share-alike 4.0 International Licence. Indexed in the Directory of Open Access Journal, African Journals Online (AJOL) at www.ajol.info, and the Education Resources Information Center (ERIC). DHET-accredited scholarly journal in South Africa.

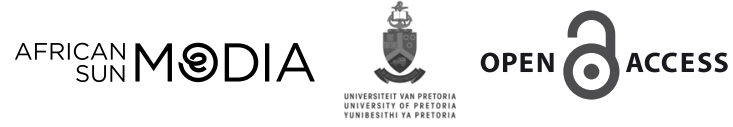




\section{Editorial team}

\section{Editor-in-chief}

Prof. Teboho Moja, New York University

\section{Editorial executive}

Prof. Teboho Moja, New York University

Dr Birgit Schreiber, Africa Centre, Alberts-Ludwig-Universität Freiburg (Book Review Editor)

Prof. Thierry M. Luescher, Human Sciences Research Council

Prof. Saloshna Vandeyar, University of Pretoria

Prof. Sioux McKenna, Rhodes University

Dr Bekele Workie Ayele, Kotebe Metropolitan University

Dr Martin Mandew, University of the Free State

Dr W.P. Wahl, University of the Free State

Ms Maretha Joyce, Stellenbosch University (Journal Manager)

\section{International editorial advisory board}

Dr Lisa Bardill Moscaritolo, American University of Sharjah

Prof. Cecile Bodibe, Empowaworx

Dr John Butler-Adam, SA Journal of Science

Prof. Ronelle Carolissen, Stellenbosch University

Prof. Jon Dalton, Emeritus, Florida State University

Dr Tom Ellett, New York University

Emerita Prof. Magda Fourie-Malherbe, Stellenbosch University

Prof. Ransford E.V. Gyampo, University of Ghana

Dr Manja Klemenčič, Harvard University

Prof. Patrício Langa, Universidade Eduardo Mondlane

Prof. Christina Lunceford, Bowling Green State University

Dr Ibrahim Ogachi Oanda, CODESRIA

Dr Adesoji Oni, University of Lagos

Prof. Dawn Person, California State University Fullerton

Prof. Akilagpa Sawyerr, Ghana Academy of Arts and Sciences

Prof. Juma Shabani, University of Burundi

Distinguished Prof. John Schuh, Emeritus, Iowa State University

Distinguished Prof. Vincent Tinto, Emeritus, Syracuse University

Prof. Nan Yeld, University of Cape Town

\section{Publishing and website}

MrWikus van Zyl, African Sun Media

Ms Davida van Zyl, African Sun Media

Ms Heather A. Thuynsma, University of Pretoria

Dr Johann van Wyk, University of Pretoria 


\section{Contents}

\section{Editorial}

The Impact of Covid-19 on Student Affairs and Higher Education in Africa

Thierry M. Luescher, Birgit Schreiber, Teboho Moja, Martin Mandew, W.P. Wahl E Bekele Ayele v

\section{Research articles}

Student Affairs and Services during Covid-19 in Africa: Mitigating the Pandemic's Impact on Student Success

Birgit Schreiber, Thierry M. Luescher, Brett Perozzi \& Lisa Bardill Moscaritolo 1

Challenges and Interventions of eLearning for Under-resourced Students amid Covid-19 Lockdown: A Case of a Zambian Public University

Charity L.M. Kombe \& Dingase E. Mtonga 23

Mitigating the Implications of Covid-19 on the Academic Project at Walter Sisulu University in South Africa: A Proposed Framework for Emergency Remote Teaching and Learning

Rushiella N. Songca, Clever Ndebele \& Munienge Mbodila 41

Rapid Orientation of Students for Emergency Remote Learning during the Covid-19 Lockdown

Danie de Klerk, Greig Krull \& Tshepiso Maleswena $\mathbf{6 1}$

The 'Double Transition' for First-Year Students: Understanding the Impact of Covid-19 on South Africa's First-Year University Students Annsilla Nyar 77

The Effect of the Covid-19 Pandemic on Students and the Living and Learning Spaces at a South African University

Blessing Kanyumba \& Nondumiso Shabangu 93

Disguised Blessings amid Covid-19: Opportunities and Challenges for South African University Students with Learning Disabilities

Ndakaitei Manase 107

Online Work Readiness Programme: Ready, Set, Go!

Belinda Janeke 119

\section{Reflective practice}

Responding to Covid-19: Experiences of Ashesi University's Student Affairs Team Millicent Adjei, Nina N.A. Pels \& Vanessa N.D. Amoako 135

Adaptation of Student Support Services Considering Covid-19: Adjustments, Impact, and Future Implications

Munita Dunn-Coetzee, Elmien Sinclair, Marcia Lyner-Cleophas, Jaco Brink, Marquard Timmey E Charl Davids 157

Leveraging Ed-tech in the Co-curricular Space: Reflections on Design and Development Aspects of the Class Representative Induction Programme at the University of Cape Town Christine Immenga 167 
The Impact of the Covid-19 Pandemic on Student Affairs Practitioners: A Reflective Case Study from Bindura University of Science Education in Zimbabwe Sebastian Mutambisi, Dora Dorothy Murasi \& Crispen Mazodze 183

From Didactics to Datafication: A Critical Reflection on Virtual Learning Environments and the Production of Space

Taryn Bernard 197

Inclusion in Times of Covid-19: The Case of International Students in South Africa Samia Chasi \& Orla Quinlan 205

Disability Unit Practitioners at Stellenbosch University: Covid-19 Pandemic Reflections Marcia Lyner-Cleophas, Lizelle Apollis, Ilse Erasmus, Melanie Willems, Latashe Poole, Meagan Minnaar \& Pippa Louw 223

\section{On campus}

Reflections on the South African Higher Education Leadership and Management (HELM) First Virtual Summit, 9-11 December 2020: Leadership for a Sustainable and Resilient Higher Education System in an Age of Complexity and Change Bernadette J. Johnson 235

\section{Book reviews}

Veletsianos, G. (2020). Learning Online: The Student Experience. Baltimore, Maryland: Johns Hopkins University Press.

Reviewed by Tadd Kruse $\mathbf{2 3 9}$

Hayward, F.M. (2020). Transforming Higher Education in Africa and Asia: Strategic Planning and Policy. Albany, New York: SUNY Press.

Reviewed by Patrick Swanzy 243

IASAS Global Summit 246

Conference announcements 248

Author biographies 249

Thank you to our reviewers 263

Publications by African Sun Media 264

Submissions 265 


\title{
EDITORIAL
}

\section{The Impact of Covid-19 on Student Affairs and Higher Education in Africa}

\author{
Thierry M. Luescher, ${ }^{\mathrm{i}}$ Birgit Schreiber, ${ }^{\text {ii }}$ Teboho Moja ${ }^{\text {iii }}$ Martin Mandew, ${ }^{\text {iv }}$ W.P. Wahlv ${ }^{\mathrm{v}}$
} Bekele Ayele vi

\section{A Global Pandemic with Local Realities}

Over the course of their history, African universities have had to contend with many crises, and they have learnt to quickly adapt to ensure that conditions for teaching and learning, as well as student development and support, continue. Political turmoil, economic downturns, fiscal austerity, social conflicts, staff and student strikes, virus outbreaks and even civil wars have forced universities into circumstances that require difficult decisions in a context of great uncertainty and complexity (Fomunyam, 2017). While such disaster periods and events often have deeply disruptive effects on the university community, they tend to last a limited time only. However, the choices made during such periods of crisis frequently outlive the crisis itself and come to define a university's functioning well after the crisis has passed (Adedire, 2018; Chetty \& Luescher, 2021).

In the past, crises that impacted African universities were typically limited to a particular region, nation or institution in their scope. In 2020, however, the global Corona virus disease (Covid-19) came to affect universities comprehensively and worldwide in an unprecedented manner (Schreiber \& Ludeman, 2020). African universities across the

i Prof. Thierry M. Luescher is the Research Director for Post-schooling and Work in the Inclusive Economic Development Division of the Human Sciences Research Council (HSRC), Cape Town, South Africa, and Associate Professor: Higher Education affiliated to the University of the Free State, Mangaung, South Africa. ORCid: 0000-0002-6675-0512. Email: tluescher@hsrc.ac.za

ii Dr Birgit Schreiber is a member of the Africa Centre for Transregional Research at Alberts-LudwigUniversität Freiburg, Germany, and the Vice-President of IASAS and a member of the JSAA Editorial Executive. She is a Senior Consultant for Higher Education Leadership and Management and for Stellenbosch University, South Africa. ORCid: 0000-0003-2469-0504. Email: birgitschreiber@sun.ac.za; birgitdewes@gmail.com

iii Prof. Teboho Moja is Clinical Professor of Higher Education, New York University, U.S.A. She is alo a Visiting Research Fellow at the Centre for the Advancement of Scholarship, University of Pretoria, South Africa, and an Extraordinary Professor at the Institute of Post-School Studies, University of the Western Cape, South Africa. She is JSAA's Editor-in-chief. ORCid: 0000-0001-6343-3020. Email: teboho.moja@nyu.edu

iv Dr Martin Mandew is the Principal of the Qwaqwa Campus of the University of the Free State, South Africa.. Email: mandewMDPA@ufs.ac.za

v Dr W.P. Wahl has been involved in student affairs for almost 19 years and currently serves as Director: Student Life at the University of the Free State (UFS), South Africa. ORCid: 0000-0000-0000-0000.

Email: wahlwp@ufs.ac.za

vi Dr Bekele Ayele is a senior lecturer at Kotebe Metropolitan University (KMU), Addis Ababa, Ethiopia. Email: bekeleworkie@gmail.com 
continent needed to respond to the global health threat and state-instituted lockdown restrictions. University leaders across the continent and globally had to decide on various kinds of emergency measures and reimagine teaching and learning and student engagement and support in order to 'save the academic year' (Dell, 2020; Moja, 2021). The leadership of Student Affairs and Services(SAS) were typically part of such decision-making from the start (Schreiber et al., 2020; Perozzi et al., under review). The participation of SAS leaders and practitioners in the decision-making was crucial as they often are the first port of call when students are in dire straits and require support, be it social, psychological counselling, academic advising, student governance related, access to resources, etc. And yet, even SAS practitioners were not quite prepared for the unprecedented crisis that was about to hit the higher education environment locally, on the African continent, and at a global level. This special issue provided SAS practitioners with an opportunity to reflect on their work, its appropriateness, and to implement risk-mitigating strategies even as the crisis was unfolding.

As campus after campus closed, leaving only a remnant of 'essential services' to continue on site in some cases, learning in most universities was either suspended or moved online in some form of 'emergency remote teaching' (Adotey, 2020; Commonwealth of Learning, 2020; Dell \& Sawael, 2020). Similarly, most SAS provision either moved online or was suspended if they were considered 'non-essential' services (Ayele, 2020). Key higher education actors like the Association of African Universities (AAU) swiftly realised that any form of online learning would potentially exclude many students across the continent who would normally benefit from a campus environment that made up for the lack of a conducive home learning environment or provide other forms of essential learning support (AAU, 2020; Schreiber et al., 2020). Thus, on the one hand, the AAU called on African universities to implement online learning urgently, while also urging African governments to invest in digital infrastructure in rural areas and promote access for all those unable to access online educational services (AAU, 2020; Chetty \& Luescher, 2021).

Student Affairs practitioners have been challenged to respond in innovate ways to meet the diverse needs of different students, enhance student learning and development, and advance the social justice imperative that underpins and drives SAS work.

As much as most governments issued "one size fits all” instructions to universities, on the ground the Student Affairs practitioners had to contend with their diverse local realities. Universities with international students and those with students from far-flung regions faced different challenges in assisting their students' speedy return home than others with a more local student body. There are instances where international students were sent home without financial help from their institutions or assistance from home. Some highly resourced universities were able to issue students who did not have electronic devices like a laptop or tablet with such, along with data vouchers and so forth. Some universities who already used advanced online learning platforms were able to expand their use and deliver learning in an advanced online learning environment while others had to improvise (Chetty \& Luescher, 2021). Universities who had a student body made up largely of financially needy students who needed to return to their communities, often permeated by 
crime and violence, needed to mitigate the impact of these factors and support students or bring them back to campus (UNDP, 2020). Some universities, which had faced crisis prior to the Covid pandemic, had experienced Student Affairs staff and programmes that were attuned to crisis and remote contexts (Schreiber et al., 2020).

Considering higher education and SAS in Africa during the Covid-19 pandemic while moving forward, there are a number of lessons we need to keep in mind. Firstly, the experience of past crises on the African continent and beyond teaches that emergency protocols often turn into, or inform, new standard operational policy after a crisis subsides (Chetty \& Luescher, 2021). In light of this, it is clearly imperative to describe and analyse these moments of crisis, the conditions that gave rise to them, the ways the crisis was managed, and the changes in policy and practice that ensued from it, so as to be able to reflect on them, theorise and learn from them.

The closure of institutions coupled with remote teaching, added more pressure on the students and SAS practitioners. The switch to remote teaching laid bare the enormity of the digital divide on the African continent in its starkest and most iniquitous form as students in far-flung remote rural areas were unable to get access to academic programme. Quintana and Quintana (2020) and Händel et al. (2020) indicate that during the pandemic there were many factors that led to compounded anxiety amongst students including "grade anxiety", absence of adequate infrastructure and overall unpreparedness of institutions and students. There were concerns about the mental health of students and staff and in some instances, institutions added more service and resources to address the challenges (Moja, 2020). Some of the issues that came up for students as a result of being removed from their campuses had to do with them not having appropriate learning spaces and an increased food insecurity as they depended on their financial support that includes expenses related to their living expenses. For a foreseeable future there is a strong likelihood of studies to be conducted to extract more of the lessons learned and the long-term impact of the pandemic.

\section{Producing the JSAA Covid-19 Special Issue}

The idea for a special Covid-19 issue of the Journal of Student Affair in Africa was born with an email of one of the founding editors, Prof. Thierry Luescher, to the Editorial Executive of $J S A A$ on 14 March 2020 in which he proposed that: (1) a call for contributions to a special issue should be developed and sent out to SAS practitioners across the African continent and globally; (2) the special issue should publish practitioner reflections on the impact of Covid-19 on SAS in their respective contexts; (3) a task team of editors should be established to oversee the rapid realisation of the special issue. On the same day, JSAA's Editor-in-Chief, Prof. Teboho Moja and the other founding editor, Dr Birgit Schreiber, responded affirmatively. Within a week the task team of editors was established and a call for papers finalised for distribution. Before the end of the month, an advert had been placed in the University World News Africa Edition to call for papers.

The $J S A A$ call for papers was short and to the point:

"The Covid-19 epidemic has sparked an unprecedented challenge for higher education in general and Student Affairs and Services in particular. The different ways that national ministries, higher education 
institutions and Student Affairs departments and units are responding to the challenge and opportunities in different contexts - by means of social distancing, introducing blended and online development, support and learning, closure, etc. - and the way this affects and implicates the provision of co-curricula and student development and support services, the Student Affairs practitioners, as well as students in general and specific student groups, urgently needs to be documented and presents an opportunity for sharing experiences and learning. The Journal of Student Affairs in Africa is preparing a special issue on 'The Impact of Covid-19 on Higher Education and Student Affairs in Africa' in which we publish the research and reflections of Student Affairs practitioners, university leaders, policy makers, researchers, students, and journalists on the impact of Covid-19 in the context of African higher education and other relevant contexts."

The response from the African and global Student Affairs community was extraordinary. By 31 May 2020, the editorial task team had received 110 proposals from SAS practitioners and scholars hailing from Botswana, Eswatini, Ethiopia, Ghana, Ivory Coast, Kenya, Lesotho, Liberia, Malawi, Namibia, Nigeria, Rwanda, South Africa, Sudan, Tanzania, Uganda, Zambia, Zimbabwe, as well as from Bangladesh, Germany, India, the United Arab Emirates and the United States of America. The task of assessing the abstracts fell upon

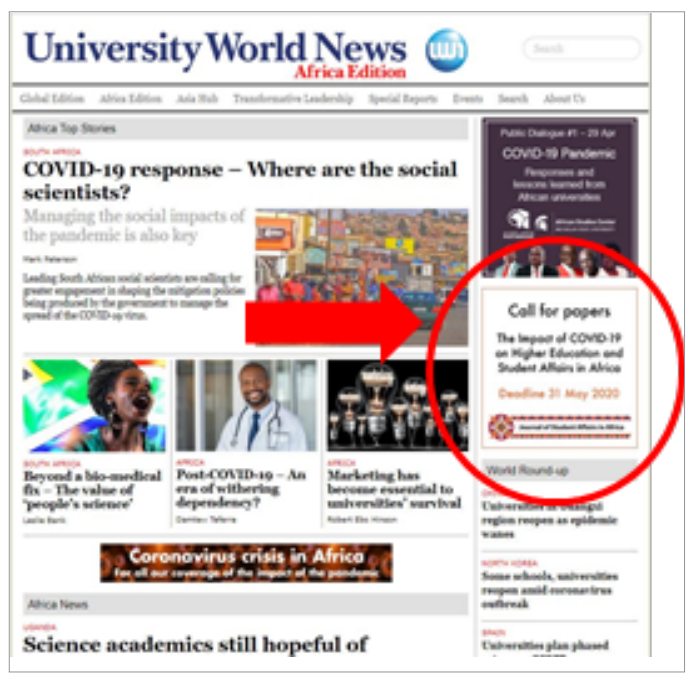
the editors. Within two weeks, they gave the green light to thirty proposals from twelve countries and many more university contexts. Their assessment was guided by the normal assessment criteria of $J S A A$ : scope and interest, originality, significance, and scholarship. Many proposals had to be redirected to journals that focus on teaching and learning in higher education or other specialised aspects like ICT in education.

Within only three months, the authors completed full papers from their proposals. Of the initial thirty accepted proposals, twenty full papers were received and distributed amongst the editorial task team who vetted each of them individually. It was eminently clear that African Student Affairs practitioners had a lot to report on from the impact of the pandemic on their work, staff and students; however, in completing the papers some colleagues were also overrun by crisis work and eventually could not submit. In some cases of submitted papers, the editors requested some corrections from the authors before sending the revised manuscripts to two independent experts for a double-blind review process. The peer review process, which started in December and lasted into late February in some cases, removed a further five papers from the final list. 


\section{The Contents of the Special Issue}

The present special issue is the result of this yearlong process. It is being published while the world is still in the throes of the pandemic, with many countries experiencing a "third wave", while the recently approved vaccines provide the only light at the end of the tunnel. In an analogous sense, this issue presents SAS practitioners' efforts at re-engineering a super-aircraft in mid-flight in an effort to "save the academic year" while "leaving no student behind". As can be seen, it shines like a light in the darkness: in the midst of the tragic of pandemic, a great deal of knowledge has been created. While virologists were developing vaccines, Student Affairs professionals and scholars across Africa invented new ways of operating and supporting the diverse learning needs of future virologists and their peers across the disciplines. The shape and size of the special issue is therefore as follows:

- The issue publishes 15 peer-reviewed articles comprising of eight research articles and seven reflective practitioner accounts.

- There are contributions from seven countries providing in-depth studies from nine different universities.

- Articles focus on career services, disability services, first year students, international students, living and learning support, students with learning disabilities, student governance, Student Affairs staff, the use of student data, and under-resourced students. In addition there is an article that compares the response of SAS to the pandemic in Africa with that of SAS professionals across the globe.

- More than half of the authors are female Student Affairs practitioners and/or researchers.

The first article in this issue is based on a global survey conducted in May 2020 by a group of Student Affairs professionals and scholars from Germany, South Africa, the United Arab Emirates and the United States of America (Schreiber et al., 2021). Their study explores how SAS mediates the impact of personal, socio-cultural and familiar, macro-infrastructural and systemic influences on student success in the context of Covid-19. The article compares survey data collected from SAS practitioners from across the African continent with that of SAS practitioners from other world regions to show the similarities as well as differences in their respective responses to the pandemic. The article proposes a systemiccontextual model of Student Affairs' role in higher education to illustrate the domains that impact on student success and where SAS plays a mitigating role in supporting students.

The second research articles comes from Zambia. In this article Kombe and Mtonga, from Mulungushi University in Kabwe provide empirical evidence in relation to the challenges and interventions of eLearning for under-resourced students in a Zambian public university during the pandemic. This article provides deeper insight into how higher education practitioners and administrators could provide enhanced eLearning support to students, especially students hailing from disadvantaged backgrounds.

Authors Songca, Ndebele and Mbodiba from Walter Sisulu University in South Africa argue that it is unrealistic for universities to advocate for a fully online approach to teaching and learning during Covid-19. They present a model that could be useful to respond to 
Covid-19, underpinned by a framework that accommodates students who choose online learning, students with intermittent access to online and finally students who cannot access online learning.

De Klerk et al. (2021) from the University of the Witwatersrand in South Africa researched the efficacy of an online orientation programme aimed at preparing students to rapidly move to emergency remote learning as a result of a nation-wide lockdown and highlight the need for support of adjustment processes to promote online engagement.

Nyar from the South African National Resource Centre for the First-Year Experience and Students in Transition (SANRC) at the University of Johannesburg, uses the notion of a 'double transition' to conceptualise the two transitions that first-year students face in the context of Covid-19: navigating their entry into the unfamiliar terrain of academia while simultaneously navigating the Covid-19 pandemic. It concludes with four key strategies for supporting first-year students as the pandemic continues.

Kanyumba and Shabangu from the Durban University of Technology conducted a qualitative research study to create a deeper understanding of the ways in which the Covid-19 pandemic influenced the living-learning environment of students in residences.

The broad scope of SAS is highlighted by Manase from the University of the Free State who discusses the pedagogical challenges and opportunities that emerged from remote development, teaching and learning for students who live and learn with disabilities. Her study reveals how some of the Covid-19 related changes offer positive shifts in terms of overcoming social and academic barriers for students with disabilities.

A second study from the University of the Free State by Janeke looks at career development programme in the context of Covid-19. Janeke examines the university's online work readiness programme and illustrates the innovations involved in migrating a career development programme into an online space as well as the impact this career development programme has even under these circumstances.

The set of peer-reviewed reflective practitioner accounts opens with the article by Adjei, Pels and Amoako from Ashesi University in Ghana. Using Schlossberg's Transition Theory the authors analyse the transitional experiences of students amidst the Covid-19 pandemic. Their findings suggest that i) advising, ii) engagement, and iii) timely online support interventions, contributed immensely to students' success in transitioning from in-person to remote learning.

The second reflective article by Dunn-Coetzee and her colleagues at Stellenbosch University in South Africa highlights the challenges that faced Student Affairs professionals when their mode of operation changed quickly to virtual operations. The authors emphasise the importance of making adjustments under those circumstances for the sake of minimising a negative impact on students as well as negative impact on their relationship with students.

Educational technology is used increasingly in the SAS space and Immenga from the University of Cape Town discusses in her article how technological tools can be leveraged to aid in the delivery of co-curricular programmes. Her article particularly deals with the training of class representatives as part of the university's suit of training opportunities for 
students having representative mandates in university governance. She reflects on working with a design team to transition the face-to-face synchronous training of approximately 420 class representatives to an online mode of delivery.

The article by Mutambisi, Murasi and Mazodze from Bindura University of Science Education in Zimbabwe focuses on the pandemic's impacts on the composition, wellbeing and skills requirements of Student Affairs professionals and how the unexpected disengagement with students impacts on SAS. It illuminates some influences which are not immediately visible, but significant. They include having to adjust to new work arrangements, loss of income, mental health problems and resource constrains. Training and development, social media, employee support systems and employee incentives were catalysts in the early adoption of change.

How has the pandemic further complicated the idea of transformation of higher education? A key feature of higher education's response to the pandemic has been the mass migration of the delivery of the curriculum from physical space to cyberspace or Virtual Learning Environments. In her article, Bernard reflects on the problematic and challenging idea of "space" and its impact on the academic project, and specifically on students traditionally categorised as disadvantaged and requiring "special" interventions.

The reflective practitioner account of Chasi and Quinlan illustrates that our lens needs to include international students when deliberating national considerations for higher education. It highlights the specific challenges and constraints that international students faced in light of Covid-19 related restrictions including travel bans, university closures and the national lockdown. They thus explore different aspects of the international student experience including travel home, communication, accommodation and immigration issues.

Finally, Lyner-Cleophas et al. argue that the biggest potential threat of Covid-19 was and still remains the exacerbation of structural inequalities and systemic inequities within the higher education system. How do SAS practitioners practically ensure that students with disabilities are not further excluded as we switch to emergency remote teaching and learning? The authors reflect on the efforts to make existing policies and practices responsive to the needs of students with disabilities in the new and unprecedented environment.

In our 'on campus' section, Bernie Johnson of Wits reflects on the higher education leadership and management (HELM) summit held by Universities South Africa (USAf) in December 2020 and calls explicitly for a wider understanding of factors that support student and university success. She argues that a "supportive political economy is needed for transformation across the sector. We cannot anchor the university if municipalities for example are falling apart in the local contexts". Johnson thus emphasises the role of social, cultural, economic and political context is creating a milieu in which universities and students can indeed be successful, be this in face to face learning or in remote conditions.

Our Covid-19 special issue includes two book reviews. The first is by Tadd Kruse who reviews Learning Online: The Student Experience, authored by George Veletsianos, which puts the student experience into the centre of the learning and development debates. 
The second book review is by Patrick Swanzy who reviews Fred Hayward's Transforming Higher Education in Africa and Asia: Strategic planning and policy (2020). Swanzy highlights that Hayward's discussion on the critical role of strategic planning - be this done intentional or left to unintentional factors - is the critical aspect to building high-quality higher education.

\section{JSA A Organisational}

The Editorial Executive of $J S A A$ would like to announce an exciting development. Since mid-last year we have been in conversation with colleagues in the Education Faculty of the University of Pretoria about hosting the JSAA at Pretoria University. JSAA was founded in 2013 at the University of the Western Cape with technical support from the UWC library and incubation support from the open access scholarly publisher, African Minds. In the course of 2016, the Journal moved to Stellenbosch University, which sponsored a number of issues, hosted and administered the Journal on its e-journal platform, and provided administrative support. We are now happy to announce the move of JSAA to the University of Pretoria's collection of scientific journals. The JSAA Covid-19 Special Issue is the first issue hosted at the University of Pretoria. In addition to hosting the Journal on its e-journal platform (https://upjournals.up.ac.za/index.php/jsaa) and supporting the journal technically, the University of Pretoria has also committed to a level of financial and administrative support for the Journal that will ensure that $J S A A$ continues to operate as a diamond open access journal. This means that we are able to continue to offer free access to our readers (no subscription cost or article-purchase cost) and free publishing for authors (no article processing charges or page fee). We are exceptionally proud of being able to continue this diamond open access format for authors and readers as our contribution to the professionalisation of Student Affairs in Africa.

Finally, the $J S A A$ Editorial Executive wishes to thank the peer reviewers of articles reviewed in 2020 (and, in some cases, published in Volume 8) for their time and expertise. As customary, we list all our distinguished peer reviewers in the first issue of the year. This list serves to certify their commitment to the academic project as trusted peers, and more especially their contribution to the scholarly development and professionalisation of Student Affairs in Africa.

\section{References}

AAU (Association of African Universities) (2020). Appeal to African Ministers of Higher Education: Opportunities for building resilient educational institutions. Accra. https://bit.ly/3sYecv0

Adedire, A.A. (2018). Civil Wars and the African Universities: The University of Ibadan Example, 1967-1970. Ufahamu: A Journal of African Studies, 40(2). https://bit.ly/3aK9BGr

Adotey, S.K. (2020). What will higher education in Africa look like after Covid-19? World Economic Forum. https://bit.ly/2S4Pqwl [Accessed 21 August 2020].

Ayele, B.W. (2020). Life in the time of Covid-19. Ethiopia: The response of Ethiopian Higher Education Institutions to the Covid-19 crisis: SAS is a high focus area. In: R.B. Ludeman \& B. Schreiber (Eds.), Student Affairs and Services in Higher Education: Global Foundations, Issues, and Best Practices (Third edition) (pp. 32-33). IASAS \& Deutsches Studentenwerk (DSW) Publishers. https://bit.ly/3gKOUOf 
Chetty, K. \& Luescher, T.M. (In press, 2021). African Universities - Working towards an inclusive digital future in a post-Covid-19 world. Africa Insight.

Commonwealth of Learning (2020). Guidelines on Distance Education during Covid-19. Burnaby. https://bit.ly/2S92Vv7

Dell, S. (2020, May 15). HE department unveils plan to "save the academic year". University World News (Africa Edition). https://bit.ly/3vnD2Wx

Dell, S. \& Sawahel, W. (2020, 20 March). African universities urged to put classes online urgently. University World News. https://bit.ly/3xxtiLh

Fomunyam, K.G. (2017). Student protest and the culture of violence at African universities: An inherited ideological trait. Yesterday and Today, (17), 38-63. https://doi.org/10.17159/2223-0386/ 2017/n17a3

Händel, M., Stephan, M., Gläser-Zikuda, M., Kopp, B., Bedenlier, S. \& Ziegler, A. (2020). Digital readiness and its effects on higher education students' socio-emotional perceptions in the context of the Covid-19 pandemic. Journal of Research on Technology in Education, 1-13. https://doi.org/ 10.31234/osf.io/b9pg7

Hayward, F. (2020). Transforming Higher Education in Africa and Asia: strategic planning and policy. State University of New York Press.

Moja, T. (2021, January 3). National and institutional responses - reimagined operations - pandemic disruptions and academic continuity for a global university. Studies in Higher Education, 19-29. https://doi.org/10.1080/03075079.2020.1859688

Perozzi, B., Bardill Moscaritolo, L., Schreiber, B. \& Luescher, T.M. (Under review). Global Student Affairs and Services in the Context of Covid-19: Toward a Heuristic Model for SAS Impact on Student Success. Manuscript under review.

Quintana, R. \& Quintana, C. (2020). When classroom interactions have to go online: the move to specifications grading in a project-based design course. Information and Learning Sciences, 121(7/8), 525-532. https://doi.org/10.1108/ILS-04-2020-0119

Schreiber, B., Bardill Moscaritolo, L., Perozzi, B. \& Luescher, T.M. (2020, September 5). The impossibility of separating learning and development. University World News. https://bit.ly/3eDeYIy

Schreiber, B. \& Ludeman, R.B. (2020). Life in the time of Covid-19: Overview. In: R.B. Ludeman $\&$ B. Schreiber (Eds.), Student Affairs and Services in Higher Education: Global Foundations, Issues, and Best Practices (Third edition), (pp. 19-21). IASAS \& Deutsches Studentenwerk (DSW) Publishers. https://bit.ly/3eCUIXr

UNDP (United Nations Development Programme) (2020). Rivera, C., Hsu, Y., Esbry, F., Dugarova, E. (2020). Gender inequality and the Covid-19 crisis. https://bit.ly/2R5i3Jv

Veletsianos, George (2020). Learning Online: The Student Experience. Johns Hopkins University Press.

\section{How to cite:}

Luescher, T.M., Schreiber, B., Moja, T., Mandew, M., Wahl, W.P. \& Ayele, B. (2021). The Impact of Covid-19 on Student Affairs and Higher Education in Africa. Journal of Student Affairs in Africa, 9(1), v-xiii. DOI: 10.24085/jsaa.v9i1.1721 
RESEARCH ARTICLE

\title{
Student Affairs and Services during Covid-19 in Africa: Mitigating the Pandemic's Impact on Student Success
}

\author{
Birgit Schreiber, ${ }^{\mathrm{i}}$ Thierry M. Luescher, ${ }^{\mathrm{ii}}$ Brett Perozziii ${ }^{\mathrm{iii}}$ \& Lisa Bardill Moscaritolo ${ }^{\mathrm{iv}}$
}

\section{Abstract}

The Covid-19 pandemic has highlighted the challenges that present obstacles to equitable learning and development in higher education in various parts of the world. African higher education and Student Affairs and Services (SAS) are faced with a set of challenges that are in part related to the resources within the institutions and in part due the sociocultural context into which the institutions are embedded. It is with this background that this study explores the impact of Covid-19 on SAS in Africa, as part of a wider lens on SAS across the globe.

The study was conducted with an online survey which generated 781 responses of Student Affairs practitioners from across the globe, of which 118 were from the African continent. The data show SAS's critical role in mediating the various domains within and beyond the higher education institution that impact on student success. The domains that impact on student success include the students' personal experiences, the public domain, the sociocultural community and familial milieu, and the institutional/ SAS domain. Thus, this article discusses SAS's critical role in mediating the impact of these four domains on the student living and learning experience. The purpose of this article is to discuss the data and to use the data to gain insights into the way SAS has played a role in mitigating the impacts of Covid-19 in four domains relevant for student success.

Based on our findings, a systemic-contextual model is proposed that illustrates the relevance of four domains that need to synergise for students to be successful. Our data suggests that while SAS and universities do a great deal to support students in their learning, factors in the public domain, factors in the sociocultural community and familial milieu need to be conducive to learning to enable more student success in Africa.

\section{Keywords}

comparative international higher education; Covid-19; ICT in Student Affairs; personal factors; public infrastructure factors; sociocultural factors; Student Affairs theory

i Dr Birgit Schreiber is a member of the Africa Centre for Transregional Research at Alberts-LudwigUniversität Freiburg, Germany. ORCid: 0000-0003-2469-0504. Email: birgitdewes@gmail.com

ii Prof. Thierry M. Luescher is the Research Director for Post-schooling and Work in the Inclusive Economic Development Division of the Human Sciences Research Council (HSRC), Cape Town, South Africa, and Associate Professor: Higher Education affiliated to the University of the Free State, Mangaung, South Africa. ORCid: 0000-0002-6675-0512. Email: tluescher@hsrc.ac.za

iii Dr Brett Perozzi is Vice President of Student Affairs at Weber State University, USA. ORCid: 0000-0003-1378-8223. Email: brettperozzi@weber.edu

iv Dr Lisa Bardill Moscaritolo is the Vice Provost for Student Life at the American University of Sharjah, United Arab Emirates. ORCid: 0000-0003-2809-0012. Email: 1moscaritolo@aus.edu 


\section{Introduction}

During the Covid-19 pandemic, Student Affairs and Services (SAS) has proved to be amongst the most responsive and relevant divisions in higher education institutions across the globe, seeking to mitigate the impact, and engage with and provide students with development and support (McCarthy, 2020). In every world region and in different countries and institutions, SAS's ability to respond to Covid-19-related health scares and government-imposed precautions and restrictions has been impacted differently depending on a range of factors, including higher education structures and regulatory bodies, culture and resources, sociopolitical factors, size and shape of institution, and the demographics of the student body and student characteristics (Aristovnik et al., 2020). Some students were left with laptops, mobile devices and phones, data packs and Wi-Fi codes and some with even less (Schreiber et al., 2020).

Many African ${ }^{1}$ universities closed and left students to wait for further instructions (Crawford et al., 2020; Tesar, 2020; UNDP, 2020). Even though some universities in Africa rallied to provide online teaching, what is beyond the remote teaching and learning model are infrastructure and network holes, social-cultural inequities, and social-community environments that have "toxic social norms" (UNDP, 2020, p. 8) which may render a home environment unconducive to learning. It is this combination of challenges that has made remote learning away from the university campus extremely hard for some students, especially those from the most disadvantaged sections of society for whom attending a university offers a unique avenue for upward social-economic mobility (Heckman \& Mosso, 2014; Marope, 2019). When students step off campus into significant social inequalities or only access education via online modalities, the tool of empowerment and emancipation, especially for vulnerable groups, is impaired (Altbach et al., 2010, p. 31). Accessing higher education was already a challenge for many vulnerable groups (Marinoni, 2020; Schendel \& McCowan, 2016; UNDP, 2020), but with Covid-19 it has now become an even greater hurdle (Humphrey, 2020; Marinoni, 2020; UNDP, 2020, p. 9) whereby the pandemic is likely to widen the gender gap, increase teenage pregnancies, reduce participation in self-determination for many and cause significant setbacks for human development in Africa (UNDP, 2020).

SAS is instrumental in paving the way for student access, student persistence, retention, and success through its impact within and on institutions and through the support it provides to students in general, and particularly to certain student populations that require special services and required contextual conditions conducive for learning (Ludeman \& Schreiber, 2020; Osfield et al., 2016). The overarching function of SAS in higher education across the globe is to contribute to equitable opportunity and support a developmental

1 'Africa' is used here as a collective continental term and for purposes of this study is used as part of the regional nomenclature suggested and used by UNESCO, including Asia, Europe, Middle East, Oceania, North America and South America (UNESCO, 2018). The authors note that the terminology and naming of these world regions are somewhat problematic and simplistic, are imprecise, are culturally, geographically and politically biased, susceptible to misrepresentation and tend to be Anglo-centric (see, for instance, Somerville's discussion on the "many histories of the continent" $(2017$, p. 6). 
model of higher education in pursuit of the global as well as national social justice and human development agenda (Ludeman \& Schreiber, 2020). By promoting student engagement, enabling compatible living and learning contexts, providing health care and counselling, offering housing and residence life programmes, facilitating social, learning and personal safe spaces, implementing co-curricular programmes for students to learn beyond their discipline and develop into healthy, critically thinking, active citizens, by mapping learning and career pathways and supporting students to overcome their unique challenges, SAS ensures equity and fairness on the campuses of institutions in our massified higher education systems (Kuh et al., 2005; Ludeman \& Schreiber, 2020; Luescher-Mamashela, 2011; Pascarella \& Terenzini, 2005). Covid-19 has issued a massive challenge to SAS in Africa to be able to still provide its various engagement, social justice, and developmental functions in the face of emergency remote teaching.

In this article, we explore a range of different impacts that Covid-19 has had on the role and function of SAS in Africa, especially focusing on SAS service provision, involvement in institutional and national decision-making, resources, vision, and mission. For this purpose, we explore and discuss the results of the Global Covid-19 Student Affairs and Services Survey, paying special attention to responses received from African student affairs practitioners.

Based on our findings, we propose a systemic-contextual model that illustrates the importance of four domains that need to be functional for students to be successful. While SAS contributes significantly to making universities inclusive and supportive spaces conducive to student development, our data show that factors in the public macro context, factors in the social-cultural milieu, and factors in the community context need to be favourable to learning to enable sustained student success in Africa.

\section{Theory and Practice of Student Affairs and Services}

The theory and practice of Student Affairs have developed unevenly across the globe because of different levels of higher education development, differences in the historical origin and context-specific emphases of national higher education systems, institution-level variations, and different ways in which SAS relates to higher education and how epistemic communities and discourse has evolved, making this a 'low-consensus field' (Torres et al., 2019). However, the theory and practice of SAS tend to follow a trajectory observed widely by Pascarella and Terenzini (2005) from essentially an in loco parentis function of SAS to service delivery and extra-curricular programme delivery, and more recently towards embedded co-curricular programmes for students and the intentional pursuit of integrated systemic-institutional impact on higher education to shape the living and learning contexts of students. The Smith's 2019 summary of '60 years of scholarship' highlights the breadth and depth of research and knowledge of SAS (Smith, 2019).

Learning and development does not occur in isolation but within a context where many factors play together to create adequate conditions for learning and development to take place (Tinto, 2014). Students are sandwiched at the intersection of these factors, and while impacted by these, students simultaneously and dynamically respond to and impact 
them in turn. It is this systemic-dynamic and contextual understanding of the ecology of learning that provides a framework for understanding this research into the impact of Covid-19 on SAS in Africa.

Theories and practices in SAS have mainly emerged from the USA and have been developed further in these and other contexts and can be broadly clustered into developmental theories and environmental impact theories of student learning and development (Pascarella \& Terenzini, 2005; Tinto, 2014).

The developmental theories of SAS concentrate on the individual-socialpsychological changes of students before, during, and after higher education, focusing on the cognitive, moral, psycho-social and identity development of late adolescence and early adulthood (Pascarella \& Terenzini, 2005). These developmental theories are made up, for instance, of Perry's stage theories, Baxter-Magolda's identity development theory, and Gilligan's moral development as well as Chickering's vector model of college student development (Pascarella \& Terenzini, 2005). According to these theories, the SAS focus on student development in all its facets emphasises the students' development towards achieving autonomy and independence, theorising the intra- and inter-personal factors that are affected by living and learning influences and their interplay (Hamrick et al., 2002).

The environmental impact theories of student success broaden the scope of impact on student development from intra-psychic and inter-social to include the contextual, thus making student development a shared responsibility between environmental impacts and students. Agency for success is in each student where the site of development occurs, but also, and critically so, foregrounds the environmental and contextual factors into which the student is embedded. The environmental impact theorists of student success, comprising Tinto, Astin, Pascarella, Weidman, Kuh and others, all focus on the interplay of at least three influences that impact on a meaningful educational experience, albeit with different emphasis: (1) personal-cognitive resources of the students; (2) institutional-teachinglearning inputs; and (3) familial-social influences and social norms, into which the students' learning and development experiences are embedded. These three sets of influences need to converge to support the success of higher education and the success of students.

Astin $(1993,1996)$ proposed the Input-Environment-Outcome (I-E-O) model, based on Kurt Lewin's famous equation of $\mathrm{B}=\mathrm{F}(\mathrm{PxE})$ - stating that behaviour is the result of the interaction of the person with her/his environment. Astin's (1977) notion of 'student involvement' along with Tinto's 'student retention' $(1997,1998)$ highlight the critical importance of students' connectedness, integration, and inclusion into communities of learning, all of which are key determinants of persistence and retention (Mannan, 2007; Hamrick et al., 2002). In Astin's model, the 'E' includes all staff, students, practices and policies, institutional cultures, and social contexts that impact on the student. Astin famously declared that "students learn by being involved" (Astin, 1985, p. 133) in the living and learning experience.

Tinto's integrative model has been described as "the most influential model" of environmental impact theories (McCubbin, 2003, p. 1). It highlights the students' interaction with the university context and coined the now ubiquitously used concept of 
'learning communities', thus firmly shifting the focus towards the complimentary relationship between social integration and academic integration of students as fundamental to student success, including the critical role that student living contexts play (Mannan, 2007; Tinto, 2014; Schreiber, Luescher \& Moja, 2019). Tinto (1993, p.12) described his "integrative model" as primarily "sociological" in that students' intentions are continuously shaped by academic and social structures. In a study by McCubbin (2003), the correlation between integration and student success was less convincing for mature and returning students, but the relevance of integration for first time entering student has been firmly established (Pascarella \& Terenzini, 2005; Kuh et al., 2005, 2009, 2010; Strydom et al., 2017).

Weidman $(1984,1989)$ expanded on Astin's and Tinto's models and included formal and informal influences of family and community as critical contributors to student success and termed these "undergraduate socialisation factors" (Weidman, 1989, p. 299). Weidman (1989) emphasised the synergy of micro and macro factors including factors beyond the ambit of the higher education institution, including society's role in student success.

Kuh $(2005,2009,2010)$ seminally theorised and researched student engagement that has become the global measure of integration of students in their learning environment (Trowler, 2010; Coates, 2007). Student engagement, although critiqued for focusing on higher education institution-centric engagement practices (Trowler \& Schreiber, 2020), has become a strong correlate of student success (Trowler, 2010; Coates, 2007). It is the interactions with academic staff (i.e. professors, lecturers, and teaching support), peers, and with the out-of-class experience that are reliable correlates of student success (Kuh et al., 2005, 2010). Some of the expansions of student engagement include the notions of oppositional engagement (Altbach et al., 2010; Trowler \& Schreiber, 2020; Case, 2007; Luescher, 2017, 2018) that include discussions of oppositional behaviours, which nonetheless are behaviours and intentions that connect with the wider living and learning context.

Researchers from South Africa have shown that the experiences of alienation play a critical negative role in student persistence (Carolissen \& Kiguwa, 2018; Case 2007). Scott $(2009$, p. 27), remarking on the South African higher education context, highlights that a "co-ordinated approach" is required and Lange (in Swingler, 2018, n.p.) states that "the interface between students' psychosocial and academic worlds is mediated by several services and infrastructures that are not in sync, and some of which operate as if the others did not exist".

Carollissen and Kiguwa (2018) highlight the importance of 'belonging' as a critical factor in theorising about student experience and student persistence and the role of alienation is also cited as a critical factor by others (Bozalek \& Boughey, 2012; Davids, 2020). More broadly, the United Nations Human Development Reports point towards factors in the context of the student's life, including social norms, home life, safety and security, access to amenities and technology (UNDP, 2020) as critical in shaping a conducive environment for male and particularly female students' success. 


\section{Methodology}

The purpose of this study has been to gather and explore responses of SAS practitioners and professionals on how Covid-19 impacted their ability to respond to factors that affect student learning and development during the pandemic, and the extent to which they engaged in university decision-making and supported students. Through the lens of systemic-environmental impact theories, we seek to understand the factors that impact on SAS to support student development. For this purpose, our research employed a survey and online questionnaire, designed in Qualtrics, with a combination of closed response questions and open text answers. The quantitative data was analysed in SPSS (Statistical Package for the Social Sciences) producing descriptive statistics, and the qualitative responses were explored using content and thematic analysis in NVivo.

\section{Sampling and sample}

Survey respondents were sourced by virtual snowball sampling, also called chain sampling, chain-referral, or referral sampling (Creswell, 2013), which is a nonprobability sampling technique. The sample generated is a non-random, non-representative but stratified convenience sample, and does not represent a statistically representative group. This kind of sampling enabled us to seek information during extraordinary conditions, and to seek information from potentially hard-to-reach groups (see how to survey hard-to-reach populations at https://inclusivegrowth.be/downloads/output/ms87-m20-5-hard-tosurvey-groups.pdf and surveying non-random and non-representative samples at http:// www.sociology.org.uk/notes/SocShortcuts_methods16.pdf). This kind of sampling enables theory development and hypothesis development rather than hypothesis testing. We aimed to generate hypothesis and to generate theory, describe and compare data to gain insights, based on the data, rather than making statistically reliable generalisations.

In our case, potential respondents were sourced via virtual social and professional networks, via emailing and via acquaintance pathways. Email was the primary mode of communication when initially contacting processional associations, who were encouraged to engage their members and share the request to participate with them. Other distribution avenues were SAS personal and professional national and global networks and acquaintance pathways where colleagues were asked to complete the survey and forward the request to others. Social media was used (Facebook, LinkedIn, Twitter) to further the potential reach of the survey. This method facilitated rapid responses that reached a level deemed adequate for statistical purposes and for meaningful interpretation (Goodman, 2011; Salganik \& Heckathorn, 2004). This allowed us to reach regions that may not have responded well to postal services and assisted where the list and identity of participants was unclear (Baltar \& Brunet, 2012; Salganik \& Heckathorn, 2004).

One potential limitation of this method is that although it increases participation, bias might be towards participants who comfortably use online media, neglecting responses from subjects who are either not using online media readily or do not have access to online media as might be the case in some areas where Wi-Fi is fragile or only intermittently available, or are otherwise prevented from participating in online data gathering. 


\section{Sample}

The realised sample were 781 SAS practitioners who responded, either in full or in parts, to the online questionnaire, completed the consent form, and closed their responses, thus consenting and including themselves in the survey. The respondents hail from the following regions, as identified from their IP address (Table 1). The researchers used UNESCO (2018) and the International Association of Student Affairs and Services (IASAS) geographical regions as the primary guide to world regions. For the purpose of global comparison, these UNESCO regions have been used widely and yet pose complex challenges around misrepresentations of cultural or political homogeneity in these regions (see footnote in the introduction of this article). The 118 responses from across the vast African continent discourage reliance on statistical confidences, but nonetheless enable theorising about the data.

Table 1: Respondents by World Region

\begin{tabular}{|l|c|}
\hline Region & Number of respondents \\
\hline Africa & 118 \\
\hline Asia & 144 \\
\hline Europe & 207 \\
\hline Middle East & 35 \\
\hline Oceania & 108 \\
\hline North America & 149 \\
\hline Latin America and Caribbean & 20 \\
\hline Total & 781 \\
\hline
\end{tabular}

Table 1 shows that inter-regional comparison is possible because in all regions there are more than 100 responses, except Latin America and the Caribbean (LAC) and the Middle East.

The respondents were asked about their professional seniority/position in SAS. Figure 1 illustrates the relative positions and/or seniority of respondents. Titles and organisational conceptualisations/structures vary widely globally, and variation is evident in the data. Although not everyone completed this question, most respondents (47\%) identified as mid-level to senior SAS managers. The next largest grouping of respondents (39\%) were officers or in entry-level positions. The smallest percentage $(14 \%)$ were the most senior SAS position in their institution. 


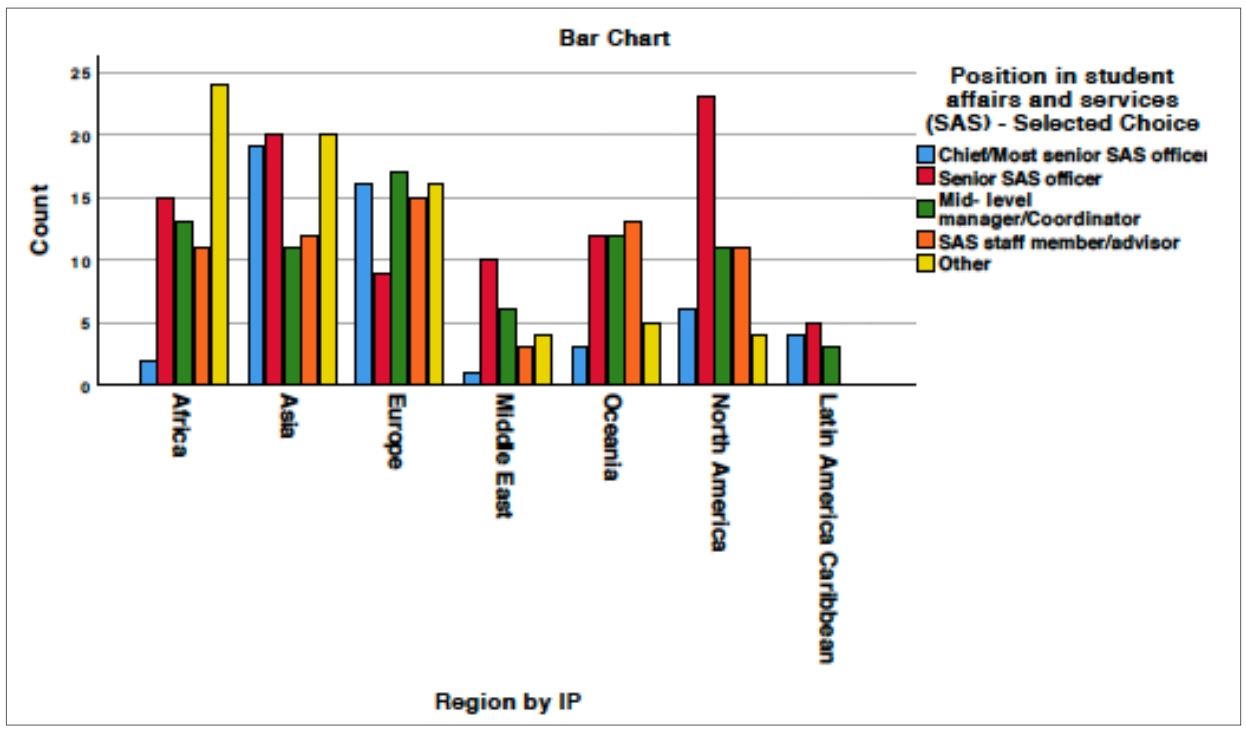

Figure 1: Respondents by seniority/position

In addition to asking about seniority/position, we asked the respondents about the number of years they have been working in SAS. Table 2 below shows how the African sample compares to the rest of the regions in terms of years of experience working in SAS. Overall, the African respondents, as well as respondents from Asia, have been working slightly fewer years than those in other world regions.

Table 2: Respondents by number of years working in Student Affairs

\begin{tabular}{|l|r|r|r|r|r|r|r|r|}
\hline & Africa & Asia & Europe & $\begin{array}{c}\text { Middle } \\
\text { East }\end{array}$ & Oceania & $\begin{array}{c}\text { North } \\
\text { America }\end{array}$ & LAC & Total \\
\hline $1-5$ & $46 \%$ & $50 \%$ & $30 \%$ & $9 \%$ & $34 \%$ & $15 \%$ & $25 \%$ & $34 \%$ \\
\hline $6-10$ & $21 \%$ & $24 \%$ & $21 \%$ & $26 \%$ & $23 \%$ & $11 \%$ & $25 \%$ & $21 \%$ \\
\hline $11-15$ & $13 \%$ & $12 \%$ & $19 \%$ & $35 \%$ & $11 \%$ & $26 \%$ & $17 \%$ & $17 \%$ \\
\hline$>15$ & $20 \%$ & $14 \%$ & $30 \%$ & $30 \%$ & $32 \%$ & $48 \%$ & $33 \%$ & $28 \%$ \\
\hline Total & $100 \%$ & $100 \%$ & $100 \%$ & $100 \%$ & $100 \%$ & $100 \%$ & $100 \%$ & $100.0 \%$ \\
\hline
\end{tabular}

\section{Data collection and analysis}

As noted above, data was collected via an online questionnaire, which contained a total of 53 questions. They were made up of (1) nine questions dealing with SAS decision-making in higher education institutions in the context of Covid-19; (2) four questions on SAS engagement with pandemic related issues; (3) three questions on the pandemic's financial implications; (4) three questions on predictions of how the pandemic will affect SAS. The questionnaire included eight questions on residence halls/student accommodation, eight questions on working online and instittuaional preparation, three questions on engagement 
and communication with students, and seven questions on the impact on particular student groups. Demographic questions were included at the end. Not all questions needed answering and a variety of question types were included such as closed choice options (most using Likert scale), open-ended questions, ranking and graded questions (e.g., full, partial, no/none). The survey was open for one month (May, 2020).

The data results were statistically analysed using SPSS, which offered the use of statistical functions, including frequency tables, cross-tabulation and a granulated examination of data, with special emphasis on data from African responses. Text responses were exported into the qualitative data analysis program NVivo. We then coded the open-ended responses using this software for thematic analysis.

\section{Ethics}

The research methodology and all written materials (i.e. informed consent form, questionnaire, project outline) were submitted to the institutional review board of the American University of Sharjah, United Arab Emirates (which is the home institution of one research team member) which granted full research ethics approval on 29 April 2020.

\section{Limitations}

Creswell discusses the inherent limitations in online surveys (Creswell, 2013). Online surveys, by definition, only include those who have access to the survey which may bias the sample. However, given that the situation around Covid-19 presented challenges around paper responses, we opted for this avenue for data collection and are noting the non-representation of this sample. In terms of using countries and continents as respondents' identifier it may have been preferable to use countries to capture richer and more textured data. However, low sample size per country compromised this option.

\section{Results of the Global SAS-Covid-19 Research: Spotlight on Africa}

The coronavirus pandemic has compelled universities around the continent and the world to send their students home and, in most cases, switch to some form of emergency remote teaching. Over a remarkably short period of time, academics and SAS professionals devised creative ways to deliver learning and support to students (Schreiber et al., 2020). However, what could not be fixed in many cases in the emergency remote teaching and learning model were stubborn social-public infrastructure and mobile network insufficiencies, substantial social-cultural inequities and social-community environments that are not conducive to learning and, in some cases, present barriers to learning. With African responses to this global Covid-19 survey as the focus, we concentrate in on these questions that deal with the systemic context of student learning and development during Covid-19. The data from 'Africa' is not viewed as statistically sufficient nor significantly representative to allow confident generalisations, but rather, offer an avenue to understand and illuminate the issues around responses to Covid-19. The insights gleaned from the data are discussed below. In addition, a more textured comparison of Africa with the other five regions of 
the world is beyond the scope of this article, but will be the focus of other publications emanating from this global research.

\section{The impact of Covid-19 on different student groups}

Covid-19 impacted on a number of student groups more severely than others. Figure 2 shows a word cloud of the open responses from SAS practitioners across Africa of which students were the most affected. At the centre and with the most frequent response were 'poor students' (14), followed by 'rural students' (8) and 'students with special needs' (7), such as students with disabilities and mental health challenges (5). Also specially impacted were students with no internet access at home (5), no devices (like tablet or laptops) (5) and those who remained on campus to study because their home situations were not conducive to learning (3). Other special student groups mentioned by African SAS practitioners were international students (4) and other students who studied far from home (5).

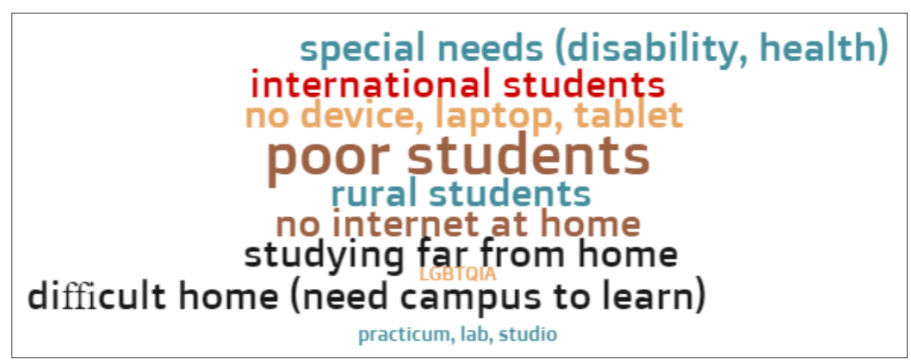

Figure 2: Most affected student groups in Africa $(\mathrm{N}=56)$

The African responses show interesting variations from the complete global sample. In both samples, 'poor students', 'students with special needs', and 'rural students' feature prominently. However, much more prominent in the global sample than in the African one is the group of 'international students' and especially 'Chinese and other Asian students' who have been affected greatly. In addition, in the global sample 'students who work to pay for their studies' and have lost their employment due to lockdown featured significantly, whereas this category of students is entirely absent in the African responses.

\section{Mitigating the financial impact and enhancing online access}

Given the widespread observation that poorer students have been more affected by Covid-19, a great deal of focus went to mitigating the financial impact. Whereas many universities in other parts of the world refunded students for costs such as student housing, tuition, and other fees including parking, in Africa, universities provided much less frequent financial relief to students by means of refunds (see Figure 3). This might well be due to the funding models at African institutions where government bursaries fund university costs and thus a refund would not go directly to the student but would be reimbursed to governments (see, for instance, the South African National Student Financial Aid Scheme funding model, [NSFAS, 2020]). 


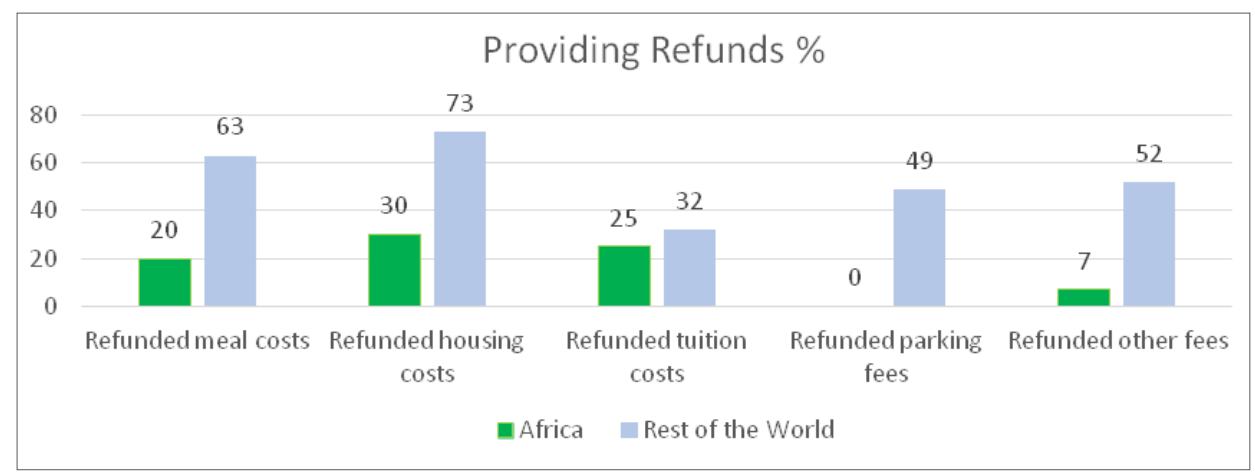

Figure 3: Providing financial relief by means of refunds $(\mathrm{N}=663)$

As Figure 3 shows, African universities rather mitigated the impact of Covid-19 financially by providing more directed financial relief to students (such as transport funds, funds for data and online devices, etc.; see Figure 4) than seen globally.

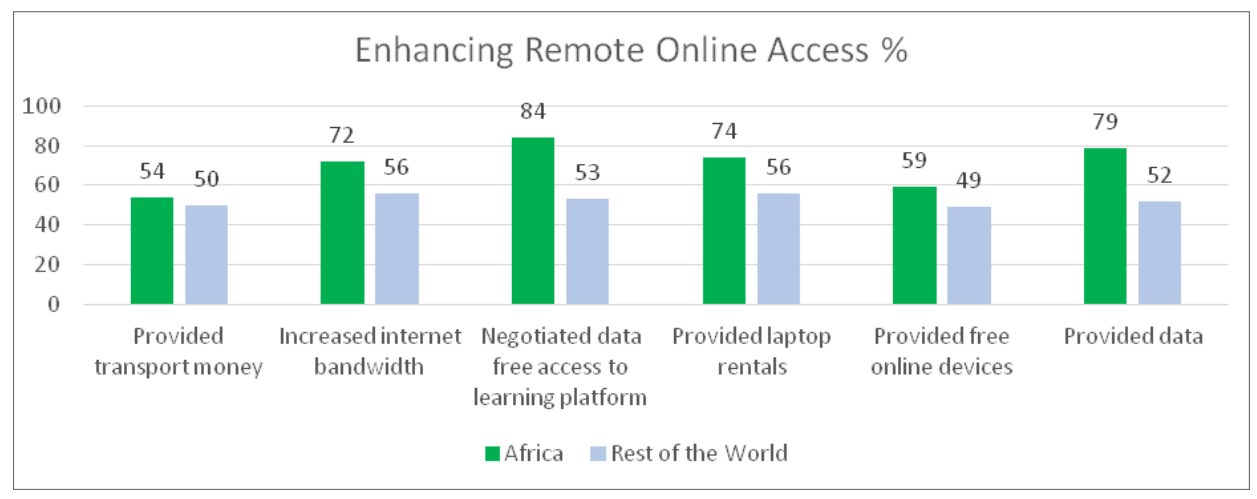

Figure 4: Enhancing students' remote online access $(\mathrm{N}=663)$

In the context of Covid-19-related lockdowns and other restrictions, African universities helped their students with transport money at about the level seen elsewhere in the world. However, African universities provided much more frequently than elsewhere in the world direct and targeted support to enhance remote online access to students who needed such support. This they did primarily by means of (1) increasing their institutional internet bandwidth; and (2) negotiating reduced data costs or a zero-rating for their websites and learning platforms; (3) procuring laptops and other learning devices for needy students; and (4) by directly providing data to students. In this respect, being mindful of the observation that poor students and students in remote and rural areas were the most affected (see Figure 2 above), African universities focused their (financial assistance) on these students to enhance their access to learning. This is in line with the social justice mandate of universities and SAS in particular (Schreiber, 2014), where access to learning for particularly vulnerable groups is foregrounded. 


\section{An essential partner in decision-making and service delivery}

Overall, when asked whether Student Affairs was considered "a key player in institutional decision-making" during the pandemic, $77 \%$ of African practitioners agreed or strongly agreed (which is comparable to similar levels elsewhere). Overall, slightly less frequently than the rest of the world, certain SAS services were declared essential $67 \%$ Africa vs. $76 \%$ rest of the world). Figure 5 shows the variation between different services and world regions.

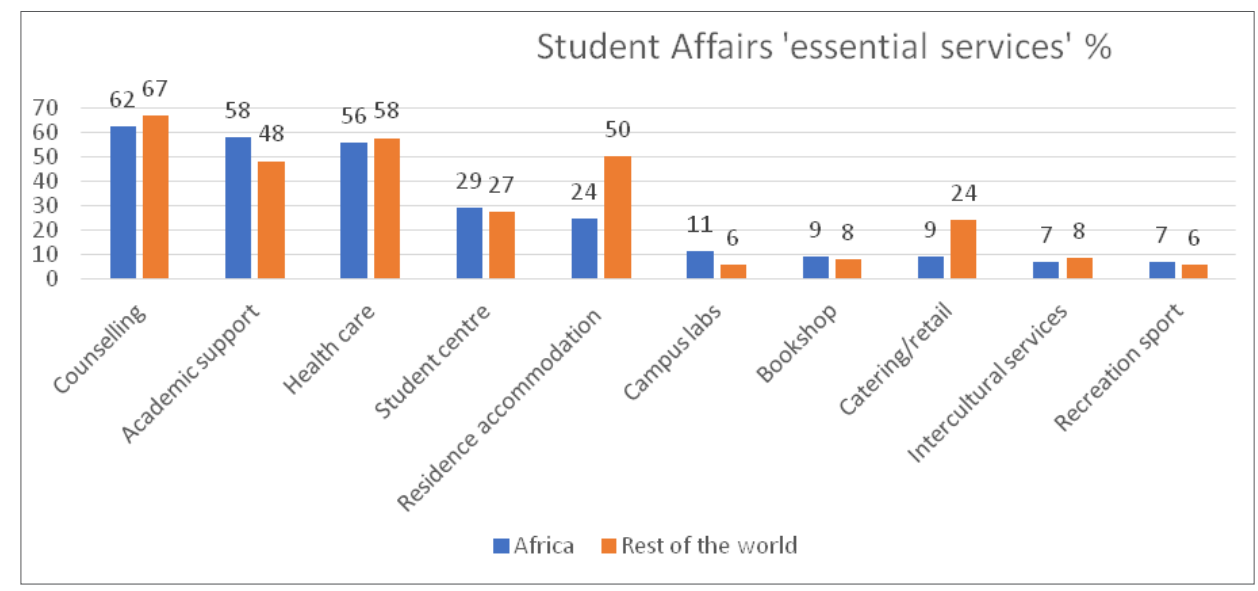

Figure 5: Student Affairs essential services $(\mathrm{N}=288)$

Figure 5 shows interesting variation. Firstly, it is evident that a similar range of SAS services were declared as 'essential services' during the national lockdowns across the world. Of those, globally and in Africa, the top three essential services were: counselling, academic support and health-related services. A thought-provoking variation in the data is that in Africa, student accommodation and related catering and retail services were considerably less frequently declared essential than elsewhere in the world. Conversely, academic support was mentioned slightly more frequently as an essential service in African universities than in the rest of the world.

\section{Innovative responses, mistakes and challenges}

The respondents also indicated many innovative ways in which they managed Covid-19 that can be grouped into six categories as indicated in Figure 6.

Figure 6 illustrates that SAS practitioners in Africa found the rapid move towards online provision of teaching and learning, student development, and support services a most innovative way of responding to the threat of Covid-19. Existing e-platforms were used as well as other ways to reach students. Respondents also mentioned a number of social media and communication platforms including Teams, WhatsApp, Zoom for interactive life communication as well as email and other social media for communication. 
Another frequently noted category of innovative responses relates to the institutional lockdown itself and related initiatives, such as the immediate deep cleaning and fumigation of campuses, organising travel for students, and implementing working from home policies for staff to continue work. African SAS staff also considered the responses to enhance equal online access (noted above in Figure 4) as innovative responses, such as providing devices and data to students who needed such, and communicating frequently and transparently using multiple platforms and addressing various constituencies, including staff, students, specific student populations, and student organisations.

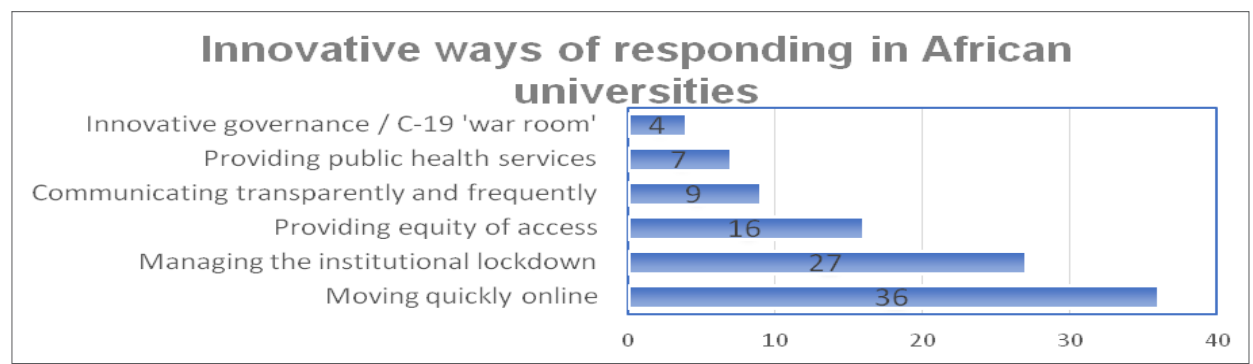

Figure 6: Innovative ways of responding to the pandemic in African universities $(\mathrm{N}=99)$

Moreover, African universities offered public health services of various kinds. SAS staff particularly noted: the dissemination of health-related information, using university facilities for quarantine, training health workers, keeping the campus clinics open, and offering medical students as health volunteers. Finally, there were management-related innovations such as reorganising workstreams to suit an online work environment, and establishing coordinated task teams including a central 'Covid-19 response room'.

Correspondingly, mistakes were identified by respondents. African SAS practitioners' coded responses particularly mentioned mistakes with respect to consultation and involvement in decision-making of students and staff. In the case of students, this caused resistance with respect to the implementation of some decisions and delays in the adoption of online learning in some cases. With respect to staff, an argument was that SAS mid-level staff should have been more involved. Institutional 'mistakes' were also noted with respect to the IT infrastructure of the institution; the eLearning platform's fragility and crashing due to overload; staff not being sufficiently trained; and communication not always being adequate.

It is especially these responses of 'mistakes made' that contributed to the development of the systemic-contextual model of SAS presented here. For example, one respondent noted that: "Only post grads, post docs and the academic research community can successfully work from home. Most people can't, due to numerous socio-economic and even sociopsychological issues."

This quote draws attention to the socio-economic challenges (of household level poverty) and socio-psychological issues (of personal, familial and communal factors) involved in determining whether the home is conducive to learning and working from 
home. Added to this comes a comment on 'mistakes made' from another respondent who points to the macro infrastructure challenges confronting students at home: "What we could call a mistake is actually a societal problem that is related to power supply and connectivity to the internet; these serve as bottlenecks to accessing the eLearning by some students." Both these responses from participants point directly to the role of influences beyond the institution that are critical in enabling or presenting barriers to student success.

\section{Discussion}

The higher education sector has been shaken by the Covid-19 pandemic and supporting the institutions and students across Africa has been an unprecedented challenge. SAS has been instrumental in a variety of ways in responding to and mitigating the impact of Covid-19 on the learning and development context, by supporting the change to virtual learning, providing digital access and support for online learning competencies, maintaining safe spaces on campuses conducive to learning and development, reaching out to rural students and supporting poor students, offering personal, academic, and social counselling and health care, and responding swiftly and innovatively to the various needs of students and the institution.

The data reveal a compelling relationship between SAS and the systemic-contextual factors and their impact on student success. The factors that impact on student learning and development include the personal domain of students, the sociocultural milieu into which they are embedded, the university at which they are enrolled, and the public macros structures which support basic services and functions. SAS is organisationally, conceptually and practically integrated into institutional processes, especially the teaching, living and learning spaces, and this makes the SAS mediation of academic-disciplinary process for student learning particularly relevant.

Figure 7 summarises the discussion and represents the factors explored in this study. The authors assert that individual student development is the result of the dynamic interplay of four 'systems' or 'domains' that are interrelated. These include (1) personal: internal intra-personal factors (such as motivation, intelligence, persistence, optimism, and 'grit' (Wilson-Strydom, 2017); (2) sociocultural: the family and social-cultural milieu including social norms, beliefs, and cultural practices; (3) academic-faculty: living and learning experience, institutional culture and practices, teaching and learning frameworks, epistemological access, SAS is closely related to this factor, and (4) public: macro systems, including basic service infrastructure such as electricity, water, shelter, health, safety, internet access, etc.

SAS is centrally involved, albeit to different degrees and in different ways, in mediating these four systems/domains to enable, facilitate and improve the learning experience of the student. The SAS mediates, mitigates, facilitates and improves these domains' impact on the students' (and institutional) success. The student, centrally located and sandwiched amongst these systems, navigates these domains and SAS is a key supportive role player in this navigations process. 
Each factor is mediated differently by SAS, overlaps and often is jointly impacted by SAS. For instance: the SAS and academic-faculty influence on student learning is, in some institutions, closely related and integrated, is well-coordinated and aligned to synergise to enable conditions conducive to student learning and development, together shaping a learning and development context. Yet in other institutions, SAS mediates and facilitates student support 'outside of academic processes' to promote access for disability, facilitate learning programmes, and offer orientation and academic support programmes. SAS is involved in mediating the social-cultural domains of students by assisting minority students who may be exposed to social-cultural challenges, including gender-based difficulties, and by providing accommodation. SAS supports students on a personal basis, by offering health and counselling services. During Covid-19, SAS was particularly active around support for public services, including access to Wi-Fi and mobile devices, facilitating transport and offering safe spaces for students who lived in precarious contexts.

The theoretical dimensions, including the developmental theories and environmentalimpact theories, as well as insights from the survey, all integrate to give a holistic understanding of the SAS impact on different domains of student learning and development.

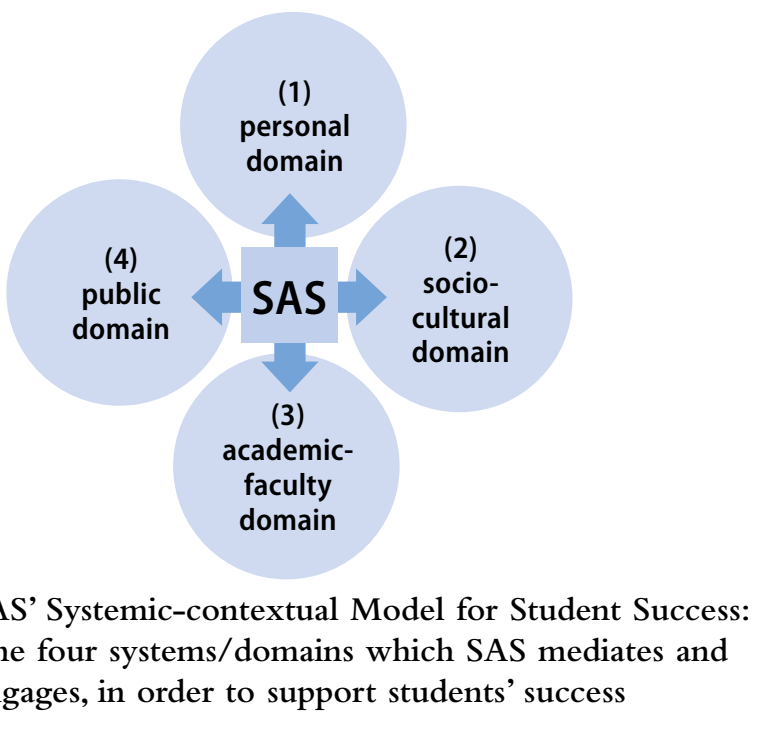

Four identified domains - the personal, social-cultural, public, and the academic-faculty domain - need to converge to support student persistence and success. SAS is centrally involved in mediating these four domains for students and mitigating any subverting influences the domains may have on students' ability to persist and succeed in a meaningful learning and development experience. The four domains are simultaneously contextual, meaning that they shape the situation and environment, and also systemic, meaning that they dynamically and reciprocally impact each other (i.e., are not discreet but mutually influential). What emerges from the data is that SAS is critically involved, with varying 
degrees and emphasis, depending on institution, context and sociocultural environment of the students, in mediating the living and learning context for students.

The personal domain includes the personal characteristics, abilities, motivations, preparedness and resources that students bring towards their success. Examples include engagement (Kuh et al., 2005, Strydom et al., 2017), academic preparedness (MonnapulaMapesela, 2017), motivation and grit (Wilson-Strydom, 2017) which have been widely researched and are evidently linked to student success.

The public domain includes the macro infrastructure, economic and political influences and factors, resources and provisions that are typically provided at public/ municipal/city level, including electricity, water, transport, health care, public order and safety, sanitation, and essential social services (UNDP, 2020). Included here are Wi-Fi networks, even if provided by private corporations, as these rely on a myriad of public service functions listed here. These public service provisions are powerful influences on the student's chance of success.

The sociocultural domain refers to the social and cultural practices and attitudes, at community and family level, which include religious prescriptions, gender roles and expectations, and norms ranging from the explicit to the unspoken. These social and cultural values powerfully impact student success, and can either support and accelerate or present barriers.

The academic-faculty domain is focused on the institutional learning and teaching strategies, the resources and institutional culture and practices, the size and shape of the learning environment and the academic engagement practices prevalent. The relational interplay of the various epistemological fields in higher education include the formal administrative, discursive-academic and informal experiential domains of students in their development and learning experience (Bernstein, 2000; Schreiber, 2013). Here, SAS is typically very powerfully influencing student success.

These four domains - the personal, the public, the sociocultural and the academicfaculty domain - are mediated by SAS in a variety of ways. The domains work synergistically, both negatively and positively, and the data reveals that SAS in Africa, with the onset of Covid-19, is critically relevant in organising responses that mitigate these impacts to shape a more supportive context for student success.

The data shows that SAS supported personal functioning of students (for instance by providing more and online counselling, etc.), mitigated the public service provision failure (for instance by providing free access and online mobile devices, etc.), compensated for sociocultural practices that were less conducive for studying (for instance by providing safe accommodation where communities and households had toxic influences on students, etc.), and facilitated learning (for instance, by offering tutorials and academic support, etc.).

By using data from the survey, the relevance of SAS's role and function vis-à-vis the personal, public, sociocultural, and academic-faculty impacts on students' learning and development is demonstrated. Overall, SAS mediates the students' experience which is nestled into these domains. SAS facilitates access, dilutes barriers, compensates for omissions 
and augments the living and learning experience for students, thus advancing student success. The overarching social justice agenda of SAS, i.e. to level the playing field, to enable fairer conditions and to support more equitable access to educational experiences, is grounded in the SAS's mediation of these four domains.

The context beyond the university has never been more important than during Covid-19 times, and this includes the macro public infrastructure, societal norms and practices, community-based structures and familial milieu, and all that makes an environment more - or less - conducive to a meaningful learning experience. There is a strong association between higher education attainment levels and higher levels of social equity and human development (Peercy \& Svenson, 2016; UNDP, 2020). Higher education is a tool for human development but 'it takes a village' - a community with functional structures and supportive social norms - to enable higher education to deliver on its promise.

\section{Conclusion}

The analysis of the data in this research enabled insight into the domains that are mitigated by Student Affairs and Services (SAS) in order to support student success. From the role and function of SAS, which emerged so cogently during Covid-19, we developed a systemic-contextual model of SAS for student success.

SAS's responses are unique, varied and tailored to compensate for the hindrances, explicit and invisible, systemic and situational, that students experience in their quest for a meaningful learning and development higher education experience. Particularly in Africa, the context is to varying degrees equipped to enable an environment conducive to student success. What emerges powerfully from this research is that it is precisely this context, including and beyond the higher education institutions, the sociocultural community, the familial milieu and the public domain into which the learning experience is embedded, that is particularly implicated in playing a significant role in student success. Universities are embedded into wider social and cultural communities and rely on family, community and public systems and it is these domains, together with the institutional and personal, that enable a context conducive to student success. African SAS theory development, based on empirical research, as is done in this article is urgently required to expand upon prevailing SAS theories and practices so that student success continues to be a significant national and continental development avenue.

SAS's influence on these factors that impact on student success is critical to sustained student success in Africa. Moreover, SAS needs to focus on equipping students to become social justice agents so that students themselves can powerfully impact on the personal, institutional, social, cultural and public influences on student success. Higher education offers a powerful learning and development experience for students and for this to be more meaningful, the four domains - the personal, the public, the sociocultural community and family milieu, and institutional - need to synergistically align to support student success. SAS plays a critical role in mitigating and harmonising these domains. 


\section{Potential Conflict of Interest}

The authors declare that they have no competing interest.

\section{Funding}

This research received no specific grant from any funding agency, commercial entity, or non-profit organisation.

\section{References}

Altbach, P., Reisberg, L. \& Rumbley, L. (2010). Tracking a global academic revolution. Change, 42(2), 30-39. https://doi.org/10.1080/00091381003590845

Aristovnik, A., Keržič, D., Ravšelj, D., Tomaževič, N. \& Umek, L. (2020). Impacts of the COVID-19 pandemic on life of higher education students: A global perspective. Sustainability, 12, 8438. https:// doi.org/10.3390/su12208438

Astin,A. (1977). Four critical years: Effects of college on beliefs, attitudes and knowledge. Jossey-Bass.

Astin, A. (1985). Achieving education excellence: A critical assessment of priorities and practices in higher education. Jossey-Bass.

Astin,A. (1993). What matters in college? Four critical years revisited. Jossey-Bass.

Astin, A. (1996). Involvement in learning revisited: Lessons we have learnt. Journal of College Student Development, 37(2), 123-134.

Baltar, F. \& Brunet, I. (2012). Social research 2.0:Virtual snowball sampling method using Facebook. Internet Research, 22(1), 55-74. https://doi.org/10.1108/10662241211199960

Bernstein B. (2000). Pedagogy, symbolic control and identity. Theory, research, critique, Vol. V. Rowman and Littlefield.

Bozalek, V. \& Boughey, C. (2012). (Mis)framing higher education in South Africa. Social Policy and Administration, 46(6), 688-703. https://doi.org/10.1111/j.1467-9515.2012.00863.x

Carolissen, R. \& Kiguwa, P. (2018). Narrative explorations of the micro-politics of students' citizenship, belonging and alienation at South African universities. South African Journal of Higher Education, 32(3). https://doi.org/10.20853/32-3-2542

Case, J. (2007). Alienation and engagement: Exploring students' experience of studying engineering. Teaching Higher Education, 12(1), 119-133. https://doi.org/10.1080/13562510601102354

Coates, H. (2007). A model of online and general campus-based student engagement. Assessment and Evaluation in Higher Education, 32(2), 121-141. https://doi.org/10.1080/02602930600801878

Crawford, J., Butler-Henderson, K., Rudolph, J., Malkawi, B., Glowatz, M., Burton, R., Magni, P. \& Lam, S. (2020). Covid-19: 20 Countries' higher education intra-period digital pedagogy responses. Journal of Applied Teaching \& Learning, 3(1), 120. https://doi.org/10.37074/jalt.2020.3.1.7

Creswell, J. (2013). Research design: Qualitative, quantitative, and mixed methods approaches. Sage.

Davids, N. (2020). The consequences of increasing student alienation in higher education institutions. https://www. researchgate.net/publication/339975135_The_consequences_of_increasing_student_alienation_in_ higher_education_institutions

Goodman, L.A. (2011). Comment: On respondent-driven sampling and snowball sampling in hard-toreach populations and snowball sampling not in hard-to-reach populations. Sociological Methodology, 41(1), 347-353. https://doi.org/10.1111/j.1467-9531.2011.01242.x

Hamrick, F., Evans, N. \& Schuh, J. (2002). Foundations of student affairs practice: How philosophy, theory and research strengthen educational outcomes. Jossey-Bass. 
Heckman,J. \& Mosso, S. (2014).The economics of human development and social mobility. Annual Review of Economics, 6, 689-733. https://doi.org/10.3386/w19925

Humphrey, D. (2020). Colleges must attend to three crucial areas. Inside Higher Ed. https://www.inside highered.com/views/2020/08/17/higher-ed-responds-covid-it-should-focus-three-areas-ensurequality-and-equity [Accessed 22 September 2020].

Kuh, G. (2009). What student affairs professionals need to know about student engagement. Journal of College Student Development, 50(6), 683-706. https://doi.org/10.1353/csd.0.0099

Kuh, G., Kinzie, J., Schuh, J. \& Whitt, E. (2010). Student success in college. Jossey-Bass.

Kuh, G., Kinzie, J., Schuh, J., Whitt, E. \& Associates. (2005). Student success in college: Creating conditions that matter. Jossey-Bass.

Ludeman, R. \& Schreiber, B. (2020). Student affairs and services in higher education: Global foundations, issues and best practices (3rd ed.). Deutsches Studentenwerk Publishers.

Luescher-Mamashela, T.M. (with S. Kiiru, R. Mattes, A. Mwollo-ntallima, N. Ng'ethe \& M. Romo) (2011). The university in africa and democratic citizenship: Hothouse or training ground? African Minds. https://doi.org/10.47622/9781920355678

Luescher-Mamashela, T.M., Moja,T. \& Schreiber, B. (2013). Towards a professionalisation of student affairs in Africa. Journal of Student Affairs in Africa, 1(1\&2), vii-xiii. https://doi.org/10.14426/jsaa.v1i1-2.18

Luescher, T.M. (2017). From student enragement to student engagement: What is your theory of change? HSRC Review, 15(2), 13-15.

Luescher, T.M. (2018). Altbach's theory of student activism in the twentieth century: Ten propositions that matter. In Jodi Burkett (Ed.), Students in twentieth century Britain and Ireland. Palgrave MacMillan. https://doi.org/10.1007/978-3-319-58241-2_13

Mannan, M. (2007). Student Attrition and academic and social integration: Application of Tinto's model at the University of Papua, New Guinea. Higher Education, 53, 147-165. https://doi.org/10.1007/ s10734-005-2496-y

Marinoni, G., Van't Land, H. \& Jensen, T. (2020). The impact of Covid-19 on higher education around the world. International Association of Universities Global Survey. International Association of Universities Publishers. https://www.iau-aiu.net/IMG/pdf/iau_covid19_and_he_survey_report_ final_may_2020.pdf

Marope, P.T. (2019). Education: The key to development. Prospects, 47, 305-307. https://doi.org/10.10 07/s11125-019-09454-0

McCarthy, C. (2020). Review colleagues' lessons learned for managing impact of COVID-19 crisis. Student Affairs Today, 23(3), 1-5. Wiley Periodicals Publishers. https://doi.org/10.1002/say.3074

McCubbin, I. (2003). An examination of criticism made of Tinto's 1975 student integration model of attrition. https://www.psy.gla.ac.uk/ steve/localed/icubb.pdf [Accessed 4 October 2020].

Monnapula-Mapesela, M. (2017). Students' perception of own preparedness for higher education: Case study. International Journal of Educational Sciences, 9(2), 255-264. https://doi.org/10.1080/09751122. 2015.11890315

NSFAS (2020). South African National Student Financial Aid Scheme guidelines. https://bit.ly/3rorWhN

Osfield, K., Perozzi, B., Bardill Moscaritolo, L. \& Shea, R. (2016). Supporting students globally in higher education:Trends and perspectives for student affairs and services. NASPA Publishers.

Pascarella, E. \& Terenzini, P. (2005). How college affects students: Findings and insights from twenty years of research. Jossey-Bass.

Peercy, C. \& Svenson, N. (2016). The role of HE in equitable human development. International Review of Education, 62,139-160. https://doi.org/10.1007/s11159-016-9549-6 
Salganik, M. \& Heckathorn, D. (2004). Sampling and estimation in hidden populations using respondentdriven sampling. Sociological Methodology, 34(1), 193-239. https://doi.org/10.1111/j.0081-1750.20 04.00152.x

Schendel, R. \& McCowan, T. (2016). Expanding higher education systems in low- and middle-income countries: The challenges of equity and quality. Higher Education, 72, 407-411. https://doi.org/ 10.1007/s10734-016-0028-6

Schreiber, B. (2013). Using Bernstein's notion of re-contextualising fields to understand the challenges around integration of discursive and formal communities at UWC. Paper presented at the UWC Teaching \& Learning Colloquium. Cape Town, 19 July. http://www.youtube.com/watch?v=9ew $\mathrm{JCd} 2 \mathrm{HcBQ}$

Schreiber, B. (2014). The role of Student Affairs in promoting social justice in South Africa. Journal of College \& Character, 15(4), 211-218. https://doi.org/10.1515/jcc-2014-0026

Schreiber, B., Bardill Moscaritolo, L., Perozzi, B. \& Luescher, T. (2020). The impossibility of separating learning and development. University World News. https://www.universityworldnews.com/post.php? story $=2020090210200929$

Schreiber, B., Luescher, T. \& Moja, T. (2019). Living communities. Journal of Student Affairs in Africa, 7(2), v-vii. https://doi.org/10.24085/jsaa.v7i2.3820

Schreiber, B. \& Lewis, J. (2020). Professionalization of student affairs and services around the world: More than a matter of degree(s). In R. Ludeman \& B. Schreiber (Eds.), Student Affairs \& Services in Higher Education: Global Foundations, Issues, and Best Practices (3rd ed., pp. 57-63). Deutsches Studentenwerk Publishers.

Scott, I. (2009). First-year experience as terrain of failure or platform for development? Critical choices for higher education. In B. Leibowitz, A. van der Merwe \& S. van Schalkwyk (Eds.), Focus on First-Year Success: Perspectives from South Africa and beyond. African Sun Media. https://doi.org/10.18 820/9781920338220/01

Smith, R.A. (2019). Structuring the conversations: Using co-citation networks to trace 60 years of The Journal of College Student Development. Journal of College Student Development, 60(6), 695-717. https://doi.org/10.1353/csd.2019.0063

Somerville, K. (2017). Africa's long road since independence: The many histories of a continent. Penguin Publishers.

Strydom, F., Kuh, G. \& Loots, S. (Eds.) (2017). Engaging students: Using evidence to promote student success. African Sun Media. https://doi.org/10.18820/9781928424093

Swingler, H. (2018, 20 July). Adopt Mbembe's 'pedagogies of presence'. UCT News. https://www. news.uct.ac.za/article/-2018-07-20-adopt-mbembes-pedagogies-of-presence-lis-lange [Accessed 23 September 2020].

Tesar, M. (2020). Towards a post-Covid-19 'new normality?': Physical and social distancing, the move to online and higher education. Policy Futures in Education, 18(5), 556-559. https://doi.org/ $10.1177 / 1478210320935671$

Tinto, V. (1993). Leaving college: Rethinking the causes and cures of student attrition (2nd ed.). University of Chicago Press. https://doi.org/10.7208/chicago/9780226922461.001.0001

Tinto, V. (1997). Classroom as communities: Exploring the educational character of student persistence. The Journal of Higher Education, 68(6), 599-623. https://doi.org/10.1080/00221546.1997.11779003

Tinto,V. (1998). Taking research on student persistence seriously. Review of Higher Education, 21(2), 167-177.

Tinto, V. (2014). Tinto's South Africa lectures. Journal of Student Affairs in Africa, 2(2), 5-28. https://doi. org/10.14426/jsaa.v2i2.66

Torres, V., Jones, S. \& Renn K. (2019). Student Affairs as a low-consensus field and the evolution of student development theory as foundational knowledge. Journal of College Student Development, 60(6), 645-658. https://doi.org/10.1353/csd.2019.0060 
Trowler, V. (2010). Student engagement literature review. Higher Education Academy, York.

Trowler, V. \& Schreiber, B. (2020). Student engagement from beyond the US: Increasing resonance through reframing the construct. Journal of College and Character, 21(4), 315-322. https://doi.org/ 10.1080/2194587X.2020.1822878

UNDP (2020). Rivera, C., Hsu,Y., Esbry, F. \& Dugarova, E. (2020). Gender inequality and the COVID-19 crisis. http://hdr.undp.org/sites/default/files/gendercovid_final.xlsx

UNESCO (2018).w Definition of regions. https://unesdoc.unesco.org/ark:/48223/pf0000261751/ PDF/261751eng.pdf.multi.page $=142$

Weidman, J. (1984). Impacts of campus experiences and parental socialization on undergraduates' career choices. Research Higher Education, 20(4), 445-476. https://doi.org/10.1007/BF00974923

Weidman, J. (1989). Undergraduate socialization: A conceptual approach. In J. Smart (Ed.), Higher Education: A handbook of theory and research (pp. 289-322). Agathon.

Wilson-Strydom, M. (2017). Disrupting structural inequalities of higher education opportunity: "grit", resilience and capabilities at a South African university. Journal of Human Development and Capabilities, 18(3), 384-398. https://doi.org/10.1080/19452829.2016.1270919

\section{How to cite:}

Schreiber, B., Luescher,T.M., Perozzi, B. \& Bardill Moscaritolo, L. (2021). Student Affairs and Services during Covid-19 in Africa: Mitigating the Pandemic's Impact on Student Success. Journal of Student Affairs in Africa, 9(1), 1-21. DOI: 10.24085/jsaa.v9i1.1425 
RESEARCH ARTICLE

\title{
Challenges and Interventions of eLearning for Under- resourced Students amid Covid-19 Lockdown: A Case of a Zambian Public University
}

\author{
Charity L.M. Kombe ${ }^{i} \&$ Dingase E. Mtonga ${ }^{i i}$
}

\begin{abstract}
This article reports the challenges of eLearning faced by under-resourced students in a Zambian public university during the 2020 Covid-19 lockdown. The article further examines the interventions made by the university to mitigate the challenges of eLearning faced by under-resourced students. The article is based on empirical data derived from an online closed-and open-ended questionnaire completed by 73 under-resourced students, and an interview with two university staff. The quantitative and qualitative data collected were analysed using descriptive statistics and thematic analysis respectively. The article provides evidence that under-resourced students encountered various challenges related to eLearning categorised under the following interlinked themes: technical, environmental, psychological, sociocultural, financial, and material. Lack of ICT facilities/devices (laptops, smartphones, tablets and desktops), internet, electricity, and support systems were the most critical barriers to eLearning. Findings further showed that the sampled university made efforts to mitigate the challenges faced by students during eLearning amid the 2020 Covid-19 lockdown. However, there were no focused interventions to specifically address the actual challenges under-resourced students encountered. Regrettably, this suggests that the needs of under-resourced students were overlooked. Thus, the authors suggest strategies universities should put in place to uphold the participation of all students during eLearning regardless of the circumstances.
\end{abstract}

\section{Keywords}

Covid-19 lockdown; eLearning; interventions; under-resourced students; university; Zambia

\section{Introduction}

On 18 March 2020, Zambia declared the Covid-19 outbreak when the first two cases were confirmed (Cabinet Office Circular Minute of 2020-CO 7/6/2). The pandemic affected various sectors in the country. The education sector was one of the most affected as learning institutions were compelled to abruptly close down on 20 March 2020 (Hapompwe et al., 2020; Mulenga \& Marbán, 2020; Naciri et al., 2020; Sintema, 2020a).

i Dr Charity Lengwe Meki Kombe is a Lecturer and Researcher at Mulungushi University, Kabwe, Zambia. ORCid: 0000-0003-3207-6598. Email: cmekikombe@yahoo.com

ii Ms Dingase E. Mtonga is a Lecturer and Researcher at Mulungushi University, Kabwe, Zambia. ORCid: 0000-0002-9456-8830. Email: mtongadingase@gmail.com 
To ensure continued learning, some universities opted to remain open by switching to eLearning (online learning) (Mulenga \& Marbán, 2020). While this move was forwardlooking, in Zambia eLearning is generally not a popular mode of instruction because the education system is largely based on traditional face-to-face instruction. The unpopularity of eLearning is attributed to various challenges such as power outages, unreliable internet access and lack of eLearning devices by instructors and students. Internet access is also expensive and largely restricted to urban areas (Chola et al., 2020). Poor ICT (Information and Communication Technology) skills and unfavourable academic conditions at home are also serious challenges to eLearning (Chola et al., 2020; Hapompwe et al., 2020; Mulenga \& Marbán, 2020; Sintema, 2020b).

Studies conducted outside Zambia have revealed that students experienced challenges relating to eLearning during the Covid-19 lockdown (Dube, 2020; Hussain, 2020; Kapasia et al., 2020; Kunju, 2020; Upoalkpajor \& Upoalkpajor, 2020). The aforementioned challenges for effective eLearning were more prominent amongst under-resourced students. This is, amongst others, because they have limited access to essential educational resources which consequently derail their education (Krodel et al., 2008; Adnan \& Anwar, 2020; Pawloski, 2020). The desperate needs of these students become even more critical in times of emergencies such as the outbreak of Covid-19. For instance, Upoalkpajor and Upoalkpajor (2020) reported that the impact of Covid-19 was “... severe for underprivileged families ... causing intermittent learning' (p. 25). As Dube (2020, p. 137) argues, it seems as though eLearning "favours ... well-privileged learners, thus, widening the gap between the poor and the rich..."

In this article, an 'under-resourced student' is one who has limited or no access to certain resources to address a specific situation or negotiate a particular environment. Resources include finances, materials (pertinent instructional resources such as smartphones and computers); support systems (friends, family, and backup resources available to access in times of need); and mentors (any role model and highly proficient person such as a lecturer, ICT staff and student counsellor helping students get the most from their educational experience). The term under-resourced shall also refer to having inadequate resources, being poor and under-funded (Krodel et al., 2008; Payne, 2008).

In Zambia, a number of studies relating to Covid-19 vis-à-vis education have been conducted (Chola et al., 2020; Hapompwe et al., 2020; Mulenga \& Marbán, 2020; Naciri et al., 2020; Sintema, 2020a). While some of these scholars (Hapompwe et al., 2020; Sintema, 2020a) observed that under-resourced students experienced eLearning challenges during the 2020 Covid-19 lockdown, strikingly, none of them critically examined the specific challenges such students encountered.

Therefore, the aim of this article is to report on the specific challenges of eLearning faced by under-resourced students amid the 2020 Covid-19 lockdown in a Zambian public university. Furthermore, the article examines interventions made by the sampled university to mitigate the challenges of eLearning faced by under-resourced students. The '2020 Covid-19 lockdown' refers to the period between 20 March 2020 when learning institutions in Zambia were closed to mid-July 2020 when data collection for the current study was concluded. 
This discussion is significant as it is expected to inform policy and practice on the actual experiences and challenges under-resourced students go through when it comes to eLearning at universities. The research may also provide insight into universities on how to appropriately respond to challenges faced by under-resourced students to ensure equity in education. The study may also contribute to the existing body of knowledge on the subject and stimulate interest for further research.

\section{Literature Review}

Studies on education during the Covid-19 crisis are increasing. Although the specific objectives of the various studies differ, they generally focus on examining the impact of Covid-19 on education, assessment and its various stakeholders - students, teachers, school administrators, families, etc (Hapompwe et al., 2020; Kapasia et al., 2020; Sintema, 2020a; Upoalkpajor \& Upoalkpajor, 2020). It is also apparent that the studies generally centre on examining the shift from the traditional face-to-face method of instruction to eLearning owing to the abrupt closure of learning institutions around the world (Naciri et al., 2020).

Seemingly, however, fewer studies at international level (Kapasia et al., 2020; Kunju, 2020) bring up the challenges that under-resourced students have encountered as learning institutions unexpectedly changed instruction from face-to-face to eLearning. There are examples, like a study conducted in India that assessed the impact of Covid-19 lockdown on undergraduate and postgraduate students at various colleges and universities of West Bengal. Findings indicated that students faced challenges relating to eLearning like poor internet connectivity, unconducive study environments, stress, depression, and anxiety. Students from remote areas and marginalised sections of society, in particular, faced unique challenges, like being denied eLearning due to lack of electricity and poor internet connectivity. Consequently, it was recommended that interventions be created to provide space for studying amongst students from the vulnerable sections of society (Kapasia et al., 2020).

While the study by Kapasia et al. (2020) provides useful insights regarding eLearning during the Covid-19 lockdown, amongst whom can be classified as under-resourced students, it does not go into much depth with regards to the detail of the specific challenges that this group of students faced. The current study therefore provides more insight into the discussion considering that it specifically focuses on under-resourced students in relation to the actual challenges of eLearning they encountered during the Covid-19 lockdown in Zambia.

Still in India, a survey was conducted amongst school students across the country to understand the consequences of the Covid-19 lockdown on their studies and the challenges encountered with regards to exploring alternative modes of learning. Findings revealed that the abrupt closure of educational institutions negatively affected students, especially those from the Economically Weaker Section (EWS) of the country. Most EWS students were unable to explore eLearning resources due to lack of eLearning know-how and the inaccessibility of needful eLearning necessities such as smartphones and internet. Further, above 70 per cent of the participants indicated that they found eLearning challenging because they had never done it before, while 79 per cent stated that they 
were uncomfortable with it (Kunju, 2020). Findings by Kapasia et al. (2020) and Kunju (2020) provide a good basis for understanding the contextual similarities and differences of eLearning during the Covid-19 lockdown amongst different countries.

In Africa, literature on Covid-19 and education is gaining grounds (Dube, 2020; Hussain, 2020; Upoalkpajor \& Upoalkpajor, 2020). Generally, the literature provides evidence on the impact of Covid-19 as well as lessons that have been learnt on the matter under scrutiny. The literature also focuses on the challenges that students and instructors encountered during the pandemic which include lack of appropriate resources for eLearning, unreliable internet connectivity, power outages, unfavourable learning environment, anxiety and stress, amongst others. The marginalised in society such as the under-resourced were the most affected. This is affirmed by scholars such as Dube (2020) who documents rural learners having been left out from learning as a result of lack of various means to access online learning in South Africa. These findings are echoed by Hussain (2020) who argues that the inevitable mode of instruction adopted by the Nigerian Federal Ministry of Education excluded the already vulnerable and disadvantaged students.

Available literature on Covid-19 and education in Zambia focuses on different areas with little attention paid to challenges under-resourced students encountered during the Covid-19 lockdown (Chola et al., 2020; Mulenga \& Marbán, 2020; Naciri et al., 2020; Sintema, 2020a). For example, Sintema (2020a) examined the views of teachers of science, technology, engineering, and mathematics (STEM) at a public secondary school on the probable effects of Covid-19 on STEM education vis-a-vis performance of students in STEM subjects. Similarly, Hapompwe et al. (2020) investigated the impact of Covid-19 on grades 7,9 and 12 learners' national examinations academic performance following the premature closure of schools. Chola et al. (2020) assessed students' perceptions towards eLearning amid the Covid-19 pandemic through an online survey involving 210 Physics students at a medical university in Lusaka. Notably, what cuts across in the literature is the concern about many learners not accessing eLearning.

The foregoing documented literature raises critical questions such as: 'How should governments and universities ensure inclusion and equity for all learners during emergencies?' 'In what ways could the Zambian government ensure continuity of learning amongst the vulnerable and disadvantaged students in times of crisis?' 'What would be the best policies and practices to emancipate the marginalised groups in eLearning during emergencies such as Covid-19 and beyond?'

\section{Conceptual and Theoretical Underpinnings}

This study is framed by the concept of Inclusive Education (IE) which, in its most 'traditional' conceptualisation, entails educational institutions that are made or transformed with the purpose of accommodating children with special needs (disabilities) and how they can adapt easily in the school environment (Florian, 2014; Schuelka, 2018; Schuelka et al., 2020). From a broader perspective, IE is used to name the process of recognising and giving 'support to the groups that are in any way marginalized' (Petrović, 2013, p. 31). The broader view of IE looks at the diversity of students and how learning institutions could respond to these differences (Armstrong et al., 2010). 
IE can therefore be defined as learning that upholds personal, academic, and professional development of all learners irrespective of their age, gender, language, economic status, disability, and other forms of differences. In this regard, learning institutions are called upon to transform education to meet the needs of the student, i.e. transforming the system to accommodate the student and not vice versa (Armstrong et al., 2010; Tomlinson, 2014; Schuelka, 2018).

IE is anchored on the principle of 'Education For All' with the assumption that every learner has a right to equal and quality educational opportunities and benefits (Cobley, 2018; UNESCO-IBE, 2016). The provision of quality education is in line with the fourth Sustainable Development Goal which emphasises inclusive and equitable quality education (Boeren, 2019).

The practice of IE calls for an understanding that requires a continuous process which strives to sustain the participation of all students. It also aims at restructuring the cultures, policies, and practices in learning institutions as a response to the diversity of learners (Schuelka, 2018; Schuelka et al., 2020). Schuelka (2018) brings out success elements to effective implementation of inclusive education which include inclusive polices and legal support that promote high outcomes for all students; adequate and equitable distribution of school resources and facilities; sufficient teacher training in inclusive thinking and techniques; flexible curriculum that offers personalisation; and supportive leadership.

Grimes (2010) developed a useful list of indicators to evaluate the level of inclusive education in Laos (Asia) that could be applied in other contexts. These indicators basically focus on vulnerable learners having a sense of belonging in a school; being supported by school staff and treated fairly; their voices valued; access to all lessons; and having a conducive environment to enable them to succeed in their learning.

IE also calls for the "presence, participation, and achievement of all learners" (Booth \& Ainscow, 2011; Messiou, 2017). This implies that learners must be in attendance and actively engage in learning in order to have a positive educational experience. Booth and Ainscow (2002, p.3) define participation in terms of collaborative learning in shared learning experiences with learners "being recognised, accepted and valued".

In addition to IE, this study was also framed by ideas advanced under the Critical Emancipatory Research (CER). The CER is associated with the critical theory established at the University of Frankfurt in the early 1920s. The CER has its "philosophical roots in several traditions such as Marx's analysis of socio-economic conditions and class structure, Habermas' notion of emancipatory knowledge and Freire's transformative and emancipatory pedagogy" (Nkoane, 2013, p. 99). The aim of CER is not merely to explain or understand society but to transform it. The task of the researchers therefore is to challenge people in authority and uncover any repressive structures that suppress people and facilitate disparities (Patton, 2002).

The CER also seeks to explain and encourage participation and to shape the world into a better place for all. To do so, CER researchers problematise "historical and social conditions of crisis, oppression, inequality and replace them with emancipatory ones" (Sinnerbrink, 2012, p. 370). The CER endeavours to ensure that no one is excluded from experiences that transform their lives while promoting inclusion, social justice, equality, and human rights. 
IE and CER are both relevant to interrogate learning amongst under-resourced students amid the Covid-19 lockdown due to the following reasons. First, the concept of IE and CER aim at ensuring that all categories of people, regardless of their vulnerability, have access to common provisions and equitably participate in experiences that can emancipate them (Grimes, 2010; Nkoane, 2013). Secondly, IE and CER both promote 'emancipatory' values such as equity, social justice, inclusion and human rights amongst disenfranchised groups. Both frames therefore provide a valuable lens to ponder on the challenges of eLearning faced by under-resourced students during the Covid-19 lockdown. Further IE and CER offer a frame to appreciate the 'emancipatory' interventions that could be made by the universities to ensure inclusive and equitable eLearning.

\section{Research Methodology}

This research adopted a cross-sectional survey design which employed qualitative and quantitative methods of data collection, where data was collected and analysed at a specific point in time (Creswell, 2014;Yin, 2017).

A public university from Zambia was purposively sampled as it is one of the institutions that conducted eLearning during the 2020 Covid-19 lockdown. The sampling of participants in the study was done in collaboration with the student affairs and student counsellor officers. A list of 83 students who presented themselves as 'under-resourced' by virtue of having limited or no access to finances to meet their educational needs was availed to the researchers by the university. The student affairs and student counsellor officers revealed not having a 'formal' system in which the university captures under-resourced students. They pointed out that those that are classified as under-resourced usually present themselves to the office of the student affairs and student counsellor as such. The fact that the students present themselves to the aforesaid offices implies that the number of underresourced students could have been more than the 83 captured at the time of the study.

This research employed two data collection methods namely, an online questionnaire created using 'Google form' and interviews. The online questionnaire link was sent to the 83 identified students through email, WhatsApp and Short Text Messages. Ultimately, 73 students successfully participated. An online questionnaire was deemed an appropriate mode of data collection for the students because the study was conducted during the 2020 Covid-19 lockdown.

The questionnaire contained closed- and open-ended questions. Closed-ended questions were used to collect biographical and quantifiable data such as the type of devices and online platforms used by the students during eLearning. The open-ended questions were used to collect qualitative data such as personal challenges related to eLearning experienced by participants during the lockdown.

Face-to-face interviews were conducted with staff in charge of students' affairs (SISA) and a university student counsellor (USC). The two participated in the study by virtue of being custodians of information on under-resourced students. The interview with the SISA and USC focused on obtaining data such as the challenges reported to the university on eLearning by the under-resourced students and how the institution responded to the challenges. The face-to-face interviews were a suitable mode of data collection because 
they provided the researchers with an opportunity to gain an in-depth understanding on the subject under investigation.

The quantitative data collected through the online questionnaire was analysed using descriptive statistics and presented in figures and tables. The qualitative data collected through the questionnaire and the face-to-face interview was manually analysed by reading through the data repeatedly; coding and categorising it into themes. The analysed data was presented and interpreted in line with the objectives of the study, the literature review, and conceptual and theoretical underpinnings.

To ensure the validity and reliability of the quantitative findings, the questionnaire was reviewed by experts and piloted while the trustworthiness of the qualitative data was achieved through member checking, an extensive discussion of the results, and use of verbatim quotes obtained from the interviews and questionnaires. The findings were also triangulated through the use of two methods of data collection and the involvement of two categories of participants (Creswell \& Creswell, 2017).

\section{Ethical Considerations}

Ethical principles were adhered to by obtaining permission from the sampled university to carry out the research focusing on under-resourced students. Consent was obtained from the participants and they were informed of their voluntary participation and right to withdraw from the study. Confidentiality was taken care of by not exposing details of any participant and the sampled institution. Furthermore, no financial benefits were offered to participate in the research (Creswell \& Creswell, 2017).

\section{Findings and Discussion}

This section presents and discusses the findings of the study. It commences with the biographical data of the students followed by the rest of the findings under two headings derived from the study objectives.

\section{Biographical data of participants}

Table 1: Distribution of participants from each school by gender

\begin{tabular}{|l|c|c|c|}
\hline \multirow{2}{*}{ Faculty/School } & & \multicolumn{2}{|c|}{ Gender } \\
\cline { 3 - 4 } & Number of participants & $\mathrm{M}$ & $\mathrm{F}$ \\
\hline Education & 14 & 07 & 07 \\
\hline Agriculture \& Natural Sciences & 05 & 02 & 03 \\
\hline Social Sciences & 05 & 03 & 02 \\
\hline Business Studies & 05 & 02 & 03 \\
\hline Science, Engineering \& Technology & 41 & 32 & 09 \\
\hline Medicine \& Health Sciences & 03 & 01 & 02 \\
\hline Totals & $\mathbf{7 3}$ & 46 & $\mathbf{2 7}$ \\
& & $(63 \%)$ & $(37 \%)$ \\
\hline
\end{tabular}


As indicated in the table, more males (63\%) than females (37\%) participated in the study (Table 1). This was expected because the list of under-resourced students obtained from the university from which the participants were drawn contained more males than females. As highlighted in the methodology, under-resourced students present themselves to the university in order to be identified as such. Therefore, two questions arise: Could it be that males are more prone to vulnerability than their female counterparts? Are females shy to be identified as under-resourced? These questions still require further interrogation.

\section{Objective 1: Challenges of eLearning faced by students}

To contextualise the major findings of the study, results on participants' involvement in eLearning before and during the lockdown are examined. Thereafter, eLearning platforms and devices used by participants during the lockdown are presented and discussed.

\section{Students' involvement in eLearning before and during the lockdown}

Most of participants (79\%) compared to a few (21\%) reported that they had never been involved in eLearning before the lockdown (Figure 1). This raises a question as to why eLearning is under-utilised in the sampled university. This is despite the fact that the sampled university has basic on-campus internet and eLearning facilities. This calls for further research.

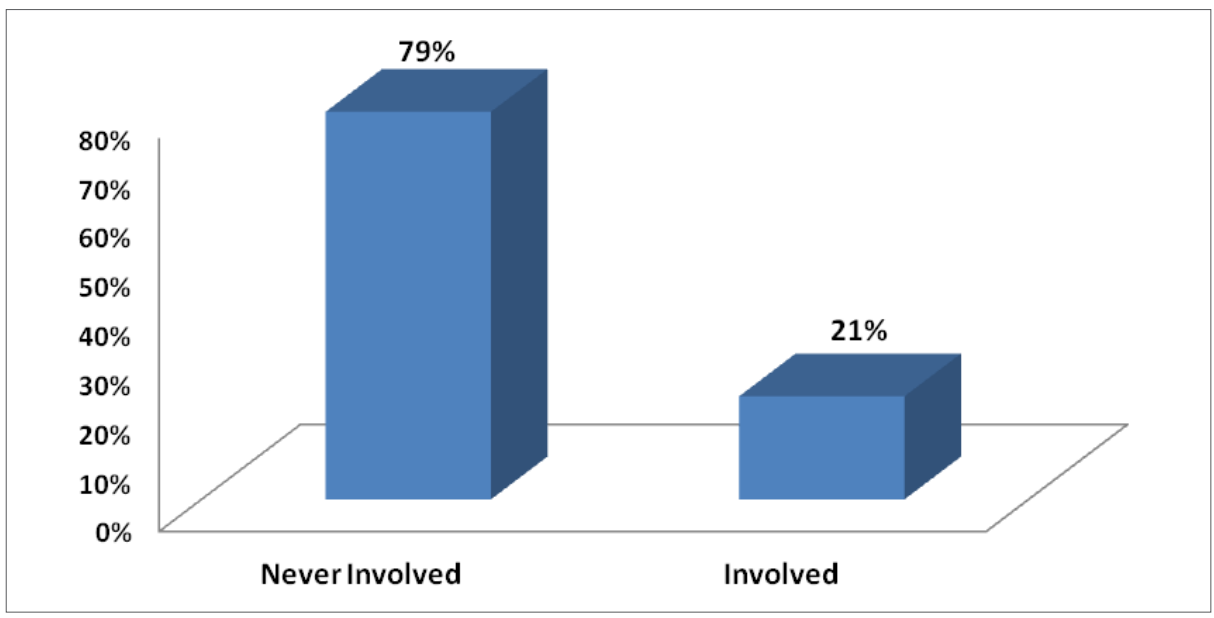

Figure 1: Students' involvement in eLearning before the lockdown (Source: Field data, July 2020)

Almost all the students (95\%) were involved in eLearning during the lockdown while 5 per cent reported not being involved (See Figure 2). Students who participated in eLearning reported different levels of involvement with 33 per cent indicating that they were 'very involved' to 'involved' compared to 62 per cent who were 'rarely' to 'very rarely' involved. For the 5 per cent of students who reported not being involved in eLearning, the findings suggested that they were eager to participate but excluded due to various challenges to be discussed in the subsequent section. 


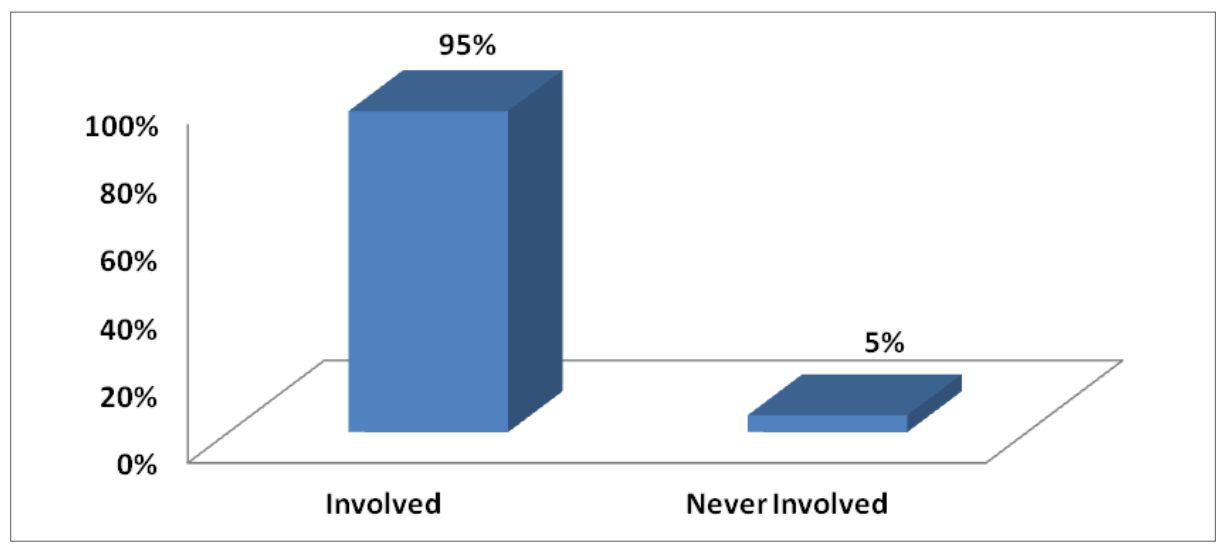

Figure 2: Students involvement in eLearning during the lockdown (Source: Field data, July 2020)

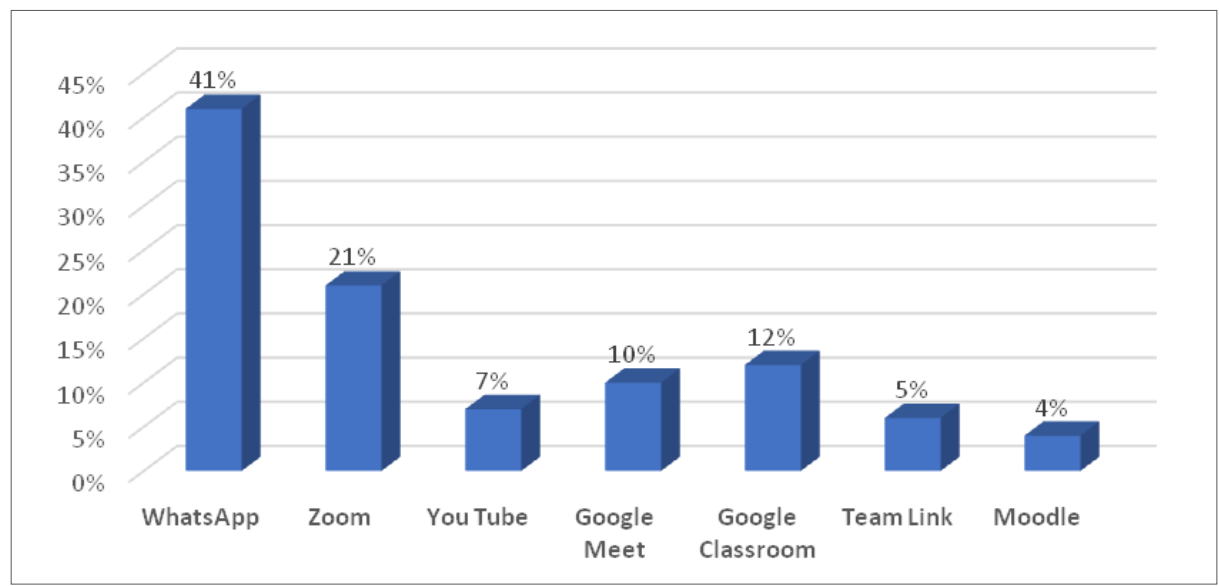

Figure 3: eLearning platforms used during the lockdown (Source: Field data, July 2020)

Findings (Figure 3) showed that the most frequently used eLearning platform was WhatsApp (41\%) followed by Zoom (21\%) with Moodle (the official institutional eLearning platform) being the least (4\%). Most students stated that they preferred to use WhatsApp because they were familiar with its features and because it was reasonably affordable when it came to data bundle usage. This finding is similar to other study results (Cetinkaya, 2017; Mulenga \& Marbán, 2020; Suardika et al., 2020; Susilo, 2014) that showed WhatsApp as an emerging valuable educational tool in other educational set-ups. This is especially for under-resourced students, who may only have smartphones and low data availability.

Moodle was the least preferred platform because students reported not being familiar with it. This reveals gaps in the training the university offered to its students. The students also indicated having some difficulties accessing Moodle due to technical challenges such as poor internet connectivity. 
To access eLearning, students used various electronic devices which included smartphones $(89 \%)$, laptops $(7 \%)$, desktops $(3 \%)$ and tablets (1\%). This finding aligns with Chola et.al. (2020) who found smartphones to be the most frequently utilised devices amongst students at a private university in Zambia. Worth noting is that many students $(78 \%)$ reported borrowing devices from parents, siblings, friends, and other relatives, confirming the struggles under-resourced students encounter in their learning (Krodel et al., 2008).

\section{E-learning challenges}

Four interlinked themes regarding challenges of eLearning experienced by underresourced students during the 2020 Covid-19 lockdown were identified as illustrated in Figure 4 .

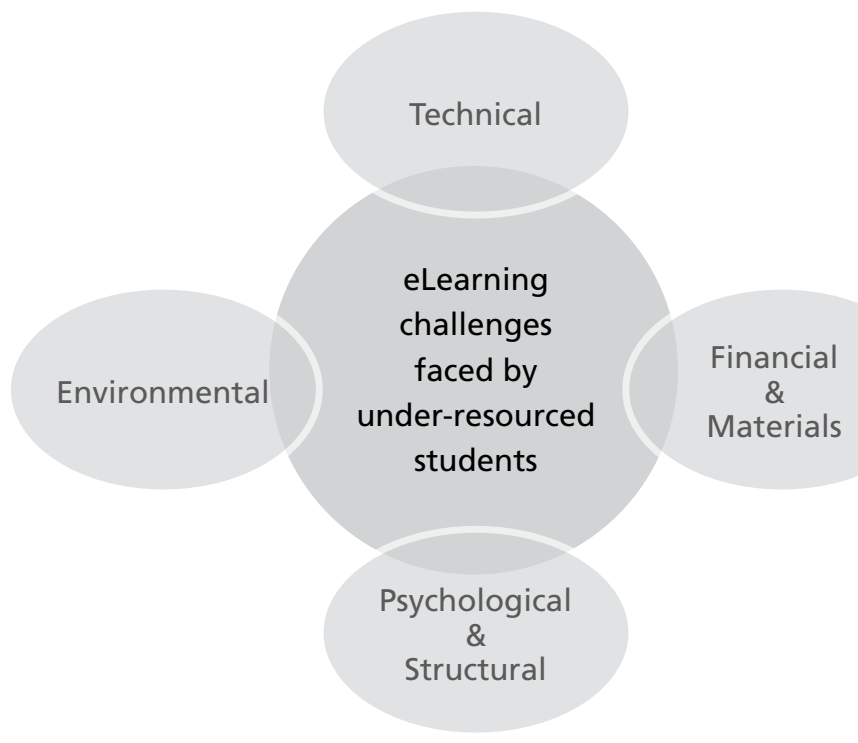

Figure 4: Themes on challenges of eLearning

(Source: Field data, July 2020)

\section{Theme 1: Environmental challenges}

Environmental challenges were reported in the form of crowded homes, noisy locations, lack of internet and electricity provision. Overcrowded homes hindered the success of students' eLearning in the sense that they could not secure privacy to effectively participate in the lessons. Furthermore, some family members were reported doing different activities such as playing loud music, and children playing around during lessons. Some students further lamented that the locality of their homes was near the marketplaces where there were various noisy activities. A student lamented:

Home is not a convenient place to do e-learning due to so many disturbances ... so much activity happening at home... (Male Participant 20) 
Another participant also complained:

... my neighbourhood is too noisy to concentrate. (Female Participant 31)

Students coming from remote parts of Zambia complained that they were not connected to the power grid and internet which completely cut them off from accessing eLearning and important information. The affected students stated finding various means to access online lessons and important information pertaining to their studies. For instance, a student said they had to travel to the nearest place in order to access internet and power, as stated below:

I stay in a remote area where there is no power, no internet. The nearest place where I can find internet and power is about 10 to 12 kilometres. This made it very difficult for me to participate in online learning... (Male Participant 18)

The finding that students were cut off from eLearning due to lack of power and internet connectivity coincides with results established in India where students were reported to have been excluded from accessing eLearning due to similar reasons (Kunju, 2020; Kapasia et al., 2020).

\section{Theme 2: Financial and material challenges}

Findings on financial and material challenges to eLearning included inaccessibility to learning materials and lessons due to lack of eLearning devices, data bundles and non-payment of tuition fees. According to the policy of the sampled university, each student was expected to meet at least the 50 per cent payment of tuition fees before accessing the institutional eLearning platform (Moodle).

The finding that students lacked the necessary eLearning devices confirms the high number of students who used borrowed devices. Findings also affirm the negative financial impact the pandemic had on under-resourced families where one student reported a parent having no source of income due to the Covid-19 lockdown, as indicated in the subsequent quotation. This finding is in line with Upoalkpajor and Upoalkpajor's (2020) study results which indicated that the impact of Covid-19 was severe for underprivileged families.

E-learning for me was a big challenge because my father did not manage to pay my fees. He has not been paid his salary because the bar where he was working from closed due to coronavirus. This prevented me from accessing Moodle where most materials were uploaded by the lecturers. (Male Participant 3)

It raises serious concerns that such students were further disadvantaged from the most basic mode of instruction due to unpaid fees. The university could have devised considerate means of collecting fees.

The foregoing finding was affirmed by the SISA who had the following to say:

There are a good number of under-resourced students who could not afford a smartphone... Some students deferred their exams due to financial challenges... 


\section{Theme 3: Technical challenges}

Technical issues consisting of power outages, poor internet connectivity, lack of computer skills and absence of effective institutional support systems were reported as barriers to eLearning. In terms of load shedding, one of the students had the following to say:

There is serious load shedding in our area because power goes even for three days and sometimes, we only have it in the night ... e-learning is conducted during the day, so I missed out a lot. At least our friends from well to do families use generators... (Female Participant 7)

Technical challenges in relation to poor internet connectivity was affirmed by the SISA who reported that the university received numerous calls from students on the failure to access Moodle due to poor internet connectivity as indicated in the excerpt below:

As a university, we received many calls from students reporting challenges to access Moodle due to poor internet.

Students also reported lack of technical skills as a barrier to effective eLearning. They also indicated ineffective and inefficient institutional support systems whenever they encountered technical challenges. A participant complained:

... I reported my challenges through the contact numbers given but no help was given by the university ... they always said if your friends are managing how are you failing, which was a very unfair statement. (Female Participant 71)

Owing to the foregoing, it appears that the under-resourced students received little institutional help to mitigate challenges they encountered during eLearning. This is against the principles of inclusive learning which advocate for the provision of equitable access to education by all students (Schuelka, 2018). Considering the situation, the institution could have put in a place an effective $24 / 7$ call centre to address technical challenges.

\section{Theme 4: Psychological and sociocultural challenges}

Psychological and sociocultural challenges is another theme that emerged from the findings encompassing stress, anxiety, isolation, inadaptability to change and household chores. Stress, anxiety, and isolation were linked to the various challenges students encountered. For example, some students were anxious as they could not access materials and important information posted on Moodle. Other students also reported stress especially towards the final examinations because they had missed some lessons. In some cases, students expressed feelings of isolation because of unreliable and inconsistent mentors and support systems.

Many students also found it difficult to adapt from face-to-face to eLearning which confirms previous findings that many students find it challenging to adjust to eLearning (Xu \& Jaggars, 2013). This difficulty to adapt could be attributed to the fact that the majority of the students had never been involved in eLearning and lacked the necessary technical know-how. For example, two students stated: "To be honest, I don't like online learning" (Female Participant 71) and "We should just open school and learn physically..." (Male Participant 11). These students' sentiments were corroborated by the SISA who had 
the following to say: "most students were used to having face-to-face classes, and suddenly changing to online learning proved to be very difficult for them to adapt..."

In some cases, students were distracted from eLearning as they were expected to do some house chores during lessons. This was mostly reported by female students who had to engage in various domestic activities such as cooking and taking care of young siblings. For instance, a participant had the following to say:

Learning from home is challenging especially for a girl-child, we have to work, cook, and run the house in absence of mom, in short, a lot of duties to attend to. (Female participant 29)

The above finding is echoed by Chola et al. (2020) who indicated that females could be disadvantaged when it comes to eLearning. However, they did not ascertain the actual factors that made them disadvantaged. Kakumbi et al. (2016) add that the girl-child in Zambia is culturally expected to do various household chores which stands as a barrier to her education. In line with the CER, there is a need to liberate the girl child from oppressive cultural beliefs and practices and replace them with emancipatory ones which advocate for inclusion, social justice, equality and human rights (Sinnerbrink, 2012, p. 370).

\section{Objective 2: Interventions by university authorities to mitigate challenges}

In order to have a broader perspective of the interventions that were put in place to mitigate the eLearning challenges encountered by under-resourced students, participants were asked to submit their responses. Most students (92\%) reported that the university did not put in place any particular intervention to mitigate the challenges they encountered during eLearning. However, some of them mentioned the free 100 megabytes (MB) bundles provided to all students to enable them to access Moodle, while others talked of the contact numbers they were given to call in case of technical challenges. For example, a student lamented: "...nothing, the only notable thing I noticed was providing a number from the ICT Department for challenges with Moodle and free 100 MB bundles” (Male Participant 19).

It is also important to note that the students lamented that the $100 \mathrm{MB}$ offer was not adequate to access all lessons in all courses, especially when it came to downloading big files. One wonders how the allocated MB were arrived at.

The SISA and USC confirmed the submissions by the students on the interventions put in place by the university and added the following: Unlimited access to Moodle following partnership with a local mobile network provider; offering educational tablets (Edu Tabs) on credit; video lessons on how to use Moodle; giving students three chances to upload quiz responses on Moodle in case of failure on first or second attempt; and a 24-hour duration for writing and uploading examination answer scripts for each course.

The researchers observed that the offer of unlimited access to Moodle was not mentioned by any student. This implies that the students may not have been aware of the service offered due to communication lapses in the system. Unlimited access to Moodle was a laudable intervention by the university to ensure inclusion and participation in eLearning for all students. However, the intervention appeared not to have value because most of the sampled students were not conversant with it. 
From the findings, the university made efforts to put in place some interventions to ensure students' participation in eLearning. However, further consideration could have been given to under-resourced students in response to principles of IE and CER. For instance, educational tablets were offered on credit to everyone without considering the already existing financial challenges faced by the under-resourced students. This is as reported by the SISA:

We have quite a number of students who can't even afford a smartphone and are considered to be really vulnerable ... they were encouraged to get Edu Tabs on credit though it was an extra cost added to them.

The SISA further added:

... apart from the arrangement with the two mobile network providers..., nothing was done particularly to respond to the needs of the under-resourced ... this interview is actually an eye-opener to start considering planning for such category of students...

The above findings point to a lack of inclusive thinking and techniques at the sampled university (Schuelka, 2020). This is a gap that requires urgent attention.

Regrettably, the USC (see excerpt below) revealed that there was no defined system to collect data on under-resourced students, making it difficult to have definite data. This is another identified gap that requires immediate intervention. This is because inclusive education calls for a firm system to data collection and management (Grimes, 2010; Schuelka, 2018):

... the current arrangement is that students come on their own to present their problems to the student counselling centre ... It is from this information where we draw the under-resourced students.

Overall, the findings indicated that the university might be putting less value on practices and policies that promote inclusion, equality and social justice. This stands against the ideals of IE as well as CER (Schuelka, 2020; Sinnerbrink, 2012).

\section{Limitations of the Study}

Findings of this research cannot be generalised to other universities because the study was confined to one public university. However, the results provide useful insights that could be applicable to similar contexts.

\section{Conclusion and Recommendations}

The article provides evidence that under-resourced students encountered various challenges related to eLearning during the 2020 Covid-19 lockdown. The challenges are categorised under the following interlinked themes: technical, environmental, psychological, sociocultural, financial, and material. Lack of devices, internet, electricity and support systems were the most critical barriers to eLearning. Findings showed that the university made attempts to mitigate the challenges students faced during eLearning. However, there were no distinctive interventions to specifically address the challenges under-resourced students 
encountered. Sadly, this suggests that the needs of these students were overlooked. The question is, why could this be the case? Could it be that the university does not have effective policies to promote inclusive education? This calls for further research.

In the light of the study findings, the practices of IE and CER, the study makes the following broad recommendations: First, there is a need at national level to have clearly defined policies tied to an effective implementation strategy to specifically cater for under-resourced students. This recommendation is to be taken up by the Zambian Higher Education Authority (HEA) and domesticated at individual higher learning institutions. Secondly, HEA should ensure that lecturers, university leadership and entire staff are oriented in inclusive thinking and techniques in order to promote inclusive education. It is also important that the voices of marginalised groups in education are heard and valued. This could be effectively done through various channels such as student associations.

The following specific recommendations apply to universities: ensure equitable delivery of eLearning to under-resourced students by exploring and implementing low technological modes of eLearning; providing for free affordable devices and access to eLearning platforms; effective training on ICT to students; reducing the threshold on tuition fees and sourcing sponsorship for vulnerable students. In addition, it is imperative that universities devise a firm system of data collection and management of underresourced students to ensure equitable distribution of resources. Researchers are also implored to use CER to interrogate the plight of under-resourced students as this could be an effective means to emancipate them. Overall, universities should constantly strive to support the participation of all students regardless of the circumstances, especially in times of emergencies (Grimes, 2010; Schuelka, 2018).

\section{Potential Conflict of Interest}

The authors declare that they have no competing interest.

\section{Funding}

This research received no specific grant from any funding agency, commercial entity, or non-profit organisation.

\section{References}

Adnan, M. \& Anwar, K. (2020). Online Learning amid the COVID-19 Pandemic: Students' Perspectives. Online Submission, 2(1), 45-51. https://doi.org/10.33902/JPSP.2020261309

Armstrong,A.C., Armstrong, D. \& Spandagou, I. (2010). Inclusive education: International policy \& practice. Sage.

Boeren, E. (2019). Understanding Sustainable Development Goal (SDG) 4 on "quality education" from micro, meso and macro perspectives. International Review of Education, 65(2), 277-294. https://doi. org/10.1007/s11159-019-09772-7

Booth, T. \& Ainscow, M. (2002). Index for inclusion: Developing learning and participation in schools (3rd ed.). England: Centre for Studies on Inclusive Education (CSIE). https://www.eenet.org.uk/resources/ docs/Index\%20English.pdf [Accessed 8 February 2016].

Cabinet Office Circular Minute of 2020-CO 7/6/2. Enhancement of Government Response to the Outbreak of the Coronavirus Disease (COVID-19). 
Cetinkaya, L. (2017). The impact of WhatsApp use on success in education process. International Review of Research in Open and Distributed Learning, 18(7). https://doi.org/10.19173/irrodl.v18i7.3279

Chola, R., Kasimba, P., George, R. \& Rajan, R. (2020). Covid-19 and e-learning: Perception of freshmen level physics students at lusaka apex medical university. Age, 15(19), 63. https://bit.ly/3fDUn98

Cobley, D. (2018). Disability and international development: A guide for students and practitioners. Routledge. https://doi.org/10.4324/9781315208558

Creswell,J.W. (2014). Research design: Qualitative, quantitative and mixed methods approaches (4th ed.). Sage.

Creswell, J.W. \& Creswell, J.D. (2017). Research design: Qualitative, quantitative, and mixed methods approaches. Sage.

Dube, B. (2020). Rural online learning in the context of COVID-19 in South Africa: Evoking an inclusive education approach. Multidisciplinary Journal of Educational Research, 10(2), 135-157. https://doi. org/10.17583/remie.2020.5607

Florian, L. (2014). What counts as evidence of inclusive education? European Journal of Special Needs Education, 29(3), 286-294. https://doi.org/10.1080/08856257.2014.933551

Grimes, P. (2009). A quality education for all: A history of the Lao PDR Inclusive Education Project 1993-2009. Save the Children. https://bit.ly/3sIPHTi

Hapompwe, C.C., Kukano, C. \& Siwale, J. (nd). Impact of Covid-19 on Zambia's 2020 general education examination candidates' academic performance in Lusaka: E-learning issues. http://192.168.1.248:8080/xmlui/handle/123456789/179

Hussain, T.A. (2020). Education and COVID-19 in Nigeria: Tackling the digital divide. SOAS Blog. https://study.soas.ac.uk/covid-19-nigeria-digital-divide/

Kakumbi, Z., Samuel, E.B. \& Mulendema, P.J. (2016). Pupil home background characteristics and academic performance in senior secondary schools: A case study of selected secondary schools in Kitwe District, Zambia. Journal of Education and Practice, 7(22), 19-25. https://files.eric.ed.gov/ fulltext/EJ1112816.pdf

Kapasia, N., Paul, P., Roy, A., Saha, J., Zaveri, A., Mallick, R., Barman, B., Das, P. \& Chouhan, P. (2020). Impact of lockdown on learning status of undergraduate and postgraduate students during COVID-19 pandemic in West Bengal, India. Children and Youth Services Review, 116, 105194. https:// doi.org/10.1016/j.childyouth.2020.105194

Krodel, K., Becker, K., Ingle, H. \& Jakes, S. (2008). Helping under-resourced learners succeed at the college and university level: What works, what doesn't, and why? www.ahaprocess.com/files/ HelpingURLSucceed_whitepaper05152009.pdf

Kunju, S.S. (Ed.) (2020, April 9). Lockdown hits poor students hard, $86 \%$ unable to explore online learning: Survey. https://www.ndtv.com/education/covid-19-lockdown-hits-poor-students-hard86-unable-to-explore-online-learning-survey-2209009

Messiou, K. (2017). Research in the field of inclusive education: Time for a rethink? International Journal of Inclusive Education, 21(2), 146-159. https://doi.org/10.1080/13603116.2016.1223184

Mulenga, E.M. \& Marbán, J.M. (2020). Prospective teachers' online learning Mathematics activities in the age of COVID-19: A cluster analysis approach. EURASIA Journal of Mathematics, Science and Technology Education, 16(9), em1872. https://doi.org/10.29333/ejmste/8345

Naciri, A., Baba, A., Achbani, A. \& Kharbach, A. (2020). Mobile learning in Higher education: Unavoidable alternative during COVID-19. Aquademia, 4(1), ep20016. https://doi.org/10.29333/ aquademia/8227

Nkoane, M.M. (2013). Creating sustainable postgraduate supervision learning environments through critical emancipatory research. TD: The Journal for Transdisciplinary Research in Southern Africa, 9(3), 393-400. https://doi.org/10.4102/td.v9i3.186 
Patton, M.Q. (2002). Two decades of developments in qualitative inquiry: A personal, experiential perspective. Qualitative social work, 1(3), 261-283. https://doi.org/10.1177/1473325002001003636

Pawloski,T.H. (2020). Challenges and opportunities: Leveraging the power of the brain for students in and of poverty. NationalYouth-At-Risk Conference. 108. https://digitalcommons.georgiasouthern.edu/ nyar_savannah/2020/2020/108

Payne, R. (2008). Under-resourced learners: 8 strategies to boost student achievement. Texas: aha! Process. http://www.ahaprocess.com/wp-content/uploads/2019/09/Under-Resourced-Learners-Excerpt.pdf

Petrović, Z.S. (2013). Implementation of the inclusive educational model in schools. FACTA UNIVERSITATIS - Philosophy, Sociology, Psychology and History, 12(01), 29-40. http://facta.junis. ni.ac.rs/pas/pas201301/pas201301-03.pdf

Schuelka, M.J. (2018). Implementing inclusive education. https://opendocs.ids.ac.uk/opendocs/bitstream/ handle/20.500.12413/14230/374_Implementing_Inclusive_Education.pdf?sequence $=1$

Schuelka, M.J., Braun, A.M. \& Johnstone, C.J. (2020, January). Beyond access and barriers: Inclusive education and systems change. In FIRE: Forum for International Research in Education, 6(1). https://doi. org/10.32865/fire202061198

Sinnerbrink, R. (2012). Critical theory as disclosing critique: A response to Kompridis. Constellations, 19(3), 370-381. https://doi.org/10.1111/cons.12003

Sintema, E.J. (2020a). Effect of COVID-19 on the performance of grade 12 students: Implications for STEM education. Eurasia Journal of Mathematics, Science and Technology Education, 16(7), em1851. https://doi.org/10.29333/ejmste/7893

Sintema, E.J. (2020b). E-learning and smart revision portal for Zambian primary and secondary school learners: A digitalized virtual classroom in the COVID-19 era and beyond. Aquademia, 4(2), ep20017. https://doi.org/10.29333/aquademia/8253

Suardika, I.K., Suhartini, L. \& Pasassung, N. (2020). Using Whatsapp for teaching a course on the education profession: Presence, community and learning. International Journal of Mobile and Blended Learning (IJMBL), 12(1), 17-32. https://doi.org/10.4018/IJMBL.2020010102

Susilo, A. (2014). Exploring Facebook and Whatsapp as supporting social network applications for English learning in higher education. In PDE Professional Development in Education Conference 2014, 11-12 June, Park Hotel Bandung. http://repository.ut.ac.id/id/eprint/4930

Tomlinson, C.A. (2014). The Differentiated Classroom: Responding to the Needs of All Learners (2nd ed.). ASCD.

UNESCO-IBE (2016). Reaching out to all learners: A resource pack for supporting inclusive education. Geneva: UNESCOIBE. http://unesdoc.unesco.org/images/0024/002432/243279e.pdf

Upoalkpajor, J.L.N. \& Upoalkpajor, C.B. (2020). The impact of Covid-19 on education in Ghana. Asian Journal of Education and Social Studies, 23-33. https://doi.org/10.9734/ajess/2020/v9i130238

Xu, D. \& Jaggars, S. (2013). Adaptability to online learning: Differences across types of students and academic subject areas. https://doi.org/10.7916/D82N59NB

Yin, R.K. (2017). Case study research and applications: Design and methods (6th ed.). Sage.

\section{How to cite:}

Kombe, C.L.M. \& Mtonga, D.E. (2021). Challenges and Interventions of E-learning for Underresourced Students amid Covid-19 Lockdown: A Case of a Zambian Public University. Journal of Student Affairs in Africa, 9(1), 23-39. DOI: 10.35293/jsaa.v9i1.1426 
RESEARCH ARTICLE

\section{Mitigating the Implications of Covid-19 on the Academic Project at Walter Sisulu University in South Africa: A Proposed Framework for Emergency Remote Teaching and Learning}

Rushiella N. Songca, ${ }^{\mathrm{i}}$ Clever Ndebele ${ }^{\mathrm{ii}}$ \& Munienge Mbodilaii

\section{Abstract}

Walter Sisulu University (WSU) in South Africa, like other universities worldwide, is faced with the challenges associated with the outbreak of the Covid-19 pandemic. The challenge has changed our day-to-day lives, including the way we interact and conduct business. In the midst of this, WSU has had to change the way learning and teaching occurs. Traditional face-to-face tuition had to be adapted by moving to the online mode of teaching and learning to both minimise the time lost in the academic project and protect staff and students from the devastating effects of the virus. This article reflects the actions taken by the University and describes its pilot-project approach to online learning and those processes it has put in place to ensure its effective implementation.

While it is accepted that switching to an online mode of teaching and learning can facilitate flexibility in space and time, the reality is that the majority of students at WSU - mainly due to their geographical and socio-economic environments - experience daily challenges ranging from poor network coverage, lack of internet connectivity, lack of electricity and other socio-economic impediments that make online learning stressful or beyond their reach. In this article, we present a model that could be used by higher education institutions (HEIs) to respond to Covid-19 in the short term. The proposed model is underpinned by a framework that caters for students who are readily able to access online learning, students with intermittent access to online facilities and finally, students who cannot access online education. First, we provide a brief description of online learning, highlighting the challenges presented to teaching and learning by this approach. We argue that our context and education policies present additional problems that militate against the adoption of online strategies by most HEIs. In the final instance, we present a framework that is better suited to our context and can be used during and after the lockdown. Data were collected using online questionnaires with both structured and openended questions from both lecturers and students to determine their experiences with the testing project. Lastly, we draw conclusions based on the findings of the study.

i Prof. Rushiella Nolundi Songca is the Vice-Chancellor and Principal at Walter Sisulu University, South Africa. ORCid: 0000-0002-2738-6615. Email: rsongca@wsu.ac.za

ii Prof. Clever Ndebele is Senior Director: Learning and Teaching at Walter Sisulu University, South Africa. ORCid: 0000-0002-4258-4812. Email: gcndebele@wsu.ac.za

iii Mr Munienge Mbodila is acting Head of Department, Information Technology Systems, Faculty of Economics \& Information Technology Systems at the Komani Campus of Walter Sisulu University, South Africa. ORCid: 0000-0003-4158-9037. Email: mmbodila@wsu.ac.za 


\section{Keywords}

Covid-19; emergency remote teaching; higher education; ICT; online learning; pilot project; rural universities; teaching and learning

\section{Introduction}

Walter Sisulu University (WSU), like all other contact universities in South Africa and the world, had to change its mode of teaching and learning following the outbreak of Covid-19. In South Africa, following the announcement of the nationwide lockdown level 5 by the President of the Republic on 26 March 2020, Higher Education Phase 1 response started, accompanied by an emergency planning phase for the sector (Council on Higher Education [CHE], 2020). At WSU, this planning phase was characterised by university management working to ensure that there were communication devices and access to data for students and staff, and by academic staff creating online material to be delivered to students.

As shown in the WSU 2020-2030 Draft Strategic Plan, before the Covid-19 pandemic, the University had adopted the blended learning approach as the delivery model for teaching and learning through the application of technology-enhanced pedagogies to address some of the key challenges in teaching and learning (WSU, 2020a). The outbreak of Covid-19 at the beginning of 2020 brought to the fore an urgent need for the University to implement alternative measures to deliver tuition. In the scramble to save the academic year and with insufficient time to plan and implement online learning, many institutions, including WSU, introduced what has now come to be described as emergency remote teaching and learning (Murphy, 2020; Hodges et al., 2020; CHE, 2020).

Some universities were able to adjust relatively smoothly to a multi-modal distance learning and teaching environment; but some have not been able to do so. As per WSU Term 2 Quarterly Report 2020,WSU fell into the latter category (WSU, 2020b). In response to the national initiatives, WSU adopted a primarily online and technology-infused tuition delivery model with a clear delivery plan intended to seamlessly replace the contact model. Under the contact model, which the institution is accredited to offer by the South African Department of Higher Education and Training (DHET), although a blended learning approach was adopted, the integration of technology in teaching and learning was very low before the advent of Covid 19. A technical task team was established in early April 2020 to develop online policies and other related guidelines. The team comprised academic and non-academic staff with experience in teaching online and information communication technology (ICT). This team was at the forefront of driving the online learning project at WSU. The team, which was inclusive of Deans, Campus Rectors, and other relevant staff members, met regularly to monitor progress and assess the implementation of agreed-upon interventions. The team approached the challenge by means of a pilot project, which this article describes and evaluates. This pilot project was intended to ensure the effective use of technology to aid teaching and learning at WSU.

The aim of this article is threefold. First, it discusses online teaching as an emergency resource during the pandemic and highlights the dynamics engendered by this model of teaching and learning. Secondly, we argue that our context and education policies present 
additional problems that militate against the adoption of online approaches by most universities in South Africa, especially historically disadvantaged universities such as WSU. In the final instance, we offer a framework that is best suited to the WSU context and could be used during and after the lockdown. The framework is drawn from our experience of the pilot project implemented to introduce online learning in response to the national lockdown resulting from the Covid-19 pandemic. Lastly, we draw conclusions based on the findings of the case study of the pilot project.

\section{Conceptual Framework}

Due to the outbreak of the Covid-19 pandemic, many institutions, including WSU, cancelled face-to-face (F2F) classes and moved all their courses online to continue teaching and learning while keeping both staff and students safe during periods of hard lockdown.

Globally, at the turn of the 21st century, many institutions started to use computers to teach online, and soon thereafter, eLearning was adopted to characterise the use of technologies, specifically computers and the internet (Sangra et al., 2012; Lauran et al., 2012; El-Seoud et al., 2014) to teach.

During the pandemic, many schools and universities closed to keep students and teachers safe and adopted online multi-modal models to teach in order to continue teaching and learning. As a result, distance learning, remote learning and eLearning approaches have taken centre stage during the pandemic and have been adopted by many institutions in varying degrees (Williamson et al., 2020).

\section{Online learning}

Online learning characterises 21st-century educational systems. As it entails the provisioning of programmes to students separated by distance, some researchers argue that it evolved from distance learning (Sangra et al., 2012). Initially, eLearning was understood to refer to education mediated through computers and the internet. Initially terms such as 'computer-based learning', 'computer-training', 'technology-based learning' were used before being replaced by eLearning. Recently, the term 'online learning' has gained more traction (Sangra et al., 2012).

Online learning is difficult to define. Research reveals that online learning has no single definition, and the original definition has since been expanded to include anything delivered, enabled or mediated by electronic technology for the explicit purpose of learning (Li \& Masters, 2009; El-Seoud et al., 2014). Li and Masters (2009, p. 246) argue that the ' $\mathrm{e}$ ' in eLearning is not only about electronics but should be understood to encapsulate the distinguishing characteristics of eLearning namely, "evolving, enhanced, everywhere, every time and everybody". The change in the conceptualisation and application of eLearning has resulted in the adoption of online learning as a substitute for eLearning. The latter reflects the multi-media nature of learning inclusive of the use of social media and communication platforms such as WhatsApp, Facebook and others (Ramakrisnan et al., 2012). For the purposes of this article, online learning and eLearning - as defined by Li and Masters (2009) - are used interchangeably. 
Online instruction is less personal than F2F because of a lack of physical proximity between the learner and the teacher; therefore teachers are expected to employ techniques to make the classroom more interactive to motivate the students (El-Seoud et al., 2014). To be successful, teaching online requires online instructor readiness and their ability to be flexible and adapt to formal and less formal teaching methods (El-Seoud et al., 2014). Moreover, successful online teaching requires varied approaches relating to delivery and feedback on assessment and the instructors' continued presence online (Roddy \& Lodge, 2017; Tanis, 2020).

According to Luaran et al. (2014), online learning is referred to as a learning system that maximises the use of hardware and technologies and occurs online synchronously or offline asynchronously. Interactions vary and include interactions between learnerinstructor, learner-content and learner-learner (Ramakrisnan et al., 2012; El-Seoud et al., 2014; Roddy \& Lodge, 2017; Tanis, 2020).

Online support is critical to students' learning and comes in a variety of channels such as chat rooms, e-mails, e-tutors. It provides students with answers to specific questions and enhances their understanding of a given task or content (Ramakrisnan et al., 2012; Luaran et al., 2012). Online learning, unlike emergency remote teaching (ERT), is a carefully designed process that has distinctive pedagogical dimensions such as modality, the role of online assessment and the role of the instructor (Hodges et al., 2020). Online learning also requires an effective eco-system of learner support to ensure that learners are adapting to novel ways of teaching and learning and receive the necessary support to do so. However, in most instances, these types of support initiatives take time to identify and build which is not always possible in the case of an emergency such as the one we currently face.

Online learning is often designed purposely to be remote and distant; it is accessible and voluntary and unlike ERT not urgent and has the full support of the Faculty and students (University of the People, 2020). Planning, developing and preparing a fully online course can take six to nine months before the course is delivered (Hodges et al., 2020).

\section{Emergency remote teaching}

The pandemic created a situation where we did not have the luxury of time to develop online learning as described above. In response we turned to ERT which by its nature facilitates swift response time and rapid implementation. ERT occurs when there is a departure, albeit temporarily, from the traditional mode of learning. When this shift occurs, F2F teaching is flipped or turned into digital education (University of the People, 2020; Hodges et al., 2020).

ERT is precipitated by a crisis that prevents traditional F2F teaching from taking place. Consequently, when this occurs alternative learning models such as online lessons, radio lessons, and blended learning may have to be introduced as temporary emergency measures to ensure that learning continues (University of the People 2020; Hodges et al., 2020).

ERT provides temporary access to instruction and provides lecturers with an opportunity to be creative and innovative. However, implementation of ERT in various countries, including South Africa, presents challenges to both students and lecturers alike. A study of the impact of eLearning amongst nursing students and teachers in Nepal 
(Sudedi et al., 2020) revealed that institutions in many parts of the world, including those in South Africa, grapple with similar problems. For example, teachers and students face difficulties when studying or teaching at home. Moreover, socio-economic conditions and technological skills or lack thereof may act as hindrances to the eLearning process. The Nepalese study and experiences encountered at WSU revealed that some students and lecturers had to be trained in the use of technology before they could work online.

Many lecturers may find the process of teaching online stressful because they were suddenly expected to traverse unfamiliar territory (Morgan, 2020). This was also the case at WSU.The adoption (often in a rapid manner) can result in lecturers and students claiming that they are practising online teaching and learning although this assertion is inaccurate because there are clear differences between ERT and online teaching, not least of which relate to the time taken to prepare for and implement full-scale online learning (University of the People, 2020; Hodges et al., 2020). WSU has support staff who train both academics and students to teach and learn online. However, with the move to online and increased demand for support, these support teams may be unable to deal with the increased demand as will be shown in the results' section of this article. Before Covid-19 descended upon us, very few academics at WSU were taking up the training, and those who did often needed re-training because they never actually taught digitally in practice due to a lack of access to technological tools. The Nepal study revealed similar challenges (Sudedi et al., 2020).

The success of remote teaching and learning also hinges on the ability to use a learning management system (LMS) and the reliability of those systems. Universities located in rural areas such as WSU have to contend with weak internet service and low bandwidth internet. Even those with high bandwidth internet have to deal with service interruptions or services slowing down due to collective consumption as more people use internet at home and work during the lockdown (Sudedi et al., 2020; Williamson et al., 2020). These challenges are disruptive and have a negative impact on remote teaching. Therefore, institutions have to be innovative and flexible.

According to Williamson, Eynon and Porter (2020), not all young people are necessarily digitally savvy or 'digital natives'. The use of technology is multidimensional and in as much as young people can use technologies a critical minority of young people is excluded entirely (see Williamson et al., 2020). Some students at WSU, for example, expressed their inability to navigate the LMS and unfamiliarity working with a laptop and learning online.

In addition, although WSU was at the forefront amongst historically disadvantaged universities in providing laptops and data access to students as shown in the case study below, nonetheless socio-economic factors and other challenges faced by students threatened to undermine these interventions.

\section{The Case Study}

The setting of this case study is the South African higher education system, where there are great levels of inequality between institutions due to their differing geographic locations, levels of resourcing, cultural, racial and political histories (Leibowitz et al., 2015; Leibowitz et al., 2017). Under apartheid and colonialism, social inequalities were embedded and 
reflected in all spheres of social life, including the higher education system as a product of the systemic exclusion of blacks and women (Badat, 2010). Badat further argues that this differentiation and diversification along lines of race and ethnicity, resulted in the advantaging in various ways of the historically white institutions and the disadvantaging of the historically black institutions.

Even after twenty-six years of democracy, the remnants of apartheid remain and student experiences in historically black universities (located predominantly in rural areas) are undesirable because of isolation, neglect and poor resource provisioning (HSRC, 2005; Ndebele et al., 2017). Thus, Leibowitz et al. (2017, p. 30) aver:

In the South African context, history and geography intersect: whether a university was 'previously disadvantaged' and continues to be under-resourced; and whether its physical location affects the institution's ability to attract and retain academic staff, and in this way, impacts on teaching quality.

Given its rural location, this case study shows that where WSU is located presents on the one hand an opportunity for the use of online formats in the delivery of teaching and learning to compensate for geographic isolation; on the other hand, there is often the challenge of technical and professional support for the smooth operation of online platforms (Mollenkopf, 2009; Ndebele et al., 2016).

WSU was established on 1 July 2005 through a merger of two polytechnics and a university, i.e. the former Border Technikon, Eastern Cape Technikon and University of Transkei in terms of the Higher Education Act 101 of 1997, as amended. WSU operates under a divisional governance and management system and has four campuses, each headed by a Campus Rector. The four campuses are spread across four distant locations in the Eastern Cape province of South Africa, namely in Mthatha, Butterworth, Buffalo City and Komani (formerly Queenstown). The Mthatha Campus, which comprises five faculties, is composed of three delivery sites, namely: Nelson Mandela Drive Site, Zamukulungisa Heights Site and Nkululekweni Site. Butterworth Campus, consisting of three faculties is only one delivery site. The Buffalo City Campus consists of three faculties and comprises six delivery sites spread across the city of East London, namely: Cambridge Street Site; Buffalo City Stadium Site; Heritage Building Site; College Street Site; Chiselhurst Site and Potsdam Site. Komani campus with two faculties has two delivery sites, namely: Whittlesea Site and Grey Street Site.

The University is currently in the process of finalising its next strategic plan 2020-2030 (WSU, 2020a) and underpinning the new strategic plan. The following draft new vision 2030 has been crafted in which WSU is to be a "value-driven, technology-infused African university providing a gateway for local talent to be globally competitive and make a sustainable socio-economic impact."

To realise the vision, the mission of the University is as follows: "Through quality teaching and learning, innovative research and community engagement, WSU inspires future-ready graduates to become responsible citizens who are able to address complex societal challenges in critical, ethical, scholarly, sustainable and entrepreneurial ways." 
Inspired by the liberation struggle stalwart Walter Sisulu after whom the University is named, and guided by our country's foundational norms, the University accepts as its core values: academic freedom; honesty and integrity; quality and excellence; dignified, ubuntubotho-led behaviour; incorporating respect for oneself, other persons and property; and humility, selflessness and service orientation.

The student enrolment at WSU has increased from a total of almost 26000 student headcounts in 2015 to just above 33000 in 2019. Women account for 56\% of the student body, and $99 \%$ of the student population are black Africans. The University draws most of its students from high schools located in the Eastern Cape, a province considered to be one of the poorest in the country. The majority of students enrolled at WSU (88\%) are from traditionally disadvantaged backgrounds (WSU, 2020a).

Prior to Covid-19, WSU used Blackboard as the LMS which means that there was a system in place for blended teaching and learning as well as to share information and communicate with students. On 7 August 2018, WSU announced the Blackboard Mobile App and Blackboard Collaborate Tool as additional tools to the course management system which made blended teaching and learning, interaction and communication with students more all-in-one. The potential benefits of Blackboard include: (i) increased availability, (ii) quick feedback, (iii) improved communication, (iv) tracking, and (v) skill building (Bradford et al., 2007). However, the majority of lecturers at WSU were not fully utilising the tools to enhance teaching and learning. Challenges such as technology adoption, skills, connectivity, network coverage, tools of trade and many more were amongst the major obstacles for many academics and students to make full use of the LMS. The online presence prior Covid-19 was made of only a few groups of academics, who in our context are called eLearning champions. To overcome this, a multi-modal approach was proposed and piloted phases presented in the following section.

\section{Case study phases}

The multi-modal approach at WSU, under the five lockdown levels, is represented diagrammatically in Figure 1 below.

\begin{tabular}{|c|c|c|c|c|}
\hline $\begin{array}{l}\text { PHASE } 1 \\
\text { Lockdown Level } 5\end{array}$ & $\begin{array}{l}\text { PHASE } 2 \\
\text { Lockdown Level } 4\end{array}$ & $\begin{array}{l}\text { PHASE } 3 \\
\text { Lockdown Level } 3\end{array}$ & $\begin{array}{l}\text { PHASE } 4 \\
\text { Lockdown Level } 2\end{array}$ & $\begin{array}{l}\text { PHASE } 5 \\
\text { Lockdown Level } 1\end{array}$ \\
\hline $\begin{array}{l}\text { - Needs assessment } \\
\text { for online learning. } \\
\text { - Senate approval of } \\
\text { Emergency Teaching } \\
\text { and Learning Plan. }\end{array}$ & $\begin{array}{l}\text { - Pilot testing for } \\
\text { remote learning. } \\
\text { - Asynchronous } \\
\text { learning continues for } \\
\text { all students. } \\
\text { - University academic } \\
\text { calendar amendment. } \\
\text { - Remote learning } \\
\text { continues. }\end{array}$ & $\begin{array}{l}\text { - Distribution of } \\
\text { laptops and loading } \\
\text { of data for students. } \\
\text { - Decision to delay } \\
\text { return of students } \\
\text { until beginning of } \\
\text { September. } \\
\text { - Remote learning } \\
\text { continues. }\end{array}$ & $\begin{array}{l}\text { - Preparations for } \\
\text { return of } 50 \% \text { of the } \\
\text { students. }\end{array}$ & $\begin{array}{l}\text { - Hundred per cent of } \\
\text { the students return. } \\
\text { - Online learning } \\
\text { continues with } \\
\text { restricted F2F contact } \\
\text { only for practical } \\
\text { subjects. } \\
\text { - Collection of } \\
\text { laptops continues for } \\
\text { those students who } \\
\text { could not be reached } \\
\text { during levels } 2,3 \\
\text { and } 4 \text {. } \\
\text { - Implementation } \\
\text { of alternative } \\
\text { assessment where } \\
\text { necessary. }\end{array}$ \\
\hline
\end{tabular}

Figure 1: Summary of the phases of the online multi-modal teaching approach 


\section{Phase 1: Lockdown Level 5, March/April 2020}

Following the lockdown pronouncement at the end of March 2020, an emergency multi-modal teaching plan was developed and approved by the Senate. Thereafter, various policies and procedures on remote learning such as 'Quality Standards for Online Learning, Guidelines for Online Assessments' and 'WSU New Approach to Teaching and Learning During Covid-19' were developed. This was followed by a communiqué to all Deans requesting them to indicate laptop needs for all staff. Four hundred academics out of approximately eight hundred and fifty stated that they did not have laptops. Procurement of laptops for all academics, including part-time academics, commenced. Simultaneously, a survey was sent to all students to determine their online learning device needs. $87 \%$ indicated that they needed laptops for learning and teaching. A decision was taken to issue all academics with $10 \mathrm{~GB}$ of data and all students with $30 \mathrm{~GB}$ of data, $10 \mathrm{~GB}$ during daytime and $20 \mathrm{~GB}$ at night. Following DHET communication on funding of laptops for students funded by the National Student Financial Aid Scheme (NSFAS), the University procured 21000 laptops and commenced distributing these to students at their homes using various service providers. The distribution of laptops commenced in mid-June 2020 and continued until August 2020 throughout the country using both courier companies and the University's own transport department. Students who could not be reached for any reason collected their laptops when they arrived on campus when the country moved to lockdown level 1.

To prepare for the roll-out of ERT, a decision was taken to pilot online learning, to test the readiness, effectiveness and the usability of the learning model and the related systems to achieve effective and efficient learning and teaching. A sample size of 500 students was selected from four campuses of WSU. A consent form and a pre-testing and post-testing questionnaire were designed. Specific objectives of the pilot testing were defined as follows:

(i) Examine the extent to which, in the opinion of both lecturers and the students, the training offered to lecturers has enabled them to deliver lectures online competently. In other words, are lecturers able to, for example, competently record lectures, upload recorded lessons and study materials to LMS, and share the link to the lectures with students?

(ii) Assess lecturers' ability to competently conduct 'live' online lectures. In other words, are lecturers able to log in to the online platform, invite students to join the forum, share documents 'live' during lectures, and stimulate interaction with students during online lectures?

(iii) Determine students' actual access to study materials loaded on LMS or couriered physically (for those on 'distance learning' mode of delivery). In other words, are students able to access study materials on time?

(iv) Evaluate students' participation efficacy in terms of their ability to log in to join 'live' lectures, hear the lecturer clearly, and interact with the lecturer during an online lecture.

(v) Examine students' and lecturers' levels of satisfaction with the quality of 'help' received from support staff, such as ICT and faculty office. 
The results of the pilot exercise are presented in the next section. It is worth noting that because so many students (and many academics) did not have access to computers and data off-campus, the previous use of the LMS or any other form of online learning was minimal. This is unlike at historically advantaged universities where data and laptops may have been more readily available to staff and students. In these institutions, the shift under Covid-19 was mainly an increase in their online presence and maybe involved consideration of issues of student engagement and online assessment. While this may all be complicated, it is nowhere close to the WSU experience.

To prepare for both the testing and the eventual rollout of online learning and teaching, massive training of staff was conducted on the use of the LMS on aspects such as uploading of learning materials for students to access and the population of module sites. Asynchronous instruction proved to be preferable to synchronous activities, especially for under-digitised students. Given our context and the fact that our self-hosted Blackboard LMS was struggling to cope with the demand, lecturers were advised to use Microsoft Teams and other platforms. This meant that academics also had to be trained in the use of these alternative platforms. Therefore, teams of academic 'experts' in the different faculties were established to assist other lecturers who were struggling with the use of these alternative teaching platforms. It soon became clear that the support interventions had to be enhanced. These teams also collaborated across faculties and began to share ideas and best practices.

\section{Phase 2: Lockdown Level 4, May/June 2020}

To ensure a smooth pilot stage, Tablets were distributed to the 500 students and data loaded for the pre-testing pilot on the students' cell phone numbers. A pre-testing questionnaire was sent to the students together with the tablets to assess their readiness in terms of devices, network coverage, internet access, location and other challenges that may affect their participation in the online infused teaching and learning. After the testing, a posttesting questionnaire was sent to both students and lecturers to determine the levels of satisfaction as well as to measure whether the pilot addressed the objective of the testing.

The pilot testing phase was conducted during June 2020 with regular weekly feedback timelines to allow the expeditious initiation of corrective measures as well as a postimplementation review. According to Welman and Kruger (1999), the value of a pilot study is to determine possible flaws in measurement procedure, identify unclear items in a project as well as the behaviour of the participants about any discomfort experienced concerning an item in a questionnaire. In their research, Lee, Whitehead, Jacques and Julious (2014) agreed that the primary goal of a pilot is to offer adequate assurance to permit a big definitive test to be undertaken. The testing process was scientifically and academically sound, addressing key points of strategic implications to achieve a clear and coordinated selection process, implementation plan as well as clear definition of testing units. The actual pilot testing process occurred over four weeks, and in Figure 2 are the weekly processes involved during the testing. 


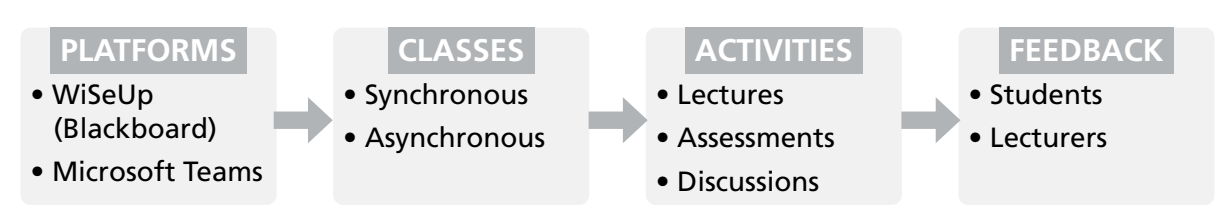

Figure 2: Weekly processes involved during the testing

- Platforms: Online access for teaching and learning during the testing, WiSeUp (Blackboard) was used as the primary LMS and Microsoft Teams as an additional eLearning platform to leverage online teaching.

- Classes: During the testing classes were conducted in both synchronised and unsynchronised online delivery mode and a standard timetable was used to avoid clashes.

- Activities: Besides regular lectures, students were given weekly tasks such as assessments, quizzes as well as participation in discussion groups.

- Feedback: To observe students' and lecturers' levels of satisfaction during the testing, a weekly survey was conducted using an online questionnaire.

While the testing was taking place, to salvage the academic year, a decision was taken to commence with asynchronous learning for the rest of the student population where students were sent materials by academics through various platforms such as the LMS, WhatsApp, Microsoft Teams and Google docs to mention a few.

\section{A synopsis of the testing pilot results}

The responses of the testing pilot from the four campuses are presented in this section according to the critical objectives of the testing. Table 1 shows the number of participants per campus according to their Faculty.

The pilot testing was conducted over four weeks, and data were collected using online questionnaires with both structured and open-ended questions from both lecturers and students to determine their experiences with the testing project. The presented results respond to the primary keys objectives of the testing pilot.

One of the objectives of the pilot was to ascertain the extent to which training provided in the University enabled lecturers to deliver online lectures, for example, competently record lectures, upload recorded lessons and study materials to LMS, and share the link to the lessons with students. Most lecturer participants from all the campuses indicated that training enabled them to deliver online classes as well as uploading of learner guides, study materials and other supporting material in the LMS. Some of them were even able to upload videos, YouTube links, and voice-over PowerPoint. This preliminary result goes along with other studies that show that training is one of the factors that needs to be considered by an institution before the implementation of eLearning (Mbodila et al., 2019; Shamase, 2016; Vale, 2016; Arden, 2014). According to Mbodila et al. (2019), staff training is a fundamental factor that equips them with essential technological and pedagogical skills related to ICT use in learning and teaching. 
Table 1: Number of participants per campus

\begin{tabular}{|c|c|c|c|}
\hline Campus & Faculty & $\begin{array}{l}\text { Number of } \\
\text { participants }\end{array}$ & Level of study \\
\hline \multirow[t]{3}{*}{ Mthatha } & $\begin{array}{l}\text { Faculty of } \\
\text { Commerce and } \\
\text { Administration } \\
\text { (FCA) }\end{array}$ & 75 & $\begin{array}{l}\text { Level } 1=25 \\
\text { Level } 2=25 \\
\text { Level } 3=25\end{array}$ \\
\hline & $\begin{array}{l}\text { Faculty of Natural } \\
\text { Sciences (FNS) }\end{array}$ & 35 & $\begin{array}{l}\text { Level } 1=15 \\
\text { Level } 2=10 \\
\text { Level } 3=10\end{array}$ \\
\hline & $\begin{array}{l}\text { Faculty of } \\
\text { Educational } \\
\text { Sciences (FEDS) }\end{array}$ & 35 & $\begin{array}{l}\text { Level } 1=15 \\
\text { Level } 2=10 \\
\text { Level } 3=10\end{array}$ \\
\hline \multirow[t]{2}{*}{ Butterworth } & $\begin{array}{l}\text { Faculty of } \\
\text { Education Science } \\
\text { (FED) }\end{array}$ & 45 & $\begin{array}{l}\text { Level } 1=25 \\
\text { Level } 2=10 \\
\text { Level } 3=10\end{array}$ \\
\hline & $\begin{array}{l}\text { Faculty of } \\
\text { Engineering and } \\
\text { Technology }\end{array}$ & 59 & $\begin{array}{l}\text { Level } 1=29 \\
\text { Level } 2=15 \\
\text { Level } 3=15\end{array}$ \\
\hline Buffalo City & $\begin{array}{l}\text { Faculty of Science, } \\
\text { Engineering and } \\
\text { Technology (FSET) }\end{array}$ & 125 & $\begin{array}{l}\text { Level } 1=45 \\
\text { Level } 2=40 \\
\text { Level } 3=40\end{array}$ \\
\hline \multirow[t]{2}{*}{ Komani } & $\begin{array}{l}\text { Faculty of } \\
\text { Education } \\
\text { and School } \\
\text { Improvement } \\
\text { (FEDSI) }\end{array}$ & 60 & $\begin{array}{l}\text { Level } 1=20 \\
\text { Level } 2=20 \\
\text { Level } 3=20\end{array}$ \\
\hline & $\begin{array}{l}\text { Faculty of } \\
\text { Economics and } \\
\text { Information } \\
\text { Systems (FEITS) }\end{array}$ & 20 & $\begin{array}{l}\text { Level } 1=10 \\
\text { Level } 2=5 \\
\text { Level } 3=5\end{array}$ \\
\hline Lecturers & & 38 & \\
\hline Online tutors & & 46 & \\
\hline Total & & 538 & \\
\hline
\end{tabular}

The study also sought to identify any challenges lecturers and students experienced concerning logging into the online platform, inviting students to join the forum, sharing documents 'live' during lectures, and stimulating interaction with students during online lectures. Both lecturers and student participants reported that they were able to access the online platform, download, and share study materials effectively. Participants also indicated that they used various platforms for sharing and conducting live classes; however, most students were using the LMS (WiSeUp) to download study material that was zero-rated by various mobile services. Lecturers and students also indicated that Microsoft Team was the platform most frequently used for synchronous, live classes. Figure 3 shows the platforms that were mostly used during the testing pilot. 


\section{Synchronous Online Platforms}

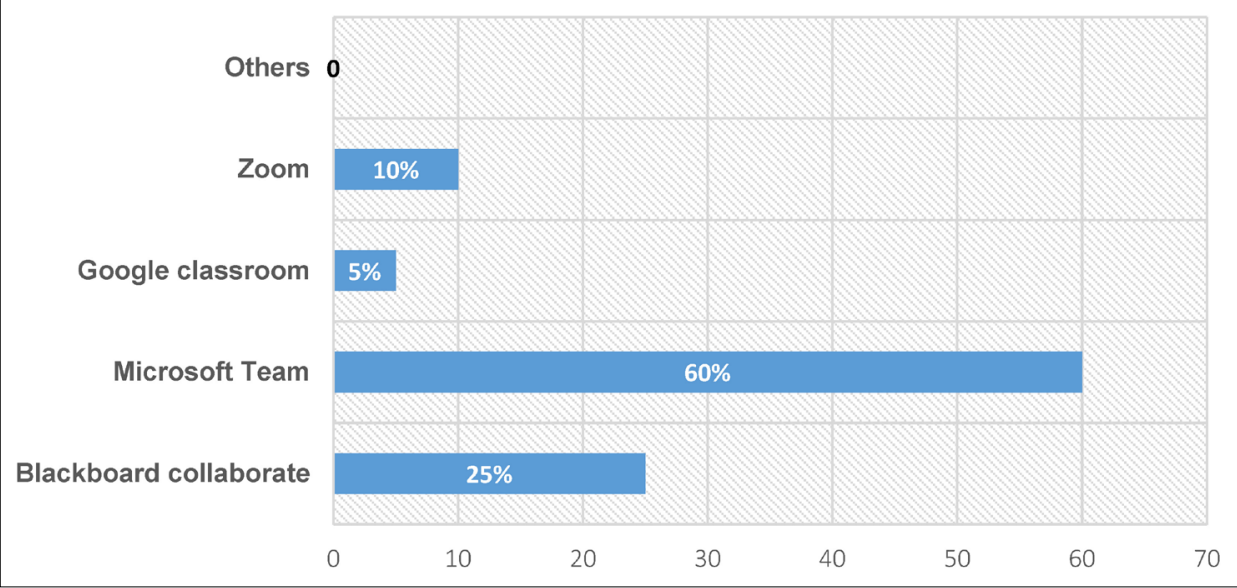

Figure 3: Online platforms for synchronous class $(\mathrm{N}=492)$

On a question as to whether or not students were able to access study materials on time, students indicated that they were able to access learning materials. However, with the challenge of the connectivity, not all of them managed to get such materials on time or participate in all the synchronous classes. This challenge is because most WSU students are located in rural areas where the network connectivity is poor which caused problems for live streaming as well as downloading or uploading materials. This shows that WSU in South Africa, like universities in other developing countries, grapples with infrastructural inequalities (see Subedi et al., 2020, p. 70; Williamson et al., 2020, p. 110). Although people may have internet access, people in city centres often enjoy faster internet compared to those living in rural areas (see Sudedi et al., 2020).

Similarly, when asked if they were able to log in to join 'live' lectures, hear the lecturer clearly, and interact with the lecturer during online lessons, the participants indicated that the internet connection was a challenge most of the time during synchronous classes. Hence, they had experienced challenges in joining live lectures, hearing the lecturers clearly while interacting with the rest of the class. The issue of network coverage in certain parts of South Africa, particularly in the rural areas in the Eastern Cape province, is still a significant delaying aspect in rolling out online teaching and learning at WSU. Students' home environments as shown in this case study presented obstacles for students studying from home during the lockdown. Some students live in small households with their siblings and extended family members. These experiences further militate against participation in synchronous learning for students living in these circumstances. In addition, young people who do not ordinarily have digital access in their homes are likely to have fewer digital skills and this may undermine their ability to learn effectively (see also Williamson et al., 2020).

The quality of internet access presents real challenges for students in rural South African universities such as WSU as well as the University of Fort Hare, University of 
Limpopo, University of Venda and the University of Zululand. To address this, most lecturers used asynchronous approaches for teaching to allow students to access study materials at a convenient time, and they adopted multi-modal pathways such as video recorded mini-lessons and made use of social media and communication platforms such as WhatsApp (see also Morgan, 2020, p. 137).

A standard Likert scale was used to determine the extent to which both students and lecturers were satisfied with the quality of 'help' received from support staff, such as ICT and faculty offices. Participants selected responses which ranged from 5 , indicating strongly agreeing to 0 indicating strongly disagreeing with the statements given. Figures 4 and 5 illustrate the responses of students and lecturers, respectively.

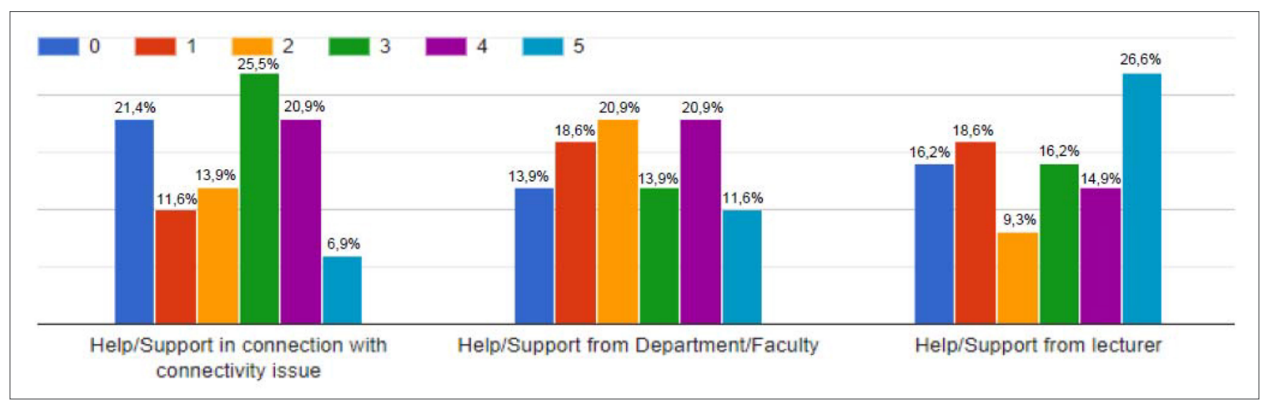

Figure 4: Students' overall satisfaction with the quality of help $(\mathrm{N}=454)$

Figure 4 shows that $54 \%$ of the students found the support they received in connection with connectivity issues either fair, agreed or strongly agreed that support was adequate, while $46 \%$ either did not receive any support at all, disagreed or strongly disagreed that there was any support. The fact that almost half the respondents were dissatisfied with ICT support was cause for concern.

Concerning support from the Faculty, specifically the Head of Department or the Dean, $46 \%$ of the respondents found such support either fair, agreed that they received enough support, or strongly agreed that support was adequate. In comparison, 54\% either did not receive any support at all, disagreed or strongly disagreed that there was any support. Again, the fact that more than half of the students did not receive any support at all is cause for concern.

A further question sought to find out student satisfaction with support from the lecturers. 58\% found such support either fair, agreed that they received enough support or strongly agreed that support was adequate while $42 \%$ either did not receive any support at all, disagreed or strongly disagreed that there was any support. It would have been expected that at least more support would have been received from the lecturers who interacted with students daily online. To mitigate these challenges, a call centre was established in the University with a dedicated operator from each Faculty responsible for receiving all student queries. The call centre also has representative operators from support functions such as the teaching and learning centre, student affairs and the ICT department. This is expected 
to help improve student support as the University moves to level 2 of the lockdown. It should be noted that all of these decisions had to be made against a backdrop of significant institutional financial constraints. A standard Likert scale questionnaire with a scale ranging from 1 to 5 and not applicable (N/A) was used to determine lecturers' satisfaction with the quality of 'help' received from support staff, such as ICT and faculty offices: $1=$ very dissatisfied; 2 = dissatisfied; 3 = neither dissatisfied nor satisifed; $4=$ satisfied; 5 = very satisfied; and $\mathrm{N} / \mathrm{A}=$ not seeking such help.

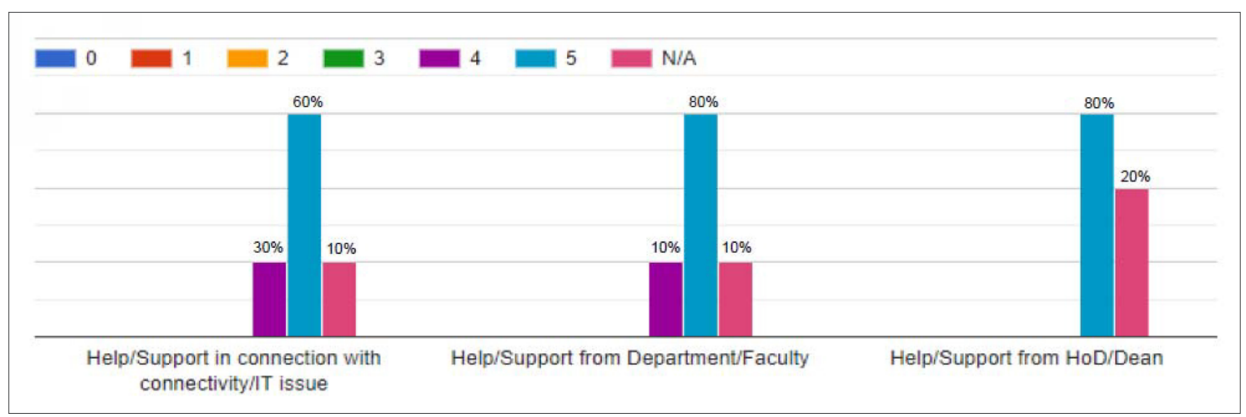

Figure 5: Lecturers' overall satisfaction with the quality of help $(\mathrm{N}=38)$

Concerning lecturer satisfaction with connectivity issues, $90 \%$ of the lecturers who responded to the question found the support satisfactory by either agreeing or strongly agreeing that support was adequate (10\% indicated not applicable to the question). With regard to support from the Faculty, specifically the Heads of Departments, again the vast majority either agreed or strongly agreed that support was adequate (90\%) while 10\% indicated that the question was not applicable to them. A further question that sought to find out lecturer satisfaction with support from the Dean revealed that $80 \%$ of the lecturers either agreed or strongly agreed that support was adequate. The positive feedback from the lecturers could be attributed to the fact that in preparation for ERT the University issued laptops and data cards to academics and academic support staff who directly support online learning. In order to mitigate challenges experienced by lecturers in the faculties, academics who are experts in eLearning were identified as champions in their respective departments so that they could assist other lecturers experiencing challenges. In addition, lecturers could also use the call centre. This is expected to help improve student support as the university moves to level 2 of the lockdown.

\section{Phase 3: Lockdown Level 3, June/July/August 2020}

Armed with the results from the testing phase, and some of the intervention measures discussed above, the 29 June 2020 was set as the roll-out date for online learning to all students. A continuous reflective questionnaire was developed for online learning to enable continuous feedback from both lecturers and students during the roll-out. The university calendar was adjusted to end in February 2021. While laptops had been procured for funded students as this would be recouped from their grants and bursaries, debate on unfunded students in light of the "no student to be left behind" principle continued. The Students' 
Representative Council argued that if no student was to be left out of the online learning and teaching process as indicated by the Minster of Higher Education and Training, then all students needed to be issued with laptops regardless of funding source. A resolution was eventually reached to issue laptops to all students who had requested them regardless of funding. Due to the dispersed geographical location of students throughout the country, challenges concerning the distribution of laptops soon emerged. The main challenges in the delivery process were inadequate, incomplete, unverifiable or incorrect contact details, especially physical addresses and phone numbers, supplied by students despite a request made to them through an online survey to update their details on the university system. For example, some students had a postal box address in rural areas without a physical address. Another challenge was the issue of students registering their parents' contact details (e.g. cell phone numbers) on registration forms instead of their own numbers. To mitigate the challenges, ICT at WSU developed an App called WSU website mobile verify to verify student and staff details. This application assisted students to update their information by including contact and address details. The issue of network connectivity also continued to affect many students.

\section{Phase 4: Lockdown Level 2, August/September 2020}

Level 2 lockdown triggered preparation for the return of students from 24 August 2020. This date was brought forward from the originally set date of 2 September 2020 for those faculties and campuses that felt ready. During deliberations at Senate, some campuses and faculties indicated that they were ready in terms of the Covid-19 health and safety protocols to accept students and were therefore given the green light to so. Online learning continued with students only accessing facilities such as residences, library, and laboratories but accessing tuition from their residences. F2F tuition commenced under strict social distancing conditions only for students involved in practical subjects for which it is not possible to learn remotely.

\section{Phase 5: Lockdown Level 1, September/October 2020}

Lockdown level 1 saw preparations for and the return of all students. A cautious approach was adopted where initially online learning continued with restricted F2F contact only for practical subjects. This was gradually relaxed with F2F allowed in venues with numbers as stipulated by the National Coronavirus Command Council. Collection of laptops continued for those students who could not be reached during levels 2, 3 and 4 . Implementation of alternative assessment was adopted where necessary to replace the traditional sit-down examinations. Following the upsurge in Covid-19 cases towards the end of November 2020 in the Eastern Cape Province, all F2F tuition was suspended again in favour of online learning. Online learning is set to continue when the 2021 academic year commences.

\section{Proposed Framework for Online Intervention}

The Covid-19 emergency has precipitated a much wider uptake of educational technology in the University, which had not been widespread prior to 2020. The benefits of such 
use are undoubted and is one of the few 'silver linings' of the pandemic in our context. Resistance to technology or lack of access to hardware, bandwidth and EdTech proficiency had been at the heart of the low number of courses with an online presence prior to 2020, but the pandemic forced the institution's hand in this regard and the achievement of the goal of blended learning will undoubtedly continue if and when WSU returns to contact classes for all in 2021 or beyond. A resolution has already been reached by the Institutional Management Committee that at the resumption of the 2021 academic year online learning will continue. Processes are already under way to procure 7200 laptops for the anticipated 2021 first-year intake.

As part of our recommendations, we present in Figure 6 a framework that can inform future long-term interventions while providing both students and staff an effective online education.

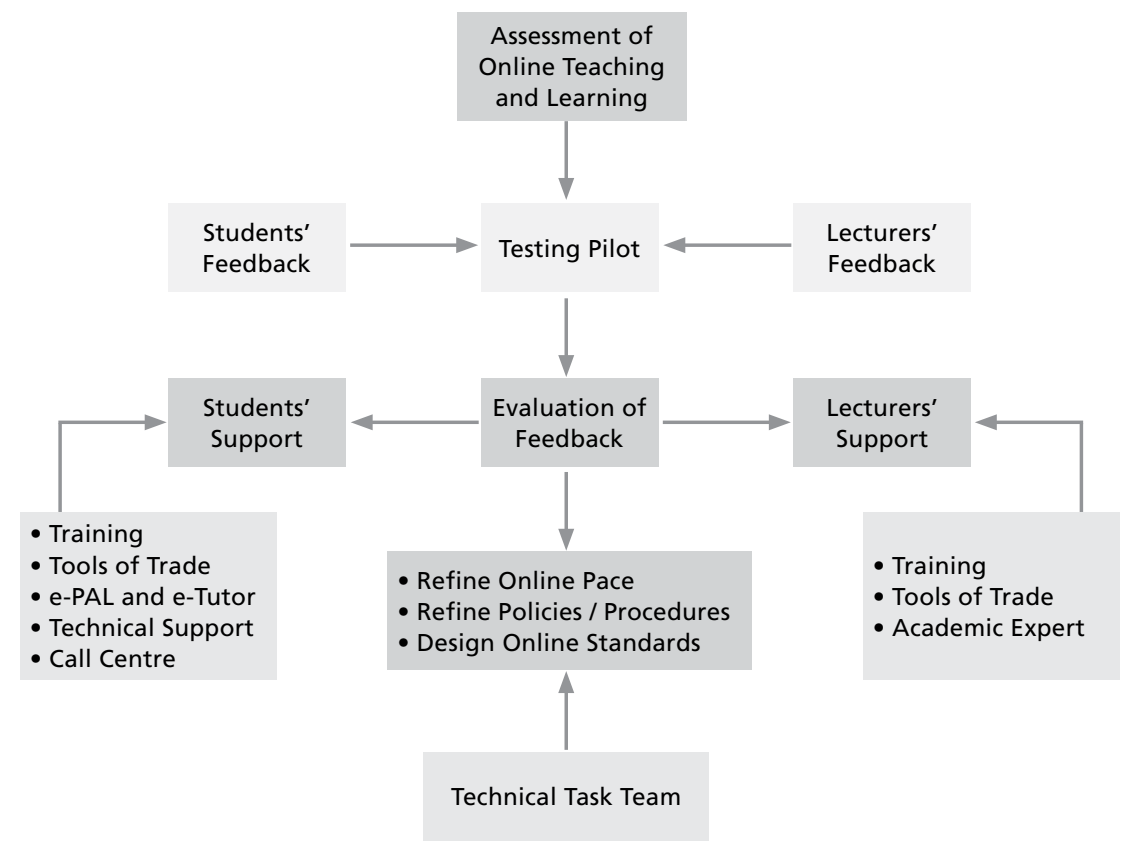

Figure 6: Proposed framework for online intervention

- Training of students, more specifically students registered with WSU for the first time, should be compulsory. Training should include sessions on how to use the LMS system. At a strategic level, the use of technologies should be integrated in the teaching and learning ecosystem of education. Most of the learning activities should be done online, such as the submission of assignments, and technologies should be used as part of the students' learning experience. Regarding the latter, lecturers should provide students with opportunities to do projects, use digital tools to collect information, create presentations and so on. E-tutor and technical support for students should form part 
of student success initiatives. As part of the blended learning model, F2F tutors should either double up as e-tutors, or e-tutors should be appointed to augment the support provided by F2F tutors. Technical support should readily be provided to students who may encounter technical problems in using their laptops or need to install software to be able to learn.

- The establishment of a call centre to respond to or redirect student queries may alleviate most of the burden felt by support staff and lecturers in the Faculties. The call centre is the first point of entry into the university and directs queries to the relevant departments. The centre deals with faculty-specific issues, academic support and psychosocial support, thus enriching students' learning experiences.

- Many historically disadvantaged universities were confronted with staff and students who lacked the tools of trade to work effectively online. Universities, especially disadvantaged institutions, should budget for laptops (and associated maintenance and insurance costs) for staff as part of their recruitment processes. As far as students are concerned, arrangements are underway to ensure that part of the government National Financial Aid Scheme (NFAS) bursary allocated for the purchase of books, for example, goes towards the provisioning of laptops.

- Technical task teams should be established to help develop, refine policies, procedures and standards on online learning. These teams should comprise both academic and support staff.

- Providing training to staff to teach online is pivotal to the success of online learning. Universities should forge partnerships with online universities both nationally and internationally and encourage academics to register for programmes on online teaching as part of their blended learning/online learning strategy and staff development.

- The importance of establishing academic experts in the Faculties is central to the success of online teaching. The experts provide assistance to lecturers struggling with online teaching and ameliorate the stresses associated with online learning. Most universities do not have enough human resources to provide training for both students and staff. Academic experts therefore provide this intervention to their own peers. These teams also collaborate across Faculties and share best practices which helps with the buy-in and provides staff with an opportunity to experiment with different platforms.

- Universities in far-flung areas have experienced connectivity challenges. In addition, students from these areas also struggle with internet connectivity at home. Consequently, asynchronous instruction, including the recording of short videos for students, should be the primary mode of teaching and learning. Social media platforms such as WhatsApp should be used as additional resources.

\section{Conclusion}

Although pandemic conditions may present challenges for education, they also afford higher education institutions an opportunity to craft long-term solutions. Moving forward, implementation of well-thought-out blended learning approaches will continue to leverage on the use of technologies and student and staff support frameworks as part 
of the education eco-system. Research and reflexive teaching are central in refining and developing strategies for online learning. Data analytics and monitoring and evaluation strategies are important interventions that will guarantee long-term solutions. While blended learning is the way of the future, we are aware that is poses many other challenges that will become evident in the immediate future. These challenges will likely relate to the issue of pedagogy, staff and student capacitation, the realities of student under-digitisation etc., which are challenges we hope to address in future submissions resulting from the WSU pilot project.

In this article we have discussed ERT as an emergency resource during times of disruption such as the Covid-19 pandemic and highlighted the dynamics and challenges engendered by this model of teaching and learning. Secondly, we have argued that our context and education policies present additional problems that militate against the adoption of online approaches to teaching and learning. In the final instance, we have offered a framework that is best suited to the WSU context and could be used during and after the lockdown. The framework is drawn from our experience of the pilot project implemented to introduce online learning in response to the national lockdown resulting from the Covid-19 pandemic working with students who are readily able to access online learning, students with intermittent access to online facilities and students who cannot access online education.

\section{Acknowledgements}

We would like to acknowledge the comments we received from the journal's peer reviewers and editors which helped improve consecutive versions of this article.

\section{Research Ethics}

This research is based on reflections from participant observation in a pilot project and document analysis. While no ethics clearance was sought for the study, informed consent was obtained directly from participants through completion of informed consent forms.

\section{Conflict of Interest}

The authors have been personally involved in the practice described and analysed in this article and declare no conflict of interest.

\section{Funding}

No funding has been received specifically for this study. The authors would like to acknowledge the time and resources and support availed by their university to conduct and write up this study.

\section{References}

Badat, S. (2010). The Challenges of Transformation in Higher Education and Training Institutions in South Africa. Development Bank of Southern Africa.

CHE (Council on Higher Education) (2020). Quality assurance guidelines for emergency remote teaching $\mathcal{E}$ learning and assessment during the Covid-19 pandemic. South Africa: $\mathrm{CHE}$. 
Hodges, C., Moore, S., Lockee, B.,Trust,T. \& Bond, M. (2020, April 27). The difference between emergency remote teaching and online learning. Educause Review. https://er.educause.edu/articles/2020/3/ the-difference-between-emergency-remote-teaching-and-online-learning

Lee, E.C., Whitehead,A.L., Jacques, R.M. \& Julious, S.A. (2014). The statistical interpretation of pilot trials: Should significance thresholds be reconsidered? BMC Medical Research Methodology, 14(41), 1-8. https://doi.org/10.1186/1471-2288-14-41

Leibowitz, B., Bozalek, V., Farmer, J., Garraway, J., Herman, N., Jawitz, J., Mc Millan, W., Mistri, G., Ndebele, C., Nkonki,V., Quinn, L.,Van der Merwe, S.,Vorster, J. \& Winberg, C. (2017). Collaborative Research in Contexts of Inequality: The Role of Social Reflexivity. Higher Education, 74, 65-80. https://doi.org/10.1007/s10734-016-0029-5

Leibowitz, B., Bozalek, V., James, G., Nicoline, H., Jeff, J., Muhuro, P., Ndebele, C., Quinn, L., Van Schalkwyk, S.,Vorster, J-A. \& Winberg, C. (2017). Learning to teach in higher education: An investigation into the influences of institutional context on the professional learning of academics in their role as teachers. Pretoria: Council on Higher Education.

Li, H. \& Masters, J. (2009). Editorial: E-learning and knowledge management in the early years: Where are we and where should we go. Knowledge Management \& E-Learning: An International Journal, 1(4), 245-250. https://doi.org/10.34105/j.kmel.2009.01.017

Luaran, J.E., Samsuri, N.N., Nadzri, F.A. \& Baharen, K. (2014). A study on the student's perspective on the effectivenees of using e-learning. Procedia-Social and Behavioural Sciences, 123, 139-144. https://doi. org/10.1016/j.sbspro.2014.01.1407

Mbodila, M., Ndebele, C. \& Muhandji, M. (2019). Assessing options for ICTs integration in the classroom at a rural based South African university. Journal of Gender, Information and Development in Africa (JGIDA), 8(2), 37-58. https://doi.org/10.31920/2050-4284/2019/8n2a3

Morgan, H. (2020). Best practices for implementing remote learning during a pandemic: The Clearing House. A Journal of Educational Strategies, Issues \& Ideas, 93(3), 135-141. https://doi.org/10.1080/000 98655.2020.1751480

Murphy, M.P.A. (2020). Covid-19 and emergency eLearning: Consequences of the securitization of higher education for post-pandemic pedagogy. Contemporary Security Policy, 41(3), 492-505. https://doi.org/ 10.1080/13523260.2020.1761749

Ndebele, C., Muhuro, P. \& Nkonki, V. (2016). Rurality and the professional development of university teachers South African Journal of Higher Education, 30(6), 127-145. https://doi.org/10.20853/30-6-728

Ramakrisnan, P., Yahya, Y., Hasrol, M.N.H. \& Aziz, A.A. (2012). Blended learning: A suitable framework for e-learning in higher education. Social and Behavioural Sciences, 67, 513-526. https://doi. org/10.1016/j.sbspro.2012.11.356

Roddy, C. \& Lodge, J. (2017). Applying best practice online learning, teaching, and support to intensive online environment: An integrative review. Frontiers in Education, 2(59), 1-10. https://doi.org/10.33 89/feduc.2017.00059

Sangra, A., Vlachopoulos, D. \& Cabrera, M. (2012). Building an inclusive definition of e-learning: An approach to the conceptual framework. The International Review of Research in Open and Distributed Learning, 13(2), 145-159. https://doi.org/10.19173/irrodl.v13i2.1161

Samir Abou El-Seoud, M., Taj-Eddin, I.A.T.F,, Seddiek, N., El-Khouly, M.M. \& Nosseir, A. (2014). E-learning and student's motivation:A research study on the effect of e-learning on higher education. International Journal of Emerging Technologies in Learning (IJET), 20-26. https://doi.org/10.3991/ijet. v9i4.3465

Shamase, N. (2016, January 14). Helping others is a no-brainer. Mail \& Guardian. 
Subedi, S., Nayaju, S., Subedi, S., Shah, S.K. \& Shah,J.M. (2020). The impact of e-learning during Covid-19 pandemic among nursing students and teachers of Nepal. International Journal of Science \& Healthcare Research, 5(3), 68-76.

Tanis, C.J. (2020). The seven principles of online learning: Feedback from Faculty and alumni on its importance for teaching and learning. Research in Teaching Technology, 28(2319), 1-25. https://doi. org/10.25304/rlt.v28.2319

University of the People (2020). Emergency remote teaching Vs online learning: A comparison. https://www. uopeople.edu/blog/emergency-remote-teaching-vs-online-learning

Vale, P. (2016, January 14). Say it in plain African Language. Mail \& Guardian.

Welman, J.C. \& Kruger, F. (2001). Research methodology for the business and administrative sciences. Oxford University Press.

Williamson, B., Eynon, R. \& Potter, J. (2020). Pandemic politics, pedagogies and practices: digital technologies and distance education during coronavirus emergency. Learning. Media and Technology 45(2), 107-114. https://doi.org/10.1080/17439884.2020.1761641

WSU (Walter Sisulu University) (2020a). WSU Draft 2020-30 Strategic Plan. Umtata: WSU.

WSU (Walter Sisulu University) (2020d). WSU Term 2 Quarterly Report 2020. Umtata: WSU.

\section{How to cite:}

Songca, R.N., Ndebele, C. \& Mbodila, M. (2021). Mitigating the Implications of Covid-19 on the Academic Project at Walt er Sisulu University in South Africa: A Proposed Framework for Emergency Remote Teaching and Learning. Journal of Student Affairs in Africa, 9(1), 41-60. DOI: $10.24085 /$ jsaa.v9i1.1427 


\title{
Rapid Orientation of Students for Emergency Remote Learning during the Covid-19 Lockdown
}

\author{
Danie de Klerk, ${ }^{\text {i }}$ Greig Krulli ${ }^{\text {ii }}$ Tshepiso Maleswena ${ }^{\text {iii }}$
}

\begin{abstract}
In response to the spread of the Covid-19 pandemic, the President of South Africa declared a national lockdown that commenced on 27 March 2020. This posed numerous challenges to the higher education sector, one of which was the preparation of students forced to stay at home to be able to study remotely under unique and often unfavourable circumstances. This article outlines and reflects on the conceptualisation, development, and implementation of an online orientation programme aimed at preparing students to rapidly move to emergency remote learning as a result of a nationwide lockdown. Teaching and Learning Centre staff in the Faculty of Commerce, Law and Management at a South African university rapidly created a short online orientation programme in the institutional Learning Management System, using Salmon's five-stage model as a conceptual framework. The objective was to enable students to acquire the skills and knowledge required for continuing with the university academic programme from 20 April 2020 via emergency remote learning. The orientation programme covered the priority areas of how to get started in emergency remote learning, broad study skills, how to use the required technologies for learning, and managing personal well-being during social isolation and emergency remote learning. In this article, the conceptualisation and development of the orientation programme is analysed, before reflecting on its implementation, challenges, mitigating measures, and lessons learned. Feedback from students indicates that the majority of students felt more prepared for continuing the academic programme, although they still reported feeling anxious about the many uncertainties. The intervention emerges as a useful strategy for helping students transition during a crisis and contributes to the understanding of how to prepare students for rapid transition to Emergency Remote Learning.
\end{abstract}

\section{Keywords}

Covid-19; emergency remote learning; orientation programme; student orientation; student success; student support

i Mr Danie de Klerk is Assistant Dean: Teaching and Learning, Teaching and Learning Centre, Faculty of Commerce, Law, and Management at the University of the Witwatersrand, South Africa.

ORCid: 0000-0001-8051-0833. Email: danie.deklerk@wits.ac.za

ii Dr Greig Krull is Director: Online Learning, Teaching and Learning Centre, Faculty of Commerce, Law, and Management at the University of the Witwatersrand, South Africa. ORCid: 0000-0002-0690-5869. Email: greig.krull@wits.ac.za

iii Ms Tshepiso Maleswena is Coordinator: Road to Success Programme, Teaching and Learning Centre, Faculty of Commerce, Law, and Management at the University of the Witwatersrand, South Africa. ORCid: 0000-0003-1182-9837. Email: tshepiso.maleswena@wits.ac.za 


\section{Introduction}

The South African Covid-19-related national lockdown meant that tertiary institutions had to rapidly move to a different mode of teaching and learning. Hodges, Moore, Lockee, Trust, and Bond (2020) refer to this shift as "Emergency Remote Teaching" (ERT), which they define as "a temporary shift of instructional delivery to an alternate delivery mode due to crisis circumstances" (para.13). The purpose of the shift to ERT is to provide quick access to teaching and support during the emergency. Emergency Remote Teaching and Learning (ERT\&L) is therefore different from the usual design and development of online learning programmes. Johnson, Veletsianos, and Seaman (2020) emphasise the importance of student support in the shift to ERT\&L classifying it as the "steps taken to support, care for, and enable students to succeed" (p. 16). Effective online learning takes place within a learning community where students are not just supported academically, but with other forms of support as well (Hodges et al., 2020). Thus, the need for the online student orientation to assist students to transition to Emergency Remote Learning (ERL) as illustrated by this article.

For student success and support entities, the shift to ERL meant orientating students from diverse backgrounds (i.e. different socio-economic contexts and levels of preparedness for tertiary studies) and (in some cases) remote locations for studying remotely during a global pandemic. Due to the unique conditions, there were no formal guidelines for how this orientation should be done, or what would be necessary to ensure that students are appropriately and adequately prepared for ERL. Nevertheless, the Academic Advisors and teaching and learning staff involved in the development of the online orientation programme, were able to draw on existing literature and a conceptual framework, survey data, and past experience to develop a suite of resources and activities aimed at rapidly preparing students for ERL. This was in part possible due to the existing policies and student support practices within the faculty (the Faculty of Commerce, Law, and Management or CLM) at the University of the Witwatersrand (Wits). Approximately 9000 registered students in the faculty were automatically enrolled in the orientation programme and 6131 students accessed at least some of the resources and activities during the orientation period (15 to 20 April 2020). The article highlights the context of the orientation programme within the institution and then reviews the current literature relevant to its approach and implementation. The conceptualisation and development of the orientation programme is then described, before reflecting critically on its implementation, challenges, mitigating measures, and lessons learned.

\section{Background and Context}

\section{Institutional framework to guide student success}

The Wits Institutional Framework for Student Success (WIFSS) (2019) forms the institutional backbone that guides Wits's approach to student success and support and places the student at the centre of the academic project. As such, it is intended to inform and guide the student success and support work done within faculties and elsewhere in 
the university. The purpose of the WIFSS (2019) is to strengthen the student success and support services on campus, strengthen the links between and amongst these services, and create a system of student support that students can navigate with greater ease. The WIFSS (2019) identifies four main areas of student support, namely (pp. 14-15):Academic Support, Health and Wellness, Material Needs, and Personal Development, all of which are addressed in annual orientation programmes (and elsewhere).

\section{Faculty approach to student success and support}

The CLM Teaching and Learning Centre houses, amongst other functions, the faculty's student success and support programme, known as the Road to Success Programme (RSP) (De Klerk, Spark, Jones \& Maleswena, 2017; Spark, De Klerk, Maleswena \& Jones, 2017). The RSP is directly involved in first-year student orientation and the institutional First Year Experience programme, annually. Four Academic Advisors and 16 peer advisors (known as Success Tutors) work in the unit to provide advisor support to students in the faculty (Spark et al., 2017). Since its inception in 2015 (De Klerk et al., 2017), the RSP has evolved to cover all four main areas of student support (including student orientation) identified in the WIFSS (2019), with all advisors either providing the required support to students or else referring them to specialists within the institution who can.

\section{Theoretical Framework}

For online students to be successful, they need to be supported through a structured development process. Salmon (2004) created the five-stage model as a framework for adopting a structured approach to online learning design in higher education, using constructivist pedagogic theory. The five stages of the model are: (i) access and motivation, (ii) online socialisation, (iii) information exchange, (iv) knowledge construction, and (v) development. The use of this model during the design process offers appropriate support to online students in each stage as they develop expertise in online learning (Salmon, 2004). Although there has been some critique of the model (Moule, 2007), it has been applied to support the design of online courses in different contexts (Johnson, 2017; Karaman \& Orhan Özen, 2016).

Given the need described earlier to rapidly design an orientation programme for students transitioning to ERL, the authors decided to focus on the first three stages of the five-stage model. The aim of Stage 1 (Access and motivation) is to provide a welcoming and encouraging introduction to the new learning environment, thus teaching students how to access the new learning environment and available technical support. The aim of Stage 2 (Online socialisation) is for students to become familiar with the online learning environment and the tools that are available. Students can start to interact with facilitators and other students by sending and receiving messages. The aim of Stage 3 (Information exchange) is for students to undertake various learning activities and make use of the available learning materials (Salmon, 2004). Once students had completed the online orientation programme, lecturers in individual courses would continue to provide scaffolded support for their students in this new learning environment. 


\section{Literature Review}

\section{Transition to emergency remote teaching and learning}

Much of the early literature examining the impact of Covid-19 on higher education has focused on the readiness of institutions, faculty experiences, and the support for staff to transition to a new way of teaching (see Bozkurt et al., 2020; Ferdig, Baumgartner, Hartshorne, Kaplan-Rakowski \& Mouza, 2020; Johnson et al., 2020). Very little of the initial literature has focused on the preparedness of students and how to assist students to transition to a new way of learning. However, several authors have raised concerns around inequities and differences in technological access for students (Adam, 2020; Bozkurt et al., 2020; Johnson et al., 2020). Adam (2020) notes that in addition to internet access, students require digital literacy and self-directed learning skills to benefit optimally from ERT. Bozkurt et al. (2020) highlight how the disruption has forced students to "regulate their own learning and become digitally savvy" (p. 3). The transition to ERT has required institutions to equip students with the necessary skills and resources to learn effectively in a remote setting.

The importance of support and care for students during the disruption has been considered by some studies. In a US survey of faculty and administrators, 58\% of staff reported needing assistance with information on how to best support students studying remotely (Johnson et al., 2020). Johnson et al. (2020, p. 17) suggest that institutions should ask the following question: "Are resources available to students to help them develop strategies for success in online learning environments?". Furthermore, these authors suggest that institutions undertake a needs assessment of students when transitioning during a crisis to determine whether they have access to the requisite technologies and to maintain awareness of socioemotional needs and inequities. To aid the transition of students during the disruption, some institutions have focused on the development of caring relations (Noddings, 2012) or the "pedagogy of care" (Bali, 2015) by listening to students and participating in open dialogue and then providing additional support to address their issues and challenges.

Due to the social isolation resulting from the pandemic, students appear to be suffering a great deal of anxiety, are dealing with issues of health and safety and are facing increasing financial pressures. This means that students would also require more emotional support than ever before and that institutions need to understand the social contexts in which their student live (Adam, 2020). Early student guidelines or reflections on the transition to ERL have highlighted the importance of setting up study routine schedules, to regularly engage with learning activities and to seek help when they have difficulties (academic or socio-emotional) (Bozkurt et al., 2020; COL, 2020). A transition to ERT\&L thus demands students are oriented to the skills and resources, study habits, and awareness of their needs befitting remote studies. Unsurprisingly, the Commonwealth of Learning's guidelines on distance education during Covid-19 therefore recommends educational institutions "provide orientation to students to effectively use online learning and to develop selfdirected learning skills by creating an engaging learning enrolment” (COL, 2020, p. 9). 


\section{Online student orientation}

As students transition from a face-to-face learning environment to an online environment, many are likely to feel anxious about their ability to succeed (Abdous, 2019). An orientation programme is commonly provided as a support mechanism for new university students to address expectations and requirements and to boost their preparedness (Abdous, 2019; Wozniak, Pizzica \& Mahony, 2012). Within online learning programmes, there are additional concerns around student success and student retention. Student orientation has been shown to have a positive impact on online student retention and success (Jones, 2013; Stone \& O’Shea, 2019). As many face-to-face institutions also began to offer online learning, they had to rethink and redesign their learner support services. This necessitated the establishment of orientation programmes that help prepare students and set expectations for their online learning experience (Farrell \& Brunton, 2020; Jones, 2013). An orientation programme also starts to build a community of students and provides direction and support for students who are encountering a new learning environment (Ludwig-Hardman \& Dunlap, 2003). Without proper induction to online learning, students may be unaware of what resources are available to help them or become challenged by the unfamiliarity of the Learning Management System (LMS) (Cho, 2012; Levy, 2006).

Several authors have proposed the objectives and topics to be contained in an online student orientation programme. Cho (2012) suggests four objectives for students: (i) to develop understanding about online learning, (ii) to use the LMS skilfully for learning, (iii) to solve any possible technical issues when using the LMS, and (iv) to develop selfawareness about the learning skills required to succeed. Bozarth, Chapman and LaMonica (2004) recommend that the topics in an orientation programme focus on "enhancing technological and self-management skills, while providing a realistic image of the online learning experience" (p. 89). Institutions also need to make decisions about whether to deliver the orientation online or in person, whether it is compulsory for all students to complete the programme (Harrell, 2008), and whether the orientation is self-paced or facilitated (Abdous, 2019). Another design consideration is the use of facilitators or moderators to encourage participation, assist those students who require help and respond to discussion posts (Wozniak et al., 2012). A benefit of an orientation course is that it provides a "risk-free playground" for students to become familiar with an online learning environment in a space that is not formally assessed (Wozniak et al., 2012). As learner needs are diverse, an orientation programme cannot address the needs of all students, but it does provide the means for students to know where to obtain further help. Wozniak et al. (2012) caution that an orientation course is not a once-off event as "students will tend to access resources as they are needed and may return to review them several times" during a semester (p. 908). This is confirmed by Douglas, Rogers and Ahuja (2018), who see an orientation as only the first part of a programme for supporting students during their firstyear experience. 


\section{CLM Student Orientation to Emergency Remote Learning}

\section{Rationale and conceptualisation}

The team involved in the conceptualisation, development, and implementation of the ERL orientation comprised Academic Advisors from the RSP, the CLM Assistant Dean for Teaching and Learning, and colleagues from the CLM Online Learning Team, all of whom work in the CLM Teaching and Learning Centre. It was acknowledged that students would have to be prepared for ERL, in the same way that mechanisms were being put in place to assist academics to transition to ERT. This would be achieved by creating a student orientation and support site in the Wits LMS, to which all CLM students would have access. Shortly after the lockdown commenced, CLM conducted an online survey of its students to gauge their technology and access needs during this period. Subsequently, survey results, coupled with information about concerns raised by students shortly after the national lockdown commenced, were used during the orientation programme development phase. This included students' apprehension about online learning, concerns about how the move to ERL might affect their performance, and uncertainty about their competence to participate in an unfamiliar mode of learning. Consequently, it was agreed that the orientation programme should introduce and orientate student to online learning (which would include how-to guides, videos, and other resources), provide low-stakes opportunities to model online assessment tools, and enable communication between students and advisors.

In order to collate their ideas, the team conducted a virtual brainstorming session using an online platform called Padlet where participants could populate and share ideas with each other. By drawing on previous interactions with students, the survey results, Salmon's (2004) five-stage model, and literature about ERT\&L and student orientation, advisors identified student needs in relation to ERL. Consequently, the team determined what type of resources needed to be developed (e.g. guidelines, infographics, videos, and activities) to achieve the desired objectives of the orientation programme. It was agreed that the orientation programme would be delivered through a platform that is easily accessible to all students (in alignment with the first stage of access and motivation of the five-stage model [Salmon, 2004]). Thus, the institutional LMS was selected as the platform for the orientation. The LMS had been zero-rated (i.e. little-to-no-data was being used when students and staff accessed the LMS) as a vital ERL resource with which many students were familiar (although this familiarity was limited, as not many had used the LMS for a full range of learning activities) and could be accessed from a variety of devices, including mobile devices. Furthermore, the issue of unpredictability meant that the orientation site had to be adaptable in order for minor changes and updates to be made throughout the period of ERT\&L. As such, delivering the orientation programme through the LMS could be of value to students not only during the orientation period, but for the remainder of the semester (and beyond ERL). 


\section{Aims and objectives of the orientation programme}

The first aim of the orientation programme was to develop resources and activities for equipping students with the requisite skills and abilities to learn remotely during the period of ERT\&L, thus aligning with the second stage (online socialisation) of Salmon's (2004) five-stage model. The programme had to provide advice and guidance for creating a home study environment conducive for learning from home, orientating parents/guardians/ family members to the demands of home study, assisting students with the development and implementation of revised time management plans and study techniques to accommodate the realities of ERL and Covid-19, and prepare them for online assessments (i.e. extended submission windows, taking quizzes through the LMS, and committing to honour pledges).

The second aim of the orientation programme was to develop a platform for communicating with students during lockdown and aligns with stage three (information exchange) of the five-stage model (Salmon, 2004). This would include explaining to students how to access student advisors within the faculty and provide information about other studentaffairs-related university support services. Regarding communication, although student correspondence occurred centrally through the Office of the Vice-Chancellor or the Dean of Students in most instances, there was faculty-specific information that had to be shared with students. Additionally, central messages with particularly important information, would be strategically reposted on the faculty student orientation site to ensure maximum exposure to the information. For students to contact faculty student advisors, the details and contact information for the advisors would be made available on the home page of the orientation site. The orientation site would also provide information on how to reach central university support services, such as the Wits Counselling and Careers Development Unit (CCDU) for booking online therapy sessions, contact details for the toll-free Wits Student Crisis Line (available 24/7 throughout the year to all registered Wits students), and information about the services offered by the Wits Gender Equity Office (GEO) during the ERT\&L period.

The third aim of the programme was to monitor student engagement with orientation activities to identify students who were, possibly, experiencing challenges with ERL. Academic Advisors would then be able to reach out to these students in an attempt to identify reasons for not engaging with the programme. It was anticipated that not all students registered on the orientation site would visit the site or participate in the orientation activities. This would apply particularly to postgraduate students enrolled for research degrees, those with connectivity and internet access challenges, those with inadequate devices or no device at all, and those who simply could not adapt to ERL. Nevertheless, analysing student engagement data daily during the orientation period would enable the team to identify, in particular, information about undergraduate students who might be struggling to access resources, which (together with reports from the institutional Business Intelligences Services) would enable Academic Advisors to contact students who were not actively accessing online resources in the LMS. 


\section{Orientation programme structure, sequencing, and pacing}

To achieve these aims and objectives, the team developed a four-day programme within the LMS. Each day was split into two parts (a morning and an afternoon session) with tasks, activities, and resources linked to each session. Once students navigated to the orientation site, they would come to a landing page where they were welcomed and introduced to the site and its objectives. On this landing page, students were able to view a three-minute orientation video that had been created using a free online resource called Biteable. With a focus on "low-tech" accessibility and to cater for students with connectivity issues as much as possible, all information contained in videos or podcasts was also made available in text format. The introductory message explained that there would be daily sessions for students to complete, with each day's activities launched on that day. This meant that students would be guided through the daily activities and they would have to come back the next day to access the next set of tasks and activities. The orientation programme was rolled out over a four-day period using this staggered approach. The team felt this would provide students with adequate time to engage with each component of the orientation programme and allow them to complete the relevant tasks and activities without overloading them with too much information. Students were given two additional days after the fourth day of the orientation programme, to submit the final assignment and complete the evaluation form. Further details about the activities and components of each day are provided in Table 1 below.

Table 1: Breakdown of activities and components of the ERL orientation programme

\begin{tabular}{|l|l|}
\hline Focus & Activities and Components \\
\hline Day 1: Getting Started & $\begin{array}{l}\text { 1. Watch orientation video and read welcome message } \\
\text { on site home page. }\end{array}$ \\
2. Take a poll about initial feelings towards ERL and \\
perceived preparedness for ERL.
\end{tabular}




\begin{tabular}{|c|c|}
\hline Focus & Activities and Components \\
\hline Day 2: Excellence Skills & $\begin{array}{l}\text { 1. Review Frequently Asked Questions section. } \\
\text { 2. Visit Faculty Information Portal for additional } \\
\text { information about ERL and Covid-19. } \\
\text { 3. Take a poll to gauge the suitability of home study } \\
\text { environments for ERL. } \\
\text { 4. Review guidelines about etiquette for engaging in } \\
\text { online spaces. } \\
\text { 5. Review infographic with ten tips for studying online. } \\
\text { 6. Review infographic with information for taking notes } \\
\text { when studying remotely. } \\
\text { 7. Read guidelines for managing time when studying } \\
\text { remotely. } \\
\text { 8. Draft a time management plan using the time } \\
\text { management template provided. } \\
\text { 9. Review the infographic for taking online assessments. } \\
\text { 10. Watch the How to Access E-Books video to be able to } \\
\text { access e-books from the library. }\end{array}$ \\
\hline Day 3: How-to Guides & $\begin{array}{l}\text { 1. Review updates about zero-rating on the Wits website. } \\
\text { 2. Watch the How to Navigate the LMS video. } \\
\text { 3. Take a poll to gauge level of comfort with using the } \\
\text { LMS for ERL. } \\
\text { 4. Watch the How to Use Turnitin video. } \\
\text { 5. Watch the video for How to Access a Microsoft Teams Live } \\
\text { Meeting. } \\
\text { 6. Read the guide on How to Use the Lesson Tool in } \\
\text { the LMS. } \\
\text { 7. Read the guide on How to Use the Chat Function in } \\
\text { the LMS. } \\
\text { 8. Read the guide on How to Take an Online Quiz in } \\
\text { the LMS. } \\
\text { 9. Take the online quiz to test your knowledge of online } \\
\text { learning and practice using the quiz tool. } \\
\text { 10. Optional activity: Complete the free Microsoft Digital } \\
\text { Literacy online course. }\end{array}$ \\
\hline Day 4: Personal Well-being & $\begin{array}{l}\text { 1. Review updates about zero-rating on the Wits website. } \\
\text { 2. Watch the video on Mental and Emotional Wellbeing } \\
\text { During Social Isolation and/or review the accompanying } \\
\text { infographic. } \\
\text { 3. Review the CCDU Lockdown Wellness Chronicles on } \\
\text { the Wits website and view the poster about Cyber } \\
\text { Bullying from CCDU. } \\
\text { 4. Take note of the Wits Student Crisis Line contact } \\
\text { details. }\end{array}$ \\
\hline
\end{tabular}




\begin{tabular}{|c|c|}
\hline Focus & Activities and Components \\
\hline $\begin{array}{l}\text { Day 4: Personal Well-being } \\
\text { (continued) }\end{array}$ & $\begin{array}{l}\text { 5. Review the South African Social Sector Directory of } \\
\text { Services Contact Particulars document with information } \\
\text { about national contact centres and services during } \\
\text { Covid-19. } \\
\text { 6. Learn about Covid-19 by reading the infographic } \\
\text { about Covid-19. } \\
\text { 7. Review the infographic about keeping your hands } \\
\text { clean to help prevent the spread of Covid-19. } \\
\text { 8. Complete the Online Orientation evaluation form. } \\
\text { 9. Watch the final assignment instruction video and do } \\
\text { the assignment. }\end{array}$ \\
\hline
\end{tabular}

\section{Methodology}

The authors adopted a Design-Based Research (DBR) methodology, which is commonly used within the learning sciences, and involves the development of a context-based solution or intervention in response to a particular educational problem (Anderson \& Shattuck, 2012). The approach would typically see researchers analyse interventions iteratively (i.e. design, review, and iterate), but owing to a lack of time and scope during the Covid-19 emergency, an exhaustive iterative approach was not possible. Nevertheless, DBR is used to address real-life issues in education, like rapidly orientating students to ERL, and entails the collection of data in multiple ways, which is what the authors did for this study. The intention is to use this orientation programme and the lessons learned from it as a baseline for subsequent online orientation programmes, such as those for incoming first-year students.

Data collection occurred in a number of ways over the course of the four-day orientation programme. Student engagement was tracked daily and at the end of the four-day period via the LMS Statistics tool. For the purposes of this article, only highlevel user access and engagement data will be analysed (i.e. the number of individual student visits for the four-day period and the number of clicks per user), although it would be possible to drill down further on activity and assessment data if required. Students' preparedness, perceptions, and level of comfort was gauged using the LMS Polls tool and this data will be analysed for this study. Additionally, final-assignment-submission data from the Assignment tool was analysed and will also be shared in the Findings and Discussion section below. Finally, student evaluation data, collected at the end of the orientation programme using an online survey created in LimeSurvey, was analysed to gauge students' perceived readiness for ERL, their level of comfort with using online tools and resources, and to identify further support needs. An analysis of the aforementioned data is shared and discussed in the Findings and Discussion section below. 


\section{Findings and Discussion}

\section{Figures and statistics}

Prior to the launch of the ERL orientation programme, 9088 registered CLM students (of which 4937 were undergraduate and 4151 postgraduate) were added to the LMS orientation site. An announcement was posted on the site to inform all students about the orientation programme that would launch the following day. The team knew that not all students would participate in the orientation activities (in particular those enrolled for fullresearch degrees and some of the postgraduate programmes), which were not compulsory. Nevertheless, they wanted to make sure that the resources on the site were available to all CLM students. The orientation programme was launched on 15 April 2020 and concluded on 18 April 2020, although students were able to submit final tasks until 19 April 2020 and could complete evaluations until 20 April 2020. During the four-day period under review, 6131 individual students accessed the orientation site and although it is difficult to determine how many completed every component of the orientation programme, the team is satisfied with a $67 \%$ engagement rate over just four days.

Table 2 shows the result of the three daily polls administered on the first three days of the orientation programme. Poll 1 was completed by 4688 individual students and asked about students' preparedness for ERL and the prospects of online studies. Poll 2 was completed by 3899 individual students and aimed to assess the suitability of their home study environment for ERL. Finally, Poll 3 was completed by 3285 individual students and asked about their level of comfort with using the institutional LMS as an online learning platform.

Table 2: Daily poll results

\begin{tabular}{|l|l|}
\hline Poll Question & Results \\
\hline $\begin{array}{l}\text { Poll 1: How do you } \\
\text { feel about taking your } \\
\text { studies online? }\end{array}$ & $\begin{array}{l}\text { - } 2464 \text { respondents (53\%) felt nervous or extremely nervous } \\
\text { about ERL and taking their studies online. }\end{array}$ \\
& $\begin{array}{l}\text { - } 1695 \text { respondents (36\%) felt both nervous and excited } \\
\text { about the prospects of ERL. }\end{array}$ \\
\hline $\begin{array}{l}\text { Poll 2: What best } \\
\text { describes your home } \\
\text { study environment? }\end{array}$ & $\begin{array}{l}\text { - } 931 \text { respondents }(24 \%) \text { said their home study environment } \\
\text { was either not suitable or less than ideal for ERL. }\end{array}$ \\
& $\begin{array}{l}1513 \text { respondents (39\%) said they could make their home } \\
\text { study environments work in the current circumstances. }\end{array}$ \\
& $\begin{array}{l}1455 \text { respondents (37\%) deemed their home study } \\
\text { environment either suitable or ideal for ERL. }\end{array}$ \\
\hline
\end{tabular}




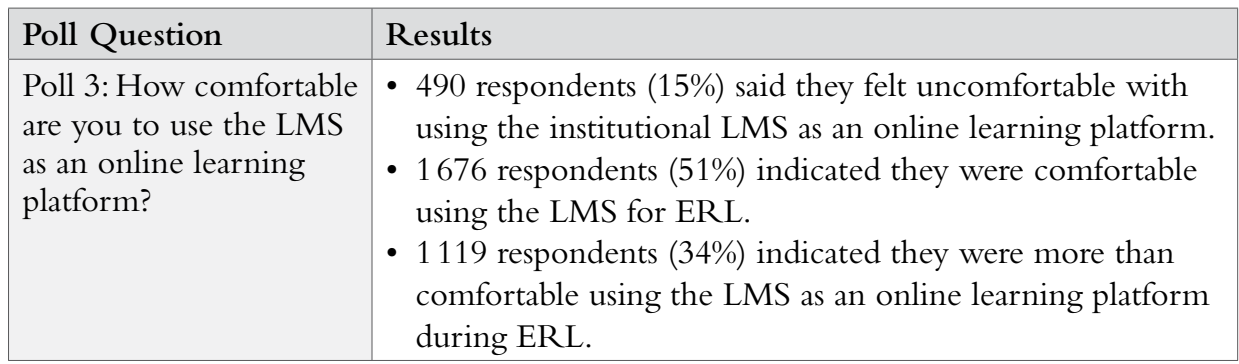

Six hundred and fifty-eight (658) individual students completed and submitted the richpicture final assignment, while 1113 individual students completed the online orientation evaluation. Assignment submissions were lower than expected, although not surprising considering that tasks were voluntary and that marks were not awarded (both factors anecdotally observed to influence students' decision to engage with learning activities). Evaluation results were resoundingly positive, with more than $80 \%$ of respondents finding the shared resources and information useful, indicating the orientation programme was worth their while, and expressing high levels of satisfaction about their ability to use online assessment and communication tools. However, the authors recognise the limitation of the study in that those students who completed the entire programme were likely those who found it most useful (thus reflecting a great deal of satisfaction in the survey). Another concern is that about $30 \%$ of the respondents indicated that they still felt apprehensive about taking their studies online and that they were uncertain about the unfamiliar learning environment they were entering.

\section{Discussion}

The development and rollout of the orientation programme presented more challenges than initially anticipated. The team had limited time in which to implement the various solutions that would achieve the desired outcomes, while having no formal guidelines on which to base the orientation programme for ERT\&L. To mitigate these challenges, the team drew on information gleaned from the online student survey conducted shortly after the lockdown commenced, Salmon's (2004) five-stage model, existing knowledge about online learning and orientation programmes (Abdous, 2019; Bozarth et al., 2004; Cho, 2012), the limited literature about ERT\&L that existed at the time, and established holistic student support principles to develop and implement the ERL orientation programme. Needless to say, this period was fraught for students as the orientation polls indicated that $53 \%$ of students were nervous or extremely nervous about ERL and $24 \%$ of students were living in home environments that were unconducive for ERL studies. Therefore, the development of this programme helped to address some student concerns and further highlight issues of accessibility and more general factors affecting learning. Furthermore, a "low-tech" approach (e.g. making available text versions of video or audio files, amongst other things) was adopted to reduce the challenges (where possible) for students with poor connectivity and limited data. 
A major concern was that some students could not access or did not benefit from this orientation programme during the orientation period. More than $20 \%$ of students enrolled on the site did not access the orientation programme during the orientation period, while only about one in six students completed the evaluation. In alignment with Douglas et al. (2018) and Wozniak et al. (2012), this was mitigated by keeping the site and resources active and accessible to students throughout the academic year. Academic Advisors and peer advisors continue to use the site to communicate and consult with students, while adding new resources when needed (e.g. guidelines for examination preparation and online examinations). Regarding the low survey response rate, although a $12 \%$ response rate to the orientation programme evaluation is less than ideal, one should bear in mind that none of the activities were compulsory, and that survey fatigue may have contributed to the low response rate. The lessons learned from the development of this online orientation programme can be applied in the development of similar programmes for online learning in the institution and the development of support mechanisms to assist students during any future periods of disruption.

\section{Conclusions}

Due to the rapid transition to ERL, an online orientation programme was quickly conceptualised and developed to support students in the Faculty of Commerce, Law, and Management to make this transition. This conceptualisation was based upon Salmon's (2004) five-stage model, a review of the literature, a student survey and the previous experiences of the orientation programme developers. The majority of students within CLM completed at least some of the activities during the orientation period and the students who responded to the evaluation mainly responded positively. The team is satisfied that the programme achieved its main objectives of introducing and orientating students to online learning, providing resources that helped students acquire knowledge and tools for ERL, providing how-to guidelines and videos for ERL, modelling the use of online assessment tools in a low-stakes environment, providing advice and guidance about personal well-being during social isolation and while studying remotely, and enabling communication between students and advisors via LMS communication tools and email. The approach to the development of this online orientation programme is offered as a contribution to the field to assist in the rapid development of online orientation programmes for any future periods of disruption to higher education. Additionally, the programme offered the team an opportunity to gain insight into the challenges students face, their needs during this period, and to identify students who were either ill-prepared for ERL or did not access the online orientation programme at all during the orientation period.

\section{Acknowledgements}

The authors would like to extend their sincere gratitude to the following individuals for their input, advice, guidance, and contribution: Prof. Jason Cohen, Dr Laura Dison, Ms Siyasamkela Jinoyi, Ms Fiona Macalister, Ms Aneshree Nayager, and Mr Mbongeni Shungube. 


\section{Research Ethics}

The authors subscribe to the highest levels of ethics during their research. Only secondary data was used in this study. All data is presented in aggregate form and no individual is identifiable from the data shared in this article.

\section{Conflict of Interest}

The authors have no conflict of interest to declare.

\section{Funding}

No funding was required to complete this study.

\section{References}

Abdous, M.H. (2019). Influence of satisfaction and preparedness on online students' feelings of anxiety. The Internet and Higher Education, 41,34-44. https://doi.org/10.1016/j.iheduc.2019.01.001

Adam, T. (2020). The privilege of \#pivotonline: A South African perspective. Open Education and Development. https://opendeved.net/2020/04/22/the-privilege-of-pivotonline/\#pivotonline/

Anderson, T. \& Shattuck, J. (2012). Design-Based Research:A Decade of Progress in Education Research? Educational Researcher, 41(1), 16-25. https://doi.org/10.3102/0013189X11428813

Bali, M. (2015). Pedagogy of Care - Gone Massive. Hybrid Pedagogy. https://hybridpedagogy.org/pedagogyof-care-gone-massive/

Bozarth, J., Chapman, D.D. \& LaMonica, L. (2004). Preparing for distance learning: Designing an online student orientation course. Educational Technology \& Society, 7(1), 87-106.

Bozkurt, A., Jung, I., Xiao, J.,Vladimirschi,V., Schuwer, R., Egorov, G., .. Paskevicius, M. (2020). A global outlook to the interruption of education due to Covid-19 Pandemic: Navigating in a time of uncertainty and crisis. Asian Journal of Distance Education, 15(1), 1-126. https://doi.org/10.5281/ zenodo. 3878572

Cho, M. (2012). Online student orientation in higher education: a developmental study. Educational Technology Research and Development 60(6), 1051-1069. https://doi.org/10.1007/s11423-012-9271-4

COL (2020). Guidelines on Distance Education during Covid-19. Canada: COL.

De Klerk, D., Spark, L., Jones, A. \& Maleswena, T. (2017). Paving the Road to Success: Reflecting critically on year one of an undergraduate student support programme at a large South African university. Journal of Student Affairs in Africa, 5(1),1-13. https://doi.org/10.24085/jsaa.v5i1.2478

Douglas, T., Rogers, M. \& Ahuja, K. (2018). Challenging the perceptions of orientation in higher education: Student perspectives of a transition initiative. In D. Wache \& D. Houston (Eds.), Research and Development in Higher Education: (Re)Valuing Higher Education, 41 (pp. 69-80). Adelaide, Australia, $2-5$ July.

Farrell, O. \& Brunton, J. (2020). A balancing act: A window into online student engagement experiences. International Journal of Educational Technology in Higher Education, 17(25). https://doi.org/10.1186/ s41239-020-00199-x

Ferdig, R.E., Baumgartner, E., Hartshorne, R., Kaplan-Rakowski, R. \& Mouza, C. (Eds). (2020). Teaching, Technology, and Teacher Education During the Covid-19 Pandemic: Stories from the Field. Association for the Advancement of Computing in Education (AACE).

Harrell, I.L. (2008). Increasing the success of online students. Inquiry, 13(1), 36-44.

Hodges, C., Moore, S., Lockee, B., Trust, T. \& Bond, A. (2020). The difference between emergency remote teaching and online learning. Educause Review. https://er.educause.edu/articles/2020/3/ the-difference-between-emergency- remote-teaching-and-online-learning 
Johnson, C.S. (2017). Collaborative technologies, higher order thinking and self-sufficient learning: A case study of adult learners. Research in Learning Technology, 25. https://doi.org/10.25304/rlt.v25.1981

Johnson, N., Veletsianos, G. \& Seaman, J. (2020). U.S. faculty and administrators' experiences and approaches in the early weeks of the Covid-19 pandemic. Online Learning, 24(2), 6-21. https://doi. org/10.24059/olj.v24i2.2285

Jones, K.R. (2013). Developing and implementing a mandatory online student orientation. Journal of Asynchronous Learning Networks, 17(1), 43-45. https://doi.org/10.24059/olj.v17i1.312

Karaman, M.K. \& Orhan Özen, S. (2016). A Survey of Students' Experiences on Collaborative Virtual Learning Activities Based on Five-Stage Model. Educational Technology \& Society, 19 (3), 247-259.

Levy, P. (2006). 'Living' theory: A pedagogical framework for the process support in networked learning. Research in Learning Technology, 14(3), 225-240. https://doi.org/10.1080/09687760600837025

Ludwig-Hardman, S. \& Dunlap, J.C. (2003). Learner support services for online students: Scaffolding for success. The International Review of Research in Open and Distributed Learning, 4(1), 1-15. https://doi. org/10.19173/irrodl.v4i1.131

Moule, P. (2007). Challenging the five-stage model for e-learning: a new approach. Research in Learning Technology, 15(1), 37-50. https://doi.org/10.1080/09687760601129588

Noddings, N. (2012). The caring relation in teaching. Oxford Review of Education, 38(6), 771-781. https:// doi.org/10.1080/03054985.2012.745047

Salmon, G. (2004) E-moderating: The key to online teaching and learning (2nd ed.). Routledge. https://doi. org/10.4324/9780203465424

Spark, L., De Klerk, D., Maleswena, T. \& Jones, A. (2017). Paving the Road to Success: A framework for implementing the Success Tutoring approach. Journal of Student Affairs in Africa, 5(2), 77-90. https://doi. org $/ 10.24085 /$ jsaa.v5i2.2703

Stone, C. \& O'Shea, S. (2019). Older, online and first: Recommendations for retention and success. Australasian Journal of Educational Technology, 35(1). https://doi.org/10.14742/ajet.3913

WIFFS (2019). Wits Institutional Framework for Student Success. University of the Witwatersrand: December.

Wozniak, H., Pizzica, J. \& Mahony, M.J. (2012). Design-based research principles for student orientation to online study: Capturing the lessons learnt. Australasian Journal of Educational Technology, 28(5), 896-911. https://doi.org/10.14742/ajet.823

\section{How to cite:}

De Klerk, D., Krull, G. \& Maleswena, T. (2021). Rapid Orientation of Students for Emergency Remote Learning during the Covid-19 Lockdown. Journal of Student Affairs in Africa, 9(1), 61-75. DOI: $10.24085 /$ jsaa.v9i1.1428 


\title{
RESEARCH ARTICLE
}

\section{The 'Double Transition' for First-Year Students: Understanding the Impact of Covid-19 on South Africa's First-Year University Students}

\author{
Annsilla Nyar ${ }^{\mathrm{i}}$
}

\begin{abstract}
While all students are affected by the advent of the Covid-19 pandemic, the first-year student population remains a special category of vulnerability for higher education. This is on account of the way the Covid-19 pandemic has disrupted their transition into university and complicated the nature of their entry into and through the formal academic cycle. This article uses the notion of a 'double transition' as a framework for positioning and locating the first-year student transition within the context of the prevailing Covid-19 pandemic. 'Double transition' refers to an additional transition coupled with that of the first-year transition, with regard to the extraordinary situation of students navigating their entry into the unfamiliar terrain of academia while simultaneously navigating the Covid-19 pandemic. The article provides a circumscribed summary of the effects of Covid-19 on university students and looks to describe and explain the nature and shape of first-year transitions in relation to the transition necessitated by the Covid-19 pandemic. It concludes with four key strategies for supporting first-year students as the pandemic continues.
\end{abstract}

\section{Keywords}

Covid-19; first-year students; online teaching and learning; student transitions; transition support systems

\section{Introduction}

This article is written at a very dire time in global and South African history, as the Covid-19 pandemic continues to reconfigure society in devastating and possibly permanent ways. The article herein focuses on one particular aspect of the Covid-19 crisis as it affects higher education: the impact of the Covid-19 pandemic on first-year university students.

In recent months, the advent of the Covid-19 pandemic has seen a fundamental and dramatic restructuring of the global and national higher education agenda, including the cessation of normal campus operations and the swift move to online teaching and learning systems. The Covid-19 pandemic caught South Africa's higher education sector mostly off-guard.This sector has had to hastily engage in relatively new and largely untested online teaching and learning systems, showing up and adversely impacting the number of students

i Dr Annsilla Nyar is Director of the South African National Resource Centre for the First-Year Experience and Students in Transition (SANRC) hosted at the University of Johannesburg, South Africa.

ORCid: 0000-0002-0535-505X. Email: anyar@uj.ac.za 
and staff who do not have access to the requisite technologies and connectivity, or even electricity in the case of those staff and students from poor or low-income backgrounds. Never before has the issue of access to, and affordability of, internet services been so crucial. It is within this prevailing context of disruption and uncertainty, that the fate of one of the sector's most vulnerable sub-populations, i.e. students in their first year of university study, has unfortunately become subsumed amongst multiple competing issues on the higher education agenda. It is anticipated and, indeed feared, that universities, preoccupied with online teaching and learning and making up for lost academic time in the academic calendar, may lose the focus on matters of student transition and support.

Over the past two decades a great deal of effort has been invested by South Africa's universities in matters of First-Year Experience, much of which has drawn from an immense body of global scholarship about student transitions and support (Nyar, 2019). Such scholarship makes a persuasive case for seeing the first year of university study as qualitatively different from the rest of the higher education journey and, further, for affording specialised attention to the first year (Gardner, 1986; Upcraft et al., 2005; Astin, 1993; Tinto, 1993; Pascarella \& Terenzini, 2005; Johnston, 2010; Greenfield et al., 2013).

The first-year transition is based on the idea that first-year students have specialised needs on account of the critical importance of the year. The first year of university study is seen as the foundation of the higher journey, one which sets the emotional and academic tone for the rest of the higher education journey of students and often determines the ways in which students respond to the rest of their studies and their time in the higher education system. Throughput data in many countries and contexts across the world has consistently shown that the initial weeks of the first year are also the time at which students are most likely to drop out from their course in the first year of study. As such, the first year may well function as the basis of students' decision to stay or exit the higher education system (Spady, 1970; Tinto, 1996; Kantanis, 2000; Thomas, 2002; Thomas \& Quinn, 2006). It is, therefore, recognised as a critical transition period which may well affect the educational outcomes of students in a more profound way than other types of transitions (Upcraft \& Gardner, 1989; Tinto, 1993; Terenzini \& Pascarella, 2005).

Given the importance of the first year of study and the corresponding disruption posed to the first year of study by the Covid-19 pandemic, a number of questions arise: How will first-year students navigate the 'new' face of the higher education journey? How is transition understood and experienced in the context of the first year of study? What can universities realistically do to support first-year students through the Covid-19 pandemic? This article seeks to respond to the aforementioned questions, by way of critical reflection and analysis.

\section{How Does Theory Assist in Our Understanding of Student Transition?}

Research and theories on life transitions are abundant in fields such as psychology and sociology, and have helped inform thinking about the subject in higher education. One of the most popular starting points for a theoretical understanding of transition in higher education is that of Nancy Schlossberg, a clinical psychologist (1981). Schlossberg's work 
on life transitions is widely used by many student affairs professionals, particularly so in the areas of academic advising and career services. Schlossberg proposed a transition model which describes transition as "any event or non-event which results in changed relationships, routines, assumptions and roles" (Goodman et al., 2006, p. 33) and identifies four major factors which allow individuals to deal with transition: Situation, Self, Support and Strategies (Schlossberg, 1981). Later, Schlossberg collaborated with student development theorist, Arthur Chickering, in order to adapt her transition theory to apply to college students. They describe the ways in which college students move through the transition process as a series of phases, termed "moving in", "moving out" and "moving through” (Chickering \& Schlossberg, 1995, p.1).

In the field of higher education, student transition is most helpfully framed through the sprawling field of student development theory, which looks to explain and understand the developmental growth of university students (Chickering, 1969; Perry, 1970; Loevinger, 1976; Vygotsky, 1978). The student development literature looks to understand the individual experience and interpretation of transition, but also explores how transition happens in the interface between the characteristics of individual students (socio-economic background, prior experiences of learning, etc.) and the broader social and political context in which the student is located. Towards this end, O'Donnell, Kean and Stevens (2016) explain the role of institutions and larger social contexts in relation to student transition. They understand transition as the intersection between the student and the social context in which the student is embedded. Further, the meaning attributed to the transition by the student experiencing it, and the ease with which the student navigates the transition, depends upon the social contexts in which the transition occurs and the amount of support available to the student.

Accordingly, higher education scholars, such as Vincent Tinto, Alexander Astin, Ernest Pascarella and Patrick Terenzini have argued persuasively that universities must support student transitions, and indeed have a responsibility to do so (Astin, 1984; Tinto, 1993; Pascarella \& Terenzini, 2005; Hussey \& Smith, 2010). Towards this end, for example, Hussey and Smith (2010) propose that part of the purpose of higher education is to support the transitions experienced by students, and further, that the design and delivery of higher education should be predicated on the concept of student transition.

Hussey and Smith state:

'Transition' is not a precise term. Transitions are large, complex and significant changes that occur in a student's life: a nested pattern of lesser changes. They may concern their learning, circumstances, self-concept, autonomy, maturity and so forth. They are changes that the student, parents, friends, prospective employers and educators judge to be of real significance. Some may be intended and brought about by design, others may emerge by happenstance; some will be evaluated as positive, others negative. Examples include such things as the transition from home to university; from dependent youngster to independent adult; from novice to knowledgeable, skilled practitioner or from engaged student to disaffected dropout. Those involved in education have the task of deciding which transitions are desirable and which are undesirable, and amongst the 
former, the priority and order in which they need to be made. Teachers and other staff have to decide how to go about helping students through these transitions and how to detect and measure progress. All this is just describing what higher education has always been about, but describing it in this way changes it from an institution-based system through which students are processed, to a student-centred system, which, at least to some extent, attends to the needs of the individual and their capacity to progress.

(Hussey \& Smith, 2010, p.120)

While centring the role of higher education institutions, it is also recognised that students hold agency. Students play an equally important role in facilitating their own transitions through higher education. It is argued that students have a joint responsibility to manage their transitions and facilitate their own educational outcomes, and further, that universities must be demanding of their expectations for students and work to develop agency and active self-government in their students (Tinto, 1993; McInnis, 2001). This is in line with Sanford's theory of student development (Sanford, 1968), which suggests a 'challengesupport balance'. The 'challenge-support balance' theory is based on the idea that too much challenge may alienate and frustrate students while too much support may never push students into achieving their full developmental potential. Sanford advocated that optimum student growth and development is best facilitated by an appropriate blend of challenge and support.

Of particular interest to this article for the purposes of understanding student transition, is the work of Gale and Parker (2014). They argue that higher education tends to see transition in terms of three broad conceptualisations of transition, i.e. induction, development and becoming, which may not do justice to the real lived experiences of student transition. They make a case for seeing transition for the dynamic, negotiated and non-linear phenomenon that it is. Similarly, Quinn (2010, p. 127) argues for seeing transition in terms of complexity. She advocates for using the pluralised form of transition, i.e. as in "multiple transitions into, out of, through, across and re-entering higher education".

Gale and Parker's (2014, p. 737) definition of transition as "the capability to navigate change" is particularly instructive in its acknowledgement that transitions affect students differentially, particularly those from low-income or historically disadvantaged backgrounds (Gale \& Parker, 2014; Briggs et al., 2012; Thomas, 2002). As expostulated by Thomas (2002, p. 413): "If a student feels that they do not fit in, that their social and cultural practices are inappropriate and that their tacit knowledge is under-valued, they may be more inclined to withdraw early." Reference is made here to Pierre Bourdieu's seminal theoretical work on habitus and cultural capital, which helps to explain differences and disparities in educational outcomes (Bourdieu, 1973). Bourdieu theorised that less advantaged students who have not had the benefit of exposure to the discourses and practices of the higher education system, will not adapt as easily as those who have already had the benefit of cultural capital acquired from their backgrounds and networks. Students from privileged class backgrounds are less likely to encounter constraints or barriers than those who are less advantaged. 
Together, these various theoretical arguments provide a framework for understanding student transition. One may, therefore, draw the following conclusions about transition:

(a) Transition is about more than the student's individual experience of it. Transition cannot be understood without reference to the context in which the transition takes place, and the social and cultural factors involved in that transition;

(b) Universities have an obligation to support students throughout transition; and that support must involve agency from students to help facilitate their own success in their studies;

(c) Transition affects students differentially. Some students will fare better than others. This is due to the amount of cultural capital to which they have access.

This more general conceptualisation of transition helps better understand the nature of educational transitions, more specifically, the first-year transition, and further, how this particular educational transition has been complicated and, indeed, disrupted by the advent of Covid-19. The first-year student population can be said to be facing a 'double' transition of sorts: first, a first-year transition involving the challenges typical of the first year of university study; and, second, an overlapping, equally unsettling, transition, involving the adaptation to a Covid-19-mediated way of life at university.

\section{Understanding the First-year Transition in the Context of Covid-19}

Transitions are a permanent and indeed inescapable part of the human condition, and often have far-reaching consequences for those experiencing them. The process of transition can require individuals to alter their perceptions of self, relinquish familiar reference points, objects or persons, de-link from previous or existing support structures, and sometimes make uncomfortable adjustments to accommodate their altered or new realities. As such, transitions can involve a wide array of emotions, some of which can leave individuals feeling disoriented, or even traumatised. Feelings of anxiety, depression or trauma can accompany transitions. In line with the arguments of scholars advocating support for the transition that takes place in higher education, there is an urgent need to develop support frameworks for students. Such support frameworks can mitigate some of the effects of the two transitions taking place simultaneously at the point of vulnerability in the higher education journey, which is the first year of study.

\section{Challenges of the first-year student transition}

The first-year student transition serves as an example of a life transition involving fundamental change in which individuals struggle to adapt and require support and coping resources. The first year of university study can be aptly described as a 'culture shock'. Students in their first year of study must familiarise themselves with the complex ecosystem of processes, procedures and specific requirements of the university system. For example, logistical competencies are required to navigate such basic university processes and procedures as timetables, maps, schedules, lecture notes, finances, etc. There is an 
acute emotional and psychological component to the first-year transition for students, as students navigate the complex bureaucracy of the universities, establish new relationships and adjust to the discourse and demands of academia. They face a wide range of challenges and stressors in their new environment, which predisposes them to high levels of anxiety and stress (Clark, 2005; Christie, 2009). While some students may possibly navigate this transition with relative ease, other students experience difficulties in adjustment and require support (Briggs et al., 2012; Gale \& Parker, 2014).

The new and changing nature of academic learning, involving departure from the predictable frameworks of school to the relative anonymity and autonomy of university, represents one of the most significant challenges for the first-year student. Students often struggle in order to develop the requirements for academic learning, i.e. flexibility, autonomy and self-directed learning involving reading and critical thinking in ways that are profoundly different from high school learning strategies (Ramsden, 1992; Cook \& Leckey, 1999; Krause, 2006; Lowe \& Cook, 2010). First-year students also struggle to adapt to teaching which takes place most often in large and unfamiliar classroom settings, generally under conditions of relative anonymity. Large class learning is typically associated with limited student engagement and insufficient depth of learning, and may, as Cuseo (2007, p. 2) notes, "initiate maladaptive learning habits or predispositions to learning that linger beyond the first year".

\section{Challenges of the Covid-19 transition}

Covid-19 is a novel disease and hence unanticipated and unexplored.The rapid transmission rate and high mortality rate of Covid-19 renders the disease especially frightening. For firstyear students undergoing their introduction to university while coping with the Covid-19 pandemic, their transition can be described as especially traumatic. As Schlossberg et al. have noted, the impact of a transition increases exponentially when the transition is unanticipated (Schlossberg, 1981). While the challenges of the first-year transition are anticipated for the most part, they are often not fully understood or the extent of those changes are unappreciated. Students are often not fully aware of the nature and extent of the first-year transition, until they are able to fully experience the transition for themselves. The Covid-19 pandemic heightens the complexity of the first-year transition on account of the wholly unanticipated nature of Covid-19.

The unanticipated nature of the Covid-19 pandemic echoes the theoretical understanding of the fundamental nature of transition as unpredictable and irregular (Briggs et al., 2012; Gale \& Parker, 2014). Under normal circumstances, the first-year transition is a destabilising process. When coupled with the exigencies of the Covid-19 pandemic, the first-year transition may well become impossible for students to navigate. For first-year students, the Covid-19 pandemic has come to represent an additional layer of complexity in the context of their introduction to higher education.

The impact of transition is also measured in terms of the degree to which it alters familiar routines and daily lifestyle. First-year students have had to negotiate their transition 
to online learning, while living under conditions of enforced social distancing - all in the context of the new and unfamiliar setting of academia and the world of the university. Due to problems with registration processes, they were only able to experience approximately six weeks of traditional contact learning before the commencement of the national lockdown on 26 March 2020 and the subsequent implementation of a raft of Covid-19 restrictions on daily life. Mathiba's article (2020) describes the challenges facing students as a result of Covid-19 as a "raft of problems". Campus closures took place in a haphazard and confusing way, with many students having to incur costs for unplanned travel, housing and last-minute relocation. Moreover, the hasty nature of South Africa's national lockdown has ensnared many students in bureaucratic predicaments regarding accommodation, transport and food, for example, in terms of refunds for meals and accommodation, or problems of lease agreements for those students who are renting accommodation off-campus and are locked into contracts with landlords.

Many students are experiencing financial hardships on account of sustained job and income losses as a result of Covid-19. The closure of universities has also cut certain students off from employment opportunities, such as those students who may have had part-time work in libraries or cafeterias; or resources, such as those students who may have been receiving food as part of a meals programme offered by their university. Accordingly, first-year students are most likely to be suffering psychological impacts on account of the profound disruptions to their daily lives. Such disruption is compounded by the Covid-19 imposed restrictions on their social lives and the sudden removal of their daily routines of socialisation. It is possible to surmise that prolonged social distancing may well predispose students towards modifying or changing their socialising habits, including their willingness to be in crowds or any or all highly populated spaces.

As an unanticipated transition, the move to online teaching and learning has been sudden and unprecedented for all of South Africa's students. While South Africa's universities have had some limited experience with online teaching and learning, including blended learning, universities are generally not well-positioned to support large-scale online learning. The move to online teaching and learning has been hasty, with little preparation and limited educator training. Students have struggled to transition to online teaching and learning, despite the availability of learning materials and zero-rated applications. Moreover, the overload of information through different software platforms, mobile applications and emails may be an additional source of anxiety and stress for students (Dell, 2020; Macupe, 2020).

Given the sudden onslaught of the Covid-19 pandemic, there are limited studies on the effects of Covid-19 on the mental health of university students. It can, nonetheless, be surmised that the Covid-19 pandemic holds serious mental health and trauma implications for students (Brookes et al., 2020; Salari et al., 2020; Rajkumar, 2020). Students may experience the disruption to the normal routines of daily life as destabilising, requiring an adaptation of their normal coping strategies towards adversity and putting them at risk of adverse adaptive strategies. For those students who may also be preoccupied with illness or 
caring responsibilities on account of Covid-19, this may represent time taken away from their studies and further anxiety about the effect on their studies. Constant exposure to news and information about the pandemic, including misinformation and sensationalist news, may also continue to compromise the mental health and well-being of students.

Given the well-established intersection between poverty and mental health, the demographic likely to be most severely affected by Covid-19 are those from low-income or disadvantaged communities. Students from such backgrounds may experience pronounced isolation and frustration in the course of their learning, in addition to the customary stressors of their daily existence, such as financial hardship, food insecurity and precarious home environments. Certain categories of vulnerable students in the first-year student population may face an increased risk of anxiety and depression during the pandemic, such as those students who are Lesbian, Gay, Bisexual, Transgender, Queer (questioning), Intersex, Asexual and Other non-heterosexual people (LGBTQIA+), disabled or with some form of illness or impairment.

The double transition is summarised below in a tabular synthesised form as Table 1. This table helps to succinctly illustrate the nature of this 'double transition' and all the disruption that is involved in the double transition with regard to the dynamics of the first-year transition which is being simultaneously experienced. By closely positioning the two transitions under the organising framework of common transition categories, viz. Academic, Social/Psychological and Logistical, it is possible to appreciate the depth and extent of the disruption of the Covid-19 pandemic and how the pandemic has deepened and intensified all the existing challenges of transition.

\section{Predicted Long-Term Impacts of the Double Transition}

\section{Prolonged financial hardship}

Depending on the trajectory of the Covid-19 pandemic in South Africa, financial hardships for students could possibly continue and extend for several years to come. First-year students may well be disillusioned by their untimely introduction to the higher education system. They may even question the value for money of an education under the restrictions of Covid-19 and possibly make the decision to leave the system altogether in light of the longer-term outlook for employment. Some may leave the system altogether simply on account of Covid-19 induced impoverishment. It is possible to surmise that South Africa's 'missing middle' (i.e. those students from poor or middle-income backgrounds who do not qualify for national government funding support on account of their combined family incomes being higher than the minimum family income amount stipulated for assistance) may expand on account of Covid-19 job losses and impoverishment of families and communities. 


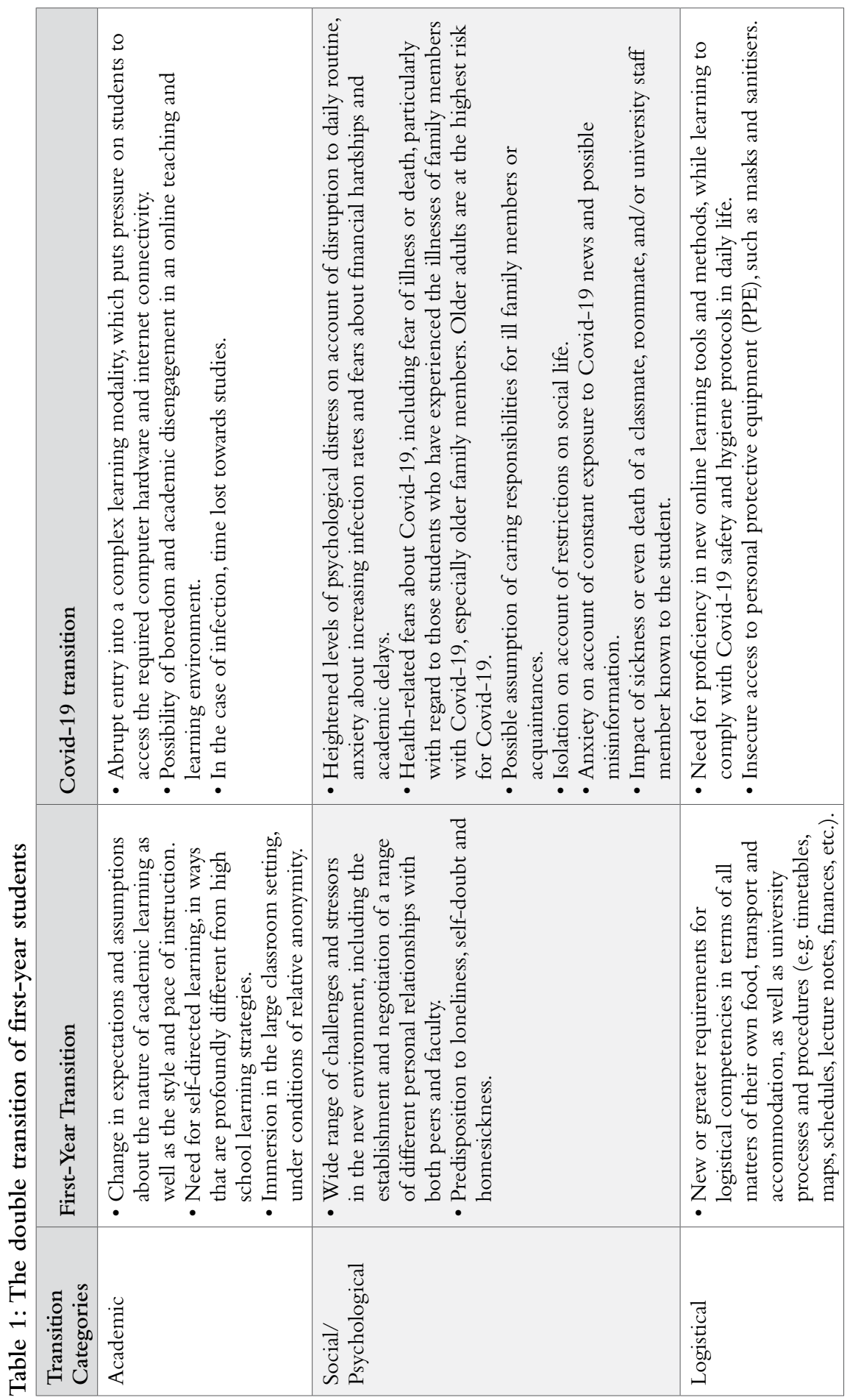




\section{Mental health crisis for students}

A long-term mental health crisis is predicted for students. The implications of a sustained immersion in the Covid-19 pandemic, with all the attendant fear, anxiety and depression in parallel with pre-existing high levels of stress, have not yet been explored for students. The timeframe of the double transition must be taken into account. Short spells of the double transition can obviously be considered less detrimental than prolonged exposure to the stresses and uncertainties of the pandemic. The potential long-term consequences for students may only be understood in the future, as the pandemic continues and depressive symptoms fully present themselves. It would be prudent for universities to invest in the mental health of students, before mental health problems become entrenched. Therefore, it can be said that monitoring and oversight of the mental health of students should be seen as an immediate strategic priority for universities. It is necessary to follow the trajectory of the mental health and well-being of students, as the pandemic continues.

\section{An uncertain future for online teaching and learning}

The extent to which online teaching and learning is able to find purchase with students, will only be seen in the coming months and years. There are few learning strategies which explicitly speak to the special needs of first-year students. The subject of specific pedagogies for first-year students remains one which is largely unexplored (Nathan, 2005; Erickson et al., 2006; Tuckman \& Kennedy, 2011). While the move to online teaching and learning has happened on account of necessity, it has also been propelled by far-reaching and naive assumptions about South Africa's digital readiness and the idea that the 21 st-century student population will be more adept at online teaching and learning than previous generations of learners. It can be argued that while students are, on average, more acclimated to technology than previous generations of students, this should not automatically assume the high levels of technological proficiency that would, for example, be needed for successful online teaching and learning. The latter is particularly true in light of the fact that modern forms of technology are continually updating and changing.

Long-term academic disengagement is a risk of the double transition. Students may quickly become bored with learning materials, particularly so in a home-centric learning environment which can be isolating and prone to distractions. The double transition may inculcate poor learning styles and habits during the pandemic which may linger throughout their time in the higher education system. It is also possible to predict that some students may embrace online teaching and learning, and appreciate the flexibility and convenience of online teaching and learning as a more appealing option than traditional classroom forms of instruction, which has long been criticised for its redundancy in terms of 21st-century learning. Of course, much depends on educator expertise, and the ability of institutions of higher education to provide the training and education which can strengthen teaching strategies. 


\section{Loss or dilution of 'the university experience'}

Universities offer a sense of social engagement and connection for students. The Covid-19 pandemic has deprived first-year students of all the experiences involved in an active and engaged student life, as well as the multiple opportunities for personal growth and social development that university life has to offer. The experiential aspect of university goes beyond teaching and learning and extends to a wider universe of campus-based experiences, such as accommodation, employment, career advice, mentoring, psychological support services, all of which encompass the student lifestyle (Morgan, 2012). Under the restrictions of the Covid-19 pandemic, first-year students miss out on the vibrancy and immediacy of the engagement with the totality of student experiences at university. Moreover, all the tools traditionally employed by universities to aid students transition (e.g., orientation, mentoring and various support services) are now significantly diluted or weakened by the recourse to all online modes of interaction.

It goes without saying that theories of transition in higher education must now take into account the 'double transition' and find ways to mitigate its insidious impact on the educational outcomes of first-year students. The Covid-19 pandemic may be seen as a critical watershed issue that could influence the life trajectories of students in both short term and long-term scenarios. As the first year is understood to be the crucial determining year for how students respond to the rest of their studies, this experience of the Covid-19 pandemic and their 'double transition' may well prove to be a formative one for students and exert a lasting impact. As this moment is evolving, it will remain incumbent on educators to study the effects of the 'double transition' on future generations of learners.

\section{Strategies to Mitigate the 'Double Transition'}

It is difficult to make definitive pronouncements in the prevailing contexts of uncertainty and unpredictability surrounding the Covid-19 pandemic. It is, in fact, impossible to predict the effects of Covid-19, and there is also much about the Covid-19 virus that yet remains clinically unclear or unknown. There are, however, a number of ways in which the double transition can be addressed in the hopes of ameliorating the challenging circumstances of first-year students and providing some (short- and long-term) relief for their circumstances. Several recommendations are advanced here, some of which relate to the broader macro-environment, and some of which can be reasonably effected within the higher education system.

First, financial relief for cash-strapped students is a matter of critical urgency. Higher education should be included in the national financial stimulus plans for economic and social recovery. Universities are also urged to explore and possibly tap into various social and economic funding measures put in place by national government in order to alleviate the financial hardships caused by the Covid-19 pandemic. The matter of fee reductions for students has not been explicitly addressed by the Department of Higher Education and Training (DHET) as well as the university sector (Deklerk, 2020). Given the costs borne by students of the shift to online platforms, the variability in quality of online teaching and the lack of access to critical elements of learning such as labs and clinical experience, 
the current fee structure bears the need for review. Moreover, innovative ways to design a safety support for students should also be considered and explored with the private sector and donors, both local and international. This recommendation for a financial safety net for students is made in light of the financial hardships suffered by universities on account of Covid-19 and the likelihood of subsidy reductions, and the curtailment in student admissions.

The future of online teaching and learning is uncertain as universities are re-examining their customary approaches to teaching and learning on account of Covid-19. A great deal of institutional introspection is currently taking place about the renewal of the current teaching and learning model, and with regard to lessons learned during the Covid-19 pandemic. It is, however, clear that universities must now disengage from the emergency mode in which the transition to online teaching and learning first took place. Universities must now improve their pedagogical practice in terms of the delivery of online teaching and learning. It is also imperative that educators receive training and support, as they continue the work of online teaching and learning under the Covid-19 pandemic. Knowledge transfer from Unisa (University of South Africa), South Africa's largest open distance higher education institution, is critical and, indeed, expected during this time.

Mental health is considered a priority under normal circumstances of the first-year student transition. In the context of the first-year double transition, provisions for the mental health of students and access to high-quality mental health services, assumes ever greater importance. It is therefore imperative that student support be scaled up as the Covid-19 pandemic runs its course. While this may mean large-scale interventions such as ensuring sufficient numbers of well-trained counsellors, it can also mean smaller thoughtful strategies such as exploring the use of electronic devices for counselling, and possibly relaxing bureaucratic restrictions on such things as loaning of devices or access to lending resources. During this time of anxiety and uncertainty, it is urged that universities actively work towards inculcating a wider institutional culture of treating students with greater care and kindness than they have previously done. All departments who actively interface with students, i.e. admissions, fees, and security, should be trained in the dynamics and nuances of the double transition for first-year students, with the goal of developing more thoughtful and considered interactions with students during the Covid-19 pandemic.

However, it is important to recognise that provisions for mental health support should not only be the province of universities. It should be considered holistically as a critical element of South Africa's broader response to the Covid-19 pandemic and expanded into the country's primary health care services, so that all those who need it have immediate access to skilled psycho-social support

While the Covid-19 pandemic has inevitably endowed universities with a new singularity of purpose in their operations (i.e. focusing on the curriculum and recovering lost academic time), matters of student support should not be overlooked or compromised in any way. It is incumbent upon the First-Year community, and indeed all university staff, at all institutions of higher education, to ensure that matters of First-Year Experience and student support remain central to institutional agendas. 


\section{Conclusion}

This article has shown the complexity of the various challenges involved in the double transition of first-year students to higher education. While the large body of theoretical work as detailed in the first part of this article, has provided a roadmap of sorts to guide student transitions, it nonetheless offers no clear roadmap to dictate how this particular transition the double transition - can best be managed. There is a need to develop a framework, as has been advanced herein and encapsulated in Table 1, that will best understand the complex trajectory of the double transition. Only time can predict how first-year students may move into different phases in this particular transition. This may involve moving beyond the current experience of turmoil and distress towards a period of acceptance in which the double transition is incorporated into the lives of first-year students. The implications of this double transition will vary widely in terms of the personalities of students and their individual repertoire of coping strategies. As Bourdieu and his various proponents remind, the extent of social capital and networks at the disposal of students will play a significant, if not defining, role in the way the double transition is managed.

It is possible to reframe the double transition as an empowering experience, despite the stress and trauma involved in this type of ordeal. Indeed, all transitions can be seen to hold a silver lining of sorts in the ways that they propel psychological growth and bring to the fore many positive qualities and characteristics in the personalities of individuals that will increase their ability to negotiate difficult and complex situations in their future. This article has advocated some strategies to mitigate the worst of the double transition, all of which can be reasonably effected by those in the higher education sector. It can be said, in closing, that for those working in the higher education sector, it is critically important to be aware of the impact of transitional experiences on the student population, and to continue to practise the kind of intentional care, trust and respect needed to guide and encourage first-year students through the challenges of the double transition.

\section{Acknowledgements}

This article was prepared by the author in line with her work as Director of the South African National Resource Centre for the First-Year Experience and Students in Transition (SANRC). The SANRC is a national initiative funded by the Department of Higher Education and Training (DHET). The views and opinions expressed in this research are that of the author's alone. The author received no financial support for the research and authorship of this article.

\section{Conflict of Interest}

The author certifies that she has no affiliations or involvement in any organisation or entity with any financial interest (such as honoraria; educational grants; participation in speakers' bureaus; membership, employment), or non-financial interest (such as personal or professional relationships, affiliations, knowledge or beliefs) in the subject matter or materials discussed in this manuscript. 


\section{References}

Astin, A.W. (1984). Student involvement: A development theory for higher education. Journal of College Student Development, 40, 518-529.

Astin,A.W. (1993). What Matters in College? Four Critical Years Revisited. Jossey Bass.

Bourdieu, P. (1973). Cultural reproduction and social reproduction. In R. Brown (Ed.) Knowledge, education and social change: Papers in the sociology of education (pp. 71-112). Tavistock Publications. https://doi. org/10.4324/9781351018142-3

Briggs, A.R.J., Clark, J. \& Hall, L. (2012). Building bridges: Understanding student transition to university. Quality in Higher Education, 18(1), 3-21. https://doi.org/10.1080/13538322.2011.614468

Brookes, S.K., Webster, S.K., Smith, L.E., Woodland, S., Greenberg, N. \& Rubin, G.J. (2020). The psychological impact of quarantine and how to reduce it: Rapid review of the evidence. Lancet (395), 912-920. https://doi.org/10.1016/S0140-6736(20)30460-8

Chickering,A.W. (1969). Education and identity. Jossey-Bass.

Chickering,A.W. \& Schlossberg, N.K. (1995). Getting the most out of college. Pearson.

Christie H. (2009). Emotional journeys: young people and transitions to university. British Journal of Sociology of Education, 30(2), 123-136. https://doi.org/10.1080/01425690802700123

Clark M. (2005). Negotiating the Freshman Year: Challenges and strategies among first year college students. Journal of College Student Development, 46(3), 296-316. https://doi.org/10.1353/csd.2005.0022

Cook, A. \& Leckey, H. (1999). Do expectations meet reality? A survey of changes in first-year student opinion. Journal of Further and Higher Education, 23(2), 157-171. https://doi.org/10.1080/030987 7990230201

Cuseo, J. (2007). The empirical case against large class size: Adverse effects on the teaching, learning and retention of first-year students. Journal of Faculty Development, 21(1), 5-21.

Deklerk, A. (2020, July 14). NSFAS needs R4.3bn more because of extended academic year. Times Live. https://www.timeslive.co.za/politics/2020-07-14-nsfas-needs-r43bn-more-because-of-extendedacademic-year/

Dell, S. (2020, April 09). Zero-rating online learning: not as simple as it sounds. University World News. https://www.universityworldnews.com/post.php?story=20200408201225155

Erickson, B.L., Peters, C. \& Weltner, D.S. (2006). Teaching first-year college students. Jossey-Bass.

Gale,T. \& Parker, S. (2014). Navigating change:A typology of student transition in higher education. Studies in Higher Education, 39(5), 734-753. https://doi.org/10.1080/03075079.2012.721351

Gardner, J.N. (1986). The Freshman Year experience. The Journal of the American Association of Collegiate Registrars and Admissions Officers, 61(4), 261-274.

Greenfield, G.M., Keup, J.R. \& Gardner,J.N. (2013). Developing and sustaining successful first-year programs: A guide for practitioners. Wiley.

Goodman, J., Schlossberg, N.K. \& Anderson, M.L. (2006). Counseling adults in transition: Linking practice with theory. Springer.

Hussey, T. \& Smith, P. (2010). Transitions in higher education. Innovations in Education and Teaching International, 47(2), 155-164. https://doi.org/10.1080/14703291003718893

Johnston, B. (2010). The first year at university: Teaching students in transition. McGraw Hill Education.

Kantanis, T. (2000). The role of social transition in students' adjustment to the first year of university. Journal of Institutional Research, 9(1), 100-110.

Krause, K. (2006, May 31). Transition to and through the first year: Strategies to enhance the first year. Inaugural Vice-Chancellor's Learning and Teaching Colloquium 2006. University of the Sunshine Coast, Queensland, Australia. 
Loevinger, J. (1976). Ego development. Jossey-Bass.

Lowe, H. \& Cook, A. (2010). Mind the gap: Are students prepared for higher education? Journal of Further and Higher Education, 27(1), 53-76. https://doi.org/10.1080/03098770305629

Macupe, B. (2020, April 23). Online push sets us up for failure. Mail and Guardian. https://mg.co.za/ article/2020-04-23-online-push-sets-us-up-for-failure/

Mathiba, G. (2020, April 9). COVID-19 and South Africa's universities: A raft of problems to ponder. Daily Maverick. https://www.dailymaverick.co.za/opinionista/2020-04-09-covid-19-and-southafrican-universities-a-raft-of-problems-to-ponder/

McInnis, C. (2001). Researching the first year experience: Where to from here? Higher Education Research \& Development, 20(2), 105-114. https://doi.org/10.1080/07294360125188

Morgan, M. (2012). Improving the student experience: A practical guide for universities and colleges. Routledge. https://doi.org/10.4324/9780203817513

Nathan, R. (2005). My Freshman Year:What a professor learned by becoming a student. Penguin.

Nyar, A. (2019). The first-year experience (fye) in South Africa: A national perspective. SANRC FYE Thought Series \#2. https://sanrc.co.za/content/2019/04/A-Nyar-Report.pdf

O'Donnell,V.L., Keane, M. \& Stevens, G. (2016). Student transitions in higher education: concepts, theories and practices. Higher Education Academy (HEA).

Pascarella, E. \& Terenzini, P. (2005). How college affects students: A third decade of research. Jossey-Bass.

Perry, W.G. (1970). Forms of intellectual and ethical development in the college years: A scheme. Holt, Rinehart \& Winston.

Quinn, J. (2010). Rethinking 'failed transitions' to higher education. In K. Ecclestone, G. Biesta \& M. Hughes (Eds.), Transitions and learning through the lifecourse (pp.118-129). Routledge.

Rajkumar, R.P. (2020). COVID-19 and mental health: A review of the literature. Asian Journal of Psychiatry, 52. https://doi.org/10.1016/j.ajp.2020.102066

Ramsden, P. (1992). Learning to Teach in Higher Education. Routledge.

Salari, N., Hosseinian-Far, A., Jalali, R.Vaisani-Raygani, A., Rasoulpour, S., Mahommedy, M. \& KhalediPavar, B. (2020). Prevalence of stress, anxiety, depression among the general population during the COVID-19 pandemic:A systematic review and meta-analysis. Globalisation and Health, 16(57), 1-11. https://doi.org/10.1186/s12992-020-00589-w

Sanford, N. (1968). Where colleges fail: A study of the student as a person. Jossey Bass. https://doi.org/10.23 $07 / 40223966$

Schlossberg, N.K. (1981).A model for analysing human adaptation to transition. The Counselling Psychologist, 9(2), 2-18. https://doi.org/10.1177/001100008100900202

Spady, W.G. (1970). Dropouts from higher education: An interdisciplinary review and synthesis. Interchange, 1, 64-85. https://doi.org/10.1007/BF02214313

Tinto, V. (1993). Leaving college: rethinking the causes and cures of student attrition. University of Chicago Press. https://doi.org/10.7208/chicago/9780226922461.001.0001

Tinto, V. (1996). Persistence and the first-year experience at the community college: Teaching new students to survive, stay, and thrive. In J.N. Hankin (Ed.), The community college: Opportunity and access for America's first-year students. Monograph Series Number 19 (pp.97-104). National Resource Center for the Freshman Year Experience and Students in Transition (ED393486). http://files.eric.ed.gov/ fulltext/ED39486.pdf

Thomas, E. (2002). Student retention in higher education: The role of institutional habitas. Journal of Education Policy, 17(4), 423-432. https://doi.org/10.1080/02680930210140257

Thomas, L. \& Quinn, J. (2006). First-generation entry into higher education. Education (UK). 
Tuckman, B.W. \& Kennedy, G.J. (2011). Teaching and learning strategies to increase success of first-term college students. The Journal of Experimental Education, 79(4), 478-504. https://doi.org/10.1080/002 20973.2010.512318

Upcraft, M.L. \& Gardner, J.N. (1989). The freshman experience: Helping students survive and succeed in college. Jossey-Bass.

Upcraft, M.L., Gardner, J.N. \& Barefoot, B.O. (Eds.) (2005). Challenging and supporting the first-year student: $A$ handbook for improving the first year of college. Jossey-Bass.

Vygotsky, L.S. (1978). Mind in society: The development of higher psychological processes. Cambridge, MA Harvard University Press. https://www.hup.harvard.edu/catalog.php?isbn=9780674576292

\section{How to cite:}

Nyar, A. (2021). The 'Double Transition' for First-Year Students: Understanding the Impact of Covid-19 on South Africa's First-Year University Students. Journal of Student Affairs in Africa, 9(1), 77-92. DOI: 10.24085/jsaa.v9i1.1429 
RESEARCH ARTICLE

The Effect of the Covid-19 Pandemic on Students and the Living and Learning Spaces at a South African University

Blessing Kanyumba ${ }^{\text {\& }}$ Nondumiso Shabangu ${ }^{i i}$

\section{Abstract}

In March 2020, the South African President Mr Cyril Ramaphosa announced a national lockdown due to the rising cases of the Covid-19 pandemic. As a result, some of the higher education institutions closed under lockdown level 5 and strategies had to be developed to adapt to the "new norm". Consequently, students and the living and learning spaces in South Africa were affected, necessitating therefore that transformation in all spheres takes place. This study, through a qualitative research design, investigated the effect of Covid-19 on students and the living and learning spaces at a selected university in South Africa. Fifteen students and ten Residence Advisors (RAs) were telephonically interviewed. The results revealed that the living and learning spaces had been significantly transformed by the Covid-19 pandemic. The operations of these spaces had been compelled to change in order to comply with the Covid-19 regulations, such that student learning was shifted from face-to-face to online learning. This meant more time spent indoors, stricter measures now in place and the $R A$ roles having been broadened to ensure that they also monitor compliance. The study also noted that even after the pandemic, things will still take time to get back to normal. This article concludes that Covid-19 has had a huge effect on the living and learning spaces as well as students at the selected university and that both students and staff should play their roles effectively to ensure that everyone remains safe.

\section{Keywords}

advising; Covid-19; living and learning; residence life; student affairs

\section{Introduction}

According to Jones Lang Lasalle (2016), there is a huge demand for student accommodation in Africa due to an increased enrolment rate. Therefore, most students opt to reside in the accommodation offered by the institution whether insourced or outsourced. Student accommodation or residences refer to a living place provided by institutions (DHET, 2015).

i Ms Blessing Kanyumba is a Residence Advisor in the Department of Student Housing and Residence Life at the Durban University of Technology, South Africa. ORCid: 0000-0001-8111-4234.

Email: blessingk1@dut.ac.za

ii Dr Nondumiso Shabangu is a Residence Advisor in the Department of Student Housing and Residence Life at the Durban University of Technology, South Africa. ORCid: 0000-0002-1097-0049.

Email: shabangunondu.sn@gmail.com 
For the purposes of this study the student residences will be termed 'living and learning spaces'. The living and learning spaces characterise the concepts of learning while living in the university's shared spaces. Furthermore, this is a concept used in integrating the accommodation and academic aspect in student development. There is limited literature on student living and learning, particularly in Africa. Gopal and Van Niekerk (2018) argue that the demand for student housing in South Africa is very high, mostly due to limited institutions of higher learning as well as unconducive learning environments at home.

Parameswaran and Bowers (2014) and Tshimangadzo, Nkhangweleni Azwitamisi and Tshifhiwa (2020) note that studies have shown that students who reside in university learning and living spaces perform better in all aspects of life than those who do not stay in residences. A study conducted by Eurostudent (2011) concluded that students residing in university residences are likely to see studying as their main occupation, and this in turn, it is believed, "may have a positive effect on their duration of study and grades". There are factors which can substantiate the reasons for student success while residing in residences. The reasons can be due to the social and educational programmes implemented in the residences which facilitate student development in all aspects. Swartz (2010) contends that student living and learning communities are strategically crucial as they are ideal locations for both learning and teaching and recreational and social life, consequently creating a sense of community, "a home away from home". Wartz (2010) argues that students in living and learning spaces ought to have four crucial functions namely:

- A leadership function - the living and learning spaces are a training ground for student leadership

- A pedagogical function - living and learning spaces are places of teaching and learning, induction, and orientation.

- A social function - the living and learning space is a place where students have fun which is crucial to student life and engagement; and

- A cultural function - societies and clubs are strongest in living and learning spaces (Swartz, 2010).

Each of the foregoing forms an important element in the development of each student, and therefore speaks to the richness of the living and learning spaces in fostering a developmental agenda.

According to Gopal and Van Niekerk (2018), living and learning spaces build unity and commonness of purpose. Thus, first-year students look up to their seniors, and find the support and encouragement that accrue from loyalty to the living and learning spaces. Students from rural communities find residences a vital bridge to the complexities and uncertainties of a large institution. Pascarella and Terenzini (2005) attest that research suggests that living in an on-campus residence when doing a four-year university degree has a positive impact on student performance, adjustment, and retention. Therefore, with the emergence of a pandemic like Covid-19, which makes social distancing mandatory, research must be conducted to assess if staying on-campus still has a positive impact on student performance. Residence students are exposed to numerous extracurricular activities which in turn promote self-growth, thus leading to improved performance. 
A study conducted by Pascarella and Terenzini (2005) further revealed that living in university residences from the first year of study increases the chances of completion on time by $12 \%$, and students regarded 'at risk students' are well nurtured due to an increase of social interaction. There are numerous advantages of living in the institution's living and learning spaces for students and these include that students interact more frequently and informally with academic peers and staff. For instance, most staff employed as residence advisors are university academic staff. Hence, they are able to interact informally with the students, making it easier for students to approach them whenever they need assistance and guidance. Students residing in the university living and learning spaces participate in more on-campus activities than those who do not. More on-campus activities are facilitated on the residences and the accessibility is easier for students who reside in on-campus residences.

Students in living and learning spaces are more likely to persist and graduate since most tutors live in the same spaces, hence making it easier to oversee their development and learning. Living and learning spaces also facilitate improved psychological development for students, hence reducing the rates of suicidal thoughts and mental health challenges experienced by students. It is of paramount importance to also note that in the living and learning spaces there are "living and learning" programmes which are implemented to enhance the integration of cultural, physical, social, intellectual and spiritual growth of students in a way that each complements the other. Ultimately, the students will attach more importance to intellectual values, liberalism, secularism, and aesthetics.

\section{The Transformation of Living and Learning Spaces due to Covid-19}

Covid-19 has left no living and learning space in the South African universities unaffected, and its consequences are felt. The impact Covid-19 has had on living and learning spaces and on students is huge and deeply felt. Universities are still trying to cope with developing or strengthening the systems of living and learning, and ensuring that students still be exposed to as much knowledge as possible. According to Mohamedbhai (2020), to be able to contain the spread of the virus and also ensure that the lockdown measures are followed, there was no choice for the African countries but to close education institutions (higher education institutions). Mohamedbhai (2020) further states that higher education institutions have had to ensure that their programmes are delivered online through distance learning to all their students with the use of information and communication technology (ITS).

One of the huge transformations that has taken place in living and learning spaces, is that where Covid-19 has accelerated the digital transformation of higher education, universities have been forced to develop virtual cultures. Classes are now online for the rest of the year 2020 as universities have been forced to stop being physically operational (Martin-Barbero, 2020). Due to this, higher education institutions have had to make sure that learning continues, and this has led to disturbances of the lives of many (MartinBarbero, 2020). Martin-Berbero (2020) states that this transformation has led to the inequalities between the students with resources and those without access to the resources. 
According to Makhanya (2020), before the Covid-19 pandemic, South African universities depended on contact teaching. This made teaching seem equal to all. However, students come from different socio-economic backgrounds and no student should be marginalised, so universities must ensure that they cater for all their students (Makhanya, 2020).

Transformation in living spaces has been well observed. According to Mzileni (2020), there is a lack of the infrastructure in the townships and villages of South Africa, that is required for students to function accordingly. Furthermore, in terms of the learning experience, it is well noted that many communities and households are non-conducive spaces for students and hence the universities were made conceptual residential institutions for the utilisation of face-to-face contact learning (Mzileni, 2020). Universities are aware that regardless of the advancements in technology and the innovations contributed thus far, the undergraduate students still require to be hosted physically in on-campus residences in order to concentrate well on their studies (Mzileni 2020). However, the reality is that not all the students residing in on-campus residences in general have high concentration levels. Research by Mzileni (2020) shows that, over 15000 campus residence students under normal circumstances would have high concentration level when off-campus. Mzileni (2020) further states that, for students with lower concentration levels it has been hard to facilitate seamless teaching, and due to this, universities have had to use their own resources every day to transport students (that under normal circumstances reside in on-campus residences) from off-campus to campuses and provide Wi-Fi connectivity to all students who live off-campus. (Mzileni, 2020). Some universities are unable to provide all required resources to all students. Consequently, the transformation Covid-19 has brought to living and learning spaces has had quite a significant impact on students as evidenced by having to move the normal learning process from lecture venues to online learning. Students also having to adhere to health protocols, most of which are new to them, and stretch the resources of institutions, thus exacerbates the fault-lines where mainly the poor and destitute students are struggling even more.

\section{Conceptual Framework}

This study will be based on a conceptual framework on e-resilience in education by Van der Laar (2020). This framework was developed as the response to the 'shock' caused by the Covid-19 pandemic in the higher education sector's teaching and learning. This framework is relevant to this study because the living and learning spaces have shown resilience to the pandemic thorough the incorporation of technology. As shown in Figure 1, the framework comprises four levels that are nested and interact together and shape e-resilience of the educational systems after a 'shock' (Van der Laar, 2020). The first layer (Dark blue) is the resilience at an individual level. Layer two (Purple) is the resilience at the programme level. The third layer (Green) highlights the resilience at an institutional level and finally layer four (Pink) reveals the resilience at the macro level. Students and residence advisors have been affected by the pandemic on a personal level in most facets of their lives. However, mechanisms had to be developed to ensure that everyone copes. The use of technology 
has affected many students, thus support from the institutional level is very crucial. Marota (2020) further reveals that during this pandemic institutions of higher learning need to upskill their staff so that they will be able to assist students as well. For this study, the importance of upskilling of the residence advisors is crucial as they are the ones who will be dealing with the students on a daily basis since contact classes are still prohibited. Hence the relevance of this conceptual framework.

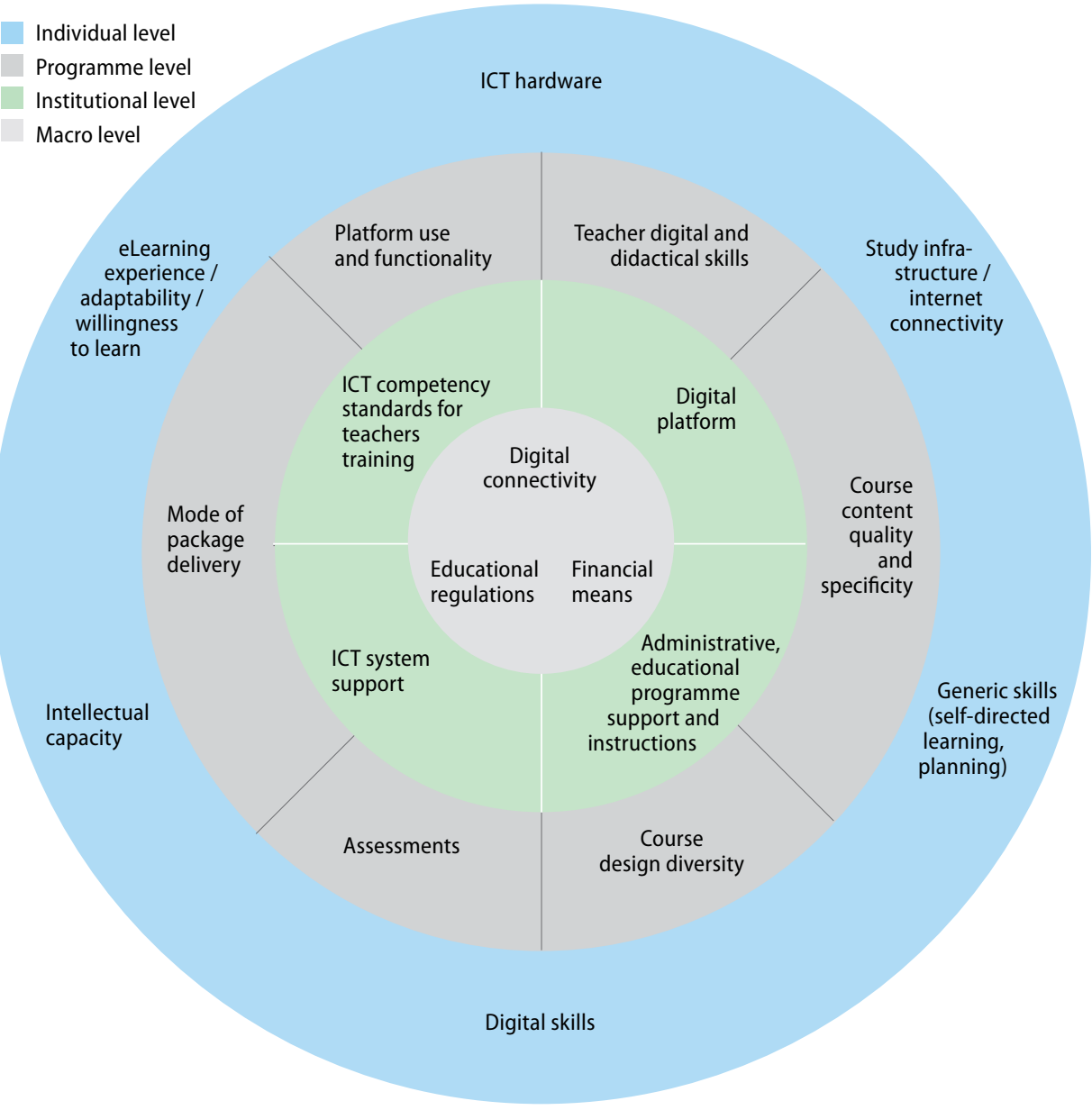

Figure 1: E-resilience in education conceptual framework (Source: after Van de Laar, 2020)

\section{Research Methodology}

The study was conducted at a University of Technology in South Africa. A qualitative research design and methodological approach through purposive sampling was utilised. Ames, Glenton and Lewin (2019) define purposive sampling as a non-probability sampling aimed at producing the sample that can be logically assumed to be representative of the 
population. The main goal of purposive sampling is to focus on particular characteristics of a population that are of interest, which will best enable researchers to answer the research questions. This sampling method was used for the study as the students and residence advisors are representative of the entire population and they were chosen from various residences. The participants for the study consist of 15 students and 10 Residence Advisors (RAs), and of the 15 students, 2 were Student Residence Assistants (SRAs). Student participants were identified through residence advisors from various residences in Durban. The RAs were personally contacted by the researchers as they are also RAs at the selected institution. The participants comprised female and male undergraduate students residing both in insourced and outsourced residences in Durban and their RAs. It is of paramount importance to note that most of the participants were from outsourced residences as shown in Table 1. This is because there are more outsourced residences than insourced at the selected institution. The age group of the student participants ranged from 19-32 as shown in Table 1.

Table 1: Student participants summary

\begin{tabular}{|l|c|c|c|}
\hline $\begin{array}{l}\text { Number of participant } \\
\text { (students) }\end{array}$ & Age & $\begin{array}{c}\text { Level of } \\
\text { study }\end{array}$ & $\begin{array}{c}\text { Insource/outsource } \\
\text { residence }\end{array}$ \\
\hline Participant 1 & 23 & 3 & Outsource \\
\hline Participant 2 & 24 & 1 & Insource \\
\hline Participant 3 & 32 & 3 & Outsource \\
\hline Participant 4 & 19 & 1 & Insource \\
\hline Participant 5 & 20 & 1 & Outsource \\
\hline Participant 6 & 22 & 4 & Outsource \\
\hline Participant 7 & 22 & 21 & Outsource \\
\hline Participant 8 & 23 & 3 & Insource \\
\hline Participant 9 & 20 & 2 & Insource \\
\hline Participant 10 & 21 & 2 & Outsource \\
\hline Participant 11 & 30 & 4 & Outsource \\
\hline Participant 12 & 23 & 3 & Outsource \\
\hline Participant 13 & 21 & 2 & Outsource \\
\hline Participant 14 & 25 & 3 & Outsource \\
\hline Participant 15 & 19 & 1 & Insource \\
\hline
\end{tabular}

Due to Covid-19 and the emphasis on maintaining social distancing, data was collected telephonically, where all participants were called during the time that their individual interview was set to suit their availability. This data collection method was appropriate for this study because the researchers and participants managed to interact, and it was easy to reach out to respondents from various residences without seeing them face to face. The interviews lasted between 10 and 15 minutes. All participants were requested to sign consent forms via email which gave permission for their participation. The interviews 
were recorded, subsequently transcribed verbatim and coded. Pseudonyms were used by the researchers in all instances to circumvent any possible link to participants. A narrative enquiry method was used to explain the students' and RAs' views on the effect of Covid-19 on the living and learning spaces and how these spaces have been transformed due to the pandemic and the national lockdown.

\section{Ethical Considerations}

Permission to conduct this study was obtained from the selected institution and the department of student housing and residence life. Ethical clearance was obtained through the selected institution's research ethics committee. Students and RAs were subsequently approached, and their participation was voluntary. Privacy and confidentiality were maintained throughout the study.

\section{Data Analysis}

Themes were identified from the transcribed interviews. Four major themes emerged from the interview with the students and three themes also emerged from the interviews with the RAs. The themes are reflected in Table 2.

Table 2: Emerging Themes

\begin{tabular}{|l|l|l|}
\hline & Students & Residence Advisors \\
\hline 1. & Introduction of online learning & Phasing of students into residences \\
\hline 2. & Improved hygiene & The issue of accessing PPEs \\
\hline 3. & Increased stress levels & $\begin{array}{l}\text { Internet connectivity issues and studying in } \\
\text { the residences }\end{array}$ \\
\hline 4. & Insufficient resources & \\
\hline
\end{tabular}

\section{Introduction of online learning}

All the participants indicated that the introduction of online learning was a huge effect of the Covid-19 pandemic. As a result of the national lockdown and Covid-19 the selected institution introduced blended learning which is defined by Ibrahim and Nat (2019) as an "effective approach to the passive knowledge engagement of a massive number of students, which also increases learning outside the traditional face-to-face learning environment". There was a huge transformation amongst students as they were not used to solely relying on online learning.

This online thing is a huge trouble for me as am not used to this, even at rez I don't have time to breathe, this is my fourth year here and this is the hardest year, am really drowning. (P6)

This online learning is not for us. $(\mathrm{P} 10, \mathrm{P} 2,15)$

Personally I am used to working in a group and I like asking my lecturers questions in class, but with this online learning it is very hard to even ask the questions as that hand icon on my team's class just disappears and I end up not asking anything, technology is still difficult but am getting there slowly but surely. (P11) 
Participant 12 also highlighted this: "Even though online learning is a challenge, I think my lecturers are trying very hard. I even send them WhatsApp messages and they do respond hence it's not that bad."

These respondents attest that one major effect of the Covid-19 pandemic was a shift from face-to-face lectures to online lectures which meant that even when they are in their residences, they have to attend classes which requires huge commitment and dedication.

\section{Improved hygienic behaviour}

The participants revealed that they are more conscious about their hygiene due to the Covid-19 pandemic. Sang and Dewi (2020) state that hand hygiene is extremely crucial in preventing the spread of the Covid-19 virus.

Covid-19 actually transformed me to be clean freak. (P3)

Most of the respondents stipulated that everyone is now aware of the importance of being clean and everyone is playing their part in ensuring that all areas are clean and sanitised. $\mathrm{P} 4$ revealed that:

Am really shocked that even our cleaners are doing a splendid job, before Covid-19 our kitchens were always dirty. I don't want to even mention the bathrooms, but since we came back from home under level 3 of the lockdown, I can really see a change. All the places are clean and even me and my roommate we make sure we sanitise again before getting into the room, we want to be safe.

WHO (2020) concluded that, for the spread of the virus to be minimised, everyone should adhere to the stipulated hygienic protocols. Therefore, it is quite interesting to note that students in the living and learning spaces are actually adhering to the protocols. Hence, the change in their hygienic behaviour would mean even after the pandemic good hygienic behaviour will still be maintained.

\section{Increased stress levels}

According to WHO (2020), It is normal to feel sad, stressed, confused, scared or angry during a crisis. Most of the participants indicated that after a month on national lockdown they have been stressed as well as bored. At level 5 of the lockdown, the participants indicated that they were at home and after a month of staying indoors and doing nothing they started getting stressed.

Just by watching news and seeing those figures rising day after day, made me anxious. (P2)

Khosravi (2020) posits that pandemics impose a spectrum of psychological impacts and at the individual level, these adverse effects can cause new psychiatric symptoms and intensify the pre-existing mental illnesses.

Khosravi (2020) further notes that in such a condition, society members may undergo some negative experiences, such as fear and anxiety about falling ill or dying and feelings of helplessness. In South Africa, students started returning to campus residence under lockdown level 3 and only $33 \%$ were the first cohort. 
When I came back to campus under level 3 I was the only one in my floor, I have never been scared in life, I thought of going back home but I couldn't as I was supposed to attend classes, it seemed like I was seeing things in the residence, I was traumatised to the extent of resorting to binging. I had no one to talk to and being stuck alone in the room is quite stressful. (P4)

It is crucial to note that under normal circumstances programmes were implemented in the residences to facilitate the living and learning aspect. Due to Covid-19 and social distancing no social or educational programmes have been implemented and previous studies have shown that living and learning programmes enhance student well-being. Therefore, without those programmes students will not be developed or assisted on how to deal with stress during a pandemic. Wahl (2013) concurs that Living and Learning programmes improve student learning, development and success at higher education level. Consequently, due to the Covid-19 pandemic, contact programmes were halted thus disadvantaging the students.

... we used to have programs [sic] at res and they were very helpful, we used to meet with each other and socialise thus easing our minds but with this corona we cannot do that and its bad, I don't know if the online programs [sic] will be effective enough. (P14)

Additionally, when asked if things will get back to normal anytime soon, most students believe that things will take time to get back to normal. Hence the institution should devise strategies that can last for a long time and not only serve short-term purposes.

Student housing should think of ways for us to have our residence programs online as the way we are living is a new normal and we should adapt, its gonna [sic] take a lot of time for things to get back to normal, we are still going to be wearing masks... (P7)

\section{Insufficient resources}

It is crucial to note that most of the participants who resided in outsourced residences indicated that there was a shortage of resources in their residences.

Our landlord just bought the sanitizers on the first week of our arrival and we are now buying our own sanitizers, at least the institution gave us masks. (P11)

Those who reside in insourced residences highlighted that everything is provided for them.

We have all the resources that we need, I just don't like that I get checked every time I come inside the gate even after 2 minutes, they still check my temperature. (P15)

DHET (2015) notes that there is a huge increase in the number of students who get accepted to study in the universities in South Africa, hence the rise in demand for student accommodation as well. The institution under study outsources $90 \%$ of their student accommodation and the landlords are responsible for providing all the resources required by the students to enhance the living and learning. However, the participants in most outsourced residences indicated that Wi-Fi is a challenge, especially during this period where it is needed the most, and there are no sanitisers and in some rooms with three people residing in a single room. 


\section{Phasing in of students into residences}

As the students are slowly being brought back to campus in a phased in manner, most of the residence advisors are experiencing challenges with adapting to the new normal way of living with the students as they state that there are so many new rules and regulations that they need to ensure they themselves and students adhere to.

The transformation is mainly noted on a communication basis as well as on an interaction basis between students and the residence advisors. Before the pandemic and the lockdown, all residences had programmes running to ensure students engage in residences they are assigned to, but since they have been phased during the pandemic, that engagement is no longer there.

... since my students have come back the interaction is no longer the same, I am starting to feel that my relationship with them is more stricter and I am not happy about that, because when they see me they think I will be hard on them with keeping to the rules and regulation. (R4)

I had so many programmes that I had organised especially since I was a new residence advisor, but now I cannot implement those programmes because we can no longer have physical interactions, but we hope we can prepare to move them to be virtual. (R7)

\section{The issue of accessing PPEs}

Most residence advisors mentioned several times during their different interviews that they are facing challenges with accessing things like masks and sanitisers and this is making their work difficult in the residences.

... the hugest [sic] transformation of this pandemic is having to constantly wash hands or sanitise them. This becomes hard when such is not regularly provided in the residence. Also the masks are an issue as some students do not wear them and have to be constantly reminded, then you end up feeling like you are on their back, but you know how significant it is to ensure to limit the spread of the virus. (R1)

\section{Internet connectivity issues and studying in the residences}

The university is now defined as no longer the building, but it is now where students reside, this being a very huge transformation. The students in the residences now have their lectures online in their rooms, they also have their tests and exams virtually in their rooms and for this to be progressive and effective they require good internet connectivity. Most residence advisors mentioned the issue of the lack of connectivity as most residences' Wi-Fi signals are not of good strength. Due to this issue, most students are struggling to study in the residences, and because of this most students end up going outside of the residence to find facilities like municipal libraries to have connection, and due to this they end up being more susceptible to the virus and increase the chances of exposure in the residences.

... most students since they have returned have been coming to me and complained about the WiFi connectivity, stating that how are they expected to keep up with their school work if the WiFi connection in the residence is so poor, another student even went further and told me that 
the transformation of blended learning is so difficult on them since they cannot connect properly like the rest of their classmates. This then means that these students are mainly behind with their schoolwork. (R5)

\section{Discussion}

This study aimed to reveal the effect of the Covid-19 pandemic on the living and learning spaces and students at a South African university. It was conducted during the period of the lockdown on levels 3 and 2. The following findings are evident from data presented:

- that the main transformation issues with residence advisors were those of policies and protocols of the phasing in of students back into residences,

- and the issue of PPEs in the residence,

- as well as the internet connection issues and studying in the residences.

According to Badrick (2017), about the internet connectivity issues, it cannot be denied that what attracts and keeps students retained is the matter of how strong the Wi-Fi connectivity is in that area. Badrick (2017) further states that the university internet users expect connectivity that is sustained and will not fail them. Ntshingila (2020) states that since institutions started implementing the online learning protocols it was noted the living circumstances and finances of all students vary and some are not pleasurable, and the students from disadvantaged backgrounds suffer the most during this time. With the incorporation of Van de Laar's (2020) conceptual framework of e-resilience in higher education into this study, it has been shown that the shift to the use of technologies at the selected institution had a huge impact since $90 \%$ of the students emanate from marginalised backgrounds. Therefore, this was a huge transformation for the students as they are expected to be resilient despite the challenges faced.

The results further revealed that the students are dealing with a lot of issues which are leading to high stress levels. Centres for Disease Control and Prevention (2020) attest to the fact that social distancing is a public health action which can make people feel lonely and isolated and can thus increase stress and anxiety. Most students are currently staying in single or double rooms and no visitors are permitted at the institution under study and no gatherings are permitted. Hence, most students feel lonely - which can increase stress levels. It is crucial to note that both students and residence advisors at the selected institution are taking their health and hygiene seriously. All the participants indicated the need to stay safe and take charge of their health, which is a huge transformation for others - especially students who did not follow basic hygiene procedures before the pandemic. From the study, it is evident that services are differently provided in outsourced and insourced residences. Most students and RAs indicated that the landlords did not provide proper resources during the pandemic, for example, Wi-Fi and PPEs. It is crucial to note that in trying to address the challenge, the institution under study released a communiqué on 28 August 2020 indicating that if landlords do not provide proper resources in the living and learning spaces, the institution will use their budget to provide resources to the residences and the funds will be deducted from the landlord's account. With this measure taken, it is believed that some of the concerns raised by students and RAs will be rectified as they have been affecting their living and learning, respectively. 


\section{Conclusion}

The study explored the various effects that Covid-19 has had on the living and learning spaces of students as well as residence advisors. The study indicated that the main issues that students were faced with since they were returned in a phased manner back into the living and learning environments, were the introduction of online learning which most struggled with at first, and the fact that hygiene was improved and increased which is a positive development. Some students stated that their stress levels were elevated in relation to coping with the transformation that was taking place in the living and learning spaces. The issue of insufficient resources was also noted, where most students did not have relevant or sufficient resources, which made it hard for them to cope with the transformation taking place. With the residence advisors, it was noted that the main issues were around the phased-in return of students into residences, where there was not a clear system of doing this. And this was a very clear indication that it was all due to the transformation from what was regarded as normal previously which is now regarded as a new normal of doing things within the living spaces of students. The other issue raised was the issue of accessing PPEs as most had not received proper directives regarding this matter. Internet connectivity issues and studying in the residences was the other main concern that was prominent between the students and the residence advisors. All these issues were due to the huge transformation in the learning and living spaces, due to Covid-19.

\section{References}

Ames, H., Glenton, C. \& Lewin, S. (2019). Purposive sampling in a qualitative evidence synthesis: A worked example from a synthesis on parental perceptions of vaccination communication. BMC medical research methodology, 19(1), 1-9. https://doi.org/10.1186/s12874-019-0665-4

Badrick, C. (2017). Campus WIFI issues that can cause network failure. [Online]. https://www.turnkeytechnologies.com/blog/article/5-campus-WIFI-issues-that-can-cause-network-failure

Centres for Disease Control and Prevention (2020). Coping with Stress. [Online]. https://www.cdc.gov/ coronavirus/2019-ncov/daily-life-coping/managing-stress-anxiety.html

DHET (Department of Higher Education and Training) (2015). The Policy on the Minimum Norms and Standards for Student Housing at Public Universities. South Africa: DHET.

Eurostudent (2011). Social and economic conditions of student life in Europe: Synopsis of indicators. (Eurostudent IV 2008-2011). Hannover: Hochschul-Information's-System. [Online]. https://www. eurostudent.eu/results/reports

Gopal, N. \& Van Niekerk, C. (2018). Safety in student residences matters! South African Journal of Higher Education, 32(10), 172-188. https://doi.org/10.20853/32-3-2524

Graham, P.A., Hurtado, S.S. \& Gonyea, R. (2016). Living on campus: Does it still make a difference? Centre for Postsecondary Research, Indiana University Bloomington. [Online]. http://nsse.indiana.edu/ pdf/presentations/2016/ACPA_2016_Graham_et_al_paper.pdf

Ibrahim, M.M. \& Nat, M. (2019). Blended learning motivation model for instructors in higher education institutions. International Journal of Educational Technology in Higher Education, 16(1), 1-21. https://doi. org/10.1186/s41239-019-0145-2

Jones Lang Lasalle (JLL) (2016). Student housing: a new asset class in Sub-Saharan Africa. [Online]. https:// propertywheel.co.za/wp-content/uploads/2016/08/Student-housing-a-new-asset-class-in-SSAAugust-2016.pdf 
Khosravi, M (2020). Stress Reduction Model of COVID-19 Pandemic. Iranian Journal of Psychiatry and Behavioural Sciences, 26(7),1-3. https://doi.org/10.5812/ijpbs.103865

Makhanya, M. (2020). COVID-19 will accelerate digital transformation in higher education sector. [Online]. https://www.iol.co.za/the-star/opinion-analysis/opinion-COVID-19-will-acceleratedigital-transformation-in-higher-education-sector-89eff6d7-0194-4848-96ad-4704c114ea83

Marotta, J. (2020). Ensuring education while protecting the well-being of everyone. [Online]. https:// www.merit.unu.edu/on-the-virtual-frontline-ensuring-education-while-protecting-the-wellbeing-of-everyone/

Martin-Barbero, S. (2020). COVID-19 has accelerated the digital transformation of higher education. [Online]. https://www.weforum.org/agenda/2020/07/COVID-19-digital-transformation-highereducation

Mohamedbhai, G. (2020). COVID-19: What consequences for higher education? [Online]. https://www. universityworldnews.com/post.php?story $=20200407064850279$

Mzileni, P. (2020). How COVID-19 will affect students. [Online] https://mg.co.za/education/2020-0423-how-COVID-19-will-affect-students

Ntshingila, B. (2020,April 3). Disadvantaged university students on online learning: "Some don't even own smartphones". Drum [Online]. https://www.news24.com/drum/news/disadvantaged-universitystudents-on-online-learning-some-dont-even-own-smartphones-20200403-2

Sang, P. \& Dewi, S. (2020). Hygiene and Sanitation Challenge for COVID-19 Prevention in Indonesia. Kesmas: National Public Health Journal, Special issue 1, 6-13.

Swartz, D. (2010). Presentation to the National Conference of the South African Chapter of the Association of College and University Housing Officers International. Unpublished PowerPoint Presentation, Durban.

Tshimangadzo, S., Nkhangweleni, D., Azwitamisi, G. \& Tshifhiwa, M. (2020). A comparative study of the academic performance of resident and non-resident students at a rural South African university. Journal of Student Affairs in Africa, 8(10),1-12. https://doi.org/10.24085/jsaa.v8i1.3468

Van de Laar, M. 2020. E-resilience in education: A conceptual framework. Policy brief: United Nations University.

Wahl, W.P. 2013. Towards evaluating a higher education residence environment that is conducive to learning, development and success. Journal of Higher Education in Africa/Revue de l'enseignement supérieur en Afrique, 11(1-2), 53-69.

\section{How to cite:}

Kanyumba, B. \& Shabangu, N. (2021). The Effect of the Covid-19 Pandemic on Students and the Living and Learning Spaces at a South African University. Journal of Student Affairs in Africa, 9(1), 93-105. DOI: $10.24085 /$ jsaa.v9i1.1430 
RESEARCH ARTICLE

\title{
Disguised Blessings amid Covid-19: Opportunities and Challenges for South African University Students with Learning Disabilities
}

\author{
Ndakaitei Manase ${ }^{\mathrm{i}}$
}

\begin{abstract}
The Covid-19 pandemic has led to changes from traditional face-to-face teaching and learning to online systems. These changes have resulted in a concerted focus by local and international scholars on how some students are disadvantaged from accessing pedagogy due to a lack of resources and supportive living conditions that enable meaningful off-campus learning. Simultaneously, disabilities in higher education is getting international attention, too, highlighting how students with disabilities are vulnerable to further exclusions and mental health problems. This article focuses on the pedagogical arrangements during the Covid-19 pandemic and the challenges and opportunities associated with online and remote learning for university students with learning disabilities. The article draws on the narratives of fifteen students with learning disabilities from a university in South Africa. An analysis of students' narratives within the Capability Approach's concept of conversion factors revealed how circumstances could enable or constrain students' abilities to achieve what they value in higher education. Students' narratives show that they engage better with online and remote learning despite some notable challenges. In conclusion, the pedagogical arrangements aimed at alleviating the disruptions caused by the Covid-19 pandemic can address the unmet educational needs of students with learning disabilities even though they have to overcome specific barriers.
\end{abstract}

\section{Keywords}

Capability Approach; conversion factors; Covid-19; learning disabilities; online learning; student affairs; university students with special needs

\section{Introduction}

The Covid-19 pandemic brought considerable changes to the higher education system that required unconventional responses (Adnan \& Anwar, 2020), such as online and remote learning. These responses rely on technology, which many universities, students, and lecturers in South Africa were not prepared for (Mhlanga \& Moloi, 2020). Overall, debates on Covid-19 and education attend more to challenges and inequalities that disadvantage students from accessing digital pedagogy within online learning. This article draws insights from students with learning disabilities' narratives to highlight both the challenges and opportunities of online learning during the Covid-19 pandemic. 
The literature on the Covid-19 experiences of students with disabilities, although scarce, discusses their mental health. Zhang et al. (2020) established that students with disabilities are affected by isolation and loneliness during the lockdown. Prolonged isolation can cause stress, anxiety, and depression (Galea et al., 2020; Benke et al., 2020), forcing students to turn to social media (Mahlaba, 2020). Asuncion et al. (2012) established that students with disabilities spend at least double the time on social media than on academic work, thus exhausting resources on non-academic activities and increasing the risk of depression and anxiety, as noted by Dobson-Lohman and Potcovaru (2020). While any student can face these challenges, those with disabilities are more susceptible to periodic acute depression and anxiety because of pre-existing conditions (Zhang et al., 2020).

\section{Online Learning for Students with Disabilities}

Online learning, which involves students' virtual participation in academic activities, offers students some degree of control over the time, place, path, or pace of learning (Hashey \& Stahl, 2014). Students can self-manage, plan, deliver and track their learning process (Almaiah et al., 2020).Various students with learning disabilities find online learning flexible (Crespo, 2020), hence suiting their academic needs. Flexible learning conditions require self-directed learners who are autonomous, responsible, show initiative in formulating and assessing their learning goals and requirements, and adopting strategies to attain goals or achieve expected learning outcomes (Mahlaba, 2020; Knowles, 1975). Students with learning disabilities might not have the same kind of control over the learning process because of difficulties with time management, problem-solving, and planning (Lee Booksh et al., 2010) - common clinical symptoms of learning disabilities. Hence, online and remote learning might not suit some of them.

Furthermore, Roberts, Crittenden and Crittenden (2011) suggest that students with learning disabilities are less likely to succeed in online learning where their disabilities interfere with accessibility and usability. Students who require accessible instructional technology such as screen-readers, can be disadvantaged if it is not available (Hashey \& Stahl, 2014). Cluttered learning content can be inaccessible to students with learning disabilities (Burgstahler, 2015), and thus they can be marginalised in online learning platforms. This subject matter becomes pertinent as the online method has become the norm owing to the Covid-19 pandemic.

\section{A Capability Approach to Understanding Students' Learning Experiences}

The Capability Approach developed by Amartya Sen (1999) accounts for individual real freedoms (capabilities), well-being ("the wellness of a person's state of being”) (Sen, 1993, p.36), and the achievement of what people have reason to value (Robeyns, 2017). Therefore, the Capability Approach is useful in examining conversion factors that affect how people function towards achieving what they value.

Conversion factors concern one's ability to transform resources or opportunities into achievements (Robeyns, 2017). These factors can be personal, social, and environmental (Robeyns, 2017) and, for students, encompass resilience or external factors such as learning 
conditions and disability policies. The conversion factors associated with online learning determine how circumstances affect what students value to achieve. Students in this study reported that they appreciate passing and having a qualification that opens up economic opportunities. Students' experiences are thus analysed to determine how they converted online learning engagements towards attaining a qualification they value as instrumental in getting employment.

\section{Methodology}

Narratives of fifteen full-time students who registered a learning disability with the University of the Free State, South Africa, were gathered through semi-structured interviews. Research participants were recruited using a combination of snowballing and convenience techniques because participants were difficult to get. Data was collected in 2019 for a broader Ph.D. study on the university experiences of students with learning disabilities. This data is useful in highlighting the challenges students experience in face-to-face classes to form the basis for arguments on whether online learning created opportunities for them. Four participants who were still studying in 2020 were contacted telephonically to follow up on how they experienced learning while working online and off the university campus during the Covid-19 pandemic. The study adopts a narrative inquiry research design (Polkinghorne, 1995), which is a qualitative research method involving first-hand accounts of experiences (Rudrum, 2005) focused on a particular population, in particular, social circumstances at a specific time (Riessman, 2008). Data were analysed descriptively to give a clear understanding of how online and remote teaching affected students. The emphasis is not on exhaustive personal life stories (Ball et al., 2013) but on the themes that focus on learning experiences during the Covid-19 pandemic. Therefore, the article seeks to answer the question: "How does online learning instituted during the Covid-19 pandemic affect students with learning disabilities?”

\section{Learning Experiences as Narrated by Students with Learning Disabilities}

Narrated accounts of students' learning experiences reveal difficulties in conventional classes as conditions are often unsupportive. Learning disabilities are invisible (Schabmann et al., 2020), and the symptoms are not typical of what many are accustomed to concerning disability. Students reported that they often devise ways of accessing and understanding learning content. One student with $\mathrm{ADHD}^{1}$ complained that: "There is nothing done for people like me in class. You have to find ways to make it work." ADHD can cause poor concentration, inattention, hyperactivity, high distractibility levels, and severe body impulsivity (Daley \& Birchwood, 2010). A student with ADHD can have trouble sustaining attention for long periods or experience difficulties following instructions, especially under pressure, even when one understands the instructions (Lee Booksh et al., 2010). Therefore, there is a need for alternative learning settings for such students.

1 Classified as a learning disability under the South African Higher Education Disability Services Association coding framework and the National Student Financial Aid Scheme disability policy. 
Nonetheless, these students have to attend face-to-face lectures and write tests and examinations on a stipulated date and time. Learning is expected to continue regardless of episodic flare-ups of adverse symptoms of ADHD as described below:

I have one or two days where I get very depressed and go through a mental shutdown that I don't have control over. During that time, I can't focus on my studies. I just go to the lecture for the sake of it. $(\mathrm{Liz})^{2}$

The above challenge can be overcome if students have options to access classes. It would help students if online learning accommodations ${ }^{3}$ form part of the university's disability support services. Unfortunately, students with learning disabilities are often denied online learning accommodations (Crespo, 2020; Barnard-Brak \& Sulak, 2010). The flexibility in accessing instruction in remote learning allows students with emotional difficulties to choose a suitable time to study and a convenient date to submit assignments.

Furthermore, the attention challenges and high levels of distractibility noted in Daley and Birchwood (2010) which affect students with ADHD are represented in participants' stories. Overcrowded classes, a reality at many universities in South Africa due to higher education's massification (Allais, 2014), compound students' difficulties. The description below is telling:

My attention is very bad such that if someone just clicks a pen, my attention goes there, then I stop listening to the lecturer. If it happens 3-4 times, I lose all attention. ... My first year was incredibly tough because we were 800 students in some classes. Students were sitting on the floor and some on the steps. It was very bad for my attention. It felt like time wasted to attend a lecture because, at the end of the day, you ask yourself, "What did I get out of that lecture?" Sadly, you can't really point at anything. (Frank)

Complexities between external and intrinsic conditions where learning conditions exacerbate learning disabilities are apparent in students' stories, as noted above. Personal and environmental factors intersect to disadvantage students with learning disabilities. A further example involves busy lecture schedules that can cause sensory overload (Kong \& Maha, 2019) and undermine students with learning disabilities' class engagement. Students expressed frustrations with long lectures through statements such as, "I lose interest after some time", "My mind shuts down after 45 minutes into the lecture," and "I end up hearing only sounds, not the actual words of a lecturer." Therefore, some lecture schedules can be restrictive for students with learning disabilities whose attention span is short. Yet, students still attend classes and contend with these limiting learning conditions.

Also, students with dyslexia raised complaints about fast-paced lectures. Of concern is lecturers' lack of skills to adapt teaching methodologies such that they accommodate the information processing needs and learning styles of students with dyslexia. Students complained about transmissionist teaching methods, as indicated in this excerpt:

2 Participant names are pseudonyms.

3 Disability accommodations are adjustments to curricular, instructional and physical settings for students with disabilities to fully-participate in higher education (Barnard-Brak \& Sulak, 2010). 
It's tough with dyslexia to understand when the lecturer is teaching fast. There's too much information given out in class. Most of the time, I am lost. I don't hear [understand] anything (Brenda)

The auditory perception and visual processing disorders that cause difficulties in making sense of sounds (Kelly, 2018) pose challenges for students with dyslexia in understanding taught content. Non-engaging teaching methods can be problematic for such students. As such, students' learning abilities can be affected negatively, as described by Brenda above.

Furthermore, this study revealed that sit-in and hand-written tests and examinations are not an ideal assessment presentation for them. Some students struggle to finish tests on time due to slow reading and writing speeds and difficulties expressing ideas on paper, common symptoms of dyslexia (Lewandowski et al., 2013). The degree of complexity varies, but students in this study acknowledged that they hardly pass when they write examinations at traditional venues because the conditions do not support the full display of their intellectual abilities. As such, students sought and received accommodations where they get extra time, separate sound-proof exam venues, and scribes to read and write for others.

Even though students reported benefits from these arrangements, the separate provisions pathologise learning disabilities and sustain students as disabled. For example, using a scribe to read and write for a student can create a sense of inadequacy in a student with a learning disability (Sainio et al., 2019). It can reinforce the idea that relying on someone else to write written exams is the only successful way of articulating exams. Alternative assessment modes (D'intino, 2017), such as online tests (with audible textreaders), can improve the accessibility and articulation of exams for students with reading and writing difficulties.

The above narrated learning experiences indicate that the set-up of learning spaces and teaching and assessment methodologies affect how students with learning disabilities engage with learning in face-to-face settings. Online and remote learning can be viewed positively for students with learning disabilities as it creates opportunities for students to learn without any worries associated with the conventional lecture method. Therefore, online-based assessments, which became mandatory after universities' closures, confirm this opportunity presented by the Covid-19 pandemic to create favourable assessment settings beneficial to most students with learning disabilities. Students also shared their experiences of online learning in the following section.

\section{Students' perspectives of online learning during the Covid-19 pandemic}

This article collected students with learning disabilities' experiences of learning during the Covid-19 pandemic. Follow-up telephonic calls were made with study participants who were still studying in 2020 as the Covid-19 pandemic unfolded. Discussion points included what was available to support online learning, what worked or not for students when working off-campus, challenges encountered in terms of resources and capacity, and any other ways online learning impacted their lives as university students. 
The narrated students' experiences indicated that they adapted well to online and remote learning. For example, students who already had proper technology, stable internet connections, technological skills, and family support sustained online learning. These students' resourcefulness before the Covid-19 pandemic positioned them at an advantage when they secured specialised computer software to aid with comprehension, spelling, and syntax. Others used dyslexia fonts and reading and writing enhancing software, which improves the accessibility, articulation, and quality of assignments. Dyslexia is associated with difficulties in the sequential naming of letters and words (Hall, McGregor \& Oleson, 2017), which can cause slow and weak reading fluency and poor comprehension of written text that necessitates assistive computer software. These arrangements support Wilde, Ryan, and Woodin's (2020) view that those with disabilities can straightforwardly become productive during the lockdown because most systems compel them to overcome obstacles and force them to be autonomous. Therefore, the level of the study participants allayed accessibility and competence challenges that Mukeredzi, Kokutse and Dell (2020) viewed as affecting students' engagement with online learning during the Covid-19 pandemic in South Africa. Students also reported no difficulties in locating learning resources on web-based sites, including accessing the university library resources while off the campus. The university continues to provide students with disabilities with extra time and extensions on submitting assignments as part of the disability accommodations. There are, therefore, indications that online learning suited most students with learning disabilities during the Covid-19 pandemic.

\section{Opportunities for learning online and remotely during the Covid-19 pandemic}

The less structured approach to learning created opportunities that suited most students with learning disabilities in this study. Students reported that learning online enabled them to engage well with their studies during the lockdown because there were few distractions compared to being in overcrowded classes that trigger severe anxiety and panic attacks. For example, one student with ADHD who appreciated the online learning arrangement stated that she "failed a test dismally" after writing in a "fully-packed exam hall" while on-campus. Others who struggle to learn in big-sized classes said that the online experience is less anxiety-inducing. Besides, students stated that online lecture content was low-datacompatible and thus shorter. Some appreciated online learning because there is access to learning material without any pressure to engage with it instantly, and there is unlimited access to recorded lectures. The following extracts capture the opportunities experienced by students with learning disabilities during online and remote learning:

I actually benefited a lot from learning online. ... Lecturers made PowerPoint slides with voice-overs, and then we could listen to them repeatedly while following the slides. What I liked is that lectures that normally take 2 hours in face-to-face classes ended up taking just 1 hour. To me, learning online was a better experience than face-to-face classes. (Sammy)

Learning online at home suited me very well. I study and work better with tests when there are no people around me. So, there was lots of working in my room and overnight when everyone was not around to call for my attention. So, I managed to do what needed to be done without anyone bothering me. (Tess) 
Online learning was also beneficial to students because they had to write assignments. Blackboard quizzes and self-marking tests that were less demanding than usual examinations. Students indicated that they prefer writing assignments to exams that usually require memorisation and good information retrieval skills, which many students with learning disabilities struggle with (Swanson \& Siegel, 2011). Thus, online assessments allowed students with learning disabilities to better integrate information better, unlike having to cram and retrieve information under pressure during the sit-in examinations. Brian, who has dyslexia, shared that replacing examinations with long assignments enabled him to perform very well and he had a 15\% increase on his average marks. With ADHD, Sammy experiences acute levels of test anxiety. She reported that she was "impressed by her marks" because online assessment methods were "friendly for her disability" as she could write when not feeling anxious, resulting in her achieving "impressive marks". Such accounts indicated some of the opportunities created by online learning for students with learning disabilities.

Students with learning disabilities often operate within rigid assessment systems (Tinklin, Riddell \& Wilson, 2004) that do not allow the full display of students' skills and capacity for learning. Limiting conditions usually cause discrepancies between students' intellectual potential and actual academic achievements (NILD, 2016). Therefore, the flexibility in Covid-19-initiated online learning allows variety and creativity in assessing students, which had positive effects on students' academic performances.

\section{Challenges associated with online and remote learning}

despite the opportunities created for students with learning disabilities through online learning, some faced challenges that affected their learning abilities (see the two narratives below). For example, the asynchronous learning approach, where students complete academic activities without direct contact with lectures (Smith \& Basham, 2014), pose some of these challenges. Firstly, the lack of student-lecturer interaction made it difficult for students to ask questions and get timely and adequate responses on academic issues of concern. These students mostly rely on and benefit from individual consultations with lecturers since some have information processing needs that affect their ability to understand the whole lecture at a given time. As confirmation two disabled students narrated how a lack of in-person teaching affected them:

In most cases, we got slides that we had to go through on our own. So it wasn't actually teaching. It affected my marks negatively. ... Sometimes, when I emailed a question, lecturers would answer it in a way they want to, without answering it satisfactorily. It was difficult to make a follow up because sometimes I got my response days after or the given answer confused me further. It is not the same as going to consult the lecturer in person, and I did not like online learning because of that. (Liz)

The only problem I had was that when you had a question, you couldn't ask it immediately I prefer to go physically and sit down with the lecturers and have them answer my questions. I didn't like emailing lecturers. It was very difficult for me to formulate my questions in an email. (Sammy) 
Liz's account exposes some lecturers' lack of skills in delivering teaching on online platforms or lack of commitment to changes in teaching modes. These challenges include lecturers who need to reach out to students and teach effectively online. The university where these students are based created an online platform with zero data rated where lecturers can present virtual classes with students so that they can chat and ask questions. Lecturers can also add audio descriptions on the PowerPoint slides to explain written text, upload videos of tutorials, and make learning content more interactive. PowerPoint with audio, however, is effective if the text and images are not distracting for students with attention difficulties or too cluttered for students with dyslexia to understand.

Students also noted that working on their computers all the time was distractive. Those with a short attention span reported that they ended up clicking on web pages that were not relevant to academic work and thus lost valuable time. The quotes below illustrate this point:

I was distracted working online at home. Now I was in front of the computer screen the whole time. I found myself clicking on new stuff and focusing on other things that pop-up instead of focusing on my assignments. (Brian)

I couldn't ignore social media. Even WhatsApp is on my laptop. I don't know, I needed that distraction while studying. The temptation of getting lost in social media was always there and it's funny how it felt like it's necessary. (Tess)

Online learning increased the students' risk of losing concentration by following nonacademic platforms. Students with ADHD who have low task vigilance (Ross \& Randolph, 2016) can lose total focus if they are distracted. Therefore, students risked losing interest in academic work where there was low motivation to learn or no strategies to self-regulate work habits (Ek \& Isaksson, 2013). These advantages and disadvantages of online learning are analysed next using the Capability Approach concept of conversion factors.

\section{Conversion Factors Associated with Online Learning for Students with Learning Disabilities}

In engaging analytically with the data, personal, environmental and social conversion factors were identified from students with learning disabilities' narrated experiences of learning online during the Covid-19 pandemic. The researcher analysed these intervening factors to determine their effect on students' conversion abilities that shape educational trajectories towards achieving suitable grades and qualifications they value.

\section{Personal conversion factors}

An inherent condition that affects a student's ability to focus on academic work or deficits that affect students' level of understanding lectures qualifies a learning disability as a personal conversion factor. A learning disability can thus pose the risk of diminishing the learning abilities of students. Students' pro-activeness in acquiring assistive software, being autonomous, resilient, and motivated to ensure that academic tasks are completed on time is evidence of their personal conversion factors. The effects of these characteristics were 
enabling, and enhanced students' ability to perform well and achieve valued educational outcomes. There are, therefore, individual personal conversion factors that affected students in different ways.

\section{Environmental conversion factors}

Environmental conversion factors are those associated with a university or home set-up (e.g. physical learning conditions, policies and practices). The study observed university arrangements that either diminish or expand students' capabilities before and after the Covid-19 pandemic. The over-crowded classes noted by students as distractive and anxietyinducing are environmental conversion factors that affected learning negatively. This study stated these factors as having a constraining effect on students' academic engagements. The home-working arrangement that some students, including Brian above, find challenging is also an environmental conversion factor. Working online all the time and spending resources on non-academic material has a potentially diminishing effect on students' efforts to achieve valued educational outcomes. However, having a home environment where students can learn when people who can distract them are out-of-reach, as narrated by Tess above, is an environmental conversion factor that contributed to students' academic success. The flexible assessment methods necessitated by online learning are also a conversion factor that positively affected students' academic performance. This was also confirmed by Sammy and Brian's narratives where students performed better than in usual assessment settings.

\section{Social conversion factors}

The research identified social conversion factors from the interaction students had with teaching staff. Sammy's and Liz's narratives reported the lack of student-lecturer interaction that made it difficult to ask questions and get immediate responses. Liz further indicated that she struggled to understand learning content because lecturers did not teach them properly in virtual classes. Therefore, the lack of face-to-face interaction, which limited students' access and understanding of content, risked underperformance for students with learning disabilities who rely mostly on individual consultations with lecturers for extra academic assistance. Limited direct access to lecturers affected students' ability to attain good marks, making it a social conversion factor that constrained students' capabilities.

\section{Conclusion and Recommendations}

This article explored the learning experiences of university students with learning disabilities, highlighting how the online learning arrangement affected their academic engagements. Insights from students suggest that online and remote learning during the Covid-19 university shutdown can support the needs of students with learning disabilities, despite some challenges. This article observes that remote learning offers students with learning disabilities opportunities to engage better with academic tasks, because some conditions under contact teaching limit their learning abilities. The researcher conceptualised students' learning experiences as opportunities and challenges, and identified conversion factors that interfered with students' abilities to achieve what they value in higher education. 
However, individual students are affected differently. Conditions that are advantageous to some can disadvantage others. The study supports the need for inclusive education systems that are not too restrictive for students to manage to learn. There is a need to diversify instructional material, teaching, and assessment modes, limiting disadvantages to students, particularly those with learning disabilities. The article recommends institutionalising the Universal Design for Learning (UDL) at universities to cater to all diversity forms. UDL involves designing learning spaces, the arrangement of physical environments, presentation of instruction, and assessment modes to be accessible and usable (without unique or separate support) by all students regardless of need (Dalton, 2020). UDL encourages the multiple means of representation of instruction and information, multiple means of learning engagement processes, and multiple means of expression by students in demonstrating their understanding of content (Smith \& Basham, 2014). Online learning, made compulsory by the Covid-19 pandemic, can fulfil these UDL principles because it allows multi-modal presentation and engagement with instruction.

\section{Acknowledgements}

I thank Drs Mikateko Mathebula and Faith Mukwananzi for their comments, the research participants for their cooperation, and greatly value my supervisors' mentoring during the main PhD study.

\section{Research Ethics}

This article is drawn from a $\mathrm{PhD}$ study with an ethical clearance number UFS-HSD2019/ 0038/2903 from the University of the Free State's General/Human Research Ethics Committee.

\section{Conflict of Interest}

None.

\section{Funding}

The PhD study is funded by the SARCHi Chair in Higher Education and Human Development, NRF grant number 86540.

\section{References}

Adnan, M. \& Anwar, K. (2020). Online learning amid the covid-19 pandemic: students' perspectives. Online Submission, 2(1), 45-51. https://doi.org/10.33902/JPSP.2020261309

Allais, S. (2014). A critical perspective on large class teaching: the political economy of massification and the sociology of knowledge. Higher Education, 67(6), 721-734. https://doi.org/10.1007/s10734-0139672-2

Almaiah, M.A., Al-Khasawneh, A. \& Althunibat, A. (2020). Exploring the critical challenges and factors influencing the e-learning system usage during Covid-19 pandemic. Education and Information Technologies, 1. https://doi.org/10.1007/s10639-020-10219-y

Ball, S., Macrae, S. \& Maguire, M. (2013). Choice, pathways and transitions post-16: New youth, new economies in the global city. Routledge. https://doi.org/10.4324/9781315043296 
Barnard-Brak, L. \& Sulak, T. (2010). Online versus face-to-face accommodations among college students with disabilities. The American. Journal of Distance Education, 24(2), 81-91. https://doi.org/10.1080/ 08923641003604251

Burgstahler, S. (2015). Opening doors or slamming them shut? Online learning practices and students with disabilities. Social Inclusion, 3(6), 69-79. https://doi.org/10.17645/si.v3i6.420

Crespo, I. (2020). Accessibility dissonance:The disability community's overlooked fight for remote learning. https://www.statepress.com/article/2020/04/spmagazine-accessibility-dissonance-the-disabilitycommunitys-overlooked-fight-for-remote-learning [Accessed 13 December 2020].

Daley, D. \& Birchwood, J. (2010). ADHD and academic performance: Why does ADHD impact on academic performance and what can be done to support ADHD children in the classroom? Child: care, health and development, 36(4), 455-464. https://doi.org/10.1111/j.1365-2214.2009.01046.x

Dalton, E.M. (2020). UDL and connected laws, theories, and frameworks. Universal Access Through Inclusive Instructional Design: International Perspectives on UDL, 3-16. https://doi.org/10.4324/9780429435515-1

D'intino, J.S. (2017). Learning disabilities in Canada: Definitions and accommodations. Canadian Psychology/psychologie canadienne, 58(3), 228. https://doi.org/10.1037/cap0000116

Ek, A. \& Isaksson, G. (2013). How adults with ADHD get engaged in and perform everyday activities. Scandinavian Journal of Occupational Therapy, 20(4), 282-291. https://doi.org/10.3109/11038128.20 13.799226

Galea, S., Merchant, R.M. \& Lurie, N. (2020). The mental health consequences of Covid-19 and physical distancing: The need for prevention and early intervention.JAMA internal medicine, 180(6), 817-818. https://doi.org/10.1001/jamainternmed.2020.1562

Hall, J., McGregor, K.K. \& Oleson, J. (2017). Weaknesses in lexical-semantic knowledge among college students with specific learning disabilities: Evidence from a semantic fluency task. Journal of Speech, Language, and Hearing Research, 60(3), 640-653. https://doi.org/10.1044/2016_JSLHR-L-15-0440

Hashey, A.I. \& Stahl, S. (2014). Making online learning accessible for students with disabilities. Teaching Exceptional Children, 46(5), 70-78. https://doi.org/10.1177/0040059914528329

Kelly, A. (2018). Working with adults with a learning disability. Routledge. https://doi.org/10.4324/9781 315172521

Knowles, M.S. (1975). Self-directed learning: A guide for learners and teachers. Association Press.

Kong, M. \& Maha, J. (2019). Sensory processing: shifting our mindset to improve care delivery. Pediatric research, 86(4), 544-545. https://doi.org/10.1038/s41390-019-0489-2

Lee Booksh, R., Pella, R.D., Singh, A.N. \& Drew Gouvier, W. (2010). Ability of college students to simulate ADHD on objective measures of attention. Journal of Attention Disorders, 13(4), 325-338. https://doi.org/10.1177/1087054708329927

Mahlaba, S.C. (2020). Reasons why self-directed learning is important in South African during the Covid-19 pandemic. South African Journal of Higher Education, 34(6), 120-136. https://doi.org/10.20 853/34-6-4192

Mhlanga, D. \& Moloi, T. (2020). Covid-19 and the digital transformation of education: What are we learning on 4IR in South Africa? Education Sciences, 10(7), 180. https://doi.org/10.3390/educsci 10070180

Mukeredzi, T, Kokutse, F. \& Dell, S. (2020, April 22). Student bodies say e-learning is unaffordable and elitist. University World News (Africa Edition). https://www.universityworldnews.com/post. php?story $=20200422075107312$ [Accessed 20 August 2020].

NILD (National Institute for Learning Development) (2016). What are the types of learning disabilities? http://nild.org/learning-disabilities/dyslexia-dysgraphia-dyscalculia/ [Accessed 9 May 2018]. 
Polkinghorne, D.E. (1995). Narrative configuration in qualitative analysis. International Journal of Qualitative Studies in Education, 8(1), 5-23. https://doi.org/10.1080/0951839950080103

Riessman, C.K. (2008). Narrative methods for the human sciences. Sage.

Roberts, J.B., Crittenden, L.A. \& Crittenden, J.C. (2011). Students with disabilities and online learning: A cross-institutional study of perceived satisfaction with accessibility compliance and services. The Internet and Higher Education, 14(4), 242-250. https://doi.org/10.1016/j.iheduc.2011.05.004

Robeyns, I. (2017). Wellbeing, freedom and social justice: The capability approach re-examined. Open Book Publishers. https://doi.org/10.11647/OBP.0130

Ross, P. \& Randolph, J. (2016). Differences between students with and without ADHD on task vigilance under conditions of distraction. Journal of Educational Research and Practice, 4(1), 1-10.

Rudrum, D. (2005). From narrative representation to narrative use: Towards the limits of definition. Narrative, 13(2), 195-204. https://doi.org/10.1353/nar.2005.0013

Sainio, P.J., Eklund, K.M., Ahonen, T.P. \& Kiuru, N.H. (2019). The role of learning difficulties in adolescents' academic emotions and academic achievement. Journal of learning disabilities, 52(4), 287-298. https://doi.org/10.1177/0022219419841567

Schabmann, A., Eichert, H.C., Schmidt, B.M., Hennes, A.K. \& Ramacher-Faasen, N. (2020). Knowledge, awareness of problems, and support: university instructors' perspectives on dyslexia in higher education. European Journal of Special Needs Education, 35(2), 273-282. https://doi.org/10.1080/088 56257.2019.1628339

Sen, A. (1993). Capability and wellbeing. The Quality of Life, 30. https://doi.org/10.1093/0198287976.0 03.0003

Sen,A. (1999). Development as freedom. Oxford University Press.

Smith, S.J. \& Basham, J.D. (2014). Designing online learning opportunities for students with disabilities. Teaching Exceptional Children, 46(5), 127-137. https://doi.org/10.1177/0040059914530102

Swanson, H.L. \& Siegel, L. (2011). Learning disabilities as a working memory deficit. Experimental Psychology, 49(1), 5-28.

Tinklin, T., Riddell, S. \& Wilson, A. (2004). Policy and provision for disabled students in higher education in Scotland and England: The current state of play. Studies in Higher Education, 29(5), 637-657. https://doi.org/10.1080/0307507042000261599

Wilde, A., Ryan, S. \& Woodin, S. (2020). Covid-19 and the academy. https://es.britsoc.co.uk/Covid-19and-the-academy/ [Accessed 22 May 2020.

Zhang, H., Nurius, P., Sefidgar, Y., Morris, M., Balasubramanian, S., Brown, J., Dey, A.K., Kuehn, K., Riskin, E., Xu, X. \& Mankoff,J. (2020). How does Covid-19 impact students with disabilities/health concerns? https://arxiv.org/abs/2005.05438

\section{How to cite:}

Manase, N. (2021). Disguised Blessings amid Covid-19: Opportunities and Challenges for South African University Students with Learning Disabilities. Journal of Student Affairs in Africa, 9(1), 107-118. DOI: $10.24085 /$ jsaa.v9i1.1431 


\title{
Online Work Readiness Programme: Ready, Set, Go!
}

\author{
Belinda Janeke $e^{\mathrm{i}}$
}

\begin{abstract}
There has always been pressure on higher education institutions to enhance the employability of graduates and to instil knowledge, skills, and attributes that will be beneficial to future employers. The impact of Covid-19 on a global, national, and local level is placing even more pressure on the topic of employability. Graduates are uncertain about job availability and there is a need for career guidance. After a national and local shutdown of university campuses in 2015 and 2016 due to \#FeesMustFall, Career Services staff at the University of the Free State designed and created online work readiness programmes in order for students to continue with work preparations, no matter what the circumstances. In 2018, the first topics on CV-writing and job interview skills were rolled out online and made available to all registered students; each semester, two additional topics were added. By the time Covid-19 led to a national lockdown in South Africa in March 2020, the transition to online work readiness programmes was fairly easy. The purpose of this study is to determine the impact of the online work readiness programmes offered on the Blackboard platform from April to June 2020 during the Covid-19 pandemic and national lockdown. This article will provide an analysis of a questionnaire conducted with willing participants who have engaged and worked through the online work readiness programmes from April to June 2020, to investigate the impact on graduates' readiness for the world of work. Through the survey, students shared their learning experiences and the influence it has had on their career planning. It is believed that the findings of this research study will create a deeper understanding of how career services, as a particular functional area in student affairs, can reposition itself during uncertain times to remain responsive to the needs of students.
\end{abstract}

\section{Keywords}

career services; co-curriculum; Covid-19; employability; higher education institution; work readiness

\section{Introduction}

South African higher education institutions are under constant pressure to address a range of challenges, including unemployment, financial pressures for students and the sector, slow sectoral transformation, and the struggling economy of South Africa in general, which is exacerbated by the recent Covid-19 pandemic (Adotey, 2020; Heleta, 2016; Mutekwe, 2018; Roodt, 2020;Viljoen, 2018).

i Ms Belinda Janeke is the Head of Career Services, Student Affairs at the University of the Free State, South Africa.Email: janekeb@ufs.ac.za 
South Africa's economy has grown slowly in the past decade due to, amongst others, declining public finances, mass unemployment, and issues with power and electricity. During the Covid-19 pandemic, matters are worsening, with an expected negative growth of the economy that will most likely be contracting by 1-3\% before the end of 2020 (Roodt, 2020).

South African higher education institutions have been impacted by noticeable changes since the country became a democratic state in 1994. These include increased diversity in student and staff populations, advances in technology, learning strategies, and increased reflection on colonialism and how its many disguises as cultural, economic, political, and knowledge-based oppression still haunt the system (Heleta, 2016; Viljoen, 2018). Furthermore, student numbers have increased significantly, the need for formal qualifications has intensified - coupled with a decrease in funding, and changes occurred in curriculums and programmes (Chipunza \& Malo, 2017; Viljoen, 2018). In addition, the unemployment problem in South Africa is structural, in the sense that the majority of the labour supply (poorly educated workers) cannot find employment as there is little demand for low-skilled workers. However, the focus and mission of most higher education institutions are to address unemployment by providing high-skilled graduates for the workforce (Oluwajodu, Greyling, Blaauw \& Kleynhans, 2015).

Intensifying the pressure on higher education institutions, Mzileni (2020) highlights three additional problems that Covid-19 is bringing to the South African higher education context, namely: the lack of infrastructure for functional learning experiences; the movement towards online teaching and the struggle for students and staff to make the mind shift from the traditional teaching and learning contact to online learning; and thirdly, the dependence of undergraduates on face-to-face traditional teaching and learning practices to address their basic educational needs.

The South African government provided resources to the Department of Higher Education and Training (DHET) to develop the National Policy for an Integrated Career Development System for South Africa (DHET, 2017) in order to address three key priorities of the government, namely unemployment, poverty, and inequality. The vision of the policy is to assist South African citizens in accessing relevant post-school education and training, in order to fulfil the economic and social goals of participation in an inclusive economy and society (Career Development Services, 2017).

Career Services (CS - a division of Student Affairs) at the University of the Free State (UFS) supports the national policy by empowering and preparing students with the necessary transferable skills for the world of work. In 2017, employed UFS graduates indicated that they were very satisfied (31\%) and satisfied (42\%) with how the UFS had prepared them for employment (UFS Graduate Exit Survey, 2020). In a recent study conducted by Universum (2020) with more than 20000 experienced hires globally, only $27 \%$ of participants indicated that they felt their qualification offered them excellent preparation for their current position. Winani Ndlovu, Research Manager at Universum, denotes that these statistics exemplify the gap between academic learning and the world of work: 
With organisations now focusing on diversity and inclusion beyond the expected gender, age and ethnic background conversation, we are seeing their recruitment interests widen to cover talent with different knowledge and skillset backgrounds. Ultimately this might start shifting employer interests to those universities that offer blended learning that includes work-related work in an effort to push their students' preparedness for the world of work.

(Ndlovu, 2020)

These statistics exhibit a low satisfaction rate in terms of preparation to enter the world of work, corresponding with employers' experiences.

Employers believe that new employees - recent graduates in particular - lack basic skills, intellectual capacity, workplace skills, applied knowledge, and the ability to work effectively in the workplace (Oluwajodu et al., 2015). Globally, employers are struggling to find capable, adaptable, and skilled employees to keep up with this age of technology and the demands of the Fourth Industrial Revolution (Laubscher, 2018). A skilled workforce is needed to increase business productivity and competitiveness, which in turn will benefit the economy and reduce poverty (Laubscher, 2018). Another factor contributing to unemployment is job search activities, where job searchers are not investing time and effort to find the correct fit (Oluwajodu et al., 2015). Therefore, CS at the UFS embarked on this mission to not only develop workshops and training to address basic skills, workplace skills, and applied knowledge, but to also upscale the offering to serve approximately 40000 registered students by designing and implementing an online work readiness programme that students can engage with at any time.

\section{Employability and Work Readiness}

Entrenching employability, as suggested by the Higher Education Academy (HEA), concerns the provision of "opportunities to develop knowledge, skills, experiences, behaviours, attributes, achievements and attitudes to enable graduates to make successful transitions and contributions, benefiting them, the economy and their communities" (HEA, 2016, p. 1). The DHET (2017) emphasises their key priorities as addressing inequality, poverty, and unemployment. Therefore, South African universities are considered key players in addressing these three priorities in terms of quality of teaching and learning, attitude and values, actively encouraging and promoting co-curriculum participation, and the use of career services to enrich the employability of students (Walker \& Fongwa, 2017).

Work readiness refers to the level on which graduates are perceived to have the necessary attitudes, attributes, worker traits, and coping mechanisms to be successful in the workplace (Brady, 2010; Caballero \& Walker, 2010; Doe, 2015). The more work-ready a graduate is, having one or more workplace skills, the more employable and successful the individual will be in the workplace (Doe, 2015). Therefore, employability does not only mean being able to get a job, but to be able to implement work readiness skills in any given job.

CS at the UFS created, and continuously updates and improves, the work-readiness programmes delivered and offered to students, staying up to date with trends and demands 
from the world of work. The programme is practice-based and in the format of online work-readiness tutorials, content, and resources. The content is structured to suit the learning preferences of any student - from reading material to engaging activities, to easily accessible information in the form of infographics or checklists, and video recordings of the workshop content (UFS Career Services, 2020).

Challenges and opportunities presented themselves in October 2015 when the first campuses were shut down due to the \#FeesMustFall movement. It was during the 2015 and 2016 campus shutdown periods that CS at the UFS re-evaluated their offering to students, the delivery methods of crucial work-readiness programmes and information, as well as the access of students to internet-based platforms. In July 2018, CS rolled out a pilot study with the two most sought-after topics for work preparedness, namely CV-Writing and Job Interview Skills. The reasons and motivation for having online work-readiness programmes were three-fold: to embrace the multi-campus model of reaching all registered students of the UFS on all three campuses (approximately 40000 students); secondly, to deliver work-readiness programmes on a scale with a staff component of one full-time staff member; and lastly, in case of another campus shutdown, that work readiness programmes could be delivered hassle-free.

The national lockdown in South Africa due to Covid-19 once again created new challenges for both academic and support staff to continue academic and service delivery by means of online platforms. Fortunately, the CS at the UFS was ready to continue to work effortlessly, positioned with six topics to prepare students for the world of work. Indeed, from 27 March 2020, all face-to-face workshops were replaced with online programmes on different online platforms generated by the UFS.

Each topic was delivered online, with various options for students - from a step-bystep tutorial process, claiming badges and completing activities, to accessing cheat sheets or infographics, watching a short video recording on the topic, or viewing various resources and examples of profiles and CVs. Students' participation in the online workshops during Covid-19 provided an opportunity to evaluate the effectiveness of using different platforms.

\section{Conceptual Framework}

The Canadian Research Working Group on Evidence-Based Practice in Career Development (CRWG) has developed a framework for evaluating the delivery of careerrelated services and the effectiveness of career development interventions (Baudouin et al., 2007). Most formal research focuses on career development or counselling, and not specifically on the evaluation of career services or programmes and the impact these have on clients or students (Benzinger et al., 2011). This framework was developed after various evaluation models in literature were researched, considering the strengths and weaknesses of each model, and ultimately deciding to develop a framework that could be easily incorporated into practice, easily understood, and still included all relevant information to evaluate career interventions comprehensively (Baudouin et al., 2017). The framework consists of three elements, namely inputs, processes, and outcomes. 
The first element, inputs, refers to the resources available to assist clients to change and to reach the outcomes. Processes signify all mechanisms involved in achieving the outcomes. Outcomes relate to the changes experienced by clients and the results of the inputs delivered through the processes. The CRWG refers to the three elements as a linear process, but states that the relationship between the elements is not strictly linear due to the outputs being influenced by the available inputs, and the nature of the inputs that can impact the process used.

Inputs include the resources available to the institution to deliver quality services, namely staff, funding, service guidelines, facilities, infrastructure, and community resources. Table 1 below indicates the inputs of CS at the UFS, namely: staff, funding, service guidelines, and facilities.

Table 1: CS inputs

\begin{tabular}{|l|l|}
\hline Staff & $\begin{array}{l}\text { 1 full-time staff member, 1 contract appointment, and 5-10 volunteers per } \\
\text { semester. }\end{array}$ \\
\hline Funding & A budget of R100000 for student relations activities per annum. \\
\hline $\begin{array}{l}\text { Service } \\
\text { guidelines }\end{array}$ & $\begin{array}{l}\text { CS's mandate is to offer a range of services and resources designed to assist } \\
\text { students to develop the employability skills they need in today's world } \\
\text { of work. The Student Relations portfolio provides career development } \\
\text { and guidance to students and delivers work readiness programmes. The } \\
\text { Company Relations portfolio offers services to employers to advertise, } \\
\text { interview, and recruit talented students. }\end{array}$ \\
\hline Facilities & $\begin{array}{l}\text { Blackboard is used as the Learning Management System. Six topics were } \\
\text { planned and designed for online learning. Thirteen activities must be } \\
\text { completed in order to receive a badge (as part of gamification), of which } \\
\text { eight activities are automatically marked, and five activities must be } \\
\text { marked manually. }\end{array}$ \\
\hline
\end{tabular}

CS inputs do not include any additional infrastructure such as consultants or support staff, and do not have community resources such as a specific section in the library dedicated to career development, or computer rooms dedicated to career services.

The second element, processes, refers to the interventions and quality service factors. First of all, interventions consist of specific interventions (singularly focused on clients' goals and outcomes with the purpose of fostering change) and generic interventions (interactions of service providers or third parties). The other factor, namely quality service, refers to the tools for measurement. Although it may provide the outcomes for this process, it is still considered as part of the process indicating the effectiveness of the process. Table 2 below indicates the CS processes at the UFS, namely: specific interventions and quality of service. 
Table 2: CS processes

\begin{tabular}{|l|l|}
\hline Specific & $\begin{array}{l}\text { A work readiness programme addressing all six categories within } \\
\text { this framework, namely: career decision-making, work-specific } \\
\text { skills enhancement, work search, job maintenance, career-related } \\
\text { personal development, and other resources (referrals). The CS work } \\
\text { readiness programme consists of six topics, with activities to test } \\
\text { the knowledge gained, and practical submissions to be marked } \\
\text { manually by staff. The six topics are CV-writing, interview skills, } \\
\text { LinkedIn, digital world: personal branding for success, networking } \\
\text { and job-hunting skills, and future of work. }\end{array}$ \\
\hline $\begin{array}{l}\text { Quality of } \\
\text { service }\end{array}$ & $\begin{array}{l}\text { CS will determine the usefulness and impact of the online } \\
\text { work readiness programmes through evaluation by means of a } \\
\text { questionnaire sent to students. }\end{array}$ \\
\hline
\end{tabular}

CS processes do not include generic interventions provided by third parties or service providers.

The third element, outcomes, is concerned with the result of an intervention, including change in the client's competence, attributes, and broader changes for the client or community. The outcomes and results are organised into three categories, namely client learning outcomes, client personal attribute outcomes, and client impact outcomes. Table 3 below indicates the CS outcomes at the UFS, namely: student learning outcomes, student personal attribute outcomes, and student impact outcomes.

Table 3: CS outcomes

\begin{tabular}{|l|l|}
\hline $\begin{array}{l}\text { Student learning } \\
\text { outcomes }\end{array}$ & $\begin{array}{l}\text { The learning outcomes include the knowledge and skills that can } \\
\text { be directly linked to the programme or intervention used, including } \\
\text { personal management, learning and work exploration, or building a } \\
\text { life or career. }\end{array}$ \\
\hline $\begin{array}{l}\text { Student personal } \\
\text { attribute } \\
\text { outcomes }\end{array}$ & $\begin{array}{l}\text { Personal attribute outcomes include changes in attitude, } \\
\text { intrapersonal skills (self-esteem, motivation, and confidence), and } \\
\text { independence. }\end{array}$ \\
\hline $\begin{array}{l}\text { Student impact } \\
\text { outcomes }\end{array}$ & $\begin{array}{l}\text { Impact outcomes refer to the learning outcomes of interventions } \\
\text { and can contribute to changes in a client's life, such as employment } \\
\text { status, pursuing training, social and relational impact, and economic } \\
\text { impact. }\end{array}$ \\
\hline
\end{tabular}

It is important to note that all student relations projects and programmes in CS are planned and created in alignment with the UFS graduate attributes, which include critical thinking, problem solving, entrepreneurship, oral and written communication, ethical reasoning, and civic engagement (Strydom \& Oosthuizen, 2019). In addition, all six student outcome domains - according to the Council for the Advancement of Standards in Higher Education (CAS) - were addressed in the work readiness programme: knowledge acquisition, construction, integration and application; cognitive complexity; intrapersonal development; interpersonal competence; humanitarianism and civic engagement; and practical competence (CAS, 2015). 


\section{Methodology}

In order to evaluate the effectiveness of career development interventions in online form, a convergent mixed-method design was used for the study. This implied gathering both quantitative and qualitative data simultaneously, analysing the data sets separately, and then comparing the findings (Creswell \& Creswell, 2018). This approach was used to draw on the strengths of both quantitative and qualitative research, and to facilitate an in-depth understanding of the qualitative data to explain the quantitative database of the collected questionnaires (Creswell, 2014).

The questionnaire was guided by the CRWG framework and consisted of 74 questions, including closed-ended, Likert type, and open-ended questions. It should be noted that participants weren't expected to answer all 74 questions; the questionnaire started with 10 questions about the online format, followed by questions regarding the six topics. For each topic selected in question 1, the participant would've been asked eleven additional questions per topic. Each workshop had its own unique questions for evaluating the intended outcomes, followed by generic open- and closed-ended questions for all respondents, particularly focusing on their experiences with the online platform, the value of the workshops for their development, and recommendations they might have. The purpose of the evaluation questions was to determine students' experiences about the online process (user-friendliness), the teaching and learning component of each topic (whether they implemented the knowledge gained), as well as the content and resources (what they found useful and informative).

The questionnaire was done electronically by sending an email with the link to the selected participants. About 2869 students completed the online workshops between April and June 2020. Most of the students were between the ages of 18 and $23(n=2221), 60,3 \%$ were female, $86,3 \%$ were African, and the majority were undergraduates $(n=2533)$ from seven faculties, of which the Faculty of the Humanities $(n=830)$ was the best represented, followed by the Faculty of Natural and Agricultural Sciences $(n=588)$, and the Faculty of Economic and Management Sciences ( $\mathrm{n}=567)$. These students were purposefully sampled to provide feedback on their experiences with the workshops. Of the 2869 workshop participants, 116 completed the survey (response rate of 4\%). Although this response rate is not representative of the larger population, it would suffice to provide the CS with feedback on how the 116 students experienced the workshops in an online format, which would in turn contribute to future planning.

Data was analysed separately (quantitative and qualitative) and then merged to allow for a side-by-side comparison to determine similarities and elaboration on experiences, as well as how data related to one another (Creswell, 2014). Completed questionnaires delivered empirical data and were analysed using SPSS software that delivered descriptive statistics. The qualitative data were analysed through inductive and deductive content analysis by first identifying the extent to which the intended outcomes were mentioned by students in their provided text, followed by a more open reading of additional outcomes (Krippendorff, 2018). Through qualitative data, the following themes were identified that are aligned with the three outcomes of the conceptual framework used: student learning 
outcomes, students' personal attributes, and impact outcomes. Additionally, the online platform was evaluated, leading to the fourth theme. Each topic of the work readiness programme had specific student learning outcomes that were measured in this research. Qualitative feedback provided insight into students' personal attributes developed through engagement with the content, as well as feedback regarding impact outcomes indicating whether participants were encouraged to move into action by implementing what they have learned. Both quantitative and qualitative data provided insight into how the online format was experienced, used, and could be improved.

\section{Findings and Discussion}

The conceptual framework discussed above consists of three elements: inputs, processes, and outcomes. There is little to no control over the inputs (staff, funding, service guidelines, and facilities); the processes consist of the specific intervention implemented (online work readiness workshops consisting of six topics), and determining the quality of service by evaluating the questionnaire sent to active participants. During the data analysis process, the conceptual framework was used to identify whether participants have developed or reached the outcomes intended with the work readiness workshops, namely: student learning outcomes, student personal attribute outcomes, and student impact outcomes. The first part of the questionnaire asked participants to identify the topics they had completed, followed by general feedback regarding the course. Participants then had to answer evaluation questions per topic they have chosen. Table 4 below shows that $\mathrm{CV}$-writing was the topic most students participated in (67\%), followed by interview skills (37\%), networking and job hunting (35\%), LinkedIn (32\%), digital world: personal branding for success (31\%), and future of work $(29 \%)$.

Table 4: Workshops/topics completed

\begin{tabular}{|l|c|c|}
\hline Topic & Percentage* & $\begin{array}{c}\text { Number of } \\
\text { participants }\end{array}$ \\
\hline CV-writing & $67 \%$ & 61 \\
\hline Interview skills & $37 \%$ & 34 \\
\hline Networking and job-hunting skills & $35 \%$ & 32 \\
\hline LinkedIn & $32 \%$ & 29 \\
\hline Digital world: personal branding for success & $31 \%$ & 28 \\
\hline Future of work & $29 \%$ & 26 \\
\hline *Note: The majority of students participated in more than one workshop. \\
\hline
\end{tabular}

Participants indicated that the intended student learning outcomes were reached in every topic they engaged with online. The workshops created an understanding of each topic and the variety of resources contributed to participants' implementation of knowledge through the use of practical examples. In general, participants found the content easy to understand and experienced the content as adequate to assist them in preparing for a job interview, 
writing a $\mathrm{CV}$, and developing a personal brand, amongst others. They further agreed that they were confident to go for a job interview and answer questions to the best of their ability. Some examples of respondents' comments include:

It improved my knowledge of CV writing, cover letter design, my LinkedIn account, as well as the online presence. These are the factors potential employers are looking for. I was not able to achieve such a high standard without the help of this course.

(Participant 16; overall feedback regarding programme)

I now know the steps to have a good professional CV and cover letter, how to dress for work by keeping a personal brand, and how to prepare for a job interview.

(Participant 44; overall feedback regarding programme)

Participants found the activities in each topic very useful in terms of thinking critically about the implication of the specific topic on their career. For example, 78\% of participants in the CV-writing workshop found the CV-writing submission activity useful, and $77 \%$ of participants found the cover letter activity beneficial. Furthermore, in the interview skills workshop, 91\% of the participants agreed that the self-reflection activity assisted them to critically contemplate potential questions in a job interview as well as appropriate and professional answers, while an average of $84 \%$ of the participants experienced the networking and job-hunting activities as beneficial to making informed decisions, to critically think about the network they are building, and what kind of questions to ask during networking engagements.

Evidence shows that students' personal attributes were developed throughout the programme, linking to most of the UFS graduate attributes, as well as the six student outcome domains according to CAS standards (mentioned in the conceptual framework section). Evaluation data were categorised according to the six student outcome domains of the CAS standards, namely: knowledge acquisition, construction, integration and application; cognitive complexity; intrapersonal development; interpersonal competence; humanitarianism and civic engagement; and practical competence (Council for the Advancement of Standards in Higher Education [CASHE], 2015). It is important to note that evidence did not clearly reflect whether participants gained an understanding and appreciation of the humanitarianism and civic engagement, although these aspects were included in the step-by-step tutorials and activities.

Participants referred in various ways to their knowledge acquisition, construction, integration, and application that were supported and made possible by the format and layout of each workshop topic, and that led to self-reflection (CASHE, 2015). Example 1:

The cheat sheets are just to check quickly, the step-by-step is more in-depth, and the video is also more helpful as additional resource.

(Participant 11; CV-writing workshop)

The participant reflects on the use of one tool (cheat sheets) complemented by another (step-by-step tutorials) to provide depth to the understanding of the content and knowledge gained and refers to the video as an additional resource. This demonstrates the 
acquisition of knowledge through various resources, followed by the construction and integration of the knowledge to make sense of the topic at hand. Example 2:

It helped me to think of the image I am trying to put out there for my future employers.

(Participant 25; overall feedback regarding programme)

The participant's words "helped me to think" confirm the self-reflection that took place when engaging with the content, by thinking about a personal image and how this could influence a recruiter or potential employer. The knowledge acquisition, construction, integration, and application process address the need of employers to have employees who are capable of applying knowledge and skills (Oluwajodu et al., 2015).

Participants also referred to the workshops and platforms as supportive in navigating the cognitive complexity of content and better understanding the specific topic:

If I don't understand, I can replay the video again and again until I understand.

(Participant 104; networking and job-hunting workshop)

The videos gave me an idea of how I can submit relevant documentation to different employers.

Furthermore, the tutorials are clear, address the current trends, and have the ability to make students adapt quickly in the complex world.

(Participant 60; CV-writing workshop)

Both comments refer to the video recordings and resources as the tools these two participants used to critically and reflectively think about the content and then form an opinion and creative approach to a particular problem or challenge (CASHE, 2015). This correlates with the global perspective of employers struggling to find adaptable, skilled employees (Laubscher, 2018). The second comment addressed both the student learning outcomes and the impact outcomes that Participant 60 achieved.

Participants referred to the intrapersonal development and interpersonal competence they gained in order to communicate or participate in a job interview, how to be professional, and how to adapt to the changing world of work, for example:

I learnt that professionalism and how to carry yourself, speaks volumes for future employers.

(Participant 35; overall feedback regarding programme)

This remark corroborates Ndlovu's (2020) appeal to universities to offer blended learning that includes work-related work to prepare students for the world of work.

Arguably, the attribute most developed by students through the workshops is the confidence to implement learned objectives (practical competence). For example, 92\% of participants in the CV-writing workshop acknowledged their confidence to write a $\mathrm{CV}$ and $89 \%$ to write a cover letter. In the interview skills workshop, $88 \%$ of participants indicated their confidence to go for a job interview, and $94 \%$ were confident to answer questions during an interview. Furthermore, in the networking and job-hunting skills workshop, $87 \%$ of participants were confident to communicate and network with other people, $90 \%$ were confident to make informed decisions between two job offers, and $90 \%$ were confident to apply for jobs and to keep track of email communication, requirements per job, and progress with applications. All participants (100\%) in the future of work 
workshop indicated that they were confident to enter the world of work, recognising the importance of being flexible, and $96 \%$ were confident to expand their core skills, competencies, and mindset skills. In the digital world: personal branding for success workshop, all participants $(100 \%)$ were confident to use social media and online platforms to market their personal brand, and to build a good reputation in person and online. Lastly, $83 \%$ of participants in the LinkedIn workshop were confident about the appearance of their LinkedIn profile, 90\% knew how to use the job application tool, and 96\% were confident to use LinkedIn as a networking tool. The high percentages in all workshops mentioned above are representative of workshop outcomes reached, and the purpose of the work readiness programme met.

Some participants addressed the practical competence they gained throughout the programme, which is referred to as the impact outcomes. Participants reflected on how they updated their personal brands, CVs, LinkedIn profiles, and knowledge regarding workplace changes and technology. Some examples include:

I improved my CV, I am able to go for a job interview without being nervous. My LinkedIn account is up to date and I am not stressing to start working.

(Participant 11; overall feedback regarding programme)

I find it hard to talk to people. The workshop gave me courage to be the first one to start talking to people, asking relevant questions to know more about the industry I want to be in.

(Participant 44; networking and job-hunting workshop)

The video provided me with nice pictures that are accompanied with proper information explaining the slide to me. I preferred this method because 25 minutes later I knew what personal branding was as well as what not to do on my internet platforms.

(Participant 25; digital world: personal branding for success workshop)

These impact outcomes address the concern of unemployment raised by Oluwajodu et al. (2015) in linking unemployment with job seekers who do not invest time and effort to find the correct fit. It seems that participants grasped the content of each workshop topic, followed by critical thinking and reflection on the outcomes, such as the portrayal of their image online, networking abilities, or creating a LinkedIn profile, and then implementing it by making adjustments and decisions, or by creating that CV needed to apply for a job.

Regarding the online format, participants experienced the design as effective for selfstudy (89\%), they liked the 'look and feel' of the workshops (86\%), and most participants attempted to implement the knowledge they had acquired (87\%) to prepare for entering the world of work. Participants 'strongly agreed' with the notion that each topic addressed their needs for preparation to enter the world of work (91\%); they also liked having options (92\%) to learn about a certain topic (options between using a step-by-step tutorial, infographics and checklists, additional resources, or a video recording of the workshop). Because most students experienced the online format of the workshops as easy to navigate (81\%), the variety of electronic content helpful to learn about a specific topic (93\%), and the selections sufficient to learn about a topic through tutorials, videos, infographics, and/ or activities (91\%), it is evident that students received all the necessary information, even 
though not through face-to-face engagements. However, most students (74\%) still prefer face-to-face workshops, which could relate to the fact that the format of this online programme is new, and UFS students having voiced their struggles to adapt to online teaching and learning methods in general due to possible access or network issues. These findings are corroborated by Mzileni (2020), who highlights the three problems brought forward in higher education during Covid-19, namely: the lack of infrastructure for functional learning experiences; the movement to online teaching and the struggle for students and staff to make the mind shift from traditional teaching and learning contact to online learning; and the dependence of undergraduates on face-to-face traditional teaching and learning practices to address their basic education needs. This is also reflected by the mere $7 \%$ of the UFS student population who engaged with the CS work readiness programme between April and June 2020.

Each workshop was designed with a variety of digital tools to help students selfnavigate, including (but not limited to) step-by-step tutorials, cheat sheets, video recordings of the workshops, and examples of CVs, profiles, and interview questions. When asked which of these platforms were the most useful, students' responses varied within as well as between workshops. For example, while $71 \%$ of CV-writing workshop participants found practical examples most useful, $52 \%$ in the interview skills workshop found cheat sheets and the video recordings of the workshop most useful. In the network and job hunting, as well as the digital world workshops, most students (54\% and $72 \%$ respectively) favoured the step-by-step tutorials.

The qualitative data indicated that the workshops contributed to the management of participants' expectations of the workplace. Suggestions for all topics included the possibility to download videos for future use; to market this programme more; to include a variety of resources, such as more interview questions and possible answers; demonstrations of certain skills, such as a real job interview or a success story of students who used their personal branding to get a job. For the LinkedIn topic, participants suggested the inclusion of videos and information on how to navigate the platform, and how to establish and use connections.

\section{Conclusion}

CS's plan to move online after the 2015 and 2016 protests allowed time to plan, develop, organise, and implement topics. Every year, evaluation data is used to improve the topics over time, and when Covid-19 and the national lockdown happened, CS repositioned itself to use the opportunity to move completely online - with positive results, as confirmed by the data.

First, it is important to note the difficulties that students experienced with online teaching and learning due to a lack of resources such as computers, internet connectivity, and anxiety about the unknown. However, the 2869 students who did engage with CS's work readiness programme, appreciated the online format of the work readiness programmes, which included a variety of tools to self-navigate through the learning 
outcomes. This, together with the feedback on activities that allowed students to develop more skills and knowledge, ultimately led to the ability to implement what they have learnt.

The three overarching outcomes (student learning outcomes, personal attributes, and impact outcomes) have been achieved, with various suggestions addressing the need for more resources or demonstrations, which will be integrated into the programme going forward. For example, the one CAS standard domain of humanitarianism and civic engagement that has not been mentioned or consciously learned, should be addressed by, amongst others, incorporating information and examples of unfairness and inequality in the workplace, as well as how to address or resolve this.

The results of this study will be used to improve the online offering with more demonstrations and videos, additional content, and perhaps some peer learning activities to make the workshops more engaging. A more interactive approach might compensate for feelings of isolation when working through workshops alone. The gamification part of the work readiness programmes (offering badges for completion of each step-by-step tutorial) should also be highlighted and culminated into a co-curricular transcript explaining the skills gained. Furthermore, this offering should be explained to all faculties in order to obtain their support to implement this programme in the final-year and postgraduate curriculums. CS further considers having the work-readiness programme as an online offering only (which can be delivered on scale to the approximately 40000 UFS students), and rather using face-to-face time to address individual needs through appointments or classroom engagement, especially because of the lack of human resources (one permanent staff member responsible for student relations projects, workshops, and programmes).

Whereas some participants mentioned broader marketing of the programme, more attention should rather be given to campaigns for students about the link between employers' wants and needs, which are addressed in the online work readiness programme. Furthermore, CS will benefit by sharing some success stories to create awareness and peer approval. Using focus groups with willing participants can also provide in-depth feedback to improve the programme.

In light of the findings of the study, it is therefore crucial for CS to not only assist graduates to get a job, but also to equip them for the world of work by broadening graduates' knowledge and skillsets to enable them to make successful transitions to the workplace and contribute to the economy and their communities (HEA, 2016; Ndlovu, 2020). Recommendations for further research are the inclusion of focus groups to elaborate on the skills that graduates believe they need. Secondly, CS should host think tanks with students and employers to determine future topics and foci in order to expand the online work readiness programme. And finally, consider implementing all suggestions from participants in this study to improve the current offering, and then to re-evaluate it towards the end of 2020. It is believed that the findings of this research study will create a deeper understanding of how career services, as a particular functional area in student affairs, can reposition itself during uncertain times to remain responsive to the needs of students. 


\section{Research Ethics}

Ethical clearance was applied for and granted by the Ethics Committee of the University of the Free State, prior to the research. Student respondents indicated their willingness to partake in the study by means of informed consent on the questionnaire.

\section{Conflict of Interest}

The authors declare that they do not have financial or personal relationships that may have inappropriately influenced them in writing this article.

\section{Funding}

This work has not received any financial support.

\section{References}

Adotey, S.K. (2020). What will higher education in Africa look like after COVID-19? World Economic Forum, published on 8 June 2020. https://www.weforum.org/agenda/2020/06/higher-education-africacovid19-coronavirus-digital-online/ [Accessed 22 July 2020]

Baudouin, R., Bezanson, L., Borgen, B., Goyer, L., Hiebert, B., Lalande,V., Magnusson, K., Michaud, G., Renald, C. \& Turcotte, M. (2007). Demonstrating value: A draft framework for evaluating the effectiveness of career development interventions. Canadian Journal of Counselling and Psychotherapy, 41(3).

Benzinger, K., Kerford, K., Lumsden, L., Mahoney, K., Rodney, Y. \& Keates, C. (2011). Career centre evaluation: A practitioner's guide. Toronto, Canada: Canadian Education and Research Institute for Counselling (CERIC).

Brady, R.P. (2010). Work readiness inventory: Administrator's guide. http://jist.emcp.com/media/product attachments/files/w/o/work-readiness-inventoryadministrators-guide.pdf

Caballero, C. \& Walker, A. (2010). Work readiness in graduate recruitment and selection: A review of current assessment methods. Journal of Teaching and Learning for Graduate Employability, 1(1), 13-25. https://doi.org/10.21153/jtge2010vol1no1art546

Career Development Services (2017). Career Development Services Profile. https://www.careerhelp.org.za/ sites/default/files/cds_profile.pdf [Accessed 20 May 2020].

Chipunza, C. \& Malo, B. (2017). Organizational culture and job satisfaction among academic professionals at a South African university of technology. Problems and Perspectives in Management, 15(2), 148-161. https://doi.org/10.21511/ppm.15(2).2017.14

Council for the Advancement of Standards in Higher Education (2015). CAS learning and development outcomes. In J.B. Wells (Ed.), CAS professional standards for higher education (9th ed.). CAS.

Creswell,J.W. (2014). A concise introduction to mixed methods research. Sage.

Creswell, J.W. \& Creswell, J.D. (2018). Research design: Qualitative, quantitative, and mixed methods approaches (5th ed.). Sage.

DHET (Department of Higher Education and Training) (2017). Government Gazette, 20 April, 622(40795). Republic of South Africa.

Doe, R. (2015). Work readiness among graduate students. LSU Doctoral Dissertations. 1008. https://digital commons.lsu.edu/gradschool_dissertations/1008

Heleta, S. (2016). Decolonisation of higher education: dismantling epistemic violence and eurocentrism in South Africa. Transformation in Higher Education, 8. https://doi.org/10.4102/the.v1i1.9 
Higher Education Academy (2016). Framework for embedding employability in higher education. https:// www.heacademy.ac.uk/system/files/downloads/embedding-employability-in-he.pdf [Accessed June 2020].

Krippendorff, K. (2018). Content analysis: An introduction to its methodology. Sage.

Laubscher, E. (2018). Unskilled labour in South Africa. Medium. Published on 14 July. https://medium. com/@erichlaubscher1/unskilled-labour-in-south-africa-af56852ed443 [Accessed 22 July 2020].

Mutekwe, E. (2018). Unmasking the ramifications of the fees-must-fall-conundrum in higher education institutions in South Africa: A critical perspective. Perspectives in Education, 35(2), 142-154. https:// doi.org/10.18820/2519593X/pie.v35i2.11

Mzileni, P. (2020, April 23). How COVID-19 will affect students. Mail \& Guardian. https://mg.co.za/ education/2020-04-23-how-covid-19-will-affect-students/ [Accessed 17 April 2020].

Oluwajodu, F., Greyling, L., Blaauw, D. \& Kleynhans, E.P. (2015). Graduate unemployment in South Africa: Perspectives from the banking sector. SA Journal of Human Resource Management, 13(1), 1-9. https:// doi.org/10.4102/sajhrm.v13i1.656

Roodt, D. (2020). Coronavirus could sink South Africa's economy by 6\%. BusinessTech. https://business tech.co.za/news/business/382489/coronavirus-could-sink-south-africas-economy-by-6-dawieroodt/ [Accessed March 2020].

Strydom, J.F \& Oosthuizen, L. (2019). Developing UFS graduate attributes: Enabling graduates to compete globally and locally while enhancing academic quality. University of the Free State: Centre for Teaching and Learning.

UFS Career Services (2020). Work readiness tutorials: Career Services Blackboard page. University of the Free State.

UFS Graduate Exit Survey (2020). University of the Free State graduate exit survey: Employment-based report on the 2017 graduating cohort. University of the Free State.

Universum (2020). Universum talent research 2020: South African professionals. Universum.

Viljoen, D. (2018, March 1). Higher education: $A$ vast and changing future landscape. Fin24. https://www. fin24.com/Finweek/Featured/higher-education-a-vast-and-changing-future-landscape-20180228 [Accessed April 2020].

Walker, M. \& Fongwa, S. (2017). Universities, employability and human development. Springer. https://doi.org/ 10.1057/978-1-137-58452-6

\section{How to cite:}

Janeke, B. (2021). Online Work Readiness Programme: Ready, Set Go! Journal of Student Affairs in Africa, 9(1), 119-133. DOI: 10.24085/jsaa.v9i1.1432 
REFLECTIVE PRACTICE

Responding to Covid-19: Experiences of Ashesi University's Student Affairs Team

\author{
Millicent Adjei, ${ }^{i}$ Nina N.A. Pels ${ }^{\text {ii }} \&$ Vanessa N.D. Amoako ${ }^{\text {iii }}$
}

\title{
Abstract
}

The Covid-19 pandemic has revealed the abilities or lack thereof of many higher education institutions to adequately support the academic and co-curricular needs of students in times of crisis. In this reflective practitioner account, Schlossberg's Transition Theory is used to analyse the transitional experiences of students amid the Covid-19 pandemic and how the Office of Student and Community Affairs (OSCA) team at Ashesi University successfully supported students as they navigated the academic semester. One-to-one interviews with department heads of the five OSCA units were conducted alongside focus group discussions with a cross-section of 17 students. The findings suggest that (i) advising, (ii) engagement, and (iii) timely online support interventions contributed immensely to students' success in transitioning from in-person to remote learning.

\section{Keywords}

Ashesi University; Covid-19; crisis management; remote learning; Student Affairs; student transitions

\section{Introduction}

Students' educational success is a shared responsibility of various stakeholders including staff, faculty, parents, and institutional administrators. "Student affairs staff members are responsible for establishing the campus conditions that affirm students and providing the programmes and services to meet their academic and social needs outside the classroom" (Kuh, Kinzie, Schuh \& Whitt, 2011, p. 164). In Africa, the significance of Student Affairs continues to grow as more studies reveal how the practice is making important contributions to higher education on the continent (Moja, Schreiber \& Luescher-Mamashela, 2014).

Student affairs practice is especially vital in times of crisis in ensuring that students' basic needs including housing and dining, good health and well-being, their social worth, self-esteem, and mental health are adequately supported. Crisis is a significant sudden or unexpected event, which disrupts the normal operations and values of an institution for any

i Dr Millicent Adjei is Director of Diversity \& International Programmes, Ashesi University, Ghana. ORCid: 0000-0002-5061-7709. Email: madjei@ashesi.edu.gh

ii Ms Nina Nana Aba Pels is Assistant Director, Student Life \& Engagement, Ashesi University, Ghana. ORCid: 0000-0003-4681-9073. Email: npels@ashesi.edu.gh

iii Ms Vanessa Nana Darkoa Amoako is a Diversity \& Inclusion Coordinator, Ashesi University, Ghana. ORCid: 0000-0003-1834-6758. Email: vanessa.amoako@ashesi.edu.gh 
length of time and can threaten the well-being of personnel, property, financial resources, and/or institutional reputation (Zdziarski, 2006; Brennan \& Stern, 2017; Shaw, 2017). In the past, crisis events in global higher education institutions (HEIs) have primarily centred on issues concerning harassment, bullying and discrimination suits, administrative scandals, student unrest, strikes, mass shootings, suicides, severe weather events, and terrorist attacks (Wang \& Hutchins, 2010; Studenberg, 2017). Crisis management plans in this regard have focused mostly on human and environmental safety as part of the HEI goals (Rayburn, Anderson \& Sierra, 2020). By caring for and ensuring a safe environment for all members of the campus community during a crisis, students can readily transition to safer conditions that enable the continuity of their academic experience.

The current Covid-19 pandemic has revealed the need for institutions to have adequate short- and long-term crisis management plans to ensure that the educational process is uninterrupted and to maintain learning continuity (Rayburn et al., 2020). A recent World Bank Education (2020) report on tertiary institutions' responses to the Covid-19 crisis reveals widespread institutional disruptions including those related to mass student displacements, weakened vital campus services and support, increased inequity, and inequality in accessing education. The report also mentions the inability of HEIs in retaining at-risk student populations and significant socio-emotional impacts on student well-being. Such disruptions rattle students' experience, threatening their overall safety and well-being and eventual educational outcomes. Thus, some students are experiencing significant strain and remain uncertain about the future of their education. This article, therefore, calls on HEIs to be systematic, analytical, and intentional in understanding students' transition experiences during crises. It challenges them to choose innovative interventions to meet students' needs amid crises and uncertainties.

To ensure the continuity of the various HEI functions, programmes, and processes, while responding to Covid-19 protocols, many institutions have been compelled to shift the delivery of their core mandates of teaching, learning and engagement to innovative remote platforms to maintain learning continuity. Since its inception, Ashesi University has operated as a full-time in-person institution with no online course offerings and teaching. The Covid-19 pandemic and the government of Ghana's directive for all HEIs to cease in-person instructions until January 2021 propelled Ashesi to move all its institutional functions online in March 2020. Thus, the objectives of this article are to: (i) highlight the various innovative approaches Student Affairs Professionals (SAPs) at Ashesi University adopted to support students to navigate the Covid-19 pandemic successfully; (ii) emphasise the impact of the responses on students' experiences; (iii) demonstrate the critical role theoretical frameworks can potentially play in the practice of SAPs to make more informed and efficient decisions.

\section{Institutional Context}

Ashesi University is a four-year private, liberal arts university located in the Eastern Region of Ghana. It seeks "to train a new generation of ethical and entrepreneurial leaders for Africa" (Ashesi University, 2002). Ashesi allows students to study across a broad field 
including the humanities, arts and sciences and elect to pursue one of six majors: business administration, computer science, management information systems and three engineering programmes. The university started with a pioneer class of 30 students in 2002 and has grown steadily over the years with a current student population of 1173 from over 20 African countries.

\section{Ashesi University's Student Affairs Structure}

For most HEIs, growth in numbers comes with the expansion of services to students including job placements, career development, housing, health, counselling, and co-curricular activities (Appleton et al., 1978 p. 372). For Ashesi University, the SA department that handles these functions is referred to as the Office of Students \& Community Affairs (OSCA). It is made up of five independent units namely Career Services, Office of Diversity \& International Programmes (ODIP), Coaching, Counselling \& Academic Advising (CCA), Student Life \& Engagement (SLE), and the Health Unit. OSCA is headed by the Dean of Students and Community Affairs, who is also a member of the Ashesi Executive Committee (see Figure 1).

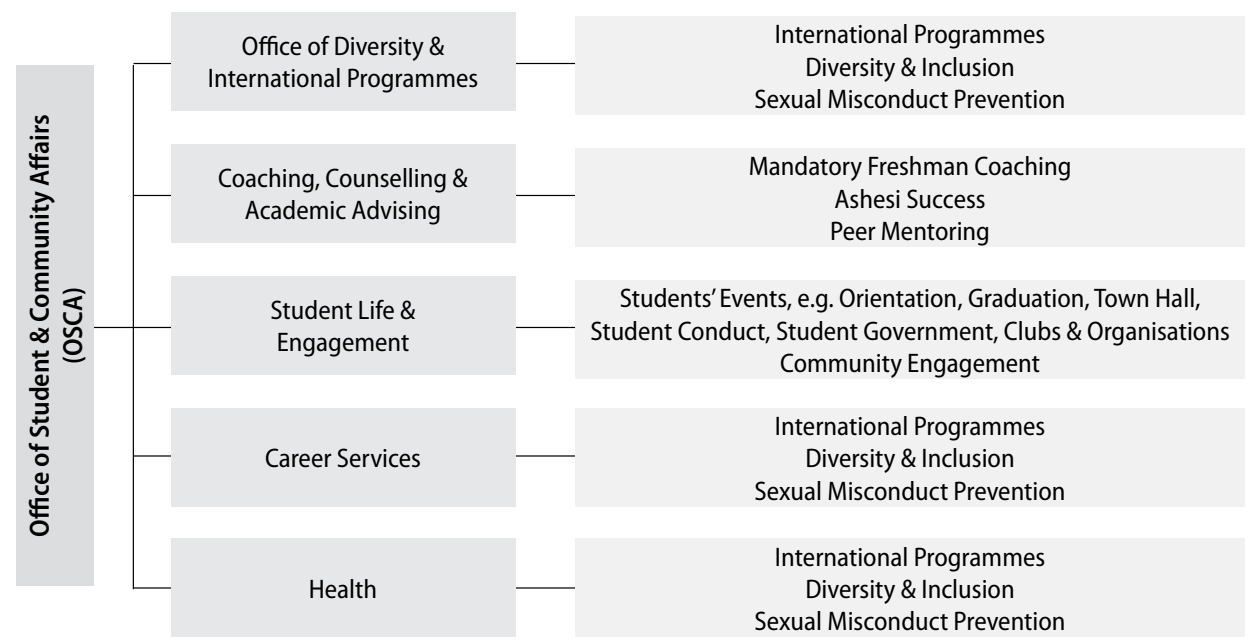

Figure 1: Organisational structure of Ashesi University's Student Affairs office

\section{Conceptual Framework}

HEIs globally are experiencing many uncertainties and changes due to the Covid-19 pandemic. While HEIs contend with providing equitable access and support for students to succeed, students are navigating various transitions in their academic and co-curricular commitments. To fully understand their experiences and the factors that influence the choices during this period, this reflective article is situated in Schlossberg's Transition Theory. The theory focuses on the various stages of transition and how individuals respond to the changes they are experiencing. This conceptual framework is necessary because the 
understanding then informs the most suitable and appropriate intervention to support students in a practical and informed way. According to Schlossberg and Goodman (2005), transition involves any life event that requires the individual experiencing the event to feel a change from their normal. They further posit that to understand the resources needed to help the individual cope with and take charge of the transition, certain conditions, also known as the 4 Ss that influence the transition process must be understood. The 4Ss include the situation causing the transition, the individual self, the support structures in place and the strategies adopted to respond to the transition.

- Situation refers to how the individual appraises what is being experienced to ascertain their understanding of the situation as good or bad, the control they have over what is happening, and the various triggers that initiate the event (Anderson, Goodman \& Schlossberg, 2012; Evans et al., 2010; Goodman, Schlossberg \& Anderson, 2006; Schlossberg, Waters \& Goodman, 1995). Covid-19 has brought about several unprecedented changes to the lifestyles and daily routines of students, forcing them to navigate many uncertainties. A deeper understanding of students' sense of agency as they navigate their changing situations is, therefore, critical to determine appropriate and relevant support to foster successful outcomes.

- Self refers to the personal, demographic characteristics and psychological resources of the individual experiencing the change, which affects their ability to cope; thus, recognising the uniqueness of each person experiencing the transition. Schlossberg and Goodman (2005) explain that factors such as socio-economic condition, gender, age, health status, ethnicity, outlook, ego, commitment, and values affect the way individuals experience any given event and determine their responses. They explain that these attributes can either provide the assets and resources needed for the transition or pose a threat or deficit, which can impact the change negatively. The onset of the Covid-19 pandemic has highlighted several factors such as socioeconomic inequities that have challenged the equitable distribution and access to resources including internet connectivity, stable home settings and income (Casey, 2020). It is crucial to understand how these factors have affected students' educational outcomes to inform the needed interventions.

- Support focuses on the social resources that give multiple options for the individual to experience the transition smoothly. It may come from family, social connections, various institutional agents and structures, friendships, and peers (Schlossberg \& Goodman, 2005). The impact of critical student support on their outcomes is buttressed by several research projects which suggest that when HEIs develop many conditions and structures to support diverse students they are more likely to be engaged, involved and to ultimately succeed (Adjei, 2019; Earwaker, 1992; Kuh et al., 2011; Quaye \& Harper, 2015).

- Finally, strategies elaborate on the coping mechanisms put in place by the individual experiencing the transition to make the best out of the options available to them. Strategies, thus, focus on the individuals' coping behaviours to confront the change during the transition process (Evans et al., 2010; Merriam \& Caffarella, 1999). Four 
different coping strategies can characterise how individuals respond to the transition: their information-seeking abilities, the direct action they take, different inhibitions of their action, and their intrapsychic behaviour (Goodman, Schlossberg \& Anderson, 2006; Schlossberg \& Goodman, 2005). SAPs are in a unique position to coach, advise and mentor students to combine and select the most effective strategies to cope with the pandemic's effect on their lives.

The 4Ss framework in Schlossberg's Transition Theory (2005), therefore, gives us an excellent framework to situate this reflective practitioner account. It centres the student experience and offers a nuanced understanding of their transitional experiences, and consequently helps HEIs to situate their interventions.

\section{Methodology}

Following the Ghanaian government's directive for all educational institutions to close their campuses to curb the spread of the Covid-19 virus, Ashesi University transitioned its functions to various remote platforms. To better understand how SAPs and students experienced this sudden change, this research was undertaken to inform student affairs (SA) practice further and to offer insights into the lived experiences of the participants. More specifically, the article seeks to answer the following questions:

(i) How did each SA unit respond to providing students with their core functions during the Covid-19 pandemic?

(ii) How did students perceive the responses of the various SA units?

\section{Data sources}

Data was collected using a qualitative approach employing one-to-one interviews with department heads of the five OSCA units and focus group discussions (FGD) with a crosssection of students. According to Creswell (2014), qualitative research is used in "exploring and understanding the meaning individuals or groups ascribe to a social or human phenomenon" (p. 4). Interviews were conducted with each unit lead to respond to the first question. This approach made it possible to ask follow-up questions to facilitate a deeper understanding of their interventions, as suggested by Merriam (2009).

The transition experiences of students caused by the Covid-19 pandemic could also best be understood by exploring the participants' lived experiences, which cannot be described solely from the perspectives of the SAPs. FGD methodology was used to gather information from the students on how the interventions adopted by the OSCA team impacted them. Kitzinger (1995) explains that FGD allows participants to interact with one another and process their experiences together by asking questions and seeking clarifications from the interviewer and other participants. This approach enhanced the understanding of the various ways students in this study were interpreting their experiences together and individually. To validate their experiences, students were asked: How have you engaged with the various OSCA units since the pandemic and the move to remote learning, and how are these interventions impacting your academic experience? The answers to these questions provided critical feedback on the effectiveness of the remote services offered by the SAPs. 


\section{Data sample and procedure}

For each SA unit, the leads were sent an invitation via email to give an account of the interventions their respective department implemented to ensure business continuity. Besides the department heads, other OSCA team members who were directly involved in the various programmes were also engaged to seek clarification and, in some cases, correction of the initial narratives received for the article. A total of 9 SAPs volunteered their time for the research (see Table 1).

\section{Table 1: Profile of Student Affairs staff}

\begin{tabular}{|l|l|l|l|}
\hline$\#$ & Gender & Department & Nationality \\
\hline 1. & Female & Coaching, Counselling and Academic Advising & American \\
\hline 2. & Male & Coaching, Counselling and Academic Advising & Ghanaian \\
\hline 3. & Female & Office of Diversity and International Programmes & Ghanaian \\
\hline 4. & Female & Office of Diversity and International Programmes & Ghanaian \\
\hline 5. & Female & Career Services & Ghanaian \\
\hline 6. & Male & Career Services & Ghanaian \\
\hline 7. & Female & Health Services & Ghanaian \\
\hline 8. & Female & Student Life and Engagement & Ghanaian \\
\hline 9. & Female & Student Life and Engagement & Ghanaian \\
\hline
\end{tabular}

After the first analysis of their responses, and to further validate them, three FGDs were organised with a cross-section of students. Research has revealed that it is important to include students' voices to ascertain the impact of institutional interventions (British Council, 2015). It also suggests that "when institutions listen to students and involve them in decision-making, they can be part of the answer in fostering empowered learners and responsive institutions" (British Council, 2015, p. 2). By including students' voices, HEIs are more responsive to students' aspirations for the future.

In recruiting students for the FGDs, a general email was sent to the entire student body, requesting them to sign up as participants. A total of 45 students enlisted and were divided into three groups of 15 to enable effective interaction and draw valuable information from their responses and insight. Ultimately, only two groups of 6 students were present for the first two sessions and 5 for the final session giving us a total of 17 for the FGD (see Table 2). Each session lasted two hours and was held via Zoom video conferencing. 
Table 2: Profile of focus group participants

\begin{tabular}{|l|l|l|l|l|}
\hline$\#$ & Gender & $\begin{array}{l}\text { Year of } \\
\text { graduation }\end{array}$ & Department & Nationality \\
\hline 1. & Male & 2021 & Business Administration & Congolese (DRC) \\
\hline 2. & Male & 2023 & Business Administration & Cameroonian \\
\hline 3. & Male & 2023 & Management Information Systems & Nigerian \\
\hline 4. & Female & 2022 & Computer Science & Nigerian \\
\hline 5. & Female & 2022 & Management Information Systems & Kenyan \\
\hline 6. & Female & 2022 & Management Information Systems & Ghanaian \\
\hline 7. & Male & 2022 & Computer Science & Ghanaian \\
\hline 8. & Female & 2022 & Mechanical Engineering & Ghanaian \\
\hline 9. & Female & 2023 & Computer Engineering & Ghanaian \\
\hline 10. & Male & 2020 & Computer Engineering & Ghanaian \\
\hline 11. & Male & 2023 & Management Information Systems & Ghanaian \\
\hline 12. & Female & 2022 & Electrical/Electronic Engineering & Ghanaian \\
\hline 13. & Female & 2022 & Management Information Systems & Ghanaian \\
\hline 14. & Female & 2020 & Business Administration & Ghanaian \\
\hline 15. & Male & 2020 & Business Administration & Ghanaian \\
\hline 16. & Male & 2023 & Mechanical Engineering & Ghanaian \\
\hline 17. & Female & 2022 & Electrical/Electronic Engineering & Ghanaian \\
\hline & & & & \\
\hline
\end{tabular}

Data collected from both groups of participants were recorded, transcribed, and coded under broad themes, namely advising, engagement, and timely online transitioning support. Morris (2015) supports the use of codes for interview data and asserts that "coding allows you to compare the responses of interviewees and convert the interviews into a meaningful, coherent analysis" (p. 128).

\section{Enhancing trustworthiness}

To ensure validity of the responses received from the OSCA unit leads, data was triangulated with that of the FGD to ascertain how the interventions enhanced students' out-of-classroom experience. Also, recognising that the authors work in different capacities in OSCA, bias was checked by being intentionally reflexive and deferring to other team members for their opinions throughout the writing of this article. The authors' positionality as insiders, however, offered significant access to the members interviewed and deeper expert knowledge and understanding of the concepts being discussed.

Despite the above measures, the limitations of this article are recognised due to the small sample size, especially for the students and the very focused and unique institutional context, which allowed the OSCA team to undertake their interventions successfully. The findings in this reflection may, therefore, not be generalisable in other HEI contexts. 


\section{Findings}

Three main themes emanated from the coding of the responses from the FGDs conducted with the students. Advising focused on the various ways students sought guidance from the OSCA team to navigate and make decisions for themselves during the transition to remote teaching and learning. Engagement focused on how students, through their involvement with different institutional agents, were able to influence broader institutional decisions and policies, thus, ensuring suitable adjustments to many non-academic co-curricular interventions. Timely online and remote transitioning support focused on how students sought support from the OSCA team, with the help of technology. This ensured the provision of the appropriate resources and assistance to enable them to transition smoothly. The ensuing sections present details of the three main thematic findings.

\section{Advising}

According to Drake (2011), student advising is "about building relationships with students, locating places where they get disconnected and helping them get reconnected" (p. 8). As Crookston (1994) explains, though advising is concerned with "a specific personal or vocational decision", it also involves "facilitating the student's rational processes, environmental and interpersonal interactions, behavioural awareness and problem-solving, decision-making and evaluation skills" (p. 5). Throughout the FGDs, students mentioned needing more direction on managing multiple personal, home and academic challenges affecting their psychosocial and emotional abilities to focus and do meaningful academic work. This was corroborated by the Counselling, Coaching and Advising (CCA) unit, which reported an overwhelming increase in the caseload of students they had to see, resulting in them extending their advising sessions beyond regular working hours, including weekends.

Students also sought the health team's support in addressing their healthcare concerns. The health team provided regular healthcare advice to students through scheduled online consultations to ensure that they were constantly equipped with the appropriate knowledge to make safe and healthy decisions during the pandemic. The department also partnered with the University's health insurance provider to run a weekly programme that enabled members of the community to call and speak to health professionals to provide advice on their various health concerns. Interactions with students to identify their specific health needs enabled the health team to lead committee discussions on ensuring the safe return of domestic and international students to their homes following the campus closure.

Thus, students indicated that (1) timely response and action, and (2) accessibility and sustained interaction, were factors that worked well for them in seeking advising support from the OSCA team (see Table 3). On the other hand, students mentioned that (1) more proactive action from the OSCA team, and (2) more targeted communication for student year groups were factors missing from the team's support (see Table 3). 
Table 3: Student perspectives on advising

\begin{tabular}{|c|c|}
\hline \multicolumn{2}{|r|}{ Positive factors } \\
\hline \multirow[t]{3}{*}{$\begin{array}{l}\text { Timely } \\
\text { response and } \\
\text { action }\end{array}$} & $\begin{array}{l}\text { "I think what works for me is how fast the people used to reply.You } \\
\text { don't have to wait for two days, one week, two weeks for someone to } \\
\text { reply. Immediately someone replies and give you the steps to follow. } \\
\text { And if you need a referral, they will do it." }\end{array}$ \\
\hline & $\begin{array}{l}\text { "I am currently doing five virtual internships and it got } \\
\text { overwhelming because most of them had some expectations. I got } \\
\text { depressed along the way. I contacted [the counsellor] and she helped } \\
\text { me to work things out." }\end{array}$ \\
\hline & $\begin{array}{l}\text { "The second one which I can share with you is the support of the } \\
\text { health centre. I remember in the beginning when we were told that } \\
\text { we were going home, people started asking me if we will get masks } \\
\text { and I remember calling the nurse and the Dean and asking them } \\
\text { about this, and at that moment they released all the masks, sanitisers, } \\
\text { and other proptective materials, so that we can go home safely. That } \\
\text { was really helpful." }\end{array}$ \\
\hline \multirow[t]{3}{*}{$\begin{array}{l}\text { Accessibility } \\
\text { and sustained } \\
\text { interaction }\end{array}$} & $\begin{array}{l}\text { "The counselling team was amazing. Though I didn't reach out to } \\
\text { [the counsellor], she reached out to me and constantly followed } \\
\text { up at every stage (whether it was time for the final exams or final } \\
\text { submissions). She was always there to send videos to help me scale } \\
\text { through those difficult times, and that was so helpful!" }\end{array}$ \\
\hline & $\begin{array}{l}\text { "It was helpful to be able just to ask [the college nurse] any question } \\
\text { at any point in time, not only when I was sick." }\end{array}$ \\
\hline & $\begin{array}{l}\text { "The counsellor came up strong. You can book appointments with } \\
\text { her. She kept listening and helping you through things, and I felt that } \\
\text { was really good. Once in a while, I think for those of us who check } \\
\text { with her she sends Whatsapp messages to check progress. So, I think } \\
\text { it was kind of touching." }\end{array}$ \\
\hline \multicolumn{2}{|r|}{ Negative factors } \\
\hline \multirow[t]{3}{*}{$\begin{array}{l}\text { More proactive } \\
\text { action }\end{array}$} & $\begin{array}{l}\text { "Some people were finding it difficult to come to class, especially } \\
\text { those in different time zones. People were having home problems } \\
\text { combining it with school. And most of these people would not go to } \\
\text { the counselling department for their own good. Some people want } \\
\text { to keep it to themselves. If there is something that can be done to } \\
\text { reach out to people more than they reach out to the department, I } \\
\text { believe that will help them." }\end{array}$ \\
\hline & $\begin{array}{l}\text { "I don't think students don't know who to go to. Going forward, we } \\
\text { can try to identify some of these students and the reasons why they } \\
\text { are not seeking help." }\end{array}$ \\
\hline & $\begin{array}{l}\text { "Sometimes we get fake news on Covid-related issues. I think the } \\
\text { health team could give us more information and precautions that we } \\
\text { could follow." }\end{array}$ \\
\hline
\end{tabular}




\section{Negative factors (continued)}

\begin{tabular}{|l|l|}
\hline $\begin{array}{l}\text { More targeted } \\
\text { communication } \\
\text { for student }\end{array}$ & $\begin{array}{l}\text { "Thear groups } \\
\text { run. But I think we need to kind of segregate the year groups and } \\
\text { do a 'new normal' kind of reorientation because people don't know } \\
\text { where to go for what at this moment." }\end{array}$ \\
\cline { 2 - 3 } & $\begin{array}{l}\text { "I think if you are going to make it more interactive for the students, } \\
\text { I think OSCA should start early. At the beginning of each semester } \\
\text { every department should post how they can be reached and what } \\
\text { they can offer the students. Maybe during the semester, every month, } \\
\text { you have a compulsory meet-up with the year group to check up } \\
\text { and get feedback from everyone. If you send forms, I don't think } \\
\text { everyone will fill them [in] to really capture what people are saying } \\
\text { and what they are feeling. Sometimes questions and responses in } \\
\text { forms can be very limiting." }\end{array}$ \\
\cline { 2 - 2 } & $\begin{array}{l}\text { "I am not sure but I feel like people don't read their emails, so they } \\
\text { might miss emails that come from the various units concerning } \\
\text { certain things. That's one challenge." [Said in reference to the OSCA } \\
\text { team exploring new ways to reach students.] }\end{array}$ \\
& $\begin{array}{l}\text { "The other thing also being that maybe for things like town hall } \\
\text { meetings, we should rethink how we meet in terms of numbers. } \\
\text { Maybe we can meet in smaller groups because you realise that } \\
\text { sometimes people have genuine concerns but their voices get missing } \\
\text { within the crowd. So most of them are not able to express how } \\
\text { they feel." }\end{array}$ \\
\hline
\end{tabular}

Despite the positive outcomes these interventions may have had, students alluded to the fact that that the OSCA team needed to have more efficient strategies in reaching out to them and to tailor these efforts specifically to their needs. The following subsection examines the steps the units took to successfully engage students outside the classroom to enhance their learning experiences.

\section{Engagement}

According to Pomerantz (2006), student engagement is purposefully involving students in the process of learning through specific and deliberate behaviours that can directly impact student learning outcomes. Thus, ensuring student engagement in all activities is key to fostering real learning and growth. The outcomes of student engagement abound in higher education literature: student identity development (Baxter Magolda, 1992), social capital development (Harper, 2008), and student persistence and graduation (Astin, 1975; Tinto, 1993, 2005; Pascarella \& Terrenzini, 2005). Thus, for the OSCA team, designing strategies to keep students engaged when they could no longer assemble physically was crucial in its responses during the Covid-19 pandemic.

Through virtual town halls organised by the SLE team, students were able to seek redress for their unique challenges including the difficulty of doing schoolwork online (particularly balancing demanding academic and home deliverables), inadequate internet bandwidth, and the difficult financial situations of some families. Proactively voicing out 
their concerns and sharing feedback enabled students to directly influence policies and decisions that the university leadership made to meet their unique needs. For example, upon recommendations from students during the town hall, the Dean of Students held two virtual parents' town hall meetings to explain the various transition phases the University had experienced and actions taken, and to explore ways their wards could meet their academic obligations. Additionally, with the feedback on the inadequate internet bandwidth, the University increased allocations from $10 \mathrm{~GB}$ a month to $20 \mathrm{~GB}$ for all students to support their online academic work. They also provided housing scholarships for students who needed to find suitable accommodation for their schoolwork. In addition, the SLE unit held special remote training sessions for student leaders and club heads to help them continue their activities online.

The onset of the pandemic brought many disruptions to plans for student job and internship placements as most opportunities were rescinded. Thus, students sought the support of the Career Services team who worked closely with them to navigate such disruptions by utilising existing Career Online Portal and College Central Network platforms to connect students with other potential employers. The team also worked closely with employers to understand their unique needs to prepare students to remain relevant amid the volatile and uncertain job market.

By engaging with their Career Peer Advisors, students were able to communicate the exact areas in which they needed help from the Career Services unit. The unit used this information to hold career sessions on interviewing online and conducted online CV clinics to enable students to highlight their most relevant skills as they sought remote opportunities. Due to these intentional approaches, the unit was able to maintain its $90+$ percentile career placement of the 2020 graduating class despite the volatility of the job market globally. These engagement interventions helped students build their self-esteem, gain valuable information and the confidence needed to access industries of interest and to find internships and employment.

Unfortunately, with little time given to send all students home because of the sudden closure of Ghana's borders and campus residences, some international students became stranded in Ghana. These students prudently engaged with the ODIP to share their predicaments and seek solutions. Thus, the ODIP worked closely with the affected students to connect several of them with the University's rich alumni network, parents, and consular missions in Ghana, through its Host Family Programme. The team also placed biweekly calls with these students, monthly calls with their host families, and fostered online engagements through hangout events for both parties to ensure their well-being.

For students, staying connected to their peers and the university environment, and being able to express their concerns were important aspects of engagement during the shift to remote learning. Students cited that (1) intentional platforms for dialogue and support, and (2) effective communication and provision of helpful resources, were factors that kept them engaged during the shift to remote work (see Table 4). However, (1) a sense of loneliness, social isolation, and (2) a disconnection from the previously lively campus environment made it difficult for them to engage effectively (see Table 4). 
Table 4: Student perspectives on engagement

\begin{tabular}{|c|c|}
\hline \multicolumn{2}{|r|}{ Positive factors } \\
\hline \multirow[t]{3}{*}{$\begin{array}{l}\text { Intentional } \\
\text { platforms for } \\
\text { dialogue and } \\
\text { support }\end{array}$} & $\begin{array}{l}\text { "Because I am on the [Student Council], I engaged more with } \\
\text { the SLE unit. They asked to speak to all the year groups, and we } \\
\text { suggested rolling out a survey so students could give their opinions } \\
\text { about how they were faring being at home. The survey and opinion } \\
\text { polls served as the main agenda items for our town hall meeting } \\
\text { where students raised the discussion on fees. The town hall [meeting] } \\
\text { we had was very helpful and resulted in the reduction of the summer } \\
\text { school fee and housing funds." }\end{array}$ \\
\hline & $\begin{array}{l}\text { "For the SLE I think it is the town hall meeting. They did so well in } \\
\text { organising the town hall meeting to kind of get every year group's } \\
\text { perspective." }\end{array}$ \\
\hline & $\begin{array}{l}\text { "I think the most important part for me is the town hall and } \\
\text { what it can do for us during next semester. The town hall gives } \\
\text { opportunities for people to air their views and perspectives." }\end{array}$ \\
\hline \multirow[t]{4}{*}{$\begin{array}{l}\text { Effective } \\
\text { communication } \\
\text { and provision } \\
\text { of resources }\end{array}$} & $\begin{array}{l}\text { "The Career Services team has been of tremendous help in } \\
\text { supporting me to secure a remote internship with a South African } \\
\text { conpamy. They sent serveral emails about remote internships and } \\
\text { resources on interviewing and personal branding. That interview was } \\
\text { one of my most challenging, however, I was prepared because I used } \\
\text { some of the resources [the Career Services] sent." }\end{array}$ \\
\hline & $\begin{array}{l}\text { "Just when the campus shut down, Cameroon also closed its borders, } \\
\text { and we couldn't go back home. The ODIP suggested to us the } \\
\text { opportunity to live with a host family and connected us to one. They } \\
\text { continued to find out how we were doing throughout our stay with } \\
\text { host families to make sure we were safe during this pandemic." }\end{array}$ \\
\hline & $\begin{array}{l}\text { "It has been so amazing to receive so much support from the ODIP } \\
\text { team while staying with a host family. I am grateful for the stipends } \\
\text { paid into our accounts, the support from my host family, who have } \\
\text { become my second family after mine in Nigeria, and the regular } \\
\text { check-up from the ODIP team." }\end{array}$ \\
\hline & $\begin{array}{l}\text { "When we had the online school I think SLE did well. We had } \\
\text { frequent updates on our timetable and assignments. That was very } \\
\text { helpful. Each time you had [a] problem with a lecturer you could } \\
\text { just reach out to SLE and they will help immediately. So when } \\
\text { school reopened, I think SLE did a good job." }\end{array}$ \\
\hline \multicolumn{2}{|r|}{ Negative factors } \\
\hline \multirow[t]{2}{*}{$\begin{array}{l}\text { Loneliness and } \\
\text { social isolation }\end{array}$} & $\begin{array}{l}\text { "The transition was a bit hard on me because it just cut me off } \\
\text { from a lot of things, a lot of friends, a lot of things I would have } \\
\text { been doing at school. But it was like I got over it. I was able to } \\
\text { recover fast." }\end{array}$ \\
\hline & $\begin{array}{l}\text { "For some of my friends we adopt once-a-week afternoon Zoom } \\
\text { lunch or Zoom snack conversations. I did one yesterday. We can } \\
\text { encourage students to support themselves by giving them suggestions } \\
\text { of things they could do to support themselves virtually." }\end{array}$ \\
\hline
\end{tabular}




\begin{tabular}{|l|l|}
\hline $\begin{array}{l}\text { Loneliness and } \\
\text { social isolation } \\
\text { (continued) }\end{array}$ & $\begin{array}{l}\text { "There is this App which people have been using during this } \\
\text { quarantine, that helps you with what you are doing with your } \\
\text { friends. It's like a zoom type of thing. So you can share your } \\
\text { thoughts. I was thinking that people could do it year group by year } \\
\text { group or depending on those who are interested to help people } \\
\text { come together during this time." }\end{array}$ \\
\hline $\begin{array}{l}\text { Disconnection } \\
\text { from lively } \\
\text { campus } \\
\text { environment }\end{array}$ & $\begin{array}{l}\text { "Other school activities that can relieve our stress could be looked } \\
\text { into more especially. I think one thing that OSCA can also do is to } \\
\text { send forms to us students to find out what kind of things we would } \\
\text { like to do virtually. Probably [students] might be able to voice out } \\
\text { their opinions and know what they want to do virtually. I actually } \\
\text { wanted a virtual aerobics session." }\end{array}$ \\
$\begin{array}{l}\text { "I think the most important things was the non-academic things } \\
\text { that can make campus life more lively and engaging because } \\
\text { like my colleagues have mentioned the academic burden hadn't } \\
\text { changed much. The workload is still a little stressful for everyone. } \\
\text { And so this other aspect of social life should also help to relieve the } \\
\text { academic stress." }\end{array}$ \\
$\begin{array}{l}\text { "Now by going virtual, there is a wide range of things that you can } \\
\text { introduce to make things interesting and you can target a wider } \\
\text { range of students. So basically, we were just thinking that campus } \\
\text { clubs could help reduce the tension and the stress among the } \\
\text { student body." }\end{array}$ \\
\hline
\end{tabular}

This article provides a practical example of how student engagement can be fostered intentionally in times of crisis. Providing students with platforms for dialogue and ensuring effective communication enables students to address their grievances and provide meaningful feedback to enhance the provision of services from the University. It also enables students and supporting SA units to find more innovative ways of keeping students connected to their peers and the campus environment, especially in a time when feelings of disconnectedness, loneliness and social isolation are heightened. The final subsection will address the shift to working and schooling online and the specific support systems each unit put in place to make the remote transitioning process smoother.

\section{Timely remote transitioning support}

Considering that the University's operations had not been previously designed for online student services delivery, Ashesi's OSCA team was guided by a strategy that ensured accessibility, inclusivity, and equity for all students. It, therefore, adopted multiple remote access technologies to support student advising and engagement. This was made possible by the university leadership who provided monthly data stipends for all campus teams.

For students, the sudden shift to remote learning was a disruption, which required guidance from the student affairs team and the provision of resources to make the transition process smoother. Thus, throughout the FGD, students indicated that (1) timely responses and access to resources, and (2) time and flexibility, were factors that aided them in their 
remote transitioning (see Table 5). However, (1) inadequate resources, and (2) heightened stress due to increased remote schooling demands, were factors that made the remote transitioning process more challenging (see Table 5).

Table 5: Student perspectives on timely remote transitioning support

\begin{tabular}{|c|c|}
\hline \multicolumn{2}{|r|}{ Positive factors } \\
\hline \multirow[t]{3}{*}{$\begin{array}{l}\text { Timely } \\
\text { responses } \\
\text { and access to } \\
\text { resources }\end{array}$} & $\begin{array}{l}\text { "The accessibility and timely responses of the OSCA team and } \\
\text { Ashesi University in general to students' needs and questions have } \\
\text { been amazing. I have friends in other universities in my home } \\
\text { country Nigeria who up till now do not know what is going on } \\
\text { because the universities are not telling them anything. My friends are } \\
\text { amazed when I tell them I can easily email the Dean of Students and } \\
\text { get a response in a few hours or be guided to who can help me. This } \\
\text { has been very helpful in this time when we are not physically on } \\
\text { campus, and everything seems to be in a flux." }\end{array}$ \\
\hline & $\begin{array}{l}\text { "So I think that one thing that we didn't mention as well is data. } \\
\text { Data factor has actually been a huge help to us while working } \\
\text { online. At Ashesi we used to have Wi-Fi and that was also incredible } \\
\text { because most of the universities don't have that. But moving away } \\
\text { now Ashesi still maintains the Wi-Fi policy I will call it by sending } \\
\text { us data and we have been able to effectively move online, and I mean } \\
\text { nobody complains about it. We can complain maybe about internet } \\
\text { connectivity but not about data shortage. That's a huge factor that } \\
\text { Ashesi considers and that has really helped us in transitioning online." }\end{array}$ \\
\hline & $\begin{array}{l}\text { "For me it is kind of an honour to be associated with an institution } \\
\text { that is student-centred and taking student feedback into designing } \\
\text { what the university experience looks like. So for me, it's a pleasure to } \\
\text { be one of Ashesi's. As we are being intentional in our planning and } \\
\text { stuff, let's not forget to incorporate a lot of human feelings into this, } \\
\text { such as active listening and stuff. Let's encourage our faculty to use } \\
\text { active listening. If more faculty and supporting staff could do that } \\
\text { actively, it will go a long way to help us grow as an institution." }\end{array}$ \\
\hline \multirow[t]{2}{*}{$\begin{array}{l}\text { Time and } \\
\text { flexibility }\end{array}$} & $\begin{array}{l}\text { "At home, I am in-charge. I have control over my timing and other } \\
\text { things. And I am able to participate more in some of these events." }\end{array}$ \\
\hline & $\begin{array}{l}\text { "For me I will say we transitioning and doing everything online was } \\
\text { very good on our part. We have been sent lecture videos and we } \\
\text { revisit everything in the video. But when we were in school, when } \\
\text { we go for lectures it is for the day. I mean, if you don't take notes, } \\
\text { you wouldn't get the opportunity to revisit some of the things that } \\
\text { the lecturer was saying, but here, we have the Powerpoint at our } \\
\text { disposal and everything. If you want to revisit something you could } \\
\text { go back and fall on these videos." }\end{array}$ \\
\hline $\begin{array}{l}\text { Time and } \\
\text { flexibility } \\
\text { (continued) }\end{array}$ & $\begin{array}{l}\text { "With regards to academics, what is working is that the online } \\
\text { learning is really amazing for me. It is flexible. Wherever you can be, } \\
\text { you can learn. That was flexible for me and I like it. I really enjoyed } \\
\text { it so much." }\end{array}$ \\
\hline
\end{tabular}




\begin{tabular}{|l|l|}
\hline \multicolumn{1}{|l|}{$\begin{array}{l}\text { Negative factors } \\
\text { Inadequate }\end{array}$} & $\begin{array}{l}\text { "So I ended up sometimes not actually doing research and a paper } \\
\text { because I discovered that I finished my data. I think that is something } \\
\text { relevant we should note and it was a big problem for some people. } \\
\text { Zoom calls take up a lot of data and more Zoom calls means more } \\
\text { data spent. I think that bothered me. We should consider other } \\
\text { options." }\end{array}$ \\
\hline $\begin{array}{l}\text { Heightened } \\
\text { stress due } \\
\text { to increased } \\
\text { remote } \\
\text { schooling } \\
\text { demands }\end{array}$ & $\begin{array}{l}\text { "Some [lecturers] weren't considerate. Like looking at the pandemic, } \\
\text { we were all trying to adjust, but some of the lecturers were still } \\
\text { making it seem like we were in normal times and gave us more to } \\
\text { do. This made it difficult for some of us to adjust." }\end{array}$ \\
\cline { 2 - 2 } & $\begin{array}{l}\text { "We got assignments everyday and had classes to attend. Sometimes } \\
\text { you don't even know what is going on until someone says 'oh we } \\
\text { have an assignment and it is due today'. That was what was going on. } \\
\text { So I think that was what didn't work for me." }\end{array}$ \\
\cline { 2 - 2 } & $\begin{array}{l}\text { "Saying it was flexible and all of that, honestly, for me, it wasn't all } \\
\text { that flexible. One thing too is that lecturers thought students were } \\
\text { being relaxed. So, it was like you have workload coming from all } \\
\text { angles. Most lecturers are being more strict whilst we are doing } \\
\text { this virtually because they feel we are more relaxed at home. Your } \\
\text { workload, therefore, becomes more." }\end{array}$ \\
\hline
\end{tabular}

Students shared throughout the FGD that they required more flexible options to connect with the OSCA team. Thus, to adequately help students access the various support interventions timeously, the OSCA units adopted several forms of technology and creative virtual platforms like Calendly, Microsoft Outlook, Zoom, Skype, Google Hangout, phone, and WhatsApp calls, depending on what was most convenient for the students. These platforms enabled students to receive timely responses from the team and allowed them to communicate their problems including experiencing fatigue from their demanding workloads and not having enough resources such as data to facilitate their work. Thus, students successfully sought remote resources and support from the OSCA team to navigate the challenges of their transition promptly.

\section{Discussion}

While HEIs are figuring out how to navigate the Covid-19 pandemic to ensure their business continuity, it is important to understand how students experienced the pandemic. The findings in this reflective article indicate that students are (i) needing more advice to navigate the many transitions they are experiencing; (ii) reclaiming spaces and opportunities to engage and negotiate for policy changes and institutional decisions; and (iii) using technology to facilitate access to resources and support they perceive to be critical for their success. The three areas listed above necessitated Ashesi University's SAPs to consequently restructure their processes and services to respond to students' needs. This required constant reimagination and flexibility of their daily business delivery to students. 
While students perceived some of these responses to have had a positive effect on their ability to transition smoothly, they also highlighted what they perceived to have affected them negatively. Schlossberg's Transition Theory (Evans et al., 2010) provides an analytical framework to understand the various transitional experiences of the students. The theory offers a nuanced and informed explanation of student behaviours and experiences and allows SAPs to address students' needs in a more targeted way.

\section{Self}

The findings in this study point to students experiencing significant financial, psychosocial, and mental stress in an exponential way. According to Schlossberg's Transition Theory, these affect the individual's sense of self and their perception of being in control of the change they experience. To understand the self-component of the 4Ss, Schlossberg and Goodman (2005) explain that it is crucial for SAPs to ask if [students] are optimistic or pessimistic about the changes they were experiencing. Do they value completion and commit to seeing whatever they start to a logical end, or do they give up? Do they possess positive psychosocial attributes such as resilience and self-efficacy which can contribute to their ability to endure the change? In responding to students' needs for advice, the OSCA team assessed students' state of being through the lens of these questions.

Students indicated that amongst other things, the timely response to their psychosocial and emotional needs through the counselling and health units to help them navigate the transition, enhanced their ability to gain the needed sense of control. This is consistent with existing student development theory situated in positive psychology, which emphasises the ability of concepts such as positive emotions (confidence, courage and optimism), traits (e.g. resilience), and institutions like universities and their agents (in this case, the SAPs) to invoke, inspire and empower students to have a positive outlook on their educational outcomes (Strayhorn, 2015). Schlossberg and Goodman (2005) posit that greater perceptions of control and positive assessments of situations are more likely to result in positive outcomes. SAPs, for instance, proactively targeted their interventions to at-risk students with pre-existing mental health conditions, who had a high propensity not to reach out for support. Despite these proactive efforts by the SAPs, students indicated that more targeted communication and actions to other student groups besides at-risk students was needed because students generally will not access psychological and counselling services on their own.

\section{Strategies}

According to Schlossberg and Goodman (2005), strategies needed during the transition include identifying the support options available and how to access these resources such as information and other financial and non-financial resources. Furthermore, the individual's ability and agency to take action to mitigate challenges and develop coping mechanisms to face conditions beyond their control is tested. Gilbert and Griffin (2015) suggest that the assistance institutions offer can impact beneficiaries significantly. Harper and Quaye (2009) 
further argue that while student engagement is the responsibility of students, institutions must be very intentional in creating conditions that facilitate students' ability to access and effectively utilise the engagement opportunities available to them. The findings of this article indicate that students seized the spaces offered them for engagement to proactively advocate for themselves and seek specific support. The town halls became a space for constant (re)negotiation for several academic deliverables such as number of assignments and extension of submission deadlines, giving feedback on what they were struggling with at home (for instance, their financial and living conditions), and putting in requests for support.

While students can sometimes appear as vulnerable, passive and incapable of advocating for themselves, this particular finding reveals a tremendous demonstration of students' agency to voice out their needs and seek redress and support to help them be successful. This finding also confirms the call for SAPs and HEIs to view students from more assetbased narratives (Adjei, 2019; Linares \& Muñoz, 2011; Yosso, 2005). Students, however, elaborated that the remote nature of the engagement created a lack of human connection and social isolation, which negatively affected their sense of belonging and community. This possibly contributed to the heightened number of students who sought psychosocial, health and other forms of advice.

A fair amount of student development literature connects students' sense of belonging to their sense of mattering (Schlossberg, 1985; Strayhorn 2015), which is fundamental in driving and facilitating a positive sense of well-being and helping students to thrive. Sense of belonging has been attributed to several student outcomes including good academic performance, well-being, happiness, and good health (Hausmann, Schofield \& Woods, 2007). According to Strayhorn (2015), students' sense of belonging must be satisfied on a continual basis. This has become a challenge for many HEIs who have had to close their campus communities due to the Covid-19 pandemic. The responses of the various SAPs to create spaces for students to continue engaging, process and develop strategies to cope with the isolation were, therefore, vital and supported by existing literature.

\section{Situation and support}

Situation refers to the assessment individuals give to their transition process and their sense of control over the situation (Evans et al., 2010). Several factors come into play in evaluating an individual's situation including whether the change is considered permanent or temporary, good, or bad, and whether other stressors heighten transitional challenges (Schlossberg \& Goodman, 2005).

Covid-19 brought about a negative outlook for most students who felt disconnected and isolated, and experienced sudden and heightened financial difficulties from parents losing their jobs. Additionally, the move to remote learning and engagement exposed some students to significant barriers such as campus accommodation, cafeteria and dining services, internet access, and libraries as they no longer had access to these and other campus resources. The constant engagement and interactions from the students consequently forced 
the various OSCA units to find innovative ways to meet the continuous changing needs of students. This finding supports existing literature which advocates the need for HEIs to also change their structures, systems, and processes to meet and support the changing demographics and situations of students which has further been complicated by the Covid-19 pandemic (Kinchloe, 2008; Kuh, Kinzie, Schuh \& Whitt, 2011).

As evidenced by this article, support for students did not come only from institutional agents like the SAPs but also from their families and peers. This affirms Schlossberg's assertion that support comes from multiple sources including those who work collaboratively on behalf of the students to ensure their success, particularly when experiencing any form of transition (Schlossberg \& Goodman, 2005). The various ways students sought support also validates other student development theories like Mahmood's (2011) theory of collective agency, Adjei's (2019) capacity to hustle, and Yosso's (2005) community cultural capital wealth. All these focus on how students harness resources around them to negotiate challenges and barriers in their academic pursuits. Despite these support resources, students recognised that they struggled with heightened stress resulting from spending long hours online, and exposure to negative and conflicting news online about the pandemic, which affected their mental health.

The findings of this article highlighted the various ways students exhibited Schlossberg's 4Ss during their transition to remote learning and emphasised ways the OSCA units at Ashesi University responded to support the multiple transitions students experienced. The findings also suggest that all 4Ss of Schlossberg's Transition Theory must be carefully addressed by institutions to ensure students do not experience significant disruptions. The final section of this article will focus on recommendations and final reflections for HEIs, SAPs, and various youth development organisations.

\section{Final Reflections}

Several literature sources posit that for HEIs to be inclusive and responsive to the changing needs of their diverse student populations, the unique experiences of students must be incorporated into their in and out of classroom engagements (Freire, 1993; Kincheloe, 2008; Rendon, 1994). Additionally, Barnett (2004) argues for HEIs to reimagine their purpose as they face continuous volatilities, uncertainties, complexities and ambiguities in executing their business functions. A global public health crisis like the Covid-19 pandemic has made these calls even more urgent. The pandemic has revealed the changing needs of students and the importance of HEIs to equally reinvent themselves and continue to remain flexible and agile. This reflective article presents findings that show that when students are experiencing uncertainties and crises they adapt, adjust, and proactively apply multiple strategies to support the transitions they are forced to navigate. The analytical framework used indicates that students examine themselves, their changed situations, available strategies, and access institutional support that goes a long way to enhance their success. While students actively seek ways to respond to changes, this article has equally demonstrated the need for HEIs to respond with strategies that support and positively impact student success. 
The article also reveals the significant contributions theory can offer and inform praxis by providing a deeper and nuanced understanding of the student experience. This can inform the various relevant, timely and useful strategies and interventions SAPs can adopt to support students especially during crises. The students in this article demonstrated a proactive and strong agentic ability to participate in the decision-making process contrary to the sometimes perceived notion and presentation of students as passive entities with no ability to participate in their development. There is, therefore, the need for SAPs, HEIs and youth development organisations to broadly tap into the many assets students bring with them to the academic environment to inform the design and implementation of interventions especially during crises.

While it was not the focus of this reflection, it would be interesting to know about the relationship between students' transition experiences, the SAPs responses, and their academic performance. The findings of this reflective article are clear that for students to achieve educational success on university campuses, they would require not only the help of faculty but also that of SAPs who commiserate with them and understand their unique needs outside the classroom. According to Ciobanu (2013), "student services contribute to the quality of students' learning experience and their academic success ..." (p. 172). Thus, HEIs need to invest resources into having a dedicated and committed team of SAPs who will complement the efforts of faculty to enhance academic success, especially in times of crisis. This study, thus, provides a rich empirical knowledge in the context of student affairs, development, support, and effort in that regard.

\section{Acknowledgements}

The authors would like to thank all the department heads in the Office of Student and Community Affairs at Ashesi University and the students who participated in the focus group discussions for their contributions to this article.

\section{Conflict of Interest}

While the authors work in various capacities with the OSCA Department at Ashesi University, they declare that they have no financial or personal relationships that may have inappropriately influenced the writing of this reflective account.

\section{Funding}

This work was financially supported by the Academic Affairs Department at Ashesi University.

\section{References}

Adjei, M. (2019). "Hustling" to succeed: A narrative inquiry of first-generation, low-income youth in an African university [Published doctoral dissertation]. University of Minnesota.

Anderson, M.L., Goodman, J. \& Schlossberg, N.K. (2012). Counseling adults in transition: Linking Schlossberg's theory with practice in a diverse world (4th ed.). Springer. 
Appleton, J.R., Moore, P.L. \& Vinton, J.C. (1978). A model for the effective delivery of student services in academic schools and departments. The Journal of Higher Education, 49(4), 372-381. https://doi. org/10.2307/1979193

Ashesi University (2002). Educating ethical, entrepreneurial leaders in Africa. https://www.ashesi.edu.gh/ about.html

Astin, A.W. (1975). Preventing students from dropping out. Jossey-Bass.

Astin, A.W. (1984). Student involvement: A developmental theory for higher education. Journal of College Student Personnel, 24(2), 297-308.

Baxter Magolda, M.B. (1992). Cocurricular Influences on college students' intellectual development. Journal of College Student Development, 33, 203-213.

British Council (2015). Students in the driving seat: Young people's voices on higher education in Africa. International Higher Education. http://www.britishcouncil.org/education/ihe [Accessed 21 August 2020].

Brennan, J.A. \& Stern, E.K. (2017). Leading a campus through crisis: The role of college and university presidents. Journal of Education Advancement \& Marketing, 2(2), 120-134.

Casey, N. (2020, April 4). College made them feel equal. The virus exposed how unequal their lives are. https://www.nytimes.com/2020/04/04/us/politics/coronavirus-zoom-college-classes.html [Accessed 23 September 2020].

Ciobanu, A. (2013). The role of student services in the improving of student experience in higher education. Procedia - Social and Behavioral Sciences, 92,169-173. https://doi.org/10.1016/j.sbspro.2013.08.654

Crookston, B.B. (1994). A developmental view of academic advising as teaching. NACADA Journal, 14(2), 5-9. https://doi.org/10.12930/0271-9517-14.2.5

Creswell,J.W. (2014). Research design: Qualitative, quantitative, and mixed methods approaches. Sage.

Drake, J. (2011). The role of academic advising in student retention and persistence. About Campus, 16(3), 8-12. https://doi.org/10.1002/abc.20062

Earwaker, J. (1992). Helping and supporting students. Rethinking the issues. Taylor and Francis.

Evans, N.J., Forney, D.S., Guido, F.M., Patton, L.D. \& Renn, K.A. (2010). Student development in college: Theory, research, and practice (2nd ed.). Jossey-Bass.

Freire, P. (1993). Pedagogy of the oppressed (M.B. Ramos, Transl.). Penguin. (Original work published 1968.)

Goodman, J., Schlossberg, N.K. \& Anderson, M.L. (2006). Counseling adults in transition: Linking practice with theory (3rd ed.). Springer. https://scholarworks.wmich.edu/books/635/

Griffin A.K. \& Gilbert K.C. (2015). Better transitions for troops: An application of Schlossberg's Transition Framework to analyses of barriers and institutional support structures for student veterans. The Journal of Higher Education, 86(1), 71-97. https://doi.org/10.1080/00221546.2015.11777357

Hausmann, L.R., Schofield, J.W. \& Woods, R.L. (2007). Sense of belonging as a predictor of intentions to persist among African American and White first-year college students. Research in Higher Education, 48(7), 803-839. https://doi.org/10.1007/s11162-007-9052-9

Harper, S. (2008). Realizing the intended outcomes of Brown: High achieving African American male undergraduates and social capital. American Behavioral Scientist, 51(7), 1-24. https://doi.org/10.1177/ 0002764207312004

Harper, S.R. \& Quaye, S.J. (2009). Beyond sameness, with engagement and outcomes for all. Student Engagement in Higher Education: Theoretical Perspectives and Practical Approaches for Diverse Populations. Routledge.

Jackson, A. \& Sheehan, J. (2005, Fall). The returning college veteran: Challenges and strategies. NASPA Leadership Exchange, 3(Fall), 26-27. 
Kincheloe, J.L. (2008). Critical pedagogy primer (Vol. 1). Peter Lang.

Kitzinger, J. (1995). Qualitative research: introducing focus groups. Bmj, 311(7000), 299-302. https://doi. org/10.1136/bmj.311.7000.299

Kuh, G.D., Kinzie, J., Schuh, J.H. \& Whitt, E.J. (2011). Student success in college: Creating conditions that matter. John Wiley \& Sons.

Linares, L.I.R. \& Muñoz, S.M. (2011). Revisiting validation theory: Theoretical foundations, applications, and extensions. Enrollment Management Journal, 2(1), 12-33.

Mahmood, S. (2001). Feminist theory, embodiment, and the docile agent: Some reflections on the Egyptian Islamic revival. Cultural Anthropology, 16(2), 202-236. https://doi.org/10.1525/can.2001.16.2.202

Merriam, S.B. (2009). Qualitative research: A guide to design and implementation (3rd ed.). Jossey-Bass.

Merriam, S.B. \& Caffarella, R.S. (1999). Learning in adulthood: A comprehensive guide. Jossey-Bass.

Moja, T., Schreiber, B. \& Luescher-Mamashela, T. (2014). Contextualising student affairs in Africa: The past, present and future. Journal of Student Affairs in Africa, 2(1). https://doi.org/10.14426/jsaa.v2i1.46

Morris, A. (2015). A practical introduction to in-depth interviewing. Sage. https://doi.org/10.4135/97814739 21344

Pascarella, E.T. \& Terenzini, P.T. (2005). How college affects students (Volume 2): A third decade of research. Jossey-Bass.

Pomerantz, N. (2006). Student engagement: A new paradigm for student affairs. The College Student Affairs Journal, 25(2), 176-185.

Quaye, S.J. \& Harper, S.R. (Eds.). (2015). Student engagement in higher education: Theoretical perspectives and practical approaches for diverse populations (2nd ed.). Routledge. https://doi.org/10.4324/9780203810163

Rayburn, S.W., Anderson, S. \& Sierra, J.J. (2020). Future thinking continuity of learning in marketing: A student perspective on crisis management in higher education. Marketing Education Review. https://doi.org/10.1080/10528008.2020.1837633

Ruh, D., Spicer, P. \& Vaughan, K. (2009). Helping veterans with disabilities transition to employment. Journal of Postsecondary Education and Disability, 22(1), 67-74.

Schlossberg, N.K. (1985). Marginality and mattering: A life span approach. In annual meeting of the American Psychological Association, Los Angeles, CA.

Schlossberg, N.K. \& Goodman, J. (2005). Counseling adults in transition. Springer.

Schlossberg, N.K., Waters, E.B. \& Goodman, J. (1995). Counseling adults in transition: Linking practice with theory (2nd ed.). Springer.

Shackelford, A.L. (2009). Documenting the needs of student veterans with disabilities: Intersection roadblocks, solutions, and legal realities. Journal of Postsecondary Education and Disability, 22(1), 36-42.

Shaw, M.D. (2017). Pathways to institutional equilibrium after a campus disaster. Journal of Contingencies and Crisis Management, 25(2), 103-110. https://doi.org/10.1111/1468-5973.12128

Strayhorn,T.L. (2015). Student development theory in higher education: A social psychological approach. Routledge. https://doi.org/10.4324/9780203458211

Studenberg, H. 2017. Chief Student Affairs Officers' perceptions of institutional crisis management, preparedness, and response [Doctoral dissertation]. Nova Southeastern University. https://nsuworks.nova.edu/ shss_dcar_etd/68

Tinto, V. (1993). Leaving college: Rethinking the causes and cures of student attrition (2nd ed.). University of Chicago Press. https://doi.org/10.7208/chicago/9780226922461.001.0001

Tinto, V. (2005). Epilogue: Moving from theory to action. In A. Seidman (Ed.), College student retention: Formula for student success. (pp. 371-333). American Council on Education and Praeger. 
Wang, J. \& Hutchins, H. (2010). Crisis management in higher education: What have we learned from Virginia Tech? Advances in Developing Human Resources, 12(5), 552-572. https://doi.org/10.1177/15 23422310394433

Wilson, V. (1997). Focus groups: A useful qualitative method for educational research? British Educational Research Journal, 23(2), 209-224. https://doi.org/10.1080/0141192970230207

World Bank Education (2020). The COVID-19 crisis response: Supporting tertiary education for continuity, adaptation, and innovation. World Bank Group.

Yosso, T.J. (2005). Whose culture has capital? A critical race theory discussion of community cultural wealth. Race ethnicity and education, 8(1), 69-91. https://doi.org/10.1080/1361332052000341006

Zdziarski, E.L. (2006). Crisis in the context of higher education. In K.S. Harper, B.G. Paterson \& E.L.Zdziarski (Eds.), Crisis management: Responding from the heart (pp. 3-24). NASPA.

\section{How to cite:}

Adjei, M., Pels, N.N.A. \& Amoako, V.N.D. (2021). Responding to Covid-19: Experiences of Ashesi University's Student Affairs Team. Journal of Student Affairs in Africa, 9(1), 135-156. DOI: $10.24085 /$ jsaa.v9i1.1433 


\title{
REFLECTIVE PRACTICE
}

\section{Adaptation of Student Support Services Considering Covid-19: Adjustments, Impact, and Future Implications}

\author{
Munita Dunn-Coetzee, ${ }^{\text {i }}$ Elmien Sinclair, ${ }^{\text {ii }}$ Marcia Lyner-Cleophas, ${ }^{\text {iii Jaco Brink, }}{ }^{\text {iv }}$ \\ Marquard Timmey ${ }^{\mathrm{v}} \&$ Charl Davids ${ }^{\mathrm{vi}}$
}

\begin{abstract}
The global pandemic caused by Covid-19 has impacted every facet of our lives and challenged service delivery to students within Higher Education Institutions (HEIs). The Centre for Student Counselling and Development (CSCD) at Stellenbosch University (SU), South Africa, is situated within the Division of Student Affairs (DSAf) and the centre's reflective practitioners had to respond to the challenge of altering services to ensure continuous support to the SU community. The CSCD aims to provide the SU community with psychological, developmental and support services, with the focus on critical engagement, advocacy, personal growth, and optimising graduate potential.

The CSCD has been functioning virtually since mid-March 2020. Each of the Centre's five units had to respond to both the challenges and opportunities to adhere to social distancing and to accommodate students who did not have access to online devices. All support sessions - whether it be academic, social justice, career, social work, psychotherapy, crisis management, with individuals or with groups - had to be done virtually or via telephone. This depended on a student's choice and practical reality in terms of space, privacy, and connectivity. This article aims to firstly share the risks and opportunities of rapidly shifting to an online supportive environment, as well as how each unit within the centre had to adjust its functioning to ensure minimum impact on student relationships and interactions. It secondly aims to portray the implications the rapid shift had on the centre's practitioners and the lessons learned during the process. Sharing these lessons might empower other HEIs in Africa too. Lastly, considering the imperative shift to online functioning caused by the Covid-19 pandemic, this article concludes with a discussion on the implications for the future functioning of the CSCD.
\end{abstract}

i Dr Munita Dunn-Coetzee is Director: Centre for Student Counselling and Development (CSCD),

Stellenbosch University (SU), South Africa. ORCid: 0000-0002-6950-0420. Email: mdunn@sun.ac.za

ii Dr Elmien Sinclair is Head: Unit for Academic Counselling and Development, CSCD, SU, South Africa.

ORCid: 0000-0001-8809-2373. Email: est@sun.ac.za

iii Dr Marcia Lyner-Cleophas is Head: Disability Unit, CSCD, SU, South Africa.

ORCid: 0000-0003-1460-6313. Email: cleophas@sun.ac.za

iv Mr Jaco Brink is Head: Equality Unit, CSCD, SU, South Africa. ORCid: 0000-0003-1258-8369.

Email: jgbrink@sun.ac.za

v Mr Marquard Timmey is Head: Unit for Graduand Career Service, CSCD, SU, South Africa.

Email: timmey@sun.ac.za

vi Mr Charl Davids is Deputy Director and Head: Unit for Psychotherapeutic and Support Services, CSCD,

SU, South Africa. ORCid: 0000-0002-5585-9491.Email: cdavids@sun.ac.za 


\section{Keywords}

adjustments; Covid-19; disability support practitioners; hybrid space; student support; South Africa; virtual service offering

\section{Introduction}

Stellenbosch University (SU), situated in the town of Stellenbosch in the Western Cape province of South Africa, was founded in 1918, has ten faculties on five campuses and currently has 31540 students. The student profile of the university consists of $64.3 \%$ undergraduate, $33.2 \%$ postgraduate and $2.6 \%$ occasional students with $44.5 \%$ identifying as male and $55.5 \%$ identifying as female. SU is known as a residential campus with active residential life. Approximately 30\% of SU students make use of residential housing, while the majority are commuting students (Stellenbosch University, 2020).

Led by the Senior Director, Dr Choice Makhetha, the Division for Student Affairs (DSAf) at SU comprises three centres which together facilitate an ecosystem of support, development, and engagement. DSAf functions to accelerate student and institutional success and contributes to the institutional and national socio-economic transformation agenda. The Centre for Student Counselling and Development (CSCD) is one of the three centres within Student Affairs.

The CSCD provides dynamic, student-centred psychological development, and support services for students. Specialists such as psychologists, a psychometrist, registered counsellors and social workers have been carefully selected to meet the needs of the university community. The CSCD comprises five units that is briefly elaborated upon.

The Equality Unit (EqU) promotes collective action towards social justice and discourse regarding social asymmetries at SU with focus on HIV/Aids, gender, sexualities, and anti-discrimination. The Unit for Psychotherapeutic and Support Services (UPSS) offers psychotherapy, group interventions and social work services for students with psychological, emotional, personal and welfare needs. The Disability Unit (DU) offers various services to students with disabilities or special learning needs, including the development of accessible texts, advice about and access to support technology and innovative academic support. The Unit for Graduand Career Services (UGCS) provides student support in the process of entering the world of work. This includes sessions about careers, compiling a CV, exposure to network opportunities and job-searching methods. The Unit for Academic Counselling and Development (UACD) offers consultations, career counselling and work sessions focused on academic skills, with the aim to equip students with the necessary skills to reach their potential.

The five-level Covid-19 alert system has been introduced by the South African government to manage the gradual easing of the lockdown period and this article refers to the different levels of lockdown experienced in South Africa since March 2020. Alert level 5 was in effect in South Africa from midnight 26 March to 30 April 2020. Since the suspension of all on-campus activity, preparations were made to ensure that a period of online learning could commence on 20 April 2020 for all SU registered students. Academic and support staff remained acutely aware that the students had to learn in an unfamiliar, 
completely virtual mode during this trying time, equipped with whatever software, devices, and internet connectivity they could access in the places where they were residing during the lockdown period.

To adapt to a shift from predominantly on-campus, contact teaching to a fully online delivery mode brought about by the lockdown accompanying Covid-19's spread, SU had rapidly generated pragmatic solutions for the complex challenges that our student body, staff and other stakeholders face. SU's Covid-19 Contingency Committee, established in February 2020, has been expanded in March 2020 to an overarching Institutional Committee for Business Continuity (ICBC). It is served by a Medical Advisory Committee, and seven workstreams, covering student services; staff; learning and teaching; communications; community impact and external relations; campus operations; finance and legal matters; as well as research. These formed the official channels of communication, ensuring students and staff remain informed.

The CSCD has been functioning virtually since 18 March 2020. Each of the centre's five units had to respond to both the challenges and opportunities while adhering to social distancing and accommodating students who do not have access to online devices. All support sessions - whether it be academic, social justice, career, social work, psychotherapy, disability related, crisis management, with individuals or with groups - had to be done virtually or via telephone. This depended on a student's choice and practical reality in terms of space, privacy, and connectivity. With the number of Covid-19 infections escalating across the country since the implementation of lockdown in March 2020, we assumed that online learning within the higher education learning environment would continue as the primary mode for studies for the remainder of 2020, along with academic assessment through online means. During the past few months, the number of vulnerable students increased - students not accessing the learning platform of SU (SUNLearn), students on financial aid, students falling into the 'missing middle' category in terms of household income, students who were previously academically excluded and students in the extended degree programmes, as well as students in university housing during the lockdown period. This had significant implications for the functioning of the CSCD.

Before the Covid-19 pandemic, 20-30\% of our students had clinically significant symptoms of psychopathology and needed psychological support, yet only about $25 \%$ of these students were receiving treatment. We anticipated that the international health crisis precipitated by Covid-19 would create additional psychosocial stress for students through the following risk factors:

- high levels of anxiety and uncertainty in society about the spread of the virus;

- disruptions in studies and the need to adjust to online learning and assessment;

- social isolation and restrictions on normal patterns of socialising and autonomy;

- interruptions to normal face-to-face student support systems and psychotherapy.

The shift to online teaching, learning, engagement and assessment was a blessing in disguise for many students, yet challenging for some, especially those experiencing challenges due to disability (Lyner-Cleophas, 2020). SU students who are disabled were reporting 
challenges in adapting to the online environment and greater levels of social isolation. They were thus at particular risk for depression and anxiety.

The staff of the CSCD have had very little time to familiarise themselves with the nuances of providing online support and the constraints associated with it before they had to start functioning primarily on an online platform. However, this provided opportunities for experimenting with different online possibilities and testing a variety of technological support options to be able to holistically support students. SU sponsored students with data to allow internet connectivity every month and the CSCD staff received a monthly stipend to contribute to their data costs. Their office telephone numbers were transferred to Skype for Business to allow them to phone clients if necessary.

The following section describes how each unit had to practically adjust the last few months to ensure minimum impact on student relationships and interactions.

\section{A Reflection on Innovative Adjustments}

\section{Unit for Academic Counselling and Development (UACD)}

The UACD offers academic and career counselling to registered students. The logical decision during Covid-19 was to move all the individual counselling, psychometric assessments, and work sessions to an online platform. Like the phenomenon of online learning, online counselling can make the service more accessible for many, but it can also exclude many.

The availability of devices and the cost of data were important factors to consider. Although SU tried to mitigate these challenges by distributing laptops to students in need of them, availing free monthly data packages and negotiating free access to SUNLearn, it was soon realised that offering online counselling presented with many potential pitfalls. Several clients, especially those who resided in rural areas, found it difficult to identify physically safe spaces where they could attend private online counselling sessions. They often shared small spaces with friends and family. Keeping counselling sessions confidential was almost impossible in these cases. The quality of data connections made online real-time conversations challenging for some clients. It was important to determine upfront with each client which limitations could potentially impact the counselling process.

When hosting work sessions online, interactive participation during a presentation could be a challenge. Having a co-facilitator that managed written comments of participants during presentations would be recommended. Interactive participation was also encouraged when a work session was pre-recorded and uploaded on the learning management system for students to watch in their own time. They were invited to send questions afterwards and these were answered during an online panel discussion.

Despite our best efforts to prevent exclusion of students from online counselling and work sessions we had to admit that it could not always be readily accessible to everyone. Self-help resources on the CSCD website were expanded with a specific focus on challenges related to online studies. Topics included: "I find it challenging to manage my time", "The workload seems more than before", "I miss peer interaction", "I am feeling demotivated, 
anxious and/or depressed" and "The online assessment format leaves me feeling uncertain". These topics were addressed in short video clips and accompanying text.

\section{Disability Unit (DU)}

Prior to Covid-19, from time to time the students requested varied ways of teaching, flexible learning materials and adapted assessments. The DU had to negotiate "special" arrangements with faculties, depending on the specific needs.

Using technology to teach was heavily relied upon during Covid-19. Chinyamurindi (2020) and Rowe (2020) explore the possibilities of students having access to inclusive technology in remote learning, which is positive, as technology can assist vastly in aiding inclusivity. A big challenge and risk was that some students could not cope with the sudden shift to online teaching and learning. The lack of structure, and the lack of face-to-face support systems was difficult for some students with disabilities and conditions marked by rigid structure preferences. Initially, bandwidth and adequate devices was a challenge, but most students with disabilities acquired their assistive devices before the first term ended, which coincided with the onset of the South African Covid-19 lockdown. Poorer academic results were evident with some of these students.

Consultations with students continued virtually, including the use of Sign Language interpreters if needed. Communication and contact were maintained through the use of email, Microsoft Teams, WhatsApp calls and telephone calls. Staff meetings continued via Microsoft Teams.

\section{Equality Unit (EqU)}

The EqU implements SU policies on unfair discrimination and harassment as well as on $\mathrm{HIV} / \mathrm{Aids}$ and is committed to dealing with social injustice. Students and staff can report all forms of unfair discrimination, sexual harassment, gender-based violence, victimisation and abuse to the unit. To assist with dispute resolution, the unit also offers mediation services. The unit renders services to staff and students as well as training and interventions to combat gender violence and HIV/Aids (prevention, testing and counselling), and gives support with issues related to the lesbian, gay, bisexual, transgender, queer, intersex and allies (LGBTQIA+) community.

Most of our services were significantly impacted by the alert level regulations imposed by the South African government in 2020. We experienced declines in the number of cases of unfair discrimination and sexual harassment reported, ceased, or very limited HIV testing and limits on the ability to safely distribute internal and external condoms on campuses. The impact on basic HIV testing and prevention services provides an interesting and concerning reality as the dual pandemic of Covid-19 and HIV/Aids continues to co-exist. Essential testing services and limited condom supplies were only made available by SU Campus Health Services when 33\% of the student population could return to campuses in June 2020. 
The challenge of lockdown and alert level regulations created the need to rapidly create safe and user-friendly virtual reporting tools, support, and services. Through the Microsoft SharePoint and Microsoft Teams applications the EqU designed and tested online reporting platforms which was only done in person pre-Covid-19. The ability to continue providing support, training and services through virtual technologies contributed to ensuring minimum impact on student relationships and interactions.

\section{Unit for Graduand Career Services (UGCS)}

This unit's mandate is to connect our students to the world of work and to facilitate their transition from education to employment. We focus on optimising opportunities for students, especially our first-generation students, by closing the 'network gap' through extending their professional networks. It is a well-known fact that having an effective network is the most powerful tool you can use to market yourself and to find the hidden work opportunities (McGowan, 2013).

Two core services that speak directly to our focus required major adjustments. Shifting from on-campus career fairs and on-campus career work sessions to virtual career fairs and online career webinars was exciting, but also challenging. Shifting to virtual career fairs provided graduate employers an alternative approach to market their organisations and to seek new potential employees (Ådne et al., 2018). Our unit was invited by the South African Graduate Employers Association (SAGEA) along with 22 other universities to participate in the virtual career fair project. Training sessions were organised on how to register and navigate the platform. Training material for students was made available. For our online career webinars, Microsoft Teams was chosen as the preferred platform.

We initially only focused on pre-recorded career webinars to make asynchronous access possible for students. This allowed students more flexibility as their academic schedules and personal responsibilities at home would vary. As students adapted to the online learning environment, we started offering live webinars. The live webinars were also recorded and posted on the Microsoft Teams platform for students to access afterwards. Students informally provided feedback on the live webinars:

- A few challenges at the beginning with sharing screens but the content of the session and the enthusiasm of the presenter made up for the lost time. I enjoyed every minute of it.

- There were glitches at the beginning. It's good that there were more facilitators. Please let us know when you have this session again.

Students could log on to the virtual career fair platform on any of the three scheduled dates. They could also access the opportunities posted by the employers afterwards, as the virtual fair platform remained open for two months thereafter. We received some informal positive feedback from students about the virtual career fair:

- I liked being able to view information about many employers in one location.

- The virtual experience was positive.

- I liked being able to apply to multiple employers from one location.

- The opportunity to chat with employers online was a good experience.

- Webcasts offered by employers helped me. 


\section{Unit for Psychotherapeutic and Support Services (UPSS)}

Covid-19 has had a substantial impact on the traditional methods of service delivery at UPSS. This is because the unit had to ensure physical distancing to comply with Covid-19 regulations. Adjustments were made in the delivery of psycho-social services and food security matters. The shift from face-to-face to online service delivery meant that screening, assessment, therapy, referrals, and implementation of intervention plans were conducted online. Initially this transition was difficult for staff and students alike due to a lack of equipment or devices and data.

Due to the lockdown and the need to provide mental health services to our students, we had to embrace innovative 'tele-health' solutions and quickly orientate ourselves to digital platforms. The method of engaging with students therefore changed from face-toface to online services through the use of digital platforms such as Microsoft Teams, Zoom, Skype, WhatsApp, and telephone. Throughout the pandemic our staff provided services that include basic containment, trauma counselling, individual psychotherapy and counselling, support groups, discussion groups and food security. The first step in the online service delivery was to revise our ethical and consent forms to ensure ethical compliance.

The unit, as far as possible, tried to ensure minimum impact of student relationships and interaction. This was done through facilitating online support groups for anxiety and depression, grief, self-care, and financial management. These group sessions allowed for students to interact and form relationships with one another in an online space. Students shared thoughts and ideas amongst one another about a theme that was being discussed in the groups.

\section{Impact on Staff}

This sudden and unexpected change in service delivery indeed put staff under pressure. They had to demonstrate tenacity and agility to react efficiently to the needs of the clients. Although CSCD's staff are well qualified and experienced in rendering support to students, they had to acquire new knowledge in a very short time about learning in an online environment.

Simultaneously they also had to acquire new skills in online facilitation and mastering new software programmes. A different skillset is needed when one only has an online medium to gain an understanding of your client as less non-verbal cues are visible. Practitioners became more directive in their therapeutic stance and had to think more carefully about containing students when physically removed from them. Student clients also used the therapeutic space more effectively as they got to the depth of issues more easily. The time spent in sessions for many students also changed. Students would end the sessions after only thirty minutes as they felt they achieved the goals of the session. This might also of course be because of constraints around data costs.

However, to ensure that each staff member had adequate digital infrastructure to work from home was quite a challenge. Due to an increase in screen time, staff had to be vigilant about digital fatigue. For practitioners, screen fatigue became a real issue as the lockdown period continued. The work-life balance, especially when working from home, became a 
matter that had to be addressed speedily and practically. The remedy was found within the flexibility of staff working from home. After online case discussions and team meetings, staff soon learned to schedule work and home time differently. This meant working early mornings, late evenings or even weekends. This also benefitted students who could now access sessions after hours and weekends. A typical workday could therefore be structured differently per staff member.

Some staff members experienced family deaths and this impacted them heavily due to social distancing requirements and the inability to traditionally bury a loved one. One of the greatest challenges is probably to be content amid uncertainty.

\section{Lessons Learned}

Covid-19 changed the way we work in fundamental ways and some lessons learnt will stay with us. The discourse espoused by Universal Design for Learning (UDL), lends itself to flexible teaching, learning and assessment practices (Bruner, 2016; Burgstahler, 2015). This way of thinking about learning responds well to student diversity, in its broadest sense, and would naturally include students with disabilities. What UDL means is that learning materials are presented in various ways, by multiple means of representation. Students, by nature of their various ways of processing information, their strengths, and preferences, will have multiple ways of engaging with learning material.

In being reflective, it is as important to acknowledge how we have been changed during Covid-19. Incorporating UDL ways of thinking about student diversity and learning opens us up to being more inclusive in our practices and improving social justice initiatives. One lesson learnt is that disabled students are not a separate entity from the rest of the student population. Students with disabilities are a part of the rest of the diverse student population and by thinking inclusively about all students, no one gets left behind in times of pandemics. Many students benefitted from the flexibility around assessments, assignments and being able to listen to recorded classes again.

Staff became more technologically literate. The enhanced technological capability can be explored further in hopes that all lecturers can use podcasts when teaching and can incorporate speech-to-text technologies for a more inclusive academic offering. The adjustments demanded lots of flexibility from staff and managers. Creating a safe environment for staff to voice their needs and uncertainties was necessary to build trust and resilience.

In virtually preparing students for a world of work, the efforts to optimise our existing online recruitment solutions, like our career services management platform, should be increased. More zero-rated applications and websites would also be a game changer in the online learning and support environment (Mhlanga \& Moloi, 2020). Employers and employees must co-invest in sufficient digital infrastructures for staff to effectively work from home. It is also imperative that the Unit for Graduand Career Services collaborates with graduate employers to better prepare students for the virtual and online recruitment space. 
Practitioners believed in having boundaries with clients but have learnt to be more flexible regarding this to successfully work online. Our fears about online or telephone counselling especially related to building therapeutic relationships, trust and support disappeared as we gained experience in online counselling. We learned that access to mental health support could be multi-faceted and students doing their practical on distributed platforms within South Africa could have efficient access to online therapeutic assistance. We did not have the waiting lists that are so common in higher education student counselling circles. This might be due to rendering services on an online platform. This brought about flexibility in service delivery where staff could conduct work after hours and weekends and did not extend their contracted work hours per week. This might be the most important lesson for us and will surely impact the way we offer services in future.

\section{Implication for Future Functioning}

The African continent does not lack creativity and can emerge with their own solutions. Our continent still struggles with internet connectivity, accessible devices, and electricity issues, to name a few. However, this period forced us to collaborate as a country: students, staff, public and private companies, and individuals as well as governmental sectors. There were endless possibilities in terms of government departments collaborating with internet service providers for zero-rated data costs and students on financial aid schemes, like the National Student Financial Aid Scheme (NSFAS) could acquire laptops. Where possible, higher education institutions could make laptops and assistive devices available to all students. The use of no, low- and high-tech solutions remain options in educational settings in the African context (Chinyamurindi, 2020; Rowe, 2020; UCT, 2020).

The development of tailored programmes to mitigate identified risks through a range of interventions, located at institutional and faculty levels, need to be prioritised with the assistance of external funding. The building of partnerships with other entities in Southern Africa should be a priority. These interventions are focused largely around increasing human resources to adapt to the ongoing demands generated through the transition to online learning and the need to ensure that there is a diverse range of support options open to vulnerable students. One of the biggest implications for future functioning as a student counselling centre in higher education, is to fully use this opportunity to re-examine our functioning and to be able to, in a new normal, work in a flexible manner where the needs of our staff can be met in order to manage their workload and get their work accomplished. This entails investigating models where staff rotate, work from home and with flexi-hours to accommodate family life and the different schedules of students. Covid-19 accelerated a stronger move to a hybrid learning model and digital transformation in higher education.

\section{Conclusion}

The Covid-19 global pandemic has impacted and challenged service delivery to students multifacetedly. The pandemic facilitated an imperative shift to online functioning for the CSCD and assisted with the creation of ample new opportunities. A great concern for future functioning is the economic uncertainty as budget cuts and the diversion of resources 
to ameliorate the effects of Covid-19 are set to negatively impact higher education in South Africa. There is great apprehension for post-Covid-19 sustainability of universities and a lot will depend on what the situation is with regards to subsidy levels for 2021.

However, learning just like working, is not totally dependent on campus boundaries. With the necessary infrastructure, work and study can happen in a hybrid way. Covid-19 created the liberating opportunity to think what the future of higher education - and specifically rendering virtual student support within higher education - can look like.

\section{Disclosure of Interests and Funding}

These are personal reflections of the authors on their experiences and learnings during Covid-19 as practitioners within student counselling in higher education. The authors have no financial or non-financial interests in the article. No external funds were provided for the article and no ethical clearance was needed.

\section{References}

Ådne, S.V., Nørbech, B.C. \& Jeske, D. (2018).Virtual career fairs: Perspectives from Norwegian recruiters and exhibitors. Future Internet, 10(2), 19. https://doi.org/10.3390/fi10020019

Bruner, D. (2016). Universal design for learning: Academic access for diverse learners. Journal of Inclusive Practice in Further and Higher Education, 7, 4-8. http://nadp-uk.org/journal/

Burgstahler, S.E. (2015). Universal design in higher education: From principles to practice. Dryden Press.

Chinyamurindi,W. (2020). Five ways academics can manage COVID-19 situations. https://theconversation. com/five-ways-academics-can-manage-covid-19-shutdowns-133947

Lyner-Cleophas, M. (2020). Online teaching should also consider students with disabilities. http://www. sun.ac.za/english/Lists/news/DispForm.aspx?ID=7441

McGowan, R. (2013). How to find work in the 21st century (6th ed). Thames River Press.

Mhlanga, D. \& Moloi, T. (2020). COVID-19 and the digital transformation of education: What are we learning on 4IR in South Africa? Education Sciences, 10(7), 180. https://doi.org/10.3390/ educsci10070180

Rowe, M. (2020). Universal principles of learning task design. Crisis edition. https://www.mrowe.co.za/ blog/2020/04/universal-principles-of-learning-task-design-crisis-edition/

Stellenbosch University (2020). About-us. [Online]. http://www.sun.ac.za/english/about-us/why-SU [Accessed 29 August 2020].

\section{How to cite:}

Dunn-Coetzee, M., Sinclair, E., Lyner-Cleophas, M., Brink, J., Timmey, M. \& Davids, C. (2021). Adaptation of Student Support Services Considering Covid-19: Adjustments, Impact, and Future Implications. Journal of Student Affairs in Africa, 9(1), 157-166. DOI: 10.24085/jsaa.v9i1.1435 


\section{REFLECTIVE PRACTICE}

\section{Leveraging Ed-tech in the Co-curricular Space: Reflections on Design and Development Aspects of the Class Representative Induction Programme at the University of Cape Town}

Christine Immenga ${ }^{\mathrm{i}}$

\section{Abstract}

Every year, class representatives are elected at the University of Cape Town to represent students on academic matters in relation to a specific academic course. A vital element of this representative role is to advocate for an enabling learning environment that promotes learning excellence. In preparing class representatives for their leadership roles, the Department of Student Affairs, in partnership with the Students' Representative Council (SRC) and the Faculty Councils, host and facilitate a class representative induction programme. The induction typically utilised face-to-face synchronous teaching methods. However, since the advent of Covid-19, adaptions to the induction programme had to be made in order to reflect the new normal imposed by the pandemic.

Against this backdrop, this article addresses various design-related choices encountered from an online education technology perspective. Key areas of reflection include working with the SRC Undergraduate Academic Co-ordinator and Faculty Councils as a design team in transitioning a, hitherto, synchronous programme catering for approximately 420 class representatives, from a face-to-face mode of delivery to an online mode of delivery. Particular attention is paid to the social constructivist design elements of the programme development process and how these elements were managed with regards to the enablements and constraints encountered in the virtual space by exploring the technological affordances of various ed-tech options available to student affairs practitioners.

This article contributes to the practitioner literature by demonstrating how ed-tech can be leveraged to aid in the preservation of existing practices as blended learning approaches continue to shape and angment the future of co-curricular programme delivery in higher education.

\section{Keywords}

blended learning; leadership development; online co-curricular programmes; online learning design; participatory curriculum development

\section{Introduction}

Annually class representatives are elected at the University of Cape Town (UCT) to represent students on academic matters in relation to a specific academic course. Class Representatives are formally recognised in the Students' Representative Council (SRC)

i Ms Christine Immenga is the Senior Co-ordinator: Student Governance in the Student Development Cluster of the Department of Student Affairs at the University of Cape Town, South Africa.

ORCid: 0000-0003-3735-6601. Email: christine.immenga@uct.ac.za 
Constitution which forms part of the UCT Institutional Statute. The SRC Constitution further recognises six undergraduate faculty councils, that represent students in each of the six academic faculties of UCT and tasks these faculty councils with ensuring "that there is a functioning system of class representatives" (UCT Council, 2016, p. 14).

The role of a class representative is to advocate for an enabling learning environment that promotes learning excellence. A class representative typically achieves this through regular engagement with the course convenor or lecturer on academic matters or challenges that may be faced by their class. Should the class representative not be able to resolve the matter at the localised class level, the class representative can escalate the matter to the faculty council to liaise with the Head of Department or Dean and if the matter remains unresolved can escalate the matter to the SRC to take up with the university executive (Figure 1).

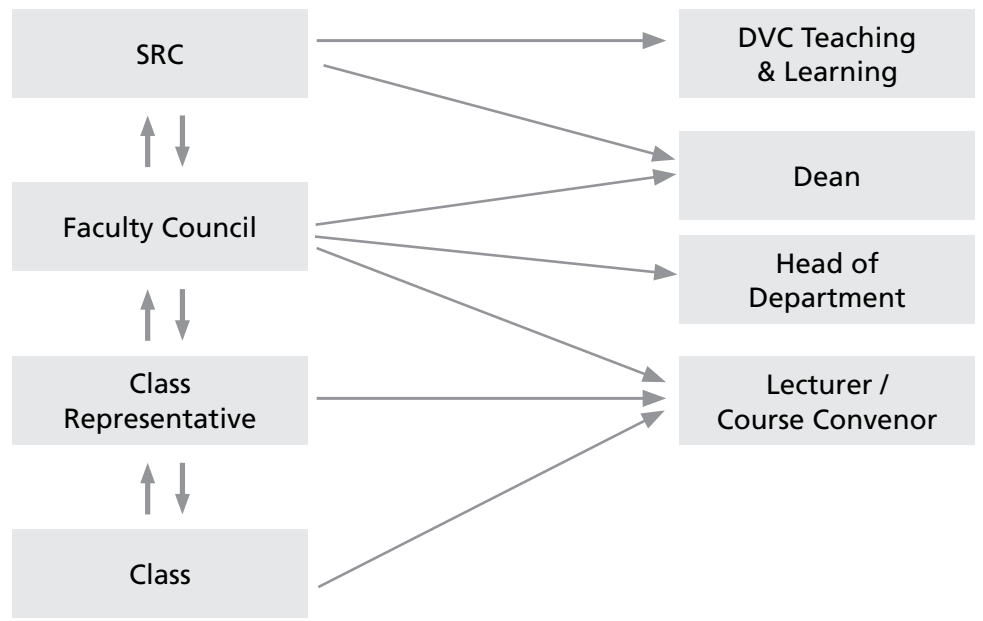

Figure 1: Class representatives' communication and complaint escalation channels

Further to this, a second responsibility of the role of the class representative is to facilitate the communication of important information to their class as well as refer their fellow class participants to the appropriate student support service should the need arise.

In an effort to prepare the class representatives for their critical role, the Department of Student Affairs (DSA) is tasked with inducting the class representatives. This is achieved through the development and implementation of the annual Class Representative Induction (CRI) programme. To facilitate the creation of a relevant and inclusive programme, the DSA utilises a participatory curriculum development (PCD) approach by partnering with both the faculty councils and the SRC Undergraduate Academics Co-ordinator to form the CRI design team (henceforth referred to as the design team). This multiple stakeholder approach is what distinguishes a PCD approach from a traditional curriculum development approach where subject matter experts and educators develop the curriculum. In drawing on the insights and experiences of stakeholders, a PCD approach essentially assumes that 
each stakeholder is an expert with regards to their own reality in relation to the curriculum being developed. The appeal of a PCD process is that it increases stakeholder "motivation, commitment and ownership of the learning process" (Taylor, 2000, p.95) thereby supporting the de facto social constructivist paradigm associated with student development in this co-curricular space (Schreiber \&Valle, 2013). Furthermore, PCD's ability to facilitate the inclusion of usually marginalised voices results in the production of "relevant, flexible, diverse and integrated curricula, improving the chance of a successful, sustainable outcome [that is] manifested through effective learning" (Taylor, 2000, p. 95).

The 2020 CRI programme was scheduled for 14 March. However, the confirmed arrival of the Covid-19 pandemic in South Africa in early March resulted in the postponement of the synchronous and face-to-face programme. The manner in which the pandemic evolved worldwide soon made it clear that a face-to-face induction would no longer be possible. It was, however, crucial that the class representatives receive training, especially since their representative role gained in significance once the institution announced that the academic year would continue via emergency remote teaching. This required that the design team re-design and re-develop the CRI programme in order for it to be facilitated fully online.

This article serves as a practitioner's reflection in addressing various design-related choices encountered in the process of developing the fully online CRI programme from an online learning and education technology perspective.

\section{Methodology}

According to Schön (1992, p. 53) "real-world problems do not come well-formed", and this was indeed the case with the advent of Covid-19 in South Africa. Covid-19 resulted in most higher education institutions being forced to move both curricular and co-curricular programmes fully online. Consequently, the use of reflective practice, as originally advocated by Schön (1982), provides a method of making explicit the practitioner knowledge gained by those practitioners who were suddenly tasked with enabling this transition (Candy, 2020; Schön, 1982).

Luescher (2018) develops the concept of reflective practice further within the context of student affairs by providing a foundation for the use of reflective practice articles as a methodology for reflective scholarship within the student development practitioner community. More specifically, Luescher proposes a set of guidelines for practitioners to draw on when engaging in reflective scholarship, namely:

Contextual information about the higher education system, the institution and its student body, and the student affairs department where a practice is housed;

Title and description of the practice, i.e. an intervention, project, initiative, programme or service;

Reasons for the practice: Why was this practice developed and adopted? What was its purpose and objectives? Who was the target group? What outcomes were envisaged? 
Conceptualisation and implementation of the practice: How was the practice conceived and developed? What was included/excluded? How was the practice implemented? What were its costs (including non-costed issues like time)? How was it managed, monitored and evaluated?

Reflections on the practice: What were the outcomes in terms of achieving its purposes? What worked, what did not work, and why? What recommendations for improvement can be made?

Reflections on ethics and transferability: What ethical considerations must be noted in relation to the practice? What is the potential of transferring the practice to other target groups or implementing it in different institutional and campus settings?

Reflections on the account: What is the trustworthiness of this reflective practice account? What biases may be implicit? How does it contribute to a scholarship of practice in student affairs? What further research may be required?

(Luescher, 2018, p. 68)

This article therefore proceeds by employing the use of reflective scholarship as a methodological approach given its well-suited relevance and hence also draws on both the structure and key components of Luescher's guidance outlined above.

This article draws on the following publicly available data sources:

- Framework for remote teaching at UCT under Covid-19 (also referred to as the Emergency Remote Teaching [ERT] framework).

- Universal Design for Learning (UDL) Guide provided by the Centre for Innovation in Learning and Teaching (CILT).

\section{The "new normal"}

Having noted that the 2020 CRI programme would need to take place in a fully online environment, a re-development of the programme was required in order to accommodate and adapt to this new normal in accordance with the provisions of UCT's Emergency Remote Teaching (ERT) framework.

In April 2020, the UCT Senate Executive Committee approved the Framework for remote teaching at UCT under Covid-19. The purpose of the framework is to ensure "an equitable experience of learning for all students" (UCT SEC, 2020, p. 1) in an effort to prevent "remote teaching [from] reinforc[ing] or increas[ing] existing inequalities" (UCT SEC, 2020, p. 1). This framework requires that "[e]mergency remote teaching [...] be asynchronous and designed for low bandwidth and restricted access to the internet in order to include as many students as possible" (UCT SEC, 2020, p. 2).

Emergency remote teaching was further enabled by the provision of laptops by the institution to students who required a device, by the monthly provision of data to students, and finally by an agreement made between the South African Department of Higher 
Education and Training and South African mobile service providers to zero rate a selection of educational websites. The result of the latter was that Vula, UCT's Learning Management System, was zero-rated and could be utilised without a data charge (ICTS, 2020).

The ERT framework made a point of distinguishing between emergency remote teaching and online teaching in that online teaching would allow for synchronous teaching activities to take place via platforms such as Zoom or Microsoft Teams (UCT SEC, 2020). In practice this meant that the face-to-face programme could not merely be moved online and be presented synchronously via an online platform. Instead, the framework challenged the CRI design team to design and develop a low-bandwidth asynchronous online induction programme.

\section{Designing for the "new normal"}

In keeping with Carpenter and Haber-Curran's (2013) recommendation of theory-based intentionality of practice, a deliberate attempt was made to draw on both education technology and online learning theory in the re-development of the CRI programme. In particular, use was made of the ADDIE framework, Affordance theory, the Universal Design for Learning (UDL) principles, the multimedia principle, and the Community of Inquiry (CoI) theoretical framework to inform the many design choices made for the programme. Each of these will now in turn be introduced and briefly discussed so as to provide the reader with the necessary background to make sense of the design choices upon which the ensuing reflections are based.

\section{The Analyse, Design, Develop, Implement and Evaluate Model (ADDIE)}

ADDIE is a five-stage instructional design model that systematically guides practitioners in the development of educational interventions (Allen, 2006). The five stages, from which it derives its acronymic name, are: Analyse, Design, Develop, Implement and Evaluate. Branch $\&$ Dousay, (2015, p. 17) characterise each of the ADDIE stages in terms of the activities associated with each stage as follows:

- $\quad[$ A]nalysis of the contexts and the needs of the learner;

- [D]esign of a set of specifications for an effective, efficient, and relevant learning environment;

- $\quad[D]$ evelopment of all student and course management materials;

- [I]mplementation of the planned instruction; and

- $\quad[$ E]valuation of the results of the design processes, both formative and summative.

According to Reiser and Dempsey (2007, p. 11) it should also be noted that when using the ADDIE framework "it is often necessary to move back and forth among the activities of analysis, design, and formative evaluation and revision" and by doing so the ADDIE framework reveals its greatest strength as being an "iterative and self-correcting" process (Reiser \& Dempsey, 2007). 


\section{Affordance theory}

In the education technology context affordance theory is interpreted as a maxim that states that when making choices about technologies, consideration must be given to both the manner in which the technologies support the learning task and how the technologies are experienced by the student (Beetham, 2007). The term 'affordance' is used to describe how a tool or technology might be used to enable online learning (Hammond, 2010; Aagaard, 2018). It then follows that by assessing what the various technologies, resources and tools may afford the student as they embark on the learning activity, learning designers are aided in determining which tool, technology or resource is best suited for the pedagogic strategy of the specific learning task.

\section{Universal Design for Learning (UDL)}

The UDL provides a framework for instructional design and curriculum development based on research from the learning sciences, the learning differences, and the creation of supportive learning environment domains. This framework consists of three principles, namely engagement, representation, and action and expression. These principles endeavour to optimise learning for all students (Hall et al., 2012; CILT, 2020). The engagement principle emphasises "the 'why' of learning" (CILT, 2020, p. 1) and requires that students connect with the content in a manner that motivates and stimulates them to learn. This can be achieved by contextualising content using local examples and the use of activities that encourage and welcome the student voice. The second principle of representation refers to "the 'what' of learning" (CILT, 2020, p. 2). This principle requires that students be enabled to make connections with the content in relation to their existing knowledge and understanding. The importance of this principle is that it acknowledges that students may interpret information differently based on their pre-existing knowledge and therefore requires that the same content be presented in multiple different formats as well as in smaller sections so as to allow for effective processing of the material.The third principle of action and expression refers to "the "how' of learning" (CILT, 2020, p. 4) and entails "creating multiple opportunities so that a wide range of diverse students can have equal access to and a means to confidently express their learnings $[\ldots]$ and participate in educational activities" (CILT, 2020, p. 4).

\section{Multimedia principle}

The multimedia principle states that human beings "learn better from words and pictures than from words alone" (Mayer, 2017, p. 404). Mayer (2017) however cautions that while multimedia can greatly aid the learning process, utilising too many elements within multimedia simultaneously can overload the cognitive processing of the learning and therefore impede learning.

\section{Community of Inquiry (CoI) theoretical framework}

A community of inquiry is defined as "a group of individuals who collaboratively engage in purposeful critical discourse and reflection to construct personal meaning and confirm 
mutual understanding" (Garrison, 2017, p. 2). The CoI framework presents "a process of creating a deep and meaningful (collaborative-constructivist) learning experience through the development of three interdependent elements - social presence, cognitive presence and teaching presence" (Cleveland-Innes et al., 2019, p. 170). A presence, also referred to as a sense of being, is fashioned through interpersonal communication. Moreover, in order for a CoI process to result in an engaging and interactive learning community all three types of presence, that is the social-, cognitive- and teaching presence must exist in a balanced confluence (Cleveland-Innes et al., 2019). These respective presences are defined as follows:

- Social presence is defined as "the ability of participants to identify with the group or course of study, communicate purposefully in a trusting environment, and develop personal and affective friendships progressively by way of projecting their individual personalities." (Cleveland-Innes et al., 2019, p. 172).

- Cognitive presence is defined as "the extent to which learners are able to construct and confirm meaning through sustained reflection and discourse" (Cleveland-Innes et al., 2019, p. 174).

- Teaching presence is defined as "the design, facilitation and direction of cognitive and social processes for the purpose of realising personally meaningful and educationally worthwhile learning outcomes" (Cleveland-Innes et al., 2019, p. 177).

\section{Design and re-development practice reflections}

In approaching the re-development and design of the CRI programme, the decision to follow a theory-based intentionality of practice was to help ensure the adoption of best practices given the more general trend towards blended learning in the Higher Education space. This approach was also inspired by pre-Covid events such as the 2019 NASDEV Best Practice Summit where strides towards harnessing the benefits and opportunities of the fourth industrial revolution (4IR) were already being encouraged. Collectively, these driving forces continued to highlight the need for more urgency amongst student affairs practitioners in general to take steps towards ensuring that the co-curricular space does not get left behind. The arrival of the Covid-19 pandemic necessitated the acceleration of this hitherto emerging agenda.

\section{ADDIE}

Having pivoted into the online learning design space, the first important decision was to adopt an instructional design model. Given the novelty of this practice as a student affairs practitioner, and the unfamiliar new normal, a flexible and simple design process model capable of supporting and maintaining the participatory curriculum development approach was sought and found in ADDIE. As Clinton and Hokanson describe ADDIE as being one of the most widely used design frameworks, it was also considered as a step towards the adoption of a best practice (Clinton \& Hokanson, 2012).

In following the ADDIE model, the design team's first task was to analyse the needs of the class representatives as well as the context in which they were going to perform 
their role. This needs analysis resulted in the identification of a key theme sub-divided into four sub-themes, along which the design team could focus their efforts. The key theme adopted took account of the demands and voluntary nature of the class representative role. This overarching theme distilled the need and realisation that we were designing for approximately 420 class representatives from across the entire academic spectrum as previously trained class representatives needed to be re-inducted given the amended institutional protocols as a result of Covid-19. This meant that the programme had to cater for students ranging from first-year students to finalists representing all six faculties. The four sub-themes addressed the programme's content requirements and included: (i) the need for class representatives to gain an appreciation of what it means to be a class representative and how this position relates to the broader student governance structures, (ii) the need for class representatives to be well versed in the academic policies and rules of the institution so that they are well equipped to answer questions or to raise concerns when policy is not being followed, (iii) the need for class representatives to be aware of the student support services offered by the institution so that they are able to refer a student to the appropriate support service, and (iv) the skills training the class representatives will need.

\section{Affordance theory}

Once the content needs for the new induction programme were established, attention needed to be focused on how best to deliver it within an online environment. As Branch \& Dousay (2015, p.17) suggest, "effective, efficient, and relevant [online] learning environment $[\mathrm{s}]$ " heavily depend on utilising the best resources and/or tools for enabling students on their learning journey, the design team turned to affordance theory. Given that the design team had first-hand knowledge, be it only anecdotal and implicit in nature, of actual student experiences in using the university's Learning Management System (Vula), the decision to house the CRI within UCT's Learning Management System was greatly simplified (Aagaard, 2018, p. 1).

Vula had been declared zero-rated which meant class representatives could access the site without incurring any data charges. This would ensure equitable access to the resources and content of the induction. Class representatives were also already well versed with Vula. Furthermore, the affordances offered by Vula included the fact that this Learning Management System has multiple tools for effective content delivery and is enabled with various communication tools that allow for collaboration and engagement. Noting that the design was underpinned by a social constructivist paradigm, the use of collaborative communication tools offered by Vula were an important consideration for the design. A further affordance offered by Vula is that site analytics can be utilised to determine how class representatives have engaged with the site. This would allow the design team to identify class representatives who have been inactive on the induction site so that a follow-up could be made with the class representative in question as well as allow the design team to determine if class representatives were experiencing any challenges with areas or aspects of the site. 


\section{Universal Design for Learning (UDL)}

After having examined the affordances of Vula, the challenge now became for the design team to optimally exploit the affordances of Vula. This entailed collating the content of the induction for the purposes of instructional delivery. The Principles of Universal Design for Learning (UDL) served to guide the design choices pertaining to the content delivery. This enabled the design team to address unseen learning barriers in an inclusive manner.

To actualise UDL's engagement principle, the design team opted for short videos to be presented by the student leaders within the design team. For this task, the design team drew on further research that informed them of the specifics required for the making of effective instructional videos. For example, the work of Day, Foley and Catrambone (2006; as cited in Fanguy et al., 2019) which found that "videos where the instructor was shown led to higher retention of information and greater understanding and ability to apply the principles featured in the lecture compared to the same content presented using either audio and a slide deck" (Fanguy et al., 2019, p. 46) formed part of the considerations in creating videos. This led to the content creation and production of videos by the student leaders that covered sub-theme (i) on the institutional role of class representatives, and sub-theme (iv) that addressed the skills requirements. The actualisation of the engagement principle was ultimately achieved through the creation of relevant and interesting videos that were presented within the student discourse and from a fellow students' perspective through the use of local and relatable examples. This was done in an attempt to motivate and stimulate class representatives to engage with the content.

Further attempts at keeping the instructional videos interesting included the use of different formats. For example, the videos for sub-theme (ii) took the form of an interview. Over a period of one hour, the SRC Undergraduate Academics Co-ordinator interviewed a Faculty Manager on the various academic policies and rules that class representatives should be aware of and how these had been amended in the Covid-19 context. This lengthy interview was then cut into shorter videos whereby one video would cover a particular question or topic. This interview method provided for an interactive and engaging discussion. For sub-theme (iii), the presenter format was reused, however this time the videos were presented by staff members representing various student support services. This provided an opportunity for each of the respective student support services to showcase their offerings in a video as well as advise how their services remained accessible and available in the Covid-19 context.

In further applying the engagement principle, the design team opted for learner-led pacing. This meant that class representatives could work through the content in their own time and at their own pace. The main reason for opting for a learner-led pace was the fact that this induction was a voluntary programme and therefore would remain secondary to the class representative's academic commitments. This flexibility allowed for class representatives to engage with the material as they felt motivated to do so. The benefits associated with this design choice, however, did not come without its own risk. The main concern being that class representatives would simply not engage with the content and 
would hence require dedicated monitoring of usage analytics and follow-up by the design team (Lowenthal et al., 2009; Hall et al., 2012).

The first step taken in incorporating the second principle of representation into the induction design was to provide an overview page within Vula that introduced the programme, stated the purpose of the induction, outlined the learning outcomes and explained the programme's methodology. A further principle of representation strategy employed by the design team was to release content in manageable portions. To this end, the content was released in accordance with the sub-themes and each sub-theme was presented within one Vula page. A further stipulation of the representation principle is that content be presented through multiple different file formats. Having noted afore that video had been chosen as the foremost tool for content delivery, the design team ensured that each video was accompanied by presentation slides, explanatory notes, a transcript of the video, relevant diagrams and images and, if applicable, additional resources and website links. The induction therefore provided for a multimedia approach that meant that the class representatives could view the video and take in visual and audio content or listen to the video and take in only the audio content or the class representative could engage with the content by reading the presentation slides accompanied by the explanatory notes and the video transcript.

The third principle of action and expression was incorporated into the design of the Vula site through the utilisation of the many tools Vula offers for asynchronous communication, collaboration and engagement. At the end of each sub-theme a comment tool was integrated into the page so as to allow for comments or questions to be posed in relation to the sub-theme. The site also featured a chat room, the question \& answer tool as well as the forum tool. The forum tool was set up to permit faculty-specific discussions which allowed for discussions to ensue between faculty-specific class representatives and their respective faculty councils. The forum tool could be utilised by class representatives to pose questions and suggestions, seek and provide advice and debate policy. Returning class representatives or more senior student leaders could also utilise the forums to provide tips and guidance to their representative peers. The chat room tool was intended for class representative to connect and engage with each other. Finally, the question \& answer tool, having the affordance and functionality to be used anonymously, meant that all class representatives could feel comfortable posing questions to the Faculty Councils, SRC or the DSA.

In a further strategy to incorporate the expression and action principle, the design team developed relevant and locally contextualised scenario-based questions that could be posed to a group of class representatives to solve. These questions were specifically designed to encourage collaboration as well as engagement with the content in answering the scenarios. The multiple and varied opportunities for communication and engagement integrated into the induction permitted the class representative's voice to be elicited within this asynchronous online space and resulted in class representatives being able to action and express their learning. 


\section{Multimedia principle}

In further unpacking the opportunities that multimedia provides in online education, the design team noted the multimedia principle which asserts that students retain more knowledge from words and images than from words alone. By incorporating relevant content pictures in the static form such as graphics, diagrams and images as well as pictures in the dynamic form such as videos and narrated PowerPoint presentations into the induction, the design team ensured a more effective learning environment for class representatives (Mayer, 2017).

As per the UDL Guide provided by CILT (2020), all videos were kept below 15 minutes. Lengthier videos were edited and cut to cover a particular question or topic. Instructional text was incorporated within the Vula pages to illuminate the content of the video as well as additional materials. All videos were embedded into the Vula site which meant videos could be watched without data being used. Further to this, for students who had intermittent or limited Wi-Fi access, videos and resources could be downloaded, stored and watched or read offline at a later stage. For students with low bandwidth or who preferred not to watch videos, a transcription of each video was provided along with presentation slides and explanatory notes.

\section{Creating a learning community}

A key benefit of the participatory curriculum development process was that the design team could draw on their own realities in assessing the needs of the target audience of this induction given their high degree of shared experience. The uncertainty presented by the Covid-19 pandemic and the sudden shift from face-to-face teaching to remote emergency teaching left students feeling distressed and overwhelmed (Morgan, 2020). Moreover, the design team was cognisant that research on the experience of online learning had revealed that students "often feel isolated and alone in online learning environments" (Lowenthal et al., 2009, p. 162). In further noting that learning communities "act as academic and social support structures that allow students to learn in more authentic and challenging ways" (Dabbagh, 2005, p.30) the design team set about ensuring the creation of a supportive and interactive online learning community within the induction programme. Class representatives needed to be enabled to perform their representative role as well as have a safe space where they could ask questions, seek guidance and engage with peers on the experiences of emergency remote learning as well as on being a class representative during these challenging times. The creation of a supportive learning community therefore was paramount to the success of the induction as well as the functioning of the class representative system as a whole (Ludwig-Hardman \& Dunlap, 2003; Robinson, 2000; Morgan, 2020).

Most noteworthy was the manner in which the design choices hitherto described culminated in an environment that would be supportive of a community of inquiry. The social presence would be enabled through the various collaborative and communication tools integrated into the induction site. These tools would allow class representatives to 
meaningfully and purposefully engage with one other. Furthermore, the ability of the Faculty Councils and SRC to be present in these virtual spaces would allow for ongoing motivation and support as well as serve as a continual reminder of the common purpose to advocate for the interest of students. The cognitive presence would be enabled through group activities and the release of scenario-based explanatory videos. The intention behind these activities is that they would encourage the "construct[ing] and confirm[ing] [of] meaning through sustained reflection and discourse" (Cleveland-Innes et al., 2019, p. 174). The third and final presence, that of the teaching presence, would be enabled through the sustained and ongoing facilitation and guidance of the design team throughout the induction programme.

Ultimately then, these design choices also served to maintain the confluence of the three presences required for the existence and maintaining of a community of inquiry.

\section{Reflections to Aid Student Affairs Practice}

In drawing on the experience of transitioning a hitherto face-to-face synchronous programme to an asynchronous online programme, the practitioner has noted five benefits that leveraging online learning and education technology could have for student development practitioners. These benefits are worthy of consideration as we shape and augment the future of co-curricular programmes in the new era of online and blended learning in a post Covid-19 world. The practitioner by no means claims that this list is exhaustive. The five benefits identified by the practitioner during the design of the CRI are:

1. Scalability - A co-curricular programme that is offered online can be presented to an unlimited number of students at no additional cost per student. In 2020, approximately 420 class representatives were elected. There are a limited number of physical venues that could accommodate that many students on campus and the cost of materials and catering for a group that size would be significant.

2. Decreased risk of disruption - The benefit of creating an asynchronous online programme has meant that we do not encounter the risks associated with running a synchronous programme. These risks would include presenters or participants being unable to attend the synchronous programme, load shedding rendering a venue unusable or a number of other possibilities resulting in a disruption to the synchronous programme. With students being able to access the content as is suitable for them, the risk of the content not being able to be presented or delivered is decreased significantly.

3. Universally accessible programmes - Designing the online programme according to the principles of Universal Design for Learning means that unseen barriers to student learning are automatically catered for and the content of the programme is accessible to all student participants.

4. Student convenience - The programme can also cater for student preferences in engaging with the content which would result in greater motivation to participate in the programme. These preferences could be in terms of when the student chooses to engage with the content, i.e. late at night or how the student 
wishes to engage, i.e. via video, audio or readings. The student can also choose the communication channel they wish to utilise when interacting with other student participants or the programme design team, presenters or facilitators.

5. Temporal affordance - A further benefit is that the content can be revisited by a student at any time and as needed. Should a student wish to refresh their memory or knowledge of a certain topic, the possibility is available at the click of a button. Further to this, the induction of new class representatives as a result of resignations or vacancies or as new courses are initiated in the second semester can easily be added to the site and the induction material is immediately available for their use.

\section{Conclusion}

While the transition to a completely online programme was daunting at first, the exposure to the benefits of online education technology theories, practice and techniques has allowed for an enriched student development practitioner experience. This article has sought to compile a reflective account of how a design team managed to preserve the strengths of their pre-Covid-19 practice and make strides towards advancing an emerging agenda within student affairs practice by leveraging blended learning. These advances would not have been possible were it not for the adoption of a theory-based intentionality of practice. Consequently, this account also demonstrates how the use of conceptual frameworks and instructional theories can guide the development and improvement of practice when encountering conditions of uncertainty.

\section{Acknowledgements}

I would like to thank the Undergraduate Academic Sub-Council for their hard work and dedication in making the CRI a reality. I am also very grateful to my UCT colleagues who supported the induction programme by creating videos and providing additional resources for the Class Representatives. I am extremely grateful to the Centre for Innovation in Learning and Teaching for facilitating webinars as well as providing guides and resources that greatly assisted in moving the CRI online. Finally, a special thank you to Edwina Brooks, the Director of Student Development, for supporting this endeavour and to the critical readers, Shanali Govender and David Redelinghuys as well as the editors and peer reviewers of this article for their extremely valuable feedback. Notwithstanding, any errors and omissions remain that of the author.

\section{Research Ethics}

The following ethical principles, as advocated by Saunders, Lewis \& Thornhill (2016), were observed during the writing and research of and associated with this article:

- Avoidance of harm,

- Maintenance of the anonymity of those taking part,

- Responsibility in the analysis of data and reporting of findings, and

- Respect for others. 


\section{Disclosure of Conflict of Interests and Funding}

No funding was provided for this reflective practice case study. The author has no conflict of interest to declare. The article serves as a personal reflection on the design process of moving the CRI online and my own involvement in this process has been explained in the article.

\section{References}

Aagaard, J. (2018). Magnetic and multistable: Reinterpreting the affordances of educational technology. International Journal of Educational Technology in Higher Education, 15(4). https://doi.org/10.1186/ s41239-017-0088-4

Allen, W. (2006). Overview and evolution of the ADDIE training system. Advances in Developing Human Resources, 8(4), 430-441. https://doi.org/10.1177/1523422306292942

Beetham, H. (2007). An approach to learning activity design. In H. Beetham \& R. Sharpe (Ed.), Rethinking pedagogy for a digital age: Designing and delivering e-learning (pp. 26-40). Routledge. https://doi.org/ 10.4324/9780203961681

Branch, R.M. \& Dousay, T.A. (2015). Survey of instructional design models. EACT.

Candy, L. (2020). The creative reflective practitioner: Research through making and practice. Routledge. https://doi. org/10.4324/9781315208060

Carpenter, S. \& Haber-Curran, P. (2013). The role of research and scholarship in the professionalisation of student affairs. Journal of Student Affairs in Africa, 1(1\&2), 1-9. https://doi.org/10.14426/jsaa.v111-2.20

Centre for Innovation in Learning and Teaching (2020). Equitable learning through universal design for learning. https://docs.google.com/document/d/1NckNyU8Vav2CFWDWWtK6ebIU2xqJCbeaHX9leLy vhxY [Accessed 25 August 2020].

Cleveland-Innes, M., Garrison, D.R. \& Vaughan, N. (2019). The community of inquiry theoretical framework. In M.G. Moore \& W.C. Diehl (Eds.), Handbook of distance education (4th ed., pp. 168-190). Routledge.

Clinton, G. \& Hokanson, B. (2012). Creativity in the training and practice of instructional designers: The Design/Creativity Loops model. Educational Technology Research and Development, 60(1), 111-130. https://doi.org/10.1007/s11423-011-9216-3

Dabbagh, N. (2005). Pedagogical models for e-Learning: A theory-based design framework. International Journal of Technology in Teaching and Learning, 1(1), 25-44.

Ertmer, P.A. \& Newby, T.J. (2013). Behaviourism, cognitivism, constructivism: Comparing critical features from an instructional design perspective. Performance Improvement Quarterly, 6(4), 50-70. https://doi. org/10.1002/piq.21143

Fanguy, M., Costley, J., Baldwin, M., Lange, C. \& Wang, H. (2019). Diversity in video lectures: Aid or hindrance? International Review of Research in Open and Distributed Learning, 20(2). https://doi.org/ 10.19173/irrodl.v20i2.3838

Garrison, D.R. (2017). E-learning in the 21st century: A community of inquiry framework for research and practice (3rd ed.). Routledge,Taylor \& Francis. https://doi.org/10.4324/9781315667263

Hall,T.E., Meyer,A. \& Rose, D. (2012). Universal design for learning in the classroom. The Guilford Press.

Hammond, M. (2010). What is an affordance and can it help us understand the use of ICT in education? Education Information Technology, 15, 205-217. https://doi.org/10.1007/s10639-009-9106-z

Information and Communication Technology Services (n.d.). Zero-rated mobile data access to specific UCT online resources. http://www.icts.uct.ac.za/Zero-rated-access-some-UCT-websites [Accessed 10 August 2020]. 
Lowenthal, P.R.,Wilson, B.G. \& Parrish, P.E. (2009). Context matters: A description and typology of the online learning landscape. In 32nd Annual proceedings: Selected research and development papers presented at the annual convention of the Association for Educational Communications and Technology, Washington, DC.

Ludwig-Hardman, S. \& Dunlap, J.C. (2003). Learning support services for online students: Scaffolding for success. International Review of Research in Open and Distance Learning, 4(1). https://doi.org/10.19173/ irrodl.v4i1.131

Luescher, T.M. (2018). Quality enhancement in student affairs and social justice:A reflective case study from South Africa. Journal of Student Affairs in Africa, 6(2), 65-83. https://doi.org/10.24085/jsaa.v6i2.3310

Mayer, R.E. (2017). Using multimedia for e-learning. Journal of Computer Assisted Learning, 33(5), 403-423. https://doi.org/10.1111/jcal.12197

Morgan, H. (2020). Best practices for implementing remote learning during a pandemic. The Clearing House: A Journal of Educational Strategies, Issues and Ideas, 93(3), 134-140. https://doi.org/10.1080/00 098655.2020.1751480

Reiser, R. \& Dempsey, J. (2007). Trends and issues in instructional design and technology (2nd ed.). Pearson/ Merrill Prentice Hall.

Robinson, P. (2000). Where is every-body? In R.A. Cole (Ed.), Issues in web-based pedagogy: A critical primer (pp. 111-123). Greenwood Press.

Saunders, M., Lewis, P. \& Thornhill, A. (2016). Research methods for business students (7th ed.). Pearson Education Limited.

Schön, D.A. (1982). The reflective practitioner: How professionals think in action. Basic Books Inc.

Schön, D.A. (1992). The crisis of professional knowledge and the pursuit of an epistemology of practice. Journal of Interprofessional Care, 6(1), 49-63. https://doi.org/10.3109/13561829209049595

Schreiber, L.M. \& Valle, B.E. (2013). Social constructivist teaching strategies in the small group classroom. Small Group Research, 44(4), 395-411. https://doi.org/10.1177/1046496413488422

Taylor, P. (2000). Improving forestry education through participatory curriculum development: A case study from Vietnam. The Journal of Agricultural Education and Extension, 7(2), 93-104. https://doi.org/ $10.1080 / 13892240008438810$

UCT Council (2016). SRC constitution. http://www.dsa.uct.ac.za/sites/default/files/image_tool/images/ 412/Student_Development/Student_Governance_Documents/SRC\%20Constitution\%20June\% 202016.pdf [Accessed 10 August 2020].

UCT SEC (Senate Executive Committee) (2020). Framework for remote teaching at UCT under Covid-19. https://www.news.uct.ac.za/downloads/media/Framework-for-Remote-Teaching-at-UCTunder-COVID-19.pdf [Accessed 10 August 2020].

\section{How to cite:}

Immenga, C. (2021). Leveraging Ed-tech in the Co-curricular Space: Reflections on Design and Development Aspects of the Class Representative Induction Programme at the University of Cape Town. Journal of Student Affairs in Africa, 9(1), 167-181. DOI: 10.24085/jsaa.v9i1.1436 


\title{
REFLECTIVE PRACTICE
}

\section{The Impact of the Covid-19 Pandemic on Student Affairs Practitioners: A Reflective Case Study from Bindura University of Science Education in Zimbabwe}

\author{
Sebastian Mutambisi, ${ }^{\mathrm{i}}$ Dora Dorothy Murasii ${ }^{\mathrm{ii}}$ \& Crispen Mazodze ${ }^{\mathrm{iii}}$
}

\begin{abstract}
The Covid-19 pandemic has had an unprecedented impact on faculty and student affairs practitioners which has changed the future of higher education worldwide. This reflective practitioner account looks into its impact on practitioners working in student affairs, some of which is not immediately visible, but unfortunately very significant and will surface in the medium and long term. There has been tremendous uncertainty for Student Affairs practitioners as a result of disruption from familiar routines and unexpected disengagement with their clients, the students. The change management perspective and scholarship of practice were adopted as methods of observing how a department in a university deals with unplanned change. The study concluded that the Covid-19 pandemic impacted practitioners negatively at the case university as new skills were required, practitioners were required to adjust to new work arrangements, lost income, suffered mental health problems and faced resource constrains. Training and development, social media, employee support systems and employee incentives were catalysts in the early adoption of change.
\end{abstract}

\section{Keywords}

change models; Covid-19; higher education; scholarship of practice; Student Affairs

\section{Introduction}

This article seeks to contribute to knowledge sharing with regard to the effect of the Covid-19 pandemic on student affairs practitioners and their practice in general. The World Health Organization (WHO) declared the novel coronavirus a Public Health Emergency of International Concern on 30 January 2020. On 11 March, WHO declared Covid-19 a global pandemic. This new reality presented both opportunities and challenges for higher education institutions (HEIs) and student affairs practitioners in particular. The Government of Zimbabwe declared the Covid-19 pandemic a national disaster on 17 March 2020.This pronouncement was followed by a national lockdown which

i Mr Sebastian Mutambisi is Director: Student Off-campus Life and Financial Aid, Bindura University of Science Education, Zimbabwe. ORCid: 0000-0001-8417-8452. Email: seba3296kd@gmail.com

ii Mrs Dora Dorothy Murasi is Director: Campus Life and Student Development Programmes, Bindura University of Science Education, Zimbabwe. ORCid: 0000-0002-5445-6770. Email: dmurasi2@gmail.com

iii Mr Crispen Mazodze is Dean of Students, Bindura University of Science Education, Zimbabwe.

ORCid: 0000-0002-2423-0420. Email: cmazodze@buse.ac.zw 
commenced on 30 March 2020. The national lockdown imposed several restrictions which impacted on learning and the implementation of campus activities on one hand while on the other hand prompted the HEIs to join hands with other progressive organisations in coming up with strategies for containing the virus in Zimbabwe. The lockdown instituted in March 2020, was preceded by a closure of all primary, secondary and higher education institutions of learning in a bid to stem the rapid spread of Covid-19. The closure created a 'new normal' for the students who had to learn online for a prolonged period.

The impact of the Covid-19 pandemic shook almost all (HEIs) globally, and Zimbabwe was no exception, coupled with the need to migrate from face-to-face to eLearning. There was no budget in place to support the retraining of human capital and retooling of services to support online learning. The switch-over to eLearning by universities was received with mixed feelings by students who were happy that in spite of the closure of campuses they could still continue with their education, but the major challenge was that they could not afford data bundles to access the new mode of learning. These challenges also reverberated at the case institution, Bindura University of Science Education (BUSE).

Like in other institutions, student affairs professionals at the institution under reflection had to grapple with managing the sudden change in their immense schedules as a result of the Covid-19 pandemic. This reflective article aims at providing insights into the impact of the Covid-19 pandemic on student affairs professionals at Bindura University of Science Education in Zimbabwe. It applies scholarship of practice as its methodology for contextualising the impact of the coronavirus on student affairs practitioners (Luescher, 2018).

The basic argument of this article is based on the principle of disruptive change and argues that student affairs practitioners were forced to deal with sudden change in executing their work. It is therefore pertinent to outline that some change models will be applied in analysing the impact of the Covid-19 pandemic on student affairs practitioners. This article employed two change management models which were developed by Kurt Lewin (1951) and John Kotter (2008) based on the experiences of student affairs practitioners at the case university.

\section{Conceptual Framework}

This study is informed by Kurt Lewin and John Potter's change management models which outline how organisational change efforts can be planned, organised and managed (McGrath \& Bates, 2017; Kotter \& Cohen, 2014). Lewin's change model is characterised by three stages namely: unfreezing, changing and refreezing (Banhegyi \& Banhegyi, 2007; McGrath \& Bates, 2017). John Kotter used the work of Kurt Lewin to develop an eightstep model of the change management process, arguing that neglecting any of the steps can be enough for the whole initiative to fail (Kotter, 2008; Kotter \& Cohen, 2014). The model is illustrated and summarised in Table 1. 
Table 1: John Kotter's change model

\begin{tabular}{|c|c|}
\hline Step & Management Activity \\
\hline Create urgency & $\begin{array}{l}\text { - Creating awareness for the need for change. } \\
\text { - Creating a forum to generate conversation of what is } \\
\text { happening. } \\
\text { - Seeking management buy-in. }\end{array}$ \\
\hline Form a powerful coalition & $\begin{array}{l}\text { - Form change team to help you. } \\
\text { - Observe team expertise and diversity. } \\
\text { - Delegate tasks organisation-wide. }\end{array}$ \\
\hline Create a vision for change & - Make an inspirational vision \\
\hline Communicate the vision & $\begin{array}{l}\text { - Sell the vision throughout the organisation. } \\
\text { - Continuously communicate the message. }\end{array}$ \\
\hline Remove obstacles & $\begin{array}{l}\text { - Identify individuals, traditions, legislation that become } \\
\text { obstacles and setbacks. } \\
\text { - Apply resources to break obstacles and setbacks. }\end{array}$ \\
\hline Create short wins & $\begin{array}{l}\text { - Identify low-hanging fruits. } \\
\text { - Set short- to medium-term targets and goals. } \\
\text { - Provide change motivation and direction. }\end{array}$ \\
\hline Build on the change & $\begin{array}{l}\text { - Sustain and cement the change. } \\
\text { - Keep setting goals for continued improvement. }\end{array}$ \\
\hline $\begin{array}{l}\text { Cement change in } \\
\text { corporate culture }\end{array}$ & $\begin{array}{l}\text { - Make change part of the core of your organisation. } \\
\text { - Keep senior stakeholders on board. } \\
\text { - Encourage new employees to adopt the changes. } \\
\text { - Celebrate individuals who successfully adopt the change. }\end{array}$ \\
\hline
\end{tabular}

Source: Kotter \& Cohen, 2014

While Lewin's model was created with reference to change in general, Kotter's model was designed with organisational change in mind (Smith, 2018). Using the example of an ice cube Lewin (1951) shows that if one intends to change it into a cone, the first step is to unfreeze it to make it amenable to change (unfreezing), then mould the melted water into a cone (changing) and finally solidify the new shape which has been created (refreezing). The main tenets of the model are discussed briefly below.

\section{Unfreezing}

The first stage of change, according to Lewin, involves changing the status quo and preparing people in an organisation for change. In order to succeed, change leaders need to challenge existing beliefs, values, attitudes and behaviours and develop an understanding of the new ways of operating in the people. Expanding on Lewin's model (McGrath \& Bates, 2017) observe that this stage is the most important and difficult stage since it often puts people off-balance and change leaders need to get the necessary buy-in (Kotter, 2008; Kotter \& Cohen, 2014). 


\section{Changing}

Before embracing change, people need to understand how they would benefit from it. People embrace change at different rates and to varying degrees (Rogers, 2003). The "change curve" as illustrated below shows the experiences of people as they undergo change.

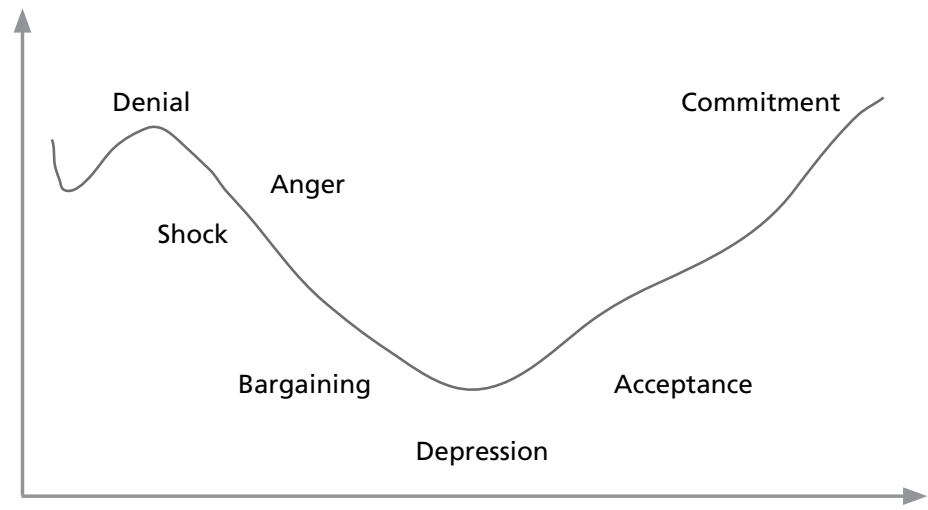

Figure 1: The change curve showing the various stages and experiences of change assimilation (Source: https://www.educational-business-articles.com)

Developed by Elisabeth Kubler-Ross (Malone, 2018), the change curve illustrates that people pass through three stages of change which encompass: shock and denial; depression and anger; and acceptance and commitment. Indeed there was a need to manage these changes within students and staff at the case university who felt the changes were drastic and unmanageable since they had not been prepared for such. People thought it was impossible to do business online - worse still to provide student support online. For students, there was an atmosphere of anxiety over the pending separation from their learning communities. There were also angry sentiments from students who felt that the institution was not being fair to migrate to online classes without providing them with cheaper data and the opportunity to get acquainted with the new modes of delivery. It was important that this change be managed for the institution to move on and manage within the new normal.

\section{Refreezing}

Refreezing takes place when people have embraced the change and adopted new ways of practice. This stage helps practitioners to internalise and institutionalise the change. Refreezing ensures that change applies to all situations in the work arena and that new ways are used continuously without reverting back to old systems. Based on these thoughts, staff and students at the case university will gradually accept new ways of learning and working as a result of the changes introduced in light of the pandemic. Use of both models as a conceptual framework will give the change initiatives the best chance of success and a form of triangulation (Smith, 2018). 


\section{Methodology}

\section{Reflective scholarship of practice in student affairs}

This article employed an experiential insight design in which the researchers describe their experiences in terms of how they experienced the impact of the Covid-19 pandemic at BUSE. Experiential insight approach is a paradigm for the study of people's experiences of a particular phenomenon (Grant, Gilmore, Carson \& Pickett, 2001). This approach allows the researcher to describe their experiences in the context of placing themselves in situations (Grant et al., 2001). In the context of this study the researchers were members of the BUSE Covid-19 Response Committee. The Committee was set up to guide the institution's response, prevention and control of the pandemic. Luescher (2018) argues that a scholarly reflection on the experiences of students and staff at a university helps in the production of knowledge that sharpens the competencies of student affairs practitioners in the craft of their practice. The impact of the Covid-19 pandemic needs to be nuanced through a reflective scholarship that critically captures their experiences at national and international levels. This was the major factor which determined our choice of a theoretical frame to guide the methodology of this research. The methodology is also grounded in Luescher's (2018) assertion that the development of scholarship of practice in student affairs entails gathering data that is comprehensive in African contexts. For the purpose of this research, data were collected through observations and documents relating to the activities of the Covid-19 Response Taskforce at the case university. This perspective clearly dovetails with our objective in this reflective article which seeks to facilitate the development and growth of knowledge that empowers student affairs practitioners in the practice of their work. Expanding on this framework, Luescher (2018, pp.67-68) identifies the following critical elements that are crucial to scholarship of practice:

1. "A scholarship of practice in student affairs deals with problems that are meaningful to practitioners and that practitioners can experientially relate to; it understands practice as action, as performance, as a deliberate, skilled way of doing things" (Luescher, 2018, p. 67).

This observation merges well with our experiential discussion and evaluation of the impact of the Covid-19 pandemic on student affairs practitioners and the application of change management theories as a response strategy.

2. "It studies practice in a scholarly manner that is intentional and part of a process of learning, which is academically rigorous and systematic, that results in trustworthy accounts, analyses and interpretations" (Luescher, 2018, p. 67).

The authors used secondary research to augment experiential insights through observations and conversational approaches through social media platforms that enabled them to capture rich and authentic feedback from respondents in order to understand the impact of the Covid-19 pandemic in their area of work. Secondary research was done through records of meetings and internal and external communications. 
3. Conversational approaches help capture sincere feedback with deeper meaning and understanding than traditional research methods that tend to make people rationalise and overly rely on recall in their responses to understanding phenomena (Reach, 2020).

\section{Research questions}

In order to put this methodological frame into context and also drawing on Morgan (2012) cited in Luescher (2018)'s template, we asked the following questions to guide this reflective study.

(i) What were the experiences of the student affairs practitioners caused by the Covid-19 pandemic?

(ii) What problems or opportunities were encountered?

(iii) How did the change process unfold and what strategies were employed to deal with the situation?

(iv) What were the outcomes?

This article was therefore developed on the grounding of this methodological template and related methods which were informed by the experiential insights of the authors. In our application of the scholarship of practice methodology, we employed some models of organisational change to reflect on the impact of the Covid-19 pandemic on our practice in student affairs at the case university. Kurt Lewin (1951)'s and John Potter (2008)'s change management models were found fit for purpose for this reflective article.

\section{Data collection methods}

Data for this study was collected through document analysis of the following documents: minutes of the student affairs board; minutes of the student affairs management committee; minutes of the Covid-19 task force, Ministry of Higher and Tertiary Education, Innovation, Science and Technology Development circulars on the Covid-19 pandemic; the student affairs strategic plan and the Dean of Students' fortnightly report to the University Senior Administrators Committee meetings. Participant observation of what took place before, during and after the outbreak of the pandemic and the experiences of the authors constituted another data-gathering technique for the study. Informal interviews with the participants in the change process yielded important information which helped shape the course of the change programme and the findings of this study.

\section{The Case University}

Bindura University of Science Education, a medium-sized university in Zimbabwe with a student population of slightly more than 7000 was chosen as the case university. Although there was nothing special about this university being chosen as the case university, the researchers felt that the account would come out clearly if conducted where all three authors worked and also that state universities in Zimbabwe resembled a more or less similar structural organisation and circumstance. The institution was born out of the 
Zimbabwe-Cuba Science Teacher Training Programme in which Zimbabwean Mathematics and Science teachers were formerly trained in the Republic of Cuba. In the year 1996, the programme was devolved to Zimbabwe and resulted in the establishment of a University College under the University of Zimbabwe, culminating in the establishment of Bindura University of Science Education in the year 2000, with a mandate to train Mathematics and Science teachers for the nation and the SADC region at large. The institution has five faculties namely: Agriculture and Environmental Science; Commerce; Science and Engineering; Science Education; and Social Sciences and Humanities (www.buse.ac.zw).

\section{Student Affairs at the case university}

The Student Affairs division at this university is headed by the Dean of Students who reports directly to the Vice-Chancellor. Reporting to the Dean of Students are various heads of sections who manage the functional areas in Student Affairs. These are Campus Life and Student Development Programmes, Student Health and Wellness, Chaplaincy and Ecumenical Services, Financial Aid, Catering Services, Counselling Services, Accommodation Services and Sports and Recreation (www.buse.ac.zw). The structural organisation of Student Affairs' functional areas at this institution does not differ much from what obtains elsewhere in Africa and the rest of the world (Leuscher, 2018; Kuk \& Banning, 2009). One would notice that the organisation of Student Affairs at the case university conforms to international best practice, hence the reflection will also compare favourably with practices elsewhere. The department's mandate is to offer a co-curriculum which would enhance the students' graduateness, citizenship skills and employability, and to offer psycho-social support to students (BUSE, Strategic Plan 2019-2023). These programmes fall under the various sections mentioned above. Like in other institutions, Student Affairs professionals at the institution under reflection had to grapple with managing the sudden change in their immense schedules as a result of the Covid-19 pandemic. This reflective article aims at providing insights into the impact of the Covid-19 pandemic on Student Affairs professionals and students at Bindura University of Science Education in Zimbabwe. It applies scholarship of practice as its methodology of contextualising the impact of the coronavirus on student affairs practitioners (Luescher et al., 2013).

\section{Conceptualising the Change Programme}

The argument of this article is based on the principle of disruptive change and argues that student affairs practitioners and students were forced to deal with sudden change which abruptly redirected the course and nature of their work. Following communication from the parent ministry, the Ministry of Higher and Tertiary Education, Innovation, Science and Technology Development to all state universities to institute measures to combat the spread of the Covid-19 virus, a University Senior Administrators meeting was held at the case university via the ZOOM platform to map the way forward. Resolutions of the meeting were that each department was to come up with plans on how they were going to migrate from a physical to a virtual campus and embrace the new normal since the physical space 
of the university was going to be closed indefinitely. The Vice-Chancellor who chaired the meeting emphasised that the university had not closed; hence learning and student support programmes had to continue through online delivery modes. The Dean of Students who was also a member of the Committee was assigned the task of driving change in his department, Student Affairs.

\section{Implementing the Change Programme}

\section{Stage One: Changing the status quo}

Armed with the Vice-Chancellor's mandate to drive change in his department and ensure that all staff in the department embrace the new normal, the Dean of Students embarked on an ambitious project code named 'Campus Wise Culture' and borrowed from Kurt Lewin and John Kotter's change management models which state that, in order to successfully implement change, one has to change the status quo first (Kotter \& Cohen, 2014). This initial stage dovetailed with Lewin's unfreezing stage and Kotter's first four principles or stages namely: create urgency; form a powerful coalition; create a vision for change; and remove obstacles. In this regard, the Dean of Students started by pointing out where the department was and where it intended to be. In order to create understanding on the direction and form of change, the Dean of Students created a WhatsApp platform for all practitioners working in student affairs to talk about what was happening and the way forward. This platform helped the Dean of Students to identify innovators and early adopters whom he appointed to spearhead the change process. This is supported by Kotter and Cohen (2014) who advocate for the creation of a forum to generate a discussion on what obtains on the ground and to map the way forward. The change agents appointed, campaigned for the required change, and provided feedback to the change leaders via social media. A change leaders' team was formed using representatives nominated by sections and student clubs and societies and were representative of the whole student affairs spectrum including gender, age, educational level, faculties, clubs, societies, sport codes and the differentially abled groups. Other members with expertise such as student health personnel and the Senior Chaplain were appointed to the team. The Dean of Students was required to report progress to the University Executive meetings which were held fortnightly. The change effort was code-named "Campus Culture Wise" to make it catchy and compelling. Sub-themes were developed which made for easier understanding throughout the department and also brought relevance to each section and level of staff. Members were asked to forward their training needs so that they could be incorporated into the training programmes being developed. The change message contained information on being "Campus Culture Wise", which educated all members to maintain social distancing, cough into the elbow, wear face masks correctly all the time, wash hands regularly, sanitise hands, clean surfaces regularly and, most importantly, embrace technology. This messages were communicated regularly by the Department of Public Relations and Protocol through staff's and students' email, social media platforms and public notice boards in various official languages. 


\section{Stage Two: The change process}

After the Dean of Students and his team were satisfied that members had been adequately prepared for change, they embarked on the process of incremental change in which they introduced the desired change in stages. During this stage of changing, data were collected on the impact of the Covid-19 pandemic on practitioners working in Student Affairs. This change process dovetailed with Lewin (1951)'s changing stage and Kotter (1988)'s stages 5 to 7 namely: remove obstacles; create short-term wins and build on the change. At this stage, members were required to embrace the new normal without fail. The proper wearing of masks, social distancing, regular washing of hands, working from home arrangements, virtual meetings, virtual student support and student development programmes and online student orientation programmes were introduced amongst others. Positive and negative reinforcement measures were taken according to Bandura (2001) for those who either complied or failed to adhere to the requirements. Teams were formed for monitoring and peer support in order to escalate the adoption of the new normal. The changing stage was the most difficult as members found it difficult to let go long-held habits and ways of doing things. It was also interesting to note that members of staff did not all change at once, since some quickly embraced the change while others took time and pain to adjust accordingly as observed by Rogers (2003) that in any change effort, there are innovators, early adopters, early majority, late majority and laggards. It was noted that students and younger workers were more amenable to change than older and more experienced practitioners since they were more computer illiterate and less adventurous in using modern gadgets and software applications.

\section{Stage Three: Refreezing/cementing change in corporate culture}

Once change had taken place, the Dean of Students and his team introduced measures to ensure that student affairs practitioners and students did not revert back to their old ways of doing things. These measures included the scheduling of virtual meetings on a weekly basis; requiring that each section designs and presents a virtual programme for students; and that registers of students who attend these virtual webinars be maintained as a way of enforcing attendance by students; going paperless and other strategies.

\section{Reflections on the Impact of the Covid-19 Pandemic}

Data gathered through the analysis of key documents, participant observation, and informal interviews with the practitioners and the authors' experiential insights were analysed using thematic analysis which, according to Braun and Clarke (2006), is generated through a close analysis of the findings in order to see existing patterns in the data. The following themes were identified from the data namely: modes of delivery; staff meetings; student support services; staff well-being; allocation and utilisation of resources; and lack of knowledge and information. The impact of the Covid-19 pandemic is brought out through a comparison between the students' and staff's experiences during the pre-Covid-19 and post-Covid-19 era. 


\section{Modes of delivery}

Findings showed that, during the pre-Covid-19 era Student Affairs practitioners and students had been used to a physical campus, classroom-based student development and pyscho-social support, and on-campus student orientation programmes. The Covid-19 era required them to utilise virtual modes of delivery where student development, psychosocial support and orientation programmes would be delivered online. This impacted them negatively as they lacked the skills, knowledge, experience, and confidence in managing virtual campuses, including delivering through online modes of learning, leading to fear, anxiety, anger, depression and later on acceptance. This culminated in the initial resistance to change as practitioners and students felt threatened by the change.

\section{Staff meetings}

During the pre-Covid-19 era, staff and students had been used to venue-based departmental and other meetings. The new normal demanded a new set of skills and tools. Most practitioners were caught off-guard since they did not have the requisite computer literacy levels coupled with a lack of either laptops or smartphones which were compatible with virtual meeting applications. Students were better placed in this regard as they were more computer literate than staff and possessed the required gadgets. Both students and staff required training in the scheduling and hosting of meetings on virtual platforms and how to join scheduled meetings.

\section{Offering student support services}

News of high deaths rates in Europe and the rest of the world due to Covid-19 related complications and the proliferation of misleading information on social media instilled fear, anxiety and restlessness amongst students and staff. This created an increased demand for psycho-social and other forms of support on the part of staff and students. The lack of adequate and accurate information meant that the staff could not adequately support students and give them guidance. This state of affairs rendered the Student Affairs practitioners useless and helpless in addressing students' concerns on one hand. On the other hand, staff and students who had been used to classroom- and office-based programmes and services were called upon to offer them virtually. This threatened the confidentiality aspect of counselling, where the student counsellors were wary of the privacy of the student's location. One counsellor remarked: "How do I know if I am not counselling the whole clan out there? There are possibilities that other people could be listening in the background. I am just not comfortable with offering student counselling online."

\section{Staff well-being}

The pandemic had its greatest impact on the well-being of staff as they were forced to separate from their work colleagues during trying times which required massive collegial support and encouragement. New sets of job skills and knowledge were required, strange 
working from home arrangements introduced, changing nature of jobs and the separation from students created a void in staff, leading to poor mental health and well-being. The de-skilling nature of Covid-19 imposed change that brought about a sense of job insecurity and some anxious moments for staff. This led to connectivity challenges if the practitioner had no internet connection at home. Practitioners in the sports and recreation section lost income due to the blanket ban on all sporting activities in the country as they were paid based on hours worked with students.

\section{Allocation and utilisation of resources}

The university's efforts to fight the pandemic meant that more resources were to be channelled towards that cause, leaving the budgeted-for student programmes without allocations. This had a negative impact on Student Affairs practitioners and even students in that they had to cancel some scheduled events and student development programmes. Relations between practitioners deteriorated as staff jostled for the few availed resources in the department, leading to low staff morale and work disengagement.

\section{What Were the Major Outcomes?}

The major outcomes were that continuous training and development enabled employees to change their attitudes, beliefs, behaviours and ways of doing work, leading to the successful adoption of change by the majority of practitioners as observed by Biech (2016), Vukotich (2011), Emerson and Stewart (2011), and Raina (2019) who all observed that training and development was a catalyst in change adoption and acceptance. Training and development provided by the Information and Communication Department was significant in that it empowered employees to embrace technology and accept change. Information given to employees through the social media eliminated employees' fears, anxiety, misconceptions, shock and depression (Lardi \& Fuchs, 2013). These platforms enabled those employees who supported change to encourage others to embrace the change and provide feedback to change leaders. Employee support systems enhanced the quick adoption of change as students and practitioners' perceptions, concerns and fears were allayed, thereby reducing negative emotions amongst them. Professional incentives were also used as a catalyst for the quick adoption of organisational change as propounded by Worley and Lawler (2006) and Wruck (2000). Critical frontline personnel were incentivised through a Covid-19 allowance. These incentives worked as a catalyst for change adoption, and these practitioners in the department went the extra mile and sacrificed in the midst of risks.

\section{Conclusion and Recommendations}

This reflective article outlined the experiences of practitioners working in Student Affairs pre- and post the Covid-19 era. These findings showed that practitioners went through a rigorous change programme which helped them embrace the new normal. The study also showed that practitioners went through a process of loss of skills, isolation and separation from their work communities, grappled with new modes of presentation, loss of income for 
some and constrained resource availability. The findings also showed that interventions such as training and development, employee support, use of social media and targeted incentives helped staff cope with the demands of the new normal induced by the Covid-19 pandemic. This article concludes that the Covid-19 pandemic had a generally negative impact on students and practitioners working in Student Affairs at the case university.

Based on the findings of this article, we therefore recommend that:

- Student Affairs practitioners be adequately resourced and capacitated in order to be able to effectively work from home.

- Student Affairs practitioners be developed in the use of online delivery modes in the same way academics are developed.

- University leaders are re-oriented to the important role played by Student Affairs in the psycho-social and cognitive development of students, so that they accord Student Affairs its rightful status.

- Lifelong learning opportunities for Student Affairs practitioners such as paid study leave and contact leave be availed.

\section{Research Ethics}

The case university where data were collected granted permission for this study to be conducted. All participants gave their informed consent and any identifying information such as names was kept confidential and anonymous.

\section{Conflict of Interest and Funding}

The authors declare that they have no financial or non-financial interests emanating from this study. No external funding was provided in order to carry out the study.

\section{References}

Bandura, A. (2001). Social cognitive theory: An agentic perspective. Annual Review of Psychology, 52(1), 1-26. https://doi.org/10.1146/annurev.psych.52.1.1

Banhegyi, S. \& Banhegyi, E. (2007, April). The art and science of change: A resource for management and leadership. Version 5.8. Steve Banhegyi and Associates.

Biech, E. (2016). Change management training:Association for training development. https://books.google.co.zw

Braun, V. \& Clarke, V. (2006). Using Thematic Analysis in Psychology. Qualitative Research in Psychology, 3, 77-101. https://doi.org/10.1191/1478088706qp063oa

BUSE (Bindura University of Science Education). Strategic Plan 2019-2023. http://www.buse.ac.zw [Accessed 27 July 2020].

Emerson,T. \& Stewart, M. (2011). The learning and development book: Change the way you think about learning and development.ASDT. https://www.td.org/books

Grant, K., Gilmore, A., Carson, D. \& Pickett, B. (2001). “Experiential” research methodology: An integrated academic-practitioner "team” approach. Qualitative Market Research: An Introductional Journal, 4(2), 66-74. https://doi.org/10.1108/13522750110388563

Kotter,J.P. (2008). A sense of urgency. Harvard Business Press.

Kotter, J.P. \& Cohen, D. (2014). Change leadership: The Kotter collection (5 Books). Harvard Business Review Press. 
Kuk, L. \& Banning, J.H. (2009). Designing student affairs organizational structures: Perceptions of senior student affairs officers. NASPA Journal, 46(1), 94-117. https://doi.org/10.2202/1949-6605.5007

Lardi, K. \& Fuchs, R. (2013). Social media strategy: A step by step guide to building your social media business. Vdf Hochschulverlag AG.

Lewin, K. (1951). Field theory in social science. Harper \& Row.

Luescher, T.M. (2018). Quality enhancement in student affairs and social justice: A reflective case study from South Africa. Journal of Student Affairs in Africa, 6(2), 65-83. https://doi.org/10.24085/jsaa. v6i2.3310

Luescher, T.M., Moja, T. \& Schreiber, B. (2013). Towards professionalization of student affairs in Africa. Journal of Student Affairs in Africa, 1(1\&2), vii-xiii.

Malone, E.D. (2018). The Kubler-Ross change curve and the flipped classroom: Moving students past the pit of despair. Education in the Health Professions, 1(2), 36-40. https://doi.org/10.4103/EHP. EHP_26_18

McGrath, J. \& Bates, B. (2017). The little book of big management theories and how to use them. Pearson Education Limited.

Morgan, M. (2012). Improving the student experience: A practical guide for universities and colleges. Routledge. https://doi.org/10.4324/9780203817513

Raina, R. (2019). Change management and organisational development. Sage.

Reach 3 Insights (2020). Experiential insights powered by conversation. https://www.reach3insights.com/

Rogers, E.M. (2003). Diffusion of innovations (5th ed). Free Press.

Smith, C. (2018). Battle of the change theories: Lewin Change Management vs. Kotter 8 Step Process. https://change.walkme.com/lewin-change-management-model/

Vukotich, G. (2011). 10 Steps to successful change management. ASTD. http://www.books.google.co.zw

Worley, C.G. \& Lawler, E. (2006). Winning support for organization change: designing employee reward systems that keep working. IVEY Business Journal. http://ivey.businessjournal.com/publications

Wruck, K.H. (2000). Compensation incentives and organisational change: Ideas and evidence from theory and practice. Dice Working Paper No 2000-3. https://doi.org/10.2139/ssrn.203268

\section{How to cite:}

Mutambisi, S., Murasi, D.D. \& Mazodze, C. (2021).The Impact of the Covid-19 Pandemic on Student Affairs Practitioners: A Reflective Case Study from Bindura University of Science Education in Zimbabwe. Journal of Student Affairs in Africa, 9(1), 183-195. DOI: 10.24085/ jsaa.v9i1.1437 


\title{
REFLECTIVE PRACTICE
}

\section{From Didactics to Datafication: A Critical Reflection on Virtual Learning Environments and the Production of Space}

Taryn Bernard ${ }^{\mathrm{i}}$

\begin{abstract}
When writing about transformation in higher education (HE) in South Africa, it is quite popular to mention the fall of apartheid, and perhaps also 1994, as a starting point for significant change. I, myself, have made this mistake (see Bernard, 2015). However, the recent \#FeesMustFall protests highlighted that many approaches to transformation have been superficial at best, and extremely problematic at worst (Luckett \& Naicker, 2019; Luckett, 2019). This is because they have done little to acknowledge the legacies that colonial modes of thinking have had, and continue to have, on the everyday lived experiences of students in spaces that still feel alienating to them. In April 2020, when the doors of South African universities closed to all, and during a swift and mass migration away from university campuses to Virtual Learning Environments (VLEs), I was presented with the opportunity to critically reflect on the impact that increased use of VLEs can have on the transformation agenda in the HE sector. My approach takes up Tumubweinee and Luescher's $(2019$, p. 2) argument that many initiatives aimed at transformation in HE have failed, because they do not pay sufficient attention to the where of transformation. Thus, like Tumubweinee and Luescher, I locate my reflection on VLEs in the postmodern, sociopolitical understandings of 'space' evident in the work of Lefebvre (1991), but more specifically his notions of conceived and abstract space. In doing so, issues of identity and coloniality are brought to the fore. My approach is critical in that it "implies possibilities, and possibilities as yet unfulfilled" (Lefebvre, 2002, pp.18-19).
\end{abstract}

\section{Keywords}

datafication; higher education; postcolonialism; space; Virtual Learning Environments

\section{Introduction: Extended Degree Programmes as Peripheral, Colonial Spaces}

I am a white, female academic who has worked in an Extended Curriculum Programme (ECP) for a little over a decade. My reflections here relate, in part, to the work I do with students on this programme, students who, in line with government policies, are not only identified according to race and socio-economic categories, but who are also frequently described in contrast to "the mainstream" (i.e. "the norm") and through deficit discourses and in deficit terms such as "disadvantaged", "underprepared", "needy" or "in need of

i Dr Taryn Bernard is a Senior Lecturer and is affiliated to the Department of General Linguistics, Faculty of Arts and Social Sciences, Stellenbosch University, South Africa. ORCid: 0000-0001-5503-6260.

Email: tbernard@sun.ac.za 
support". Since my reflections also relate to VLEs and eLearning, it is also important to mention here that, given the selection criteria for many ECP programmes across the country (which include attention to socio-economic status factors), it is likely that many students on ECPs would typically not be considered digital natives, and would have experienced the data - and digital - divide before and during the pandemic. I return to this point in the following section.

ECPs, which exist in some form in 24 universities across South Africa, are considered to be a type of intervention that aims to increase access and success rates to the category of student outlined above. This is often done by segregating these students in different ways, and extending the time of enrolment, typically by an additional academic year, in order to include additional support modules. These support modules aim to develop numeracy, literacy and other skills in order to make the discourses of the disciplines more explicit thus to grant 'epistemological access' to disciplinary knowledge. However, in a powerful contribution towards understanding ECPs and the impact they have on the experiences of students, Luckett (2019) offered a postcolonial critique of these programmes. This means that, rather than adopting the normalised developmental and modernist paradigm which portray ECPs "as a liberal anti-apartheid project motivated by a concern for equity and social justice" Luckett (2019, p. 41) reframes them "as a modernising project within a developmentalist paradigm". Through this lens, ECPs can be likened to the type of education endeavour offered by the colonial powers which sought to civilise "the natives" in order to make them fit for modernity (Luckett, 2019, p. 41). In offering this critique, Luckett urges us to question whether separate remedial programmes such as ECPs are tenable, given that, in their current form, students "speak from subject positions that still feel colonized" (Luckett, 2019, p. 38) when it is "particularly urgent that black students feel 'at home' in their universities, they must have their sense of agency restored and come to recognise themselves as sources of meaning-making” (Luckett, 2019, p. 54).

The motif of 'home', the metaphor of 'the university as home' and it's relation to 'space', the embodiment of space, and the impact that 'space' has on the identities of students at South African universities is an important topic, one that has been taken up by many scholars in various forms (see Bangeni \& Kapp, 2005). Tumubweinee and Luescher (2019), for example, analysed the ways in which 'space' is discursively constructed in South African policy documents, arguing that many initiatives aimed at transformation in HE have failed because they do not pay sufficient attention to the where of transformation. During their analysis the authors found that 'space' "is almost consistently conceived only as an object in transformation" rather than "a socio-political actor in transformation" (Tumubweinee \& Luescher, 2019, p. 10). This is an important distinction because:

We interact in this space and our interactions are limited or encouraged by this space. The way space is perceived, conceived and eventually experienced has a profound impact on students' experience of higher education.

(Tumubweinee \& Luescher, 2019, p. 10) 
Such an agentive understanding of space developed within a postmodern paradigm and with thinkers such as Lefebvre who wanted to understand the role of representation and power in the production of space. Tumubweinee and Luescher (2019)'s emphasis on space as perceived, conceived and experienced or lived in the quote above is a triad at the heart of Lefebvre's understanding of space, who was primarily concerned with how space is produced, the way in which space is abstractly conceived and the phenomenological spaces of lived experience (Wilson, 2013, p. 367). It is also important to note that Lefebvre's understanding of space developed as a reaction against capitalism and the technological tools of capitalism. In fact, Lefebvre argued that capitalism is not just about the production of things in space but, perhaps even more importantly, capitalism is about the production of space (Prey, 2015, p. 1). The relevance of this understanding of space to the internet (as cyberspace) is discussed below.

\section{E-Learning, Learning Analytics, VLEs and Datafication}

Since the development and increased use of the internet, the realm of cyberspace has not been excluded from the type of postmodern understandings of 'space' highlighted above (see, for example, Cohen, 2007). Most postmodern thinkers view cyberspace as an extension of everyday social practice rather than separate from it, since it is also experienced spatially, mediated by embodied human cognition and mediated through language and metaphors that reflect this embodied experience (i.e. "homepage", "website", "back", "forward"). In this regard the emergence of the internet can be conceptualised as the contemporary, "virtual", manifestation of the "explosion of spaces" which Lefebvre saw as capitalism's most transformative feature (Prey, 2015, p. 2).

As with many social institutions across the globe, corporate or otherwise, HE institutions have expanded into cyberspace for a variety of reasons - as a natural social progression in a digital society, for one, but also as an effort to participate in the Fourth Industrial Revolution, to create "smart campuses" and facilitate in the formation of "smart students" (Prinsloo, 2020). As a result, many social practices located in cyberspace are now part of university life. For example, electronic learning or "eLearning", which refers to the delivery of education and training through digital resources such as VLEs, as well as the practice of tracking students and/or collecting, measuring and analysing electronic educational data (known as "Learning analytics [LA]") for the purposes of understanding and potentially optimising eLearning. Today, Modular Object-Oriented Dynamic Learning Environment (Moodle) is "the world's most popular" VLE (https://moodle.org/). There are 168000 Moodle sites that are currently active, in 243 countries, with South Africa accounting for 1692 of those sites - many belonging to HE institutions (https://stats. moodle.org/sites/index.php?country=ZA). There is no doubt that VLEs like Moodle are transforming how education is being distributed and consumed.

Much of the literature on Moodle focuses on its value a VLE and an LA tool. As a VLE, Moodle has been conceptualised according to a social constructivist view of education, and "facilitates a mix of learning approaches, integrating readings, lecture videos, online reflections, quizzes and group discussion forums, utilising both asynchronous and real- 
time interaction" (Spiegel et al., 2017, pp. 277-278). When considering its value as a VLE, Mpungose (2020, p. 102) claims that Moodle facilitates the decolonisation of the university curriculum because of functions that enable facilitators to "encourage the changing of mind-set and sharing of lived experiences during the teaching and learning process". As an LA tool, Moodle is applauded because it gathers a variety of data: personal data, usage data (time spent, number of downloads, login frequency, log reports and number of views), learning data (participation for a particular activity, for example, grades, comments and feedback), allowing facilitators, researchers and other decision-makers to seek out the variables that contribute most to student learning in order to make predictions and improve performance (Mwalumbwe \& Mtebe, 2017). This literature mostly resonates with the grander utopian, and "mythological" (Boyd \& Crawford, 2012, p. 667) story that digital data, especially mass amounts of divergent digital data produced at an incredible speed (i.e. "Big Data") offers the potential of new knowledge, insights and higher forms of intelligence that can be used to address various societal ills. This utopian story is also rooted in the idea that quantitative data is objective and the mathematical and statistical models used to analyse this data are more efficient, reliable, accurate and effective (Boyd \& Crawford, 2012, pp. 663-664), an ideology which van Dijck (2014, p. 198) refers to as "dataism". It is also proclaimed that digital data, particularly Big Data, leads to greater transparency by linking disparate sources of information, and that it can democratise decision-making by rendering "social processes and social relations more knowable and more controllable" (Selwyn, 2015, p. 66). One recent example is offered by Renick (2020), who reports on a project at Georgia State University to address “achievement gaps" (Renick, 2020, p. 119) at the University, where "graduation rates were 22\% for Latinos, 29\% for African Americans, and 18\% for African American males. Low-income students completed degrees at only a $24 \%$ rate". The author presents a utopian narrative of the "high tech" processes used to track, monitor and contact students frequently ("high touch"): "Today, thanks [emphasis added] to a campus-wide commitment to student success and more than a dozen databased programmes implemented over the past several years, Georgia State's achievement gaps are gone" (Renick, 2020, p. 119).

However, not all scholars are as optimistic as Renick (2020) about the impact of technology, digital data and student tracking on the student experience. Boyd and Crawford (2012, p. 667) emphasise that, far from being objective, "working with Big Data is still a subjective, interpretative act". In focusing on technology and data, Renick (2020) seems to have overlooked important criticisms that have been directed towards the conceptual metaphor of "achievement gaps" and its links to a deficit discourse of individuals and communities - the same deficit discourse used to describe students on ECPs. This discourse is problematic because it masks the social and institutional histories and prejudices that led to and sustains these "gaps". The research thus perpetuates the idea that "closing an 'achievement gap', and equalising or levelling the school system, will lead to greater equality across society (Macgilchrist, 2019, p. 80). This means that, while Georgia State University could be commended for moving away from highly selective admissions processes to improve retention rates, critical questions need to be asked about their "commitment to the systematic use of data" that has been segmented according to "racial, ethnic, and economic 
groups". Questions should be asked about whether universities should "become far more proactive in tracking students daily [emphasis added]" to identify "when they go off path" (Renick, 2020, pp. 119-120). Which implies, of course, that there is only one path to follow.

VLEs like Moodle have not been analysed in terms of their ability to produce space, and the impact that this process can have on the transformation agenda within HE institutions across the globe. This is an important focus area because, to return to Tumubweinee and Luescher's (2019, p.10) quote "the way space is perceived, conceived and eventually experienced has a profound impact on students' experience of higher education". To considerVLEs as producers of space is to consider how stakeholders involved in producing VLE platforms abstractly conceive of space, why they do so, and how these conceived spaces have, or could have, an impact on lived experiences (Wilson, 2013, p. 367). In keeping in line with the ideological underpinnings of Lefebvre's work, to considerVLEs as a producer of space is to also consider their role within material or social space, which was in Lefebvre's time - and is increasingly so - dominated by the capitalist logic of accumulation. Zuboff (2015, p. 77) defines this logic as:

... the taken-for-granted context of any business model. It defines objectives, successes, failures and problems. It determines what is measured, what is passed over; how resources and people are allocated and organized; who is valued in what roles; what activities are undertaken - and to what purpose. The logic of accumulation produces its own social relations and with that its conceptions and use of authority and power.

In contrast to social space, Lefebvre (1991, p. 38) conceptualised conceived space as "the space of scientists, planners, urbanists, technocratic subdividers and social engineers". In the digital age, conceived space is the space of a select group of new specialists: coders, programmers and engineers, data brokers, and in the context of higher education, "online platform/programme providers, as well as individual, institutional and organizational researchers" (Prinsloo, 2020, p. 368). Conceived space for Lefebvre was also abstract space, since it is "the location and source of abstractions". Abstract space is a result of capitalist social relations, of technocratic rationality, where diversity and richness of social life is reduced to homogeneity, to divisibility and interchangeability through the emphasis on quantification and Cartesian notions of time and space as "homogenous, continuous and emptied of all natural and social content” (Wilson, 2013, p. 368).

Lefebvre's understandings of conceived and abstract space offers interesting insights into VLEs as tools that are contributing to the datafication of HE, to a process "by which objects, behaviors, actions, motions, communications and spaces are converted into machine-readable data flows" (Smith, 2016, p. 114). During this process, individuals are turned into data representations, which have also been termed "dividuals" (Deleuze, 1995) or "data doubles", representations which are quite different from the "fleshy bodies" from which the representations developed (Lupton, 2014, p. 82) but are nevertheless analysed, classified, evaluated ("surveilled") and targeted for different reasons. These mechanisms of extraction, analysis, and ultimately also control, are often illegible to, or hidden from, the sources of the data, thus effectively exiling people from their own behaviour (Zuboff, 2015, p. 75). 
Thus, conceived and abstract space is also the realm of alienation, it is the realm of "human action stripped of their living substance' (Trebitsch in Wilson, 2013, p. 366). In understanding abstract space as the spatial dimension of representation, of quantification and alienation, it is easy to understand why scholars have understood Big Data and datafication as "data colonialism" (Beer 2019, Prinsloo 2020), as an "extension of a global process of extraction that started under colonialism and continues through industrial capitalism" (Couldry and Mejias in Prinsloo 2020, p. 367). Only now, instead of raw material and labour, what is being appropriated is a new type of raw material produced by technological tools through our day-to-day social practices, often in ways that is beyond the control of the person to whom the data relates and in ways that remain unknown to them (Couldry and Mejias in Prinsloo 2020, p. 367). The point is that the underlying algorithms, the ways in which data are produced and used and the role of software companies and educational technology providers, amongst other things, are hardly understood, and very little is understood about the ethical implications of these tools (Boyd \& Crawford, 2012, p. 673, Jarke \& Breiter, 2019, p. 1, Selwyn, 2015, pp. 566-567, Jones \& McCoy, 2019, pp. 58-59).

\section{Conclusion}

The \#FeesMustFall protests and associated movements urged us to recognise that many approaches to transformation, including the formation of ECPs, have done little to acknowledge the legacies that colonial modes of thinking have had, and continue to have, on the everyday lived experiences of students in spaces that still feel alienating to them. Similarly, Luckett's (2019) postcolonial critique of ECPs highlights that, despite best efforts aimed at diversity and inclusivity, these programmes not only segregate students into separate, remedial spaces, but result in the discursive construction of ECP students in a way that is in opposition to "the norm" (or "the mainstream") and through deficit discourses and in deficit terms such as "disadvantaged" or "underprepared". When viewed through a postcolonial lens, ECPs can also be likened to the type of education endeavour offered by the colonial powers who sought to civilise "the natives" in order to make them fit for modernity (Luckett, 2019, p. 41).

When the Covid pandemic prompted a swift and mass migration to VLEs such a Moodle, I was presented with the opportunity to critically reflect on the impact that increased use ofVLEs could have on the decolonisation agenda in HE and on ECP students in particular. I located my reflection within postmodern understandings of space (Lefebvre, 1991) and did not contemplate the problems that arise when students do not have access to technology or the internet but rather focused on the trail of data that each student leaves behind when using VLEs, whether they know that this data is being collected, whether they know what data is being collected, how it is being collected and analysed, by whom, and to what ends. Outside of HE, many critical theorists have urged us to consider similar processes as a form of surveillance by those with agency and power, as "Big Brother" or "Big Other" (Zuboff, 2015, p. 77), an Orwellian nightmare. Comparisons have also been made to Franz Kafka's The Trial in which the protagonist, Josef K., wakes up to a world of "bureaucratic indifference, arbitrary errors, and dehumanisation, a world where people feel powerless and vulnerable, without any form of participation in the collection and use of 
their information" (Solove 2001, p. 1398). One can imagine a similar scenario in HE if the nature of the data, the manner in which it is collected, collated, analysed and used remains illegible to, or hidden from students, the sources of the data, at the same time at which the data impacts on their lived experience in significant ways.

Furthermore, proponents of LA in HE usually view the collection and analysis of student data in optimistic terms, as a mechanism to enhance learning. However, these discussions usually take place outside of an overt acknowledgement of the "neoliberalisation" of the university, and the way in which this space is increasingly being dominated by the logic of profit and accumulation - a logic with its own power dynamic that determines how people are organised and how much they are valued, a logic not dissimilar to colonialist logic (Zuboff, 2015; Beer, 2019; Bernard, 2020; Prinsloo 2020). Thus, when considering VLEs, such considerations should not take place outside of the ideologies that shape the datafication of HE, as they could ultimately thwart our efforts to transform HE spaces into spaces where a diverse group of students can participate equally, and where all students feel at ease and at home.

\section{References}

Bangeni, B. \& Kapp, R. (2005). Identities in transition: Shifting conceptions of home among "black" South African university students. African Studies Review, 48(3), 1-19. https://doi.org/10.1353/arw. 2006.0004

Beer, D. (2019). The data gaze. Sage.

Bernard, T. (2020). Corporate social responsibility in postcolonial contexts: A critical analysis of the representational features of South African corporate social responsibility reports. Critical discourse studies. Advance online publication. https://doi.org/10.1080/17405904.2020.1798797

Bernard, T. (2015). The discursive construction of foundation programmes in South African media texts. South African Journal of Higher Education, 29(1), 238-261.

Boyd, D. \& Crawford, K. (2012). Critical questions for big data. Information, Communication \& Society, 15(5), 662-697. https://doi.org/10.1080/1369118X.2012.678878

Cohen, J.E. (2007). Cyberspace as/and space. Columbian Law Review, 107, 210-256.

Deleuze, G. (1995). Postscript on control societies. In G. Delueze, Negotiations 1972-1990 (pp. 177-182). Columbia University Press.

Jarke, J. \& Breiter, A. (2019). Editorial: The datafication of education. Learning, Media and Technology, 44(1), 1-6. https://doi.org/10.1080/17439884.2019.1573833

Jones, K.M.L. \& McCoy, C. (2019). Reconsidering data in learning analytics: opportunities for critical research using a documentation studies framework. Learning, Media and Technology, 44(1), 52-63. https://doi.org/10.1080/17439884.2018.1556216

Lefebvre, H. (1991). The production of space. Blackwell. (Original work published 1974.)

Lefebvre, H. (2002). Critique of everyday life (Vol. 2). Verso. (Original work published 1961.)

Luckett, K. (2019). A critical self-reflection on theorising education development as 'epistemological access' to 'powerful knowledge'. Alternation, 26(2), 36-61. https://doi.org/10.29086/2519-5476/ 2019/v26n2a3

Luckett, K. \& Naicker,V. (2019). Responding to misrecognition from a (post)/colonial university. Critical Studies in Education, 60(2), 187-204. https://doi.org/10.1080/17508487.2016.1234495 
Lupton, D. (2014). Self-tracking cultures: Towards a sociology of personal informatics. In Proceedings of the 26th Australian Computer-Human Interaction Conference on Designing Futures: The Future of Design (pp. 77-86). ACM. https://doi.org/10.1145/2686612.2686623

Macgilchrist, F. (2019). Cruel optimism in Edtech: When the digital data practices of educational technology providers inadvertently hinder educational equity. Learning, Media and Technology, 44(1), 77-86. https://doi.org/10.1080/17439884.2018.1556217

Mpungose, C.B. (2020). Is Moodle a platform to decolonise the university curriculum? Lecturers' reflections. Africa Education Review, 17(1), 100-115. https://doi.org/10.1080/18146627.2018.1479645

Mwalumbwe, I. \& Mtebe, J.S. (2017). Using learning analytics to predict students' performance in Moodle Learning Management System: A case of Mbeya University of Science and Technology. The Electronic Journal of Information Systems in Developing Countries, 79(1), 1-13. https://doi.org/10.10 02/j.1681-4835.2017.tb00577.x

Prey, R. (2015). Henri Lefebvre and the production of music streaming spaces. Sociologica, 9(3), 1-22. https://doi.org/10.2383/82481

Prinsloo, P. (2020). Data frontiers and frontiers of power in (higher) education: A view of/from the Global South, Teaching in Higher Education, 25(4), 366-383. https://doi.org/10.1080/13562517.2020.1723537

Renick,T.M. (2020). Eliminating achievement gaps using data and personalized outreach. In R. Ludeman \& B. Schreiber (Eds.), Student Affairs and Services in Higher Education: Global Foundations, Issues, and Best Practices (3rd ed.) (pp.119-121). Berlin: Deutsches Studentenwerk.

Selwyn, N. (2015). Data entry: towards the critical study of digital data and education. Learning, Media and Technology, 40(1), 64-82. https://doi.org/10.1080/17439884.2014.921628

Smith, G.J.D. (2016). Surveillance, data and embodiment: On the work of being watched. Body \& Society, 22(2), 108-139. https://doi.org/10.1177/1357034X15623622

Solove, D. (2001). Privacy and power: Computer databases and metaphors for information privacy. Stanford Law Review, 53(6), 1393-1462. https://doi.org/10.2307/1229546

Spiegel, S., Gray, H., Bompani, B., Bardosh, K. \& Smith, J. (2017). Decolonising online development studies? Emancipatory aspirations and critical reflections - a case study. Third World Quarterly, 38(2), 270-290. https://doi.org/10.1080/01436597.2016.1256767

Tumubweinee, P. \& Luescher, T.M. (2019). Inserting space into the transformation of higher education. Journal of Student Affairs in Africa, 7(1), 1-13. https://doi.org/10.24085/jsaa.v7i1.3689

Van Dijck, J. 2014. Datafication, dataism and dataveillance: Big Data between scientific paradigm and ideology. Surveillance \& Society, 12(2), 197-208. https://doi.org/10.24908/ss.v12i2.4776

Wilson, J. 2013. "The devastating conquest of the lived by the conceived": The concept of abstract space in the work of Henri Lefebvre. Space and Culture, 16(3), 364-380. https://doi.org/10.1177/ 1206331213487064

Zuboff, S. (2015). Big other: Surveillance capitalism and the prospects of an information civilization. Journal of Information Technology, 30, 75-89. https://doi.org/10.1057/jit.2015.5

\section{How to cite:}

Bernard, T. (2021). From Didactics to Datafication: A Critical Reflection on Virtual Learning Environments and the Production of Space. Journal of Student Affairs in Africa, 9(1), 197-204. DOI: $10.24085 /$ jsaa.v9i1.1438 
REFLECTIVE PRACTICE

\title{
Inclusion in Times of Covid-19: The Case of International Students in South Africa
}

\author{
Samia Chasi ${ }^{i} \&$ Orla Quinlan ${ }^{\text {ii }}$
}

\section{Abstract}

The Covid-19 pandemic has caused major disruptions to the teaching, learning and research functions of universities around the globe. It has also impacted their internationalisation efforts in significant ways.

From the perspective of South Africa's public higher education sector, this article reflects on how international students at the country's universities have been affected by national and institutional responses to Covid-19. It highlights the specific challenges and constraints international students faced in light of Covid-19 related restrictions such as travel bans, university closures and the national lockdown. In doing so, several aspects of the international student experience are explored, specifically regarding travelling home, communication, accommodation and immigration. The article also addresses the issue of remote learning and academic continuity, arguing that international students, especially those who were outside the borders of South Africa, are at risk of being left behind. It advocates for the inclusion of international students in national and institutional considerations and plans for the successful completion of the 2020 academic year.

The article recognises that, in the absence of coordinated national responses, institutional approaches to the treatment of international students have differed from one university to another. Such differences can be linked to the differentiated nature of the South African higher education sector, where the capacity of institutions to deal with Covid-19 related challenges and to respond comprehensively to the needs of different groups of international students varies in accordance with the availability of relevant structures, systems, digital platforms and other resources.

As a reflective practitioner account, the article draws on the experience of the authors in higher education internationalisation as well as on the collective experience of a community of practice of the International Education Association of South Africa, which represents the majority of public universities in the country.

\section{Keywords}

Covid-19; higher education; inclusion; internationalisation practice; international students;

South Africa

i Dr Samia Chasi is the Strategic Advisor for the International Education Association of South Africa (IEASA) and a Research Fellow at the University of the Free State, South Africa. ORCid: 0000-0003-1896-0248. Email: samiachasi@yahoo.com

ii Ms Orla Quinlan has been IEASA President 2019-2020 and is Director: International Office, Rhodes University, South Africa. ORCid: 0000-0001-7464-4026. Email: o.quinlan@ru.ac.za 


\section{Introduction}

The Covid-19 pandemic has impacted higher education (HE) around the world in unprecedented ways, causing major disruptions to the teaching, learning and research functions of universities. Internationalisation activities, generally aimed at improving the quality of education and research, have also been adversely affected, most notably regarding restrictions on the international mobility of students and staff for study and research purposes as well as participation in meetings and conferences.

This article is a reflection on how Covid-19 has impacted HE internationalisation in South Africa. In particular, it focuses on how international students at the country's public universities have been affected by national and institutional responses to the pandemic. Written at a time where Covid-19 related restrictions are ongoing and the full impact of the pandemic cannot yet be foreseen, this article aims to create a public record of the impact of the global pandemic on international students in South Africa over a nine-month period, from March to December 2020.

By addressing the specific challenges and constraints international students have faced and highlighting that some of them are at risk of being left behind in terms of the successful completion of the 2020 academic programme, this article critically discusses the question of inclusion in current Covid-19 related government policy and institutional practices. The authors present a reflective practitioners' account, in which they draw on their extensive experience in HE internationalisation, most notably their current roles in the International Education Association of South Africa (IEASA). ${ }^{1}$

Based on their access to and involvement in the Directors Forum (DF), the authors share their personal reflections on the interactions of the members of this forum, who are an important community of practice for IEASA's institutional members, thus drawing on a collective voice of South African higher education institutions (HEIs). This article is informed by engagements of DF members, who are the directors of international offices of IEASA's member institutions. Through this platform, IEASA has established a community of practice, which has played a key role at this time of crisis by fostering learning and exchange to address common challenges and find practical solutions. Through formal meetings and communication via informal channels such as a WhatsApp group, the DF members engage regularly to keep each other abreast of the latest developments, identify common challenges, share examples of institutional responses to such challenges and learn from each other's good practices. As Chasi (2020, para. 10) notes, this engagement has "created a deep sense of community, as directors realised that the challenges they face are not unique to individual institutions, although their extent and severity can vary from one university to another". In the case of the Covid-19 pandemic, such a community of practice has been particularly important because institutional approaches to the implementation of

1 IEASA is a registered, non-profit organisation (NPO) dedicated to advancing the internationalisation of South African HE. It currently comprises 23 out of the 26 universities that make up the South African public HE sector. The following three institutions are currently not members of IEASA: Mangosuthu University of Technology, Sol Plaatje University and University of Mpumalanga. 
Covid-19 related government policy and its impact on internationalisation have not been coordinated and aligned at the national level.

\section{HE Internationalisation in South Africa}

\section{General internationalisation trends}

Internationalisation has been a concern of increasing importance for South African universities since the end of apartheid and its resultant international sanctions and academic boycott. After 1994, the country saw a considerable influx of international students. Reflecting on IEASA's history, Jooste (2007) notes that South African HEIs were initially under-prepared for the handling of international students coming to the country in increasing numbers. The first consultative meetings of the HE sector dealt mainly with issues arising from the presence of international students on South African campuses, including the potential for income generation, matters pertaining to immigration, language of instruction, the evaluation of non-South African qualifications as well as the provision of services to international students (Jooste, 2007). To help address these issues at a national level, it was recommended that a voluntary association be established, and IEASA was launched in January 1997 (Swemmer, 2018), resulting from the sector's need to respond to the influx of international students.

Internationalisation in the South African HE sector is no longer considered simply a matter of dealing with the presence of international students on university campuses across the country (Chasi, 2019). Internationalisation efforts of South African universities included, especially in the early years, setting up international offices and developing institutional internationalisation policies as well as activities regarding the recruitment of international students and staff, the mobilisation of local students and staff and the integration of an international dimension into programmes and curricula (Kishun, 2006). Over the past few years, there has been a focus on strengthening internationalisation of the curriculum (IoC) and internationalisation at home ( $\mathrm{IaH}$ ) dimensions as part of increased efforts to advance HE internationalisation in South Africa more equitably and inclusively. Most recently, the use of virtual exchanges and Collaborative Online International Learning (COIL) to internationalise the curriculum and to foster intercultural competence and multicultural learning has been gaining momentum, accelerated by Covid-19 related changes to the way we study, do research and work.

\section{Policy uncertainty}

In November 2020, it was formally announced that South Africa's first national policy framework for $\mathrm{HE}$ internationalisation has been ratified. However, leading up to that point, South African universities dealt with internationalisation mostly in their individual capacities for more than 20 years, with IEASA playing a facilitating and supporting role. As highlighted by Jooste and Hagenmeier (2018), IEASA identified the need for a national internationalisation policy as early as 2003 and was a major driving factor in its 
development until the Department of Higher Education and Training (DHET) published its Draft Policy Framework for the Internationalisation of Higher Education in South Africa for public comment in 2017.

In May 2020, IEASA called on the South African government to reaffirm its commitment to HE internationalisation by adopting the policy and supporting its implementation across the sector (IEASA, 2020). The need for policy clarity on internationalisation was also highlighted in a recent report on the country's HE system in the period 2005-2017, which notes that policy uncertainty brings about challenges, particularly in light of calls by some parliamentarians to introduce quotas for the recruitment of international students and academic staff, which creates political pressures on universities and funding bodies (Essop, 2020).

\section{Inequality and underfunding}

Apart from a long period of policy uncertainty, HE internationalisation in South Africa happens in a challenging HE environment characterised by inequality and underfunding. In its policy framework for HE internationalisation in South Africa, the DHET (2019) includes as rationales the positioning of the country's HE sector to be competitive in a globalised world, the advancing of HE quality as well as the benefiting of society at large and enhancing opportunities for HE to contribute to the public good. However, HE internationalisation has not been advanced evenly across the country's universities. More than 20 years after the end of apartheid, the internationalisation policy recognises that historically disadvantaged institutions (HDIs) "still have very low levels of international relations and are not yet, therefore, benefiting from internationalisation to the degree that they could" (DHET, 2019, p. 21).

In a university sector that is generally underfunded, ${ }^{2}$ when compared internationally, HE internationalisation competes for limited resources with other institutional priorities and is often put on the back burner of institutional initiatives. IEASA recognises that there is no 'one size fits all' approach to HE internationalisation in South Africa. The diversity of its member institutions manifests itself in different historical, geographical and operational contexts as well as in different institutional priorities and different levels of financial and human resource capacity allocated to internationalisation. In this context, it is imperative that internationalisation endeavours of universities are increasingly relevant and aligned to other institutional and national goals, contributing to transformation, nation-building and the public good.

2 While the level of HE spending has increased over the years, government subsidies for South Africa's 26 public universities have been declining in real terms, and one of the recommendations made by the Commission of Enquiry into Higher Education and Training (2017) was that government should work towards funding the university sector with one per cent of GDP. 


\section{Internationalisation policy focus}

As highlighted in the internationalisation policy framework, South African HEIs must design their internationalisation activities in such a way that priority is, first and foremost, given to South Africa's interests. Thereafter:

... where possible and relevant, the following order of priority focus should be observed in terms of interests: the SADC [Southern African Development Community] states; the rest of the African continent; BRICS [Brazil, Russia, India, China, South Africa]; the global South and emerging economies; and the world beyond.

(DHET, 2019, p. 22)

When it comes to student enrolments, this priority focus is already manifest in so far as the majority of international students in South Africa are African and mostly from SADC countries. The SADC focus is in line with the SADC Protocol on Education and Training Development (SADC, 1997), which recommends that member states reserve at least five per cent of their university admissions for students from other SADC nations.

\section{International students in South Africa}

\section{International student trends}

Since the end of apartheid, South Africa has been a popular destination for international students, particularly from the continent. Factors contributing to its attractiveness include the presence of several South African HEIs in major international university rankings, a well-established HE sector offering internationally recognised qualifications, the use of English as the main medium of instruction and relatively low costs of living.

International students are generally distinguished into two main categories: degreeseeking students and short-term students, of which the former are the majority of international students in South Africa. A total of 68036 international degree-seeking students were registered at South African universities in 2017, accounting for approximately 6.5 per cent of the total student population of 1036984 (CHE, 2019). ${ }^{3}$

Between 2005 and 2017, international student numbers grew by 32.5 per cent (Essop, 2020). Almost half of this growth is accounted for by an increase in postgraduate enrolments, particularly from the rest of Africa (ibid.). Between 2005 and 2017, international postgraduate enrolments increased by 106.4 per cent, and at the doctoral level, international students as a proportion of total doctoral enrolments increased from 23.1 per cent to 39.6 per cent (ibid.). This means that international students make a significant contribution towards national development, specifically the goal of having 5000 doctoral graduates annually by 2030 (NPC, 2012).

3 It is worth noting in this regard that if the total numbers are disaggregated further, it becomes apparent that 26740 international students, which equals almost 40 per cent of all international students, are not pursuing their studies in South Africa but are registered for distance education programmes, offered mostly through the University of South Africa (Unisa), the country's dedicated distance education institution (IEASA, 2019). 
The vast majority of international degree-seeking students registered at South African universities are African. In 2017, a total of 60334 students were from other countries on the continent, making up 88.7 per cent of all international students. What is more, 48641 students came from the SADC region, accounting for 71.5 per cent of international student enrolments (CHE, 2019). Many of these students come to South Africa for a variety of reasons including political instability, economic hardship and negative impacts of climate change in neighbouring countries.

Apart from degree-seeking students, South African HEIs also host international students for short-term periods and study abroad semesters. The vast majority of these students come from North America and Europe on a fee-paying basis or on the basis of fee-waiver agreements as part of institutional exchange agreements. However, national data from South African sources is not widely and easily available for this category, as it has not been gathered systematically and consistently across the sector and over time. However, Open Doors states, for example, that 341751 students from the Unites States (US) studied abroad for academic credit for periods in-between eight weeks or less to one academic year in 2017/2018. Of these students, 6001 chose South Africa as their study destination, making it the 11th most popular destination for US students in that year (Open Doors, 2019).

Notwithstanding differences in types of students and numbers, international students are present on the vast majority of university campuses across South Africa. All of IEASA's member institutions have established international offices to serve as first point of contact for international students and to provide them with general guidance and advice on matters related to their studies in South Africa.

\section{University services for international students}

Student services for international students are organised very differently across the range of South African HEIs, indicating varying degrees of importance assigned to internationalisation as an institutional priority. In some universities, internationalisation is a key part of the institution's overall forward-looking strategy, driven by the Vice-Chancellor. In others, internationalisation competes for attention with more pressing local issues such as the impact of water shortages or failing municipality services.

While international offices have been established, their positioning within each institution, function, size, capacity, role and funding model vary greatly. Most importantly, the extent of the services available to international students in any particular institution is influenced by their funding model. While some international offices are allocated a modest university budget, others generate funding through their activities in order to pay for their costs, including substantial income through bespoke short courses and study abroad programmes. In some international offices, a mixed model is adopted combining core university funding and income generated from office activities. Some universities charge international student levies and others do not. The levies themselves are also allocated differently in each institution to either the central university budget or the relevant faculty and other units including the international office, or a combination of both. 
Well-resourced offices tend to deal with internationalisation more broadly and comprehensively, including international visitors and events as well as the entire cycle of an international student's experience from initial marketing and recruiting to graduation. The services provided for international students include orientation, registration and a range of specific international student services pertaining to immigration and medical aid, as a core visa requirement. In contrast, smaller offices may deal with only some aspects of these student services, with others being provided by general student service units usually housed within the Registrar's and student affairs divisions.

As alluded to earlier, there is an unevenness about the prevalence of internationalisation and service provision for international students on South African campuses. Against this backdrop, Covid-19 has affected universities and international students in South Africa differently.

\section{Covid-19 Impact on HE Internationalisation: The Case of International Students in South Africa}

The impact of Covid-19 related restrictions on international student mobility has affected South African HEIs to varying degrees. On the one end of the spectrum, universities focused their responses to the pandemic mainly on the presence of a small number of international students. At the other end, a whole variety of international activities were at risk. For institutions that relied on income generated through international activities such as study abroad programmes and winter/summer schools, financial losses suffered due to Covid-19 potentially threatened the sustainability of the very same initiatives and programmes and, in some instances, the sustainability of the funding model of the international office.

\section{The impact of Covid-19 on international students in South Africa}

In response to Covid-19, the South African government implemented measures following a risk-adjusted approach, taking into account several factors including but not limited to the level of infections, the rate of transmissions, the capacity of health facilities as well as the economic and social impact of implemented restrictions. This approach included a fivelevel alert system, which determines the level of restrictions to be applied during different phases of the national state of disaster. The system ranges from lockdown level 5, with a high spread and a low health system readiness, to lockdown level 1, with a low spread and a high health system readiness. ${ }^{4}$

All students have been affected by measures implemented in response to Covid-19 such as travel bans, campus closures and the move to online teaching and learning. However, aspects of these measures have created specific challenges for international students that are experienced differently by local students or not shared by them at all. In addition, as the

4 More detailed information about the alert levels is published by the South African government and available at https://www.gov.za/covid-19/about/about-alert-system 
various levels of lockdown were adjusted, there was an increasing differentiation between the impact on students located inside South Africa, both local and international, and those outside the country.

\section{Travelling home before lockdown}

When universities closed for early recess from 18 March 2020, students were asked to vacate university premises and return home. As IEASA (2020) highlights, such requests created challenges for local and international students alike, particularly when travelling home was linked to fears of health risks as well as logistical and financial difficulties. International students faced some additional challenges in that regard. For example, in contrast to their local counterparts, international students often stay in residences even during recess periods and return home only at the end of their academic programme or academic year or upon completion of their studies. In this instance, however, they were expected to make international travel plans at short notice and at a cost not budgeted for. Students from countries identified as high-risk were particularly concerned about leaving South Africa and their prospects of being able to return once campuses reopened. Further challenges arose due to flight cancellations and border closures in the wake of international travel bans and, in some instances, international students were unable to travel due to pending visa extensions.

In effect, many full-time international students from beyond the SADC region could not leave the country. Study abroad students generally repatriated and resumed courses in their home institutions. With only a few days between the national lockdown being announced and it taking effect on 26 March 2020, some students had to leave the country in such a hurry that they left behind personal belongings and learning materials. Jooste and Hagenmeier (2020) point out that it was generally expected at the time that they would be able to return to their universities soon.

\section{Contact and communication}

International students are generally requested to update their contact details on an annual basis. However, after campus closures, some students could no longer be reached via the contact details provided, especially if they had crossed the border and were no longer accessing South African mobile networks. Similarly, receiving electronic communication from their institutions was a challenge for students who had left campus and no longer had access to computers, data, networks and electricity. Under such conditions, institutions experienced considerable difficulties in establishing the whereabouts of their international students. Some discovered that students they thought had left the country actually stayed within the borders of South Africa.

\section{Accommodation}

In cases where international students were, for a variety of reasons, unable to travel home or find alternative accommodation, universities had to make arrangements for continued care and support, including accommodation. Some international students were therefore 
allowed to stay in university residences on campus, with strict regulations to meet the necessary requirements regarding health standards and social distancing. Others were moved to alternative accommodation off campus. Even in cases where students stayed on campus, the provision of services for them was severely disrupted due to the closure of campus facilities as well as the shift to staff working from home, with personnel available on site reduced to a bare minimum.

Students who moved in with relatives or friends also faced specific challenges pertaining to accommodation, as they no longer had their own dedicated space. In one instance, a group of Zimbabwean scholarship students used their travel allowance to club together and rent a place, anticipating that it would be easier to continue with their studies in South Africa, in spite of inadequate financing. They feared returning home to places where there might be very little connectivity and thought they would access most of the same adaptive measures as South African students if they remained. As the lockdown continued for much longer than initially expected, they eventually ran into financial difficulty and required assistance from their host university to survive.

\section{Immigration matters}

In January 2020, the Department of Home Affairs (DHA) provided visa exemptions until the end of March, which allowed universities to register international students who had applied for extensions of their study visas inside the country on the basis of Visa Facilitation Services (VFS) receipts, as proof that their applications had been submitted. However, when campuses were closed in line with Covid-19 related restrictions, these same students were initially informed that they could not leave South Africa without the risk of being declared undesirable and unable to return. Some students crossed the border regardless, and the consequences of this decision remained to be seen until international students were finally permitted to return and re-enter the country to resume their studies.

On 26 March 2020, the Minister of Home Affairs issued a range of concessions for foreigners inside South Africa, including international students, and extended their visas until 31 July 2020 (DHA, 2020a), which permitted students to retain the same legal status as they held prior to lockdown. Subsequently, the concessions were further extended to 31 October 2020 (DHA, 2020b). While these concessions assisted students whose visas expired during lockdown in terms of their legal status in the country, there were other material hardships for students due to the closure of VFS offices and the unavailability of services. To mention some examples, there was no facility to change the conditions of visas, which affected students who wanted to change universities and could not register at their new institution. Students who had completed their $\mathrm{PhD}$ studies and were due to commence postdoctoral research could not apply for the correct visa and missed funded research opportunities. Pharmacy students, who were to complete their final year and take up internships, were delayed, which will impact on their career opportunities for 2021.

The DHET announced on 26 August 2020 that the target for completion of the 2020 academic year will be the end of February 2021 (DHET, 2020c). This means that some international students will need to extend their study visas beyond December 2020. 
Even if an extension is granted automatically by the DHA, students will incur additional, previously not anticipated expenses, such as for maintaining their medical aid cover, which is a core study visa requirement.

As the examples relating to travel, communication, accommodation and immigration show, the specific circumstances of international students are generally complex and varied. This means that universities have to accommodate international students often on a caseby-case basis, requiring ad-hoc and tailor-made solutions. In the context of Covid-19, the need for differentiated services was exacerbated even further, as students found themselves in different scenarios, depending on how measures implemented to prevent the spread of the pandemic affected them. Whatever services they provided, universities had to be mindful of the different situations international students found themselves in - on campus; off campus but in a host institution location; elsewhere in the country or at home outside South Africa.

\section{Inclusion in Times of Covid-19}

The question of inclusion arises particularly in the context of national and institutional plans to assist students in successfully completing the 2020 academic year despite severe disruptions. The Minister of Higher Education, Science and Innovation proclaimed that no student is to be left behind in that regard (SA News, 2020). However, it appears that several groups of students are at a high risk of being left behind, most notably students "living in conditions that are not conducive to online learning, without access to computers and laptops, affordable data, reliable internet connectivity, electricity or a dedicated physical space in which to study" (IEASA, 2020, p. 2). Another group of students at risk are international students, especially those who were, in adherence of lockdown regulations, outside the borders of South Africa until they were eventually able to return under lockdown level 1, which took effect on 21 September 2020.

In early June 2020, the DHET observed that the numbers of international students in university residences on and off campus were small (DHET, 2020b). Taking into account reports from universities that considerable numbers of their international students remained elsewhere in the country, the question still arose of how the DHET and other government departments accommodated the needs and interests of international students outside South Africa. These students were not at the forefront of considerations and plans for the successful completion of the 2020 academic year, as such plans, at both national and institutional levels, targeted mainly local students and international students who remained in South Africa.

\section{Return to campus}

Returning to campus was particularly important for students who were living and studying in challenging circumstances. However, in planning the phased reopening of campuses and resumption of face-to face teaching, the DHET confirmed that only under lockdown level 1, "International students who were residing outside of the country during the 
lockdown period may return (provided that international travel is permitted)" at that time (DHET, 2020b, p. 9). These students were thus essentially excluded from opportunities to return to campus in a staggered approach, in the same way as local students. This affected the students' ability to access study and research facilities on campus, which was, in turn, likely to negatively impact their academic performance and progress.

To further illustrate the complexities, on 30 April 2020 the DHET (2020a) announced that the only exception to campus closures under lockdown level 4 would be the controlled return of clinical training students in their final year to assist with ongoing health management efforts of the Department of Health (DoH). However, this directive did not make any explicit provision for the return of international students studying in their final year towards qualifications in the relevant disciplines. It was reported in the news that some final-year students returned to South Africa from Namibia at the end of May (Kandovazu, 2020). As Jooste and Hagenmeier (2020) note:

There was no clarity about whether this would include international students; the wording was at least wide enough to allow for this. Stakeholders interpreted the regulations in different ways, but at least a limited number of international final-year medical students returned from Lesotho.

(para. 8-9)

The Department of Co-Operative Governance and Traditional Affairs (COGTA, 2020) issued regulations for lockdown level 3 indicating that "daily commuters from neighbouring countries who attend school in the Republic" (p. 13) may be allowed entry. However, no similar provision was explicitly made for international students from such countries, revealing inconsistencies in the treatment of international school learners and international students.

On 26 August 2020, the DHET stated that in case international travel be permitted under lockdown level 2, "Priority may have to be given to Registrars and senior Medical Students" (DHET, 2020c, p. 11). Again, no further details regarding the implementation of such provision were provided.

\section{Remote learning}

When the DHET announced that international students would be allowed to return to campuses only under lockdown level 1, it also stated that "These international students will be supported through remote learning support until they return" (DHET, 2020b, p. 8). In practice, the capacity of universities to provide remote learning and support differed significantly. While some institutions, most notably research-intensive universities, were able to implement remote teaching and learning as an emergency measure from as early as the second term starting in April 2020, others, especially HDIs, were still struggling to adequately provide teaching and learning services online when the phased re-opening of campuses started in June 2020.

Furthermore, institutional efforts to support students by providing learning devices and data were, for the most part, limited to local and international students in South Africa for 
logistical and financial reasons. For example, laptops were more laborious and expensive to transport across borders, and data deals were more difficult to negotiate with companies outside South Africa's borders. At the same time, challenges with internet connectivity and bandwidth are often even more pronounced in students' home countries on the continent. Universities made attempts to support students by negotiating with mobile communications companies in neighbouring countries and also approached alumni networks for assistance. In some instances, students in Lesotho, Namibia and Botswana received laptops. There are also cases where universities were able to support students with free data or rebates or data allowances. Data was made available to some students in neighbouring countries, especially in Lesotho and eSwatini.

Despite these efforts, universities did not generally have the requisite contacts, mechanisms and budgets in place to support students who were outside of the country, particularly in the initial phase of adapting to the 'new normal'. There was a distinct time lag in finding ways to assist international students, which is a continuing challenge. For example, the University of the Witwatersrand, Johannesburg (Wits, 2020a) announced on 14 April 2020 that it would re-open on 20 April and institute an emergency remote teaching and learning programme to help minimise the time lost in the academic project. A few days later, Wits (2020b) confirmed that students registered on one of the four major mobile networks operating in South Africa would receive $30 \mathrm{~GB}$ of data at no cost for one month. However, it took four months until the University announced that international students based in Lesotho, eSwatini and Zimbabwe would also receive data from Wits (Belle, 2020). As this example shows, the support for international students was, even where available, delayed and neither uniform nor comprehensive across the board.

\section{Reasons for lack of inclusive approaches}

To a large extent, the lack of adequate consideration for international students can be ascribed to the unprecedented nature of the Covid-19 pandemic and the lack of relevant national and institutional resources, structures, systems, digital platforms and experiences in dealing with such a crisis. It quite literally caught everyone by surprise. Of greater concern is the lack of clarity and detail in government directives, which, in the absence of coordinated, sector-wide approaches, left each university to interpret them differently, as in the case of the return of final year medical students.

Various concerns arose regarding the return of international students from outside South Africa, as their reintegration into classes and campus life was expected to involve additional time and resources, particularly regarding requirements for quarantine and self-isolation. Furthermore, it was anticipated that international students who had left the country without awaiting the outcome of their ongoing visa extension applications might experience challenges with their visas upon re-entry. In effect, students from the SADC region returned to South Africa on visitors' visas, acquired at the border and, with DHA concessions, collected their study visa application outcomes inside South Africa. A proportion of students decided not to return to South Africa in 2020 and continued to 
learn online. Their visa outcomes await collection at VFS offices, where they will be kept for a few months before being returned to the DHA. Some students may be anticipating collecting visa outcomes early in 2021, as they come to register for the new academic year.

A possible reason why considerations and plans did not specifically cater for international students is the lack of well-informed representation at the national level. For example, when the Department of Higher Education, Science and Innovation (DHESI) established a dedicated Covid-19 Team in mid-March 2020, this did not include representation of bodies that can specifically speak for international students. This might have been an oversight giving expression to the lack of prioritisation of HE internationalisation and existing policy uncertainty at the time, as indicated earlier.

The lack of adequate and consistent concern for the needs of international students can negatively affect their individual study experiences. The psychological impact of being asked to leave and the delays in being accommodated to participate in online teaching and learning and in being allowed back onto campus may affect international students' confidence in their home institutions' ability to treat them equally and equitably in comparison to local students. In the long-term, this carries the risk of more far-reaching reputational damage to the entire sector. In that regard, Jooste and Hagenmeier (2020) point out that the way international students were being treated during the ongoing Covid-19 crisis may determine South Africa's ability "to retain its position as a regional higher education hub and whether it will be able to be a driver for $\mathrm{PhD}$ capacity development in the SADC region and Africa following the pandemic" (para. 2). They note further that any unjustified discrimination of international students "may infringe the country's internationally celebrated Constitution, taint South Africa's standing as a higher education hub and jeopardise its existing reputation as a preferred destination for international students" (para. 23). This is especially true if students are unable to successfully complete their academic programme.

\section{Way forward}

For the reasons mentioned above, it is imperative that the government's aim to not leave any student behind is achieved. In a position paper published in May 2020, IEASA (2020) appealed to universities and other HE stakeholders to ensure that international students are not left out of considerations for the successful completion of the 2020 academic programme. Learning from experiences so far, this means that internationalisation considerations need to be given more prominence in ongoing and future responses to Covid-19. It also requires a more deliberate engagement with the needs and interests of international students, which must be taken into account when designing initiatives and programmes at both national and institutional levels. Such initiatives and programmes should be equitable and afford international students the same opportunities as local students. Plans to facilitate the continuity of academic and support services need to cater for international students who are inside the country as well as those who are outside the border of South Africa. 
Based on the collective experience of IEASA's members (IEASA, 2020), institutions would benefit from greater alignment and coordination of efforts to combat Covid-19 at national level, including the collaboration of different government departments impacting on international student issues, most notably the DHESI, the DHA and the Department of International Relations and Cooperation (DIRCO). Institutions, especially those that are underprivileged and under-resourced, also stand to gain from more inclusive, sector-wide approaches, for example, regarding the pooling of institutional resources to create regional or national platforms for online teaching as well as the negotiation of internet and datarelated deals with mobile communications companies (ibid.).

\section{Concluding Remarks}

At the global level, the full impact of the Covid-19 pandemic on the future of HE internationalisation is as yet unclear. As a member of the Network of International Education Associations (NIEA), IEASA supports a recently published statement reaffirming the value and importance of international education and research, highlighting that measures implemented to limit international HE should be time-bound (NIEA, 2020). This includes any restrictions on international students.

In South Africa, the full impact of restrictions implemented in response to Covid-19 is difficult to predict at a time when it is not yet clear how successfully the 2020 academic year will be completed. Similarly, it has not yet been established how many international students were able to make use of online teaching and learning, where offered, and how this has impacted on their academic performance.

There is some indication that the 'new normal' of teaching and learning will include blended approaches. Similarly, it can be expected that some of the new ways of working remotely will find their way into service provision for international students. At the same time, international students are likely to want and need a physical campus experience to enhance their immersion and integration by ensuring conducive study conditions and human interactions.

Covid-19 has undoubtedly caused a disruptive shock to the core functions of universities. However, it also provides HEIs with an opportunity to adapt positively to an ever-changing internationalisation environment and emerge as institutions that are smarter, more inclusive and more responsive. This includes adopting creative and innovative approaches to the way in which they service and support different categories of students, including international students, who make a very valuable contribution to the intellectual and cultural diversity of South African universities and the development of the South African HE sector.

\section{Research Ethics}

Work on this article did not involve any research participants and therefore did not require ethical clearance. 


\section{Conflict of Interest}

The authors declare that they do not have financial or personal relationships that may have inappropriately influenced them in writing this article.

\section{Funding}

This work has not received any financial support.

\section{References}

Belle, Z. (2020, August 18). Wits international students to receive data. Wits Vuvuzela. http://witsvuvuzela. com/2020/08/18/wits-international-students-to-receive-data/

Chasi, S. (2019). North-South partnerships in public higher education: A selected South African case study. [Doctoral dissertation], University of the Witwatersrand, Johannesburg, South Africa. http://wiredspace.wits. ac.za/handle/10539/28064

Chasi, S. (2020, April 9). COVID-19 has put HE internationalisation under review. University World News. https://www.universityworldnews.com/post.php?story $=20200408093750683$

CHE (Council on Higher Education) (2019). VitalStats - Public Higher Education 2017. https://firebasestorage.googleapis.com/v0/b/che2020-c5efd.appspot.com/o/website\%2F1svgvakokgb1?alt=media \&token $=\mathrm{d} 76 \mathrm{cb} 24 \mathrm{a}-5931-4 \mathrm{c} 45-\mathrm{b} 652-590563314 \mathrm{c} 92$

COGTA (Department of Co-Operative Governance and Traditional Affairs) (2020, May 28). Disaster Management Act, 2002 (Act No. 57 of 2002): Determination of Alert Levels and Hotspots. Government Gazette, 659(43364). Republic of South Africa.

Commission of Enquiry into Higher Education and Training (2017). Report of the Commission of Enquiry into Higher Education and Training to the President of the Republic of South Africa. http://www. thepresidency.gov.za/sites/default/files/Commission\%20of\%20Inquiry\%20into\%20Higher\%20 Education\%20Report.pdf

DHA (Department of Home Affairs) (2020a, March 26). Directions issued in terms of regulation 10(8) of the regulations made under section 27(2) of the Disaster Management Act, 2002 (Act No. 57 of 2002): Measures to prevent and combat the spread of COVID-19. Government Gazette, 657(43162). Republic of South Africa.

DHA (2020b, July 31). Amendment of directions issued in terms of regulation 10(8) of the regulations made under section 27(2) of the Disaster Management Act, 2002 (Act No. 57 of 2002): Measures to prevent and combat the spread of COVID-19. Government Gazette, 661(43572). Republic of South Africa.

DHA (2020c, August 25). Amendment of directions issued in terms of regulation 4(8) of the regulations made under section 27(2) of the Disaster Management Act, 2002 (Act No. 57 of 2002): Measures to prevent and combat the spread of COVID-19. Government Gazette, 662(43650). Republic of South Africa.

DHET (Department of Higher Education and Training) (2019). Policy framework for internationalisation of higher education in South Africa. https://www.dhet.gov.za/Policy\%20and\%20Development\%20 Support/Policy\%20Framework\%20for\%20Internationalisation\%20of\%20Higher\%20Education $\% 20$ in $\% 20$ South\%20Africa.pdf

DHET (2020a, April 30). Minister of Higher Education, Science and Innovation statement on the measures to phase-out the lockdown and phasing in of PSET strategic functions. https://www.dhet.gov.za/ SiteAssets/Media\%20Statement\%202020/PHASING\%20OUT\%20THE\%20LOCKDOWN\%20 MEASURES\%20final.pdf 
DHET (2020b, June 8). Directions for criteria to return to public university and private higher education institution campuses as part of a risk-adjusted strategy for a phased-in return from level 3: Issued in terms of the Disaster Management Act, 2002 (Act No. 57 of 2002). Government Gazette, 660(43414). Republic of South Africa.

DHET (2020c, August 26). The Minister of Higher Education, Science and Innovation, Dr Blade Nzimande's statement on Covid-19 alert level 2 measures in the post school education and training sector. https://www.dhet. gov.za/SiteAssets/Media\%20Statement\%202020/Minister\%20Nzimande $\% 27 \mathrm{~s} \% 20$ Statement $\% 20$ on\%20Level\%202.pdf

Essop, A. (2020). The Changing Size and Shape of the Higher Education System in South Africa, 2005-2017. Ali Mazrui Centre for Higher Education Studies, University of Johannesburg. https://www.uj.ac.za/ faculties/facultyofeducation/ali-mazrui-centre

IEASA (International Education Association of South Africa) (2019). Study South Africa - The guide to South African higher education. Engaged universities: Comprehensive internationalisation - a dialogue between local and global realities (18th ed.). IEASA. https://studysa.africa/

IEASA (2020, May 29). Position paper - higher education internationalisation in South Africa in the context of the Covid-19 pandemic: Impact on international students. IEASA. http://ieasa.studysa.org/wp-content/ uploads/2020/05/IEASA-position-paper_COVID-19_May2020_Final.pdf

Jooste, N. (2007). 10 Years of IEASA history. IEASA. http://studysa.org/wp-content/uploads/2019/03/ 10-years-of-IEASA-history.pdf

Jooste, N. \& Hagenmeier, C. (2018). Draft policy framework for the internationalisation of higher education in South Africa: An IEASA perspective. In Study South Africa - The guide to South African higher education (17th ed., pp. 5-6). IEASA.

Jooste, N. \& Hagenmeier, C. (2020, July 9). South Africa's destination reputation is on the line. University World News. https://www.universityworldnews.com/post.php?story $=20200707102247518$

Kandovazu, E. (2020, June 3). Namibian students return to SA. Informanté. https://informante.web.na/ namibian-students-return-to-sa/

Kishun, R. (2006). Introduction: The internationalisation of higher education in South Africa - Progress and challenges. In R. Kishun (Ed.), The internationalisation of higher education in South Africa (pp.1-12). IEASA.

NIEA (Network of International Education Associations) (2020, July 24). Statement on the importance of international higher education and research. IEASA. http://ieasa.studysa.org/wp-content/uploads/2020/ 07/NIEA-Statement-on-the-importance-of-international-higher-education-and-research.24-July2020.pdf

NPC (National Planning Commission) (2012). National Development Plan 2030: Our future - make it work. The Presidency. https://www.gov.za/sites/default/files/gcis_document/201409/ndp-2030-ourfuture-make-it-workr.pdf

Open Doors (2019). 2019 Fast facts. https://opendoorsdata.org/fast_facts/fast-facts-2019/

SADC (Southern African Development Community) (1997). Protocol on education and training development in the Southern African Development Community. https://www.sadc.int/files/3813/ 5292/8362/Protocol_on_Education_Training1997.pdf

SA News (2020, May 1). Government vows to leave no student behind. 'The Skills Portal'. https://www. skillsportal.co.za/content/government-vows-leave-no-student-behind

Swemmer, D. (2018). Walk together and look back to move forward! In IEASA, Study South Africa - The guide to South African higher education (17th ed., pp. 50-52). IEASA. 
Wits (University of the Witwatersrand) (2020a, April 14). Wits switches to remote online teaching and learning from 20 April 2020. https://www.wits.ac.za/covid19/covid19-news/latest/wits-switches-to-remoteonline-teaching-and-learning-from-20-april-2020.html

Wits (2020b, April 19). COVID-19 Update 24: Data access: All four major mobile service providers on board. https://www.wits.ac.za/covid19/covid19-news/latest/covid-19-update-24-data-access-all-fourmajor-mobile-service-providers-on-board.html

\section{How to cite:}

Chasi, S. \& Quinlan, O. (2021). Inclusion in Times of Covid-19: The Case of International Students in South Africa. Journal of Student Affairs in Africa, 9(1), 205-221. DOI: 10.24085/jsaa.v9i1.1439 


\title{
REFLECTIVE PRACTICE
}

\section{Disability Unit Practitioners at Stellenbosch University: Covid-19 Pandemic Reflections}

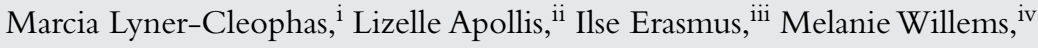 \\ Latashe Poole, ${ }^{\mathrm{v}}$ Meagan Minnaar ${ }^{\mathrm{vi}}$ \& Pippa Louw ${ }^{\mathrm{vii}}$
}

\begin{abstract}
As reflective practitioners working in disability inclusion, we constantly work with shifting realities concerning our students, who are not a homogenous group. The coronavirus pandemic (Covid-19) was a reality least expected in 2020, yet we used our flexible approach to make the transition as smooth as we possibly could. The Disability Unit (DU) is one of five units located within the Centre for Student Counselling and Development at Stellenbosch University (SU) and falls within the responsibility centre of the Deputy Vice-Chancellor:Teaching and Learning. The DU was founded in 2007 and is 15 years old in 2021. We aim to foster disability inclusion within a transformative framework at SU, with our main focus on students with disabilities. Our wider aim is universal access, which includes working towards the removal of cultural, social, language and disability barriers in the higher education context. We are guided by the Disability Access Policy (2018) of SU. Since the latter part of March 2020, we had to shift to online teaching and learning. This came at a time when we were preparing for the end of the term and student support was being put in place. The onset of Covid-19 occasioned unanticipated reflections and challenges, which we share in this article. We also reflect on what we have learnt and how we can move forward in a changed academic environment catapulted into a digital world. We do this reflection by following the Gibbs' reflective cycle (Gibbs, 1988) which offers a way to reflect and learn from experience. The cycle is weaved into the reflections as it follows a process of describing the context of the DU, expressing how the Covid-19 pandemic was felt by staff and students, evaluating and learning from what was experienced. According to Lyner-Cleophas (2020), online learning has benefits and challenges, especially considering students with disabilities.
\end{abstract}

i Dr Marcia Lyner-Cleophas is Head: Disability Unit, Stellenbosch University, South Africa. ORCid: 0000-0003-1460-6313. Email: cleophas@sun.ac.za

ii Ms Lizelle Apollis is an Inclusivity and Access Support Officer and First National Bank Bursary Fund Coordinator, Disability Unit, Stellenbosch University, South Africa. Email: ferus1@sun.ac.za

iii Ms Ilse Erasmus is a Disability Resource Officer, Disability Unit, Stellenbosch University, South Africa. Email: ilsevw@sun.ac.za

iv Ms Melanie Willems is a Disability Support Officer, Disability Unit, Stellenbosch University, South Africa. Email: mwillems@sun.ac.za

v Ms Latashe Poole is Administrative Officer, Test and Exam Concessions, Disability Unit, Stellenbosch University, South Africa. Email: latashep@sun.ac.za

vi Ms Meagan Minnaar is a Disability Resource Officer, Disability Unit, Stellenbosch University, South Africa. Email: meagans@sun.ac.za

vii Ms Pippa Louw is a Disability Resource Officer, Disability Unit, Stellenbosch University, South Africa.

Email: phlouw@sun.ac.za 


\section{Keywords}

accessible information; assistive technology; disability inclusion; disability unit; hybrid learning; online learning; pandemic; students with disabilities; universal access; universal extra writing time

\section{Introduction and Contextualising the Disability Unit}

The Stellenbosch University (SU) Vision 2040 (SU, 2018a) and Disability Access Policy (SU, 2018b) echo the values that underpin the work of the DU. Excellence, compassion, accountability, respect and equity are the values that inform our vision at SU. We hereby aim for an enabling environment for our students and the systemic disability inclusion of staff and students, although our focus is chiefly on students. We managed to pursue these values during the pandemic.

The DU had approximately 462 students who had indicated a disability on application to SU in 2020. While this is the number of students who disclosed a disability, those who seek support is far greater, totalling approximately 768 students in all years of study that were receiving support in 2020 (SU, 2020d). At times, students are known to not disclose a disability, or they do not view their difficulties as a disability.

A wide range of students with disabilities are seen at SU. These include students with physical or sensory disabilities such as deaf, blind and visually impaired students, chronically ill students and students with neurological difficulties. Mental health conditions that require support also fall into this category.

The types of support that students receive at SU can include extended time on tests and examinations, the use of a computer to write examinations (the main means of communication during Covid-19) and the use of scribes or readers (mainly electronic means are used, such as JAWS, ZoomText and Read \& Write).

The Biopsychosocial Model of Disability espoused by the World Health Organization (WHO, 2002) confirms that people with disabilities are not one-dimensional. No two students with the same disability are the same. General functioning, biological, psychological, social and political factors, education, health and economics include elements important to consider when students come to university. Psychological and emotional realities are highlighted by Watermeyer and Swartz (2008) as is the impact of the broader social and physical context by Oliver (2009).

Context is clearly important, and the nature of the disability and its manifestation impact various areas of life. A student with a disability will therefore be impacted by what is occurring in broader society and will have psychological and emotional responses to events, whether at domestic, national or international level, like all other students. On a personal level, students with disabilities experience more anxiety than students without, depending on the nature of their disability.

The Disability Access Policy is of relevance to SU as a whole. This means that disability inclusion on campus is the responsibility of everybody on campus and not only of the DU. 


\section{Our General Response to Covid-19}

Just as we were rounding off the first term at SU, the Covid-19 pandemic was thrust upon us (SU, 2020a). We were finalising our students' academic support plans and test and examination concessions, putting in place assistive technologies (hardware and software) and ensuring funding in accordance with students' specific financial and other support needs when the pandemic struck. Staff and students were asked to vacate their offices, classrooms, laboratories, libraries and residences at SU. This was an anxiety-provoking and uncertain time for staff and students. Our most vulnerable students became more anxious during this time, and we needed to acknowledge and respond to the vulnerability, as well as contain our emotions and experiences of the pandemic.

The South African government, $\mathrm{SU}$ and global organisations such as the United Nations (UN, 2020) issued notices and policy briefs that care should be shown to the most vulnerable people in society during this time. It was expected that inequalities would be exacerbated during this time and that the educational sector would not be spared.

Our main response was to provide continued support to students with disabilities through Emergency Remote Teaching, Learning and Assessment (ERLTA). While ERTLA was a challenge for some students and staff, learning took place for all.

\section{South African Realities}

The Department of Higher Education in South Africa acknowledges the barriers that exist in the post-school sector for people with disabilities and describes ways in which these obstacles can be overcome, but in broad policy terms only. Even though this national disability framework is contested (Ngubane-Mokiwa, Mutanga \& Bothwell, 2018), it nonetheless provides a foundation to build on. Emphasis is placed on the digital economy and assistive devices and how these add to the support to students with disabilities.

The Covid-19 pandemic exacerbated the inequalities in Africa (UN, 2020). Inequalities were witnessed at SU too, but these could mostly be sorted out through negotiations between students and SU despite initial South African government guidelines and policies. For example, it was easy for certain students to go home at short notice when asked to do so but more challenging for those who experienced funding restraints and had to travel long distances. Taking national or international flights home was not an easy option.

Most students commute to campus daily and stay on campus to have access to Wi-Fi and data given the existing infrastructural networks, particularly when access at their homes is non-existent or their circumstances are not conducive to study. A few students with disabilities did stay in Stellenbosch, in either private or SU residences during this time. They had to adjust to being isolated from other students and staff during the hard lockdown and to only focus on their studies. To the students who stayed behind, they felt that they were in a hard lockdown throughout the varying levels of the pandemic, as they were restricted to their residences. All safety and social distancing precautions determined by the South African government had to be adhered to. 


\section{Academic Support and Counselling Online}

The ERTLA was instituted to include all students in the online environment and to facilitate successful study (SU, 2020b). This developed to the extent that during the second semester, further student engagement was put in place. This included online tutors, flexible assessment practices, and a mentor programme for certain modules, additional online assessments and assignments, increased consultation time and increased synchronous and asynchronous teaching activities.

Accessibility in ERTLA developed well since the start of the lockdown, and flexibility was introduced. While students initially only received a PowerPoint presentation or a voice recording explaining the PowerPoint, it helped, especially deaf students, to have the recordings converted into text for better access. Deaf students who used South African Sign Language as a first language found that their interpreters could establish a workable online medium to explain presentations sent to them by their lecturers. They also did online assessments with Sign Language interpretation.

Sufficient data, access to devices, good bandwidth and electricity access became additional matters to contend with, particularly during the first semester. Lecturers had to find ways to do assessments in an inclusive manner. Many found universal extra time measures to be a good solution to connectivity issues, and this benefitted all students. They felt at ease that they would have sufficient time to complete assignments and assessments. Additional extra time during online assessments was granted where this was approved by $\mathrm{SU}$, also through an online process.

Academic support consultations took place via MS Teams, WhatsApp, telephone and Zoom. We were very flexible in our response to students during this time, providing psychosocial support as well as academic counselling as needed to students with disabilities. Most students had adjusted by the end of the second term.

\section{Collaboration-Enhanced Flexibility}

When students left campus, they increasingly experienced data constraints and problems with hardware. This was largely addressed by agreements between SU and technology service providers, telecom companies such as Mweb, Cell-C and Vodacom, the National Student Financial Aid Scheme (NSFAS) and the Department of Higher Education and Training. The University developed various work streams, including the teaching and learning work stream. Training of lecturers took place during April, and students were given further guidance on how to access teaching and learning material on their learning management system called SUNLearn. Specific information was also shared with the focus on students with disabilities, such as how to apply for test and examination concessions and how extra time would work online (SU, 2020b). In the teaching and learning work stream, there was Student Representative Council representation, including a special needs manager. This student had a visual disability and worked very closely with the DU and the teaching and learning work stream, providing pertinent information on students' experiences during the pandemic, which informed better practices. 
Some students with neurodevelopmental disabilities, for whom the lack of structure made it hard to adapt to the home environment, found the transition to ERTLA disruptive. This created increased anxiety. Classes were not always at set times and recordings of lectures were often sent later, which made it hard for students to manage their time and develop their own programme. However, students who experienced social anxiety often found this transition to be easier as they did not have to contend with the anxiety around interactions and the big classroom spaces of SU. Some students with psychosocial difficulties could also adjust their day according to their sleep pattern (Widnall, 2020).

\section{Phased-in Return of Students}

In a measured and cautious manner, a third of students were allowed to return to campus around mid-year but in an online way as far as possible, including practical and researchbased course work. The necessary physical distancing and hygiene measures were in place. Returning to the various campuses was done in phases and under controlled circumstances. Firstly, the Faculty of Medicine and Health Sciences welcomed its final-year students back to the Tygerberg campus. After this, final-year students who had to be on campus for research purposes, practical sessions and laboratory work or who were experiencing extreme difficulties at home could return to our main campus.

The return of the remaining two-thirds of students commenced at the start of writing this article and was instituted from 1 September. Detailed plans for students had not been implemented, except that the ERTLA support mechanism process was to continue in most faculties. Certain students with disabilities were requested, by invitation, to return to campus as they were struggling in the online environment to adapt to coursework, which they found useful. Additionally, if students struggled in the home environment, they could return to residences while still adhering to the necessary social distancing and hygiene regulations.

\section{Financial Support}

In South Africa, no specific ring-fenced funding for students with disabilities is built into subsidies to universities. Students in the low-income brackets can source funding through the NSFAS, a government funding scheme that ensures access to funds for tuition, accommodation, meals, books, living costs, and assistive technology and support.

When the pandemic struck, the NSFAS decided that all students receiving funding would receive laptops. This came after SU had already embarked on a drive to ascertain which students needed data and devices such as laptops to continue their studies online. About $1500 \mathrm{SU}$ students received laptops. These are on loan to students and if returned will not be charged against their student account at the end of lockdown. Those who do not return the laptop will be charged for it at the end of lockdown. The NSFAS offered to pay such charges for any NSFAS-funded student who borrowed a laptop from universities and wished to keep it after 2020. During these difficult times, all NSFAS-funded students received their full food allowances, book allowances and accommodation fees for the year, 
bearing in mind that SU did cost adjustments for students who left campus and were not using campus services such as residences on campus. A payment relief agreement was made.

However, students with annual family incomes above R600 000 South African rands do not have access to funding from NSFAS. The importance of private sector funds as an adjunct to funding in the disability sector in the post-school sector cannot be emphasised enough, given this context.

Additionally, the DU receives private sector funding from First National Bank, one of the biggest banks in South Africa. Through the FirstRand Foundation that manages the bank's corporate social investment projects, it supports a range of sectors, such as education. SU is one of the beneficiaries of such funding. The DU had built in a large contingency fund with the FirstRand Foundation to cover any unexpected expenses incurred by students with disabilities. This was invaluable as requests that arose during the pandemic were for extra tutoring in the online environment, extra data for tutors and students, and assistance with an internet package to enable academic work off campus. The funding provided by the FirstRand Foundation allowed us to provide a mentor who helped to support students during lockdown. To have a fellow student with a disability check in with a FirstRand-funded student was invaluable as students often felt isolated and confused during this time. Both the NSFAS and First National Bank were flexible about support during the pandemic.

The Michael and Susan Dell Foundation was an additional funder that enabled support in the online environment (SU, 2020c), and this funding was only procured during ERTLA.

\section{Course Workload Adaptations}

Many students reported an increase in workload during the off-campus and online work period. At times students became overwhelmed by the heavy workload and this added much stress to their already stressed lives. The University gave students a chance to deregister from study modules with no negative consequences during the first semester, and these modules could be resumed in the new academic year in 2021. This provided much relief to many students, although some were uncertain about this due to not knowing how long the pandemic would last. We provided academic counselling to a few students with disabilities who were at risk of deregistering entirely. In most cases, we managed to assist them with lightening their course load so that they did not deregister completely but rather staggered their course load by deregistering for some subjects and focusing on those that they could cope with. Some students with learning disabilities experienced increased anxiety, and they opted for this solution as well.

\section{Assistive Technology in the Online Environment}

The use of technology became increasingly universal for all students in the online environment (SU, 2020b). Support measures were put in place to assist students with online learning. Through long-time collaboration between the DU and HUMARGA (an SU computer user area for students in the humanities), specialist knowledge regarding assistive 
technology is shared and students are generally adequately supported in this way. Many students with disabilities were already acquainted with assistive technologies as an adjunct to the technology generally used by all students, such as computers, laptops, tablets and smartphones. Assistive technology commonly used for reading, assignments and assessments at SU includes JAWS, Zoom Text and Read \& Write (Lyner-Cleophas, 2019). Students are very grateful for this relatively easy access to assistive technology support. It provides invaluable academic support and allows for better access to academic material, in line with our policy of improving access to students with disabilities, which is not only physical but also regarding information.

About 49 students used the services of the Resource Office at the DU in 2020 where learning material is adapted. Staff here also source e-books. Despite the shift off campus, material could still be adapted, although the channel of distribution to the students shifted to OneDrive and Dropbox. Since the students had assistive technology available on their personal computers, they could continue to study independently. For example, a blind student studying theology is continuing his Biblical Hebrew studies with his tutor using Skype meetings and pre-recorded lectures. His learning material in Braille is made available in an electronic format that he can read on his electronic Braille display. He would not have been able to continue his Biblical Hebrew studies without this technology as it was impossible to produce hardcopy Braille material during lockdown.

Certain platforms such as SUNLearn, MS Teams and Zoom are a challenge to navigate with assistive technology such as screen readers and Braille displays. Some students needed extra training before they were able to take part in discussions, access learning material and complete assessments.

\section{Assessments in the Online Environment and Adaptations}

Students with disabilities in particular were anxious about how they would be able to link up to classes once the new term started in April 2020 and do their assessments, particularly in cases where they received scribes and extra time as support when on campus. Online quizzes were formative ways to assess students' knowledge in certain areas of work. Concerns were raised by students about being granted extra time for these quizzes.

For the most part, the online quizzes worked well and lecturers could make individual adaptations to students' quiz time. During the June 2020 examinations, all students were granted examination paper downloading time of mainly five minutes and uploading time of mainly thirty minutes after they had completed their papers. This allowed for any internet uploading and downloading difficulties that students might have experienced during the examination starting and completion process - universal extra time was allowed for the technological processes to be completed. However, there were lecturers who were not aware of this concession or forgot to provide extra time. Some lecturers also thought that the extra uploading and downloading time would be sufficient for those students with disabilities who already qualified for extra time. Such students, however, needed extra time additional to the extra uploading and downloading time granted to all. Where such 
uncertainties emerged, lecturers made the necessary allowances. Lecturers also had to learn how to adjust extra time for quizzes as this form of formative assessment was often used during ERTLA.

\section{Test and Examination Concessions: Background}

In line with the SU policy for inclusivity regarding assessments, we have a well-established process in place whereby students can apply for test and examination concessions depending on their specific disability. During ERTLA, the process to apply for concessions at SU shifted to a fully electronic system where applications for test and exam concessions were worked through on an MS Teams group and where applications could only be sent to skryftyd@sun.ac.za and the option to hand in a hardcopy was eliminated. Most buildings were closed with most staff members working online and off campus.

The Extra Writing Time Committee could not meet physically, but the members sent their comments via an electronic system to each other for approval. Once approved, the specific concessions were loaded onto the examination system. However, official letters could not be printed for students to collect at offices, due to their closure during this time. Confirmation of extra writing time letters were thus emailed to students and faculty support officers informed lecturers that the extra writing time and other concessions had been loaded onto the class lists. The practice of loading of the concessions that students are granted has been in place for a few years. An awareness already exists on the part of lecturers about specific concessions to students, and they ensure that the necessary support is put in place, such as enlarged test papers, extra writing time, writing in a separate venue and electronic question papers due to students' using screen readers to read the papers.

During level 3 lockdown, the Examinations Office officials received permission to go to the office to print the concession letters, sign them, and scan and email them to all students who needed these letters. Letters could not be sent via the postal services as these were delayed and students' addresses were not always accurate on the SU system. After the 2020 registration, most students did not receive their updated concession letters for the year. As the Covid-19 lockdown started on 26 March 2020 in South Africa, before most tests were written, students did not have their official SU letters, which caused high anxiety when online quizzes took place when the second term started. In the rush to leave campus, several students who had updated their letters for 2020 left their letters at their residences.

Numerous applications for concessions were received for the June examinations as students became anxious regarding the impact that ERTLA was having on their studies. Online assessments made students anxious too. If an assessment that stretched over a few days was given to students, extra time was normally not granted because it was not as time pressured as a one-, two- or three-hour assessment. Universal granting of extra time was practised by a few faculties as an accommodation measure during this time.

\section{Student Appointments in the Disability Unit}

Students would usually come to our offices physically to make an appointment. Some students might have been reluctant to make an appointment due to social stigma or other 
anxieties around being seen at the Centre for Student Counselling and Development where the DU is situated. Approaching a disability support facility could also be construed as stigmatising to some students. During ERTLA, students could make appointments for virtual sessions via email to a generic disability@sun.ac.za email address or contact us individually. We had updated information sent by SU regularly for students to access support services, and contact details were very clear. We had regular contact with new and existing (pre-Covid-19) students. Office phone numbers were diverted to staff members' cell phone numbers and Skype for Business. Many used MS Teams as well for calls. This provided a degree of anonymity and a less exposed way of engaging with staff about their disability. In the online space, nobody would see students walking to our offices and this brought a measure of comfort to hesitant students who see our services or their disability as stigmatised.

\section{The Disability Unit: Work-Life Balance}

One of the five values of the SUVision 2040 is compassion and respect for staff and students. Not only students but also the staff who supported them had to manage their workload and time in their home environments, which often had their own dynamics, especially when children were also not attending school and had to receive home schooling.

Staff members generally structured their day to ensure work-life balance. Flexibility and not being too hard on oneself were important for wellness and self-care. Setting small goals, taking regular breaks, practising self-discipline, doing reflection and obtaining spiritual nurturance while ensuring that national lockdown rules were observed were a challenge but kept staff members balanced and well. As for students, internet connectivity, suitable hardware and load shedding were realities that had to be dealt with.

\section{Conclusion and Learnings}

We learnt that being an effective student or worker does not restrict one to the confines of an office or a lecture hall. Flexibility emerged as a big driver for effective work and study and could be considered as an important factor in a post-Covid-19 environment given resource pressures and constraints and the holistic wellness of staff and students.

Once data and devices had been acquired or upgraded, staff could continue to function online. Students were engaged via email, WhatsApp, telephone, cell phone, Zoom and Microsoft Teams, in most instances.

A hybridised mode of working, learning and assessment is possible given our diversity. Universal extra time is possible and all students benefit from it for various reasons, and given their diverse learning needs. This has been inadvertently tested as students with specific disabilities who had difficulty with class attendance, have previously asked for recorded lectures or podcasts, and this was never deemed possible. Now we know that students can get access to lecture material in various ways. Our systemic and collaborative way of working with students with disabilities has been and will continue to be strengthened.

A new student management system, SUNStudent, is being developed and will enhance students' online presence and enable better access for all. This online system has been put to 
the test in many ways, including our test and examination concessions application processes, and will be incorporated into the student data management system.

Tele-counselling and tele-consulting constituted additional learning for us. We used all means possible to continue to reach our students. Many students already use email as their main means of communication. This was strengthened during ERTLA.

\section{In Future}

While most of what could be implemented is sustainable, we will need to think about aspects that are not, such as the data that was accessible to students during the pandemic. While it might not be possible to continue to provide data for off-campus classes, the hybrid way of working can ensure that students can access good bandwidth through their computer user areas, as done prior to the onset of the pandemic. Recorded classes or podcasts can be downloaded when on campus and be viewed data-free when at home, where there are bandwidth and data challenges.

We were afforded a chance to expand our means of communicating with our students, and in so doing reaching more students. In certain cases, students are more comfortable communicating via digital communication due to the stigma of disability and wanting to be less visible. We also became more aware of the protection of personal information in the online environment, regarding academic support and counselling sessions and students expressing their difficulties. The Protection of Personal Information Act (POPIA) will come into force in July 2021. We will need to ensure that information that should be protected is indeed protected in the increasingly digital environment and broaden access to students using our services through securing privacy for those who prefer this means of communication with our services in student affairs.

We will continue to work in a hybrid fashion with less staff presence in the office and more staff working from home. Our students will still be served effectively in a hybrid way of support, and we will meet with those whom we need to either virtually or face to face in the office and depending on their preferences for privacy. Ongoing reflection on the hybrid way of working will take place during the coming months and years.

Assistive technology and accessible information are two crucial elements that we have seen enhance student engagement with our services as well as teaching, learning and assessment. We need to ensure that no students are excluded from support services due to not having this access in place. We will continue to liaise with funding partners like we have been over many years and prior to the establishment of the DU in 2007, to continue to assist students with appropriate and updated technologies.

Ongoing collaboration with stakeholders on campus, but especially the private sector, is important in the digital educational environment. Assistive technologies (software and hardware) and access to data are strong enablers for the success of our students and how we render services. We will continue to strengthen this as we build and expand our support services. 


\section{Acknowledgements}

To all the students who mostly did well in adjusting to the online teaching and learning environment despite their specific learning needs, we are proud of you. To the staff who worked tirelessly and unselfishly and showed great flexibility to ensure that students were fully supported with their online teaching, learning, accessible texts and assessment needs. Well done! We are grateful to our partner HUMARGA who advised students on suitable assistive technologies. Our student assistant's input as a mentor and millennial is immeasurable.

\section{Research Ethics}

This is a reflective piece of writing, and all reflections are those of the relevant staff members from the DU. No ethics approval was needed for this reflection on Covid-19 and support for students with disabilities from the vantage point of the DU at SU.

\section{Conflict of Interest}

No conflict of interest arose in the writing of this reflective piece as the authentic voices of staff members and their experiences emerged.

\section{Funding}

No funding was sought for this reflective piece of writing.

\section{Disclaimer}

The views expressed in this article reflect the experiences of staff members working at the DU at SU.

\section{References}

Gibbs, G. (1988). Learning by doing, a guide to teaching and learning methods. https://www.brookes.ac.uk/ ocsld/

Lyner-Cleophas, M.M. (2019). Assistive technology enables inclusion in higher education - the role of Higher and Further Education Disability Services Association (HEDSA). African Journal on Disability, 8. https://doi.org/10.4102/ajod.v8i0.558

Lyner-Cleophas, M.M. (2020). Online teaching should also consider students with disabilities. http://www.sun. ac.za/english/Lists/news/DispForm.aspx?ID=7441

Ngubane-Mokiwa, S., Mutanga, O. \& Bothwell, M. (2018). South Africa's new higher education disability policy is important, but flawed. https://www.researchgate.net/publication/329247845_South_Africa\%27s_ new_higher_education

Oliver, M. (2009). Understanding disability. From theory to practice. Palgrave MacMillan. https://doi.org/ 10.1007/978-1-137-05492-0

SU (Stellenbosch University) (2018a). Vision 2040 and strategic framework 2019-2024. https://www.sun. ac.za/english/Documents/Strategic_docs/2018/Vision-2040-Strategic-Framework-2019-2024.pdf

SU (2018b). Disability access policy. https://www.sun.ac.za/english/policy/Policy\%20Documents/Disability \%20Access\%20Policy\%201\%20April\%202018.pdf 
SU (2020a). The role of the Institutional Committee for Business Continuity in COVID-19 pandemic. http://www. sun.ac.za/english/Documents/Institutional\%20Committee\%20for\%20Business\%20Continuity.pdf

SU (2020b). Online learning and teaching support for students. http://www.sun.ac.za/english/online-teachingsupport-students

SU (2020c). SU strengthens academic and psychosocial support for students. https://www.sun.ac.za/english/Lists/ news/DispForm.aspx?ID=7594

SU (2020d). Extra writing time report to the Registrar 2020. Unpublished report.

UN (United Nations) (2020). Policy brief: Education during COVID-19 and beyond. https://www.un.org/ development/desa/dspd/wpcontent/uploads/sites/22/2020/08/sg_policy_brief_covid-19_and_ education_august_2020.pdf

Watermeyer, B. \& Swartz, L. (2008). Conceptualising the psycho-emotional aspects of disability and impairment: The distortion of personal and psychic boundaries. Disability \& Society, 23(6), 599-610. https://doi.org/10.1080/09687590802328477

WHO (World Health Organization (2002). Towards a common language for functioning, disability and health. https://www.who.int/classifications/icf/icfbeginnersguide.pdf?ua=1

Widnall, E. (2020). School closures had positive effects on some teenagers' mental health, our new research suggests. https://theconversation.com/school-closures-had-positive-effects-on-some-teenagers-mentalhealth-our-new-research-suggests-144884

\section{How to cite:}

Lyner-Cleophas, M., Apollis, L., Erasmus, I., Willems, M., Poole, L., Minnaar, M. \& Louw, P. (2021). Disability Unit Practitioners at Stellenbosch University: Covid-19 Pandemic Reflections. Journal of Student Affairs in Africa, 9(1), 223-234. DOI: 10.24085/jsaa.v9i1.1440 


\section{ON CAMPUS}

\section{Reflections on the South African Higher Education Leadership and Management (HELM) First Virtual Summit, 9-11 December 2020: Leadership for a Sustainable and Resilient Higher Education System in an Age of Complexity and Change}

Bernadette J. Johnson ${ }^{\mathrm{i}}$

\section{What is the Purpose of Universities and Higher Education Institutions?}

2020 presented a moment to step back and to think: What just happened? What are we doing? Who are we? Moments of crisis create the opportunity for such reflection. So, for higher education it is: What is our role, what are our purposes?

The pandemic brought home the point that we are vulnerable, we are fragile, we go through trauma and we do not have control all the time, we cannot plan for every eventuality. It is a humbling and a core disruptive experience. It drove home powerfully the idea that we must stick together, we must help one another, we must build our community, and we are not separate from nor above society and humanity. We must anchor ourselves in society and serve society. We have the opportunity to be the beacon of hope for society.

This requires the university to be what society should be. Universities cannot call for inclusion, non-racisms and an end to gender-based violence and then not be sites of what inclusion and safety should look like. The pandemic reality amplified our fractured nature of society. All existing problems of gender based violence, of inequality and poverty worsened and are now perhaps forms of pandemics within the health pandemic. The university needs to be an anchor for society. What are the limits and possibilities of the university being anchored? What can we take responsibility for and what can we not take responsibility for? In which ways are universities an instrument of convergence for society?

If the past and present are not understood how can we project into the future? Unprecedented events have taken place in addition to the pandemic. \#FeesMustFall showed disconnect between university leadership and the university's relation to society. How do we strengthen our connections? What are the possibilities and limits of a university that engages with its society?

Do we understand the political economy of public universities and higher education? The nature of society is changing with the emergence of datarism. How should we respond to these new societal pressures and its focus on technology and data without losing sight of inequality and other societal fractures and contributing to new forms of inequality and fracture?

i Dr Bernadette Judith Johnson is Director: Transformation and Employment Equity at the University of the Witwatersrand, South Africa. Email: bernadette.johnson@wits.ac.za 
Universities have different strengths. We need to think more about what different universities are good for and good at. How do we ensure our sustainability? What kind of leadership is needed? Leadership needs to include thinking about humility, distributed leadership, trust and open mindedness recognising our fragility and the need to know how to work with uncertainty and adaptability. Leadership needs to contribute to healing the fractures in society.

There is a need to have a shared understanding within the sector of resilience, sustainability and what the purpose of the university is. It is no longer adequate that we have different understandings of transformation. What do we mean by transformation? We must give consideration to what has changed in the structure and what changes in the conjunctures. A supportive political economy is needed for transformation across the sector. We cannot anchor the university if municipalities, for example, are falling apart in the local contexts.

The pandemic context has introduced a new language of social distancing and online or digital learning. This too is related to transformation. What is our common understanding? If we do not develop a shared understanding of the role of the university, transformation and decolonisation, we will not know what we must be resilient and sustainable for and therefore we will remain turbulent, fragile, conflict ridden and socially divided. If we do not develop a common understanding, a social contract, how will we know we are transforming?

In setting out the role of the university we need to get clearer on which parts of the university needs competition, which parts need to be protected from competition, and which sections need to be enhanced in relation to collaboration and collective action. How do we balance competition, cooperation, and planning and university autonomy as we build a new social compact? Should we continue to engage and support rankings, for example? What would a social compact look like? We also need to recognise what South Africa has done differently and better, and what in fact the rest of the world can learn from South Africa. The challenges we have now emerge as a consequence of the transformation that has taken place. We have more black students and more black staff in universities. We struggle with institutional culture change and we struggle with black representation in management.

In thinking about our role, we need to pay attention to what we may not be seeing and what we are not talking about enough. What about the commoditisation of private data, the rise of data capitalism and how it is creating a future world. What is the relationship with industry? What is the relationship with private higher education? Our processes of accreditation of new courses take three to four years and by then their relevance is cold. The intensive complexity and concentration of power in technology such as the iPhone (as an example) means that humans are playing catch up. We cannot simply extrapolate from the past in a world that is non-linear and profoundly complex.

We need to consider the role of the university in relation to post-schooling. Universities now see and live the need for greater collaboration. What the university does for society is what it must do for itself. Technology as platforms for interaction is critical and is not a panacea. 
Arriving at a social compact requires a broader social compact in society. How do we arrive at a social compact? In being more online, will all universities become like Unisa? What is the place of blended learning and hybrid models? The same infrastructure will not be needed. Classrooms will look different. The pandemic has opened up the possibility and urgency of different ways of doing teaching and learning and research. It does not only entail acquiring the right technological infrastructures and skills by both staff and students, but it requires beyond emergency online learning and teaching what a digital learning environment looks like. How do staff experience it? How do students experience it? How does this take their needs into account to support a mind shift and mental health embedded in empathy and compassion for the problems people run into and will run into? Campuses must be experienced as caring environments that encourages giving back for life.

How can resources in relation to information, capacity and delivery be shared and re-imagined in a collaborative way both in relation to the digital learning environment and in relation to the programme qualification mix? Significant cost savings will be made and new creative platforms for collaboration and innovation created. In doing so, it will be important to develop a common language of truth so that communication creates a sense of security and shared understanding in complex disruptive contexts.

The conundrum we face is our need for the human connection and how we give space for that within the mix of contact and online engagements. What are the implications for pedagogies as well as the practical learning and assimilations that can be conducted online? The survivalist context has been challenging for staff and students. Staff miss interacting with their students and having human interaction. Online has presented the opportunity for great access by disabled students and a different experience of internationalisation of courses and programmes as well as work and learning experiences.

Retaining empathy, awareness and sensitivity will be important in ensuring that everyone is understanding and participating in the mind set change in ways that keep students at the centre, allow for retention and service back to the university as citizens and alumni. The pandemic raises the need for us to prepare the university for disruptions, agility and flexibility as there will be new future disruptions brought about by, for example, climate change. Vaccination may lead to people pushing for a return to what they regard as normal and familiar, the university as a physical location, and reverse the opportunity for the creation of new flexible, agile and resilient systems. How are we constrained by our imagination of what might be possible? At the same time, what might be lost with reduced physical human interaction? How then do we bounce forward?

What will make universities different? A re-think of the future of higher education is needed perhaps in the same ways in which it was required in 1995 with the National Commission of Higher Education (NCHE). What has worked? What has not worked? Given the new realities the funding model must change. It has not been relevant and remains irrelevant. Should a new Size and Shape for the sector be considered? For example, our cooperative governance structures are not necessarily what we need. What new structures do we need to address our needs? How are we strengthening transdisciplinary research and programmes to address knowledge problems? What is the impact of the university on society? How are we getting the input from industry and civil society to 
advice on our PQM? Which programmes can be shared across institutions and which kept and which dropped? Costing of programmes needs to be enhanced across the system. What can universities focus on in their local context? Critical to focus on is what the system funds, how it funds it, what it teaches and how it teaches. What this means for higher education must be aligned to the importance of Early Childhood Development and the financial sustainability of education as a whole. The funding formula and planning has to be informed by the sustainability of a system which is relevant. We need to take stock deeply of where we are. We need to create more opportunities to research and converse on the future of the system.

The opportunity to step back and rethink requires a leadership who is imaginative and keeps being imaginative. A leadership who continuously reflects on: re-thinking; re-imagination; and re-positioning. A leadership who embraces and engages the need for change and sees the need for a community of practice that continuously engages in processes of re-consideration.

\section{Emerging actions:}

- Research and round table conversation on the political economy of higher education and the implications for university leadership

- Future conference on the social anchoring of the university in society - what would it look like?

- Research on what has changed, is different and the rest of the world can learn from in higher education in South Africa.

- How do we go about developing a social contract which takes into account its societal embeddedness?

\section{Programmatic input into leadership development:}

- What might the future purposes and roles of higher education institutions be?

- What kind of higher education leadership is needed for the anchoring of universities in society?

\section{How to cite:}

Johnson, B.J. (2021). Reflections on the South African Higher Education Leadership and Management (HELM) First Virtual Summit, 9-11 December 2020: Leadership for a Sustainable and Resilient Higher Education System in an Age of Complexity and Change. Journal of Student Affairs in Africa, 9(1), 235-238. DOI: 10.24085/jsaa.v9i1.1442 
BOOK REVIEW

\title{
Learning Online: The Student Experience by George Veletsianos (2020). Baltimore, Maryland: Johns Hopkins University Press.
}

\author{
Reviewed by Tadd Kruse ${ }^{i}$
}

Technology continues to change the way in which we work, the way we socialise, and the way we learn under the expectation of a greater overall quality of life. Given the events of 2020 and especially the effects of the pandemic, our dependency on technology in higher education intensified. Many institutions pivoted from traditional learning settings to non-face-to-face instructional delivery methods largely facilitated through online learning mediums. In this book released in May 2020, George Veletsianos addresses the perceptions and reality of online learning settings across a myriad of perspectives and issues.

The book was written prior to the pandemic offering an in-depth look into the world of online education during a more normal period. Millions of students worldwide had engaged in online learning opportunities, and over the last 12 months those numbers have increased exponentially, making this timely and highly relevant for all tertiary educators. The author explores early on the value of online learning in comparison to face-to-face settings:

... the larger issue behind this debate is what conditions make for a high-quality educational experience, one that is effective, efficient, engaging, socially just, and meaningful and isn't exploitive, unfair or available only to those who can afford it ... ultimately, the value of an online course or degree rests upon its design and the strategies it employs rather than its modality. (p.18)

Online learning is ripe with critics questioning the authenticity, value, and credibility of this medium, and in this book Veletsianos argues that we must examine the learning experience through the lens of the student to fully appreciate this space.

Veletsianos addresses the intricacies of online learning from a student or learner experience vantage point, acknowledging the multiple roles or identities facing the modern student. The author is the Canada Research Chair in Innovative Learning and Technology and a professor in the School of Education and Technology at the Royal Roads University, a Canadian public university with its main campus in Colwood, British Columbia. George Veletsianos has published numerous journal articles and is also the author of the book Social Media in Academia: Networked Scholars.

i Dr Tadd Kruse is an Education Consultant, Membership Director for the International Association of Student Affairs and Services (IASAS) and a member of NASPA's (Student Affairs Administrators in Higher Education) Global Division and Middle East, North Africa and South Asia (MENASA) Advisory Boards. ORCid: 0000-0001-9916-9444. Email: taddkruse@gmail.com 
The text examines across 17 chapters the complicated realm of online learning, discusses the benefits and challenges within higher education settings, and suggests spaces to enhance effectiveness. Each in-depth chapter addresses online learning components ranging from effectiveness of the medium (student performance, attrition, growth of online learning, demographics, cheating, credibility), reasons students select online learning (flexibility, wider access, self-directed learning, massive open online courses or MOOCs), and interaction/performance factors (digital literacy, social support, social media, notetaking, motivation and socio-emotional factors). Throughout, Veletsianos highlights the intricacies of online learning and the need to overcome the disparities between learners, better known as the digital divide, all in a physically distant space.

The conciseness and organisation of the book, specifically the structure of the chapters, is one of the books greatest strengths. The chapter structures frame each topic via a concise and structured format first by introducing a story about single-student "learner" representing different characteristics or applied strategies in online learning, followed by a narrative digging deeper into the contributing factors. Each chapter is supported with relevant research and recognises limitations in existing research or data to propel the narrative. The referenced research in the field of online learning grounds the issues presented and provides resources for further research and consideration for educators. Finally, a summation of the perspectives are succinctly posed for consideration before closing with bulleted key points and a list of references. This concise and direct format allows educators to examine a single dimension of online learning within an empathetic real world student experience.

One area, and likely the only one, that lacks clarity throughout the book is the chapter titles. Each chapter is titled as "The Learner Who..." and presents as a listing of actions or student traits including nontraditional, self-directed, dropout, cheater, social networking user, and benefits from flexible learning. The chapter titles often allude to the topic, but are often vague so that, when flipping through the pages or looking over the table of contents, some targeted areas are not apparent without reviewing one's notes or scanning the bulleted items at the end of each chapter. More clear chapter titles would better serve educators as they consider this as a resource for the future, but may have detracted from the storybook approach to each chapter and the initial read - a small concession for a concise read that draws in the reader to the lived online learning student experience, the primary premise of the book.

Often when one hears of online learning, thoughts are immediately directed to a few characteristics of this educational capacity such as access, flexibility, or credibility issues. These immediate considerations fail to consider the multiple factors which (a) determine a student's reasons for selecting online learning options, and (b) influence the learning experience during one's educational journey. Learning Online: The Student Experience explores many of the issues confronting twenty-first century higher education and concisely presents major influences across the broad spectrum of online learning.

This book is an excellent resource for faculty and administrators to gain a broad understanding of the challenges and successes of online learning. Veletsianos, through his relaying 
of online learner experiences, presents the need for more intentional and integrated practices to make this medium more effective, mirroring steps often taken on campus to ensure greater student retention towards degree completion. Online learning presents in a multitude of forms, meeting a diverse range of needs for people around the world. The medium as a whole makes a significant contribution to society and higher education institutions. This book provides educators, regardless of geographic location, the scope to understand the complexities facing digital learning and at a timely point in history.

\section{How to cite:}

Kruse, T. (2021). Review on Learning Online: The Student Experience by George Veletsianos (2020). Baltimore, Maryland: Johns Hopkins University Press. Journal of Student Affairs in Africa, 9(1), 239-241. DOI: 10.24085/jsaa.v9i1.1443 
BOOK REVIEW

\title{
Transforming Higher Education in Africa and Asia: Strategic Planning and Policy by Fred M. Hayward (2020). Albany, New York: SUNY Press.
}

\author{
Reviewed by Patrick Swanzyi
}

In his career as a specialist in higher education, Fred Hayward has authored many scientific papers in the field. However, none is more insightful as Transforming Higher Education in Africa and Asia: Strategic Planning and Policy. Unlike other authors who shy away from writing about issues of the developing and the underdeveloped world, he resists the temptation and offer a thought-provoking discussion on strategic planning in higher education in these contexts. Backed with data from higher education systems in countries such as Afghanistan and Pakistan in Asia and Ghana, South Africa, Sierra Leone, Madagascar, Uganda and Malawi, he explores efforts to improve lives by building high-quality higher education in these countries as they face a variety of difficult challenges. The author interestingly notes that responses to these challenges, be it from political figures or institutional leaders, are often creative, sometimes exceptional, and frequently suggestive of mechanisms higher education stakeholders might find helpful. He further demonstrates with some cases why strategic planning is so important for successful higher education change and transformation. He notes that, while each of these cases is unique, there are some general lessons they suggest about both the successes and challenges for higher education change.

What is intriguing about this book is that the author unpacks strategic planning in higher education in fourteen comprehensive chapters. The book's first chapter focuses on the critical role high-quality higher education plays in national development. The author cautions that failure to focus on improving the quality of higher education puts underdeveloped and developing countries farther and farther behind the developed nations of the world year after year. He then prescribes strategic planning as one of the powerful routes to transformation and to ensure that change is tied to providing high-quality programmes that are relevant to employment or foster entrepreneurship by graduates.

In chapter two, the author discusses prelude to planning in higher education and details the overview of the case studies. Citing Bloom et al., 2011, he recounts that the 1960s and 1970s saw a period of neglect and often decay in much of Africa and parts of South Asia with the GDP largely stagnant in South Asia during this period, then falling after that. He concludes that this resulted in most of Africa and much of South Asia suffering from economic and political crises, having a profound effect on the well-being of citizens and funding for higher education.

i Dr Patrick Swanzy is a Lecturer at the Department of Teacher Education, Faculty of Educational Studies, Kwame Nkrumah University of Science and Technology, Kumasi, Ghana. ORCid: 0000-0001-6201-7703. Email: patrick_swanzy@yahoo.com 
The author focuses on Pakistan in chapter three. He diagnoses the impetus for the transformation of higher education as emerging from a number of factors, including being way behind in quality compared to India. The author asserts that the plans for the change were captured in the Medium Term Development Framework, and had four main goals: increased access; improved quality; infrastructure upgrading; and a focus on relevance. He praises the budget-making process in Pakistan as a good model of what should be done in conjunction with planning major changes in higher education, but sadly expresses that, with President Musharraf no longer in office, the plan suffered a major setback.

In chapter four, the writer shifts his attention to Afghanistan by suggesting that the motivation for the strategic plan was the general recognition of the disastrous state of higher education due to the war. He notes that Deputy Minister Babury began thinking about the strategic plan and involved other major stakeholders of education. He mentions that even though there were initial challenges, the plan was a remarkably successful effort, resulting in transformation of the system in major ways. The author concludes by inferring that the Afghanistan case demonstrates that fundamental change is possible even in a war environment.

In chapters five and six, the author argues that no country has sought to make as extensive a range of transformational changes in higher education as South Africa has. He proffers that at the forefront of demands for change was outrage over apartheid education policy, which had restricted access to education for black students. He demonstrates with examples from national and the University of Fort Hare, University of the North, and Peninsula Technikon, that though the plan faced initial challenges, the consultation process that led to the changes was amongst the most remarkable experienced anywhere.

The author mentions in chapter seven that Sierra Leone's higher education change efforts started out with a thoughtful plan and modest budget put together by a team from the Midwestern Universities Consortium and higher education leaders of the country with the support of President Momoh. He claims the plan had a well-prepared budget, with each item in the plan costed. The author sadly mentions that a coup d'état ended the government of President Momoh that had initiated the higher education rehabilitation and development effort. He concludes that this situation has negatively impacted the country's higher education system that has since struggled to recover.

Chapter eight is headed 'Fostering higher education change in Uganda'. The author notes that the Uganda Strategic Plan for Higher Education 2003-2015 had five main goals: enhancing quality and relevance; increasing equity and access; achieving efficiency and effectiveness; improving governance; and preventing HIV/AIDS. Well spelt out key performance indicators allow key stakeholders to measure implementation success. Though this suggested hope, the author laments that there was no unanimity about the funding strategies within the higher education community and left the sought changes largely unrealised.

In chapter nine, the author discusses the higher education change efforts in Madagascar. As noted in the previous chapters, political figures are crucial in facilitating strategic plans. In the case of Madagascar, the strategic planning process was initiated by Minister Haja Nirina Razafinjatovo. The author reveals that the process started in 2005 , but was plagued by 
several challenges. The chapter portrays that Madagascar's higher education began to revive in 2006 after a long neglect, however, this was short lived as the country experienced a coup. The author concludes that the proper functioning of an education system is dependent on many factors, but that political stability is key amongst them.

The book's chapter ten focuses on building transformational change at the University for Development Studies in Ghana. The author notes that the leaders of the university started an agenda for major change through their strategic plan underpinned by a "pro-poor" philosophy. He concludes that what is noteworthy in terms of fostering change was the success of people at the university in mobilising the local communities in a new kind of partnership that helped link rural Ghana to higher education in important ways that enhanced the education process.

The eleventh chapter of the book discusses the University of Malawi's (UNIMA) coalition and team building for effective change. The author asserts that coalition and team building are essential for successful strategic planning, either prior to starting the strategic planning project or at the very outset to ensure there is broad consensus on the goals for change, the process, priorities, and implementation. The author acknowledges that the successful changes that took place at UNIMA were in many respects a product of exceptional leadership.

Chapter twelve presents strategic planning challenges at Kabul Polytechnic University (KPU) which has suffered substantial war damage following the Russian invasion and Taliban rule. The author emphasises that the objectives of the KPU strategic plan are: to build up the capacity of faculty members; to improve the quality of teaching and learning; and to increase opportunities to promote science based on the recent developments in science and technology. He concluded the chapter by advising that the introduction of a strategic plan written in a captivating style is very important and has the potential to attract funding.

In chapters thirteen and fourteen, the author discusses leadership and transformational change in developing countries. The author notes that the examined higher education transformation cases involve a wide range of leadership experiences, in some cases as the initiators of change, as the facilitators of strategic plans, the actual planners, the mobilisers of support, or as the implementers. The author points out that in a few cases such as Pakistan and Ghana successful change was the result of the work of a few leaders, while in most cases it was a collective effort at many levels and involved broad mobilisation of people in support of the strategic plan within the university and/or higher education community such as Malawi. The author acknowledges that successful leaders' strategies geared towards change are either conscious or unconscious.

Fred Hayward's book is a masterpiece and a groundbreaking contribution to strategic planning in higher education and will be valuable to stakeholders of higher education.

\section{How to cite:}

Swanzy, P. (2021). Review on Transforming Higher Education in Africa and Asia: Strategic Planning and Policy by Fred M. Hayward (2020). Albany, New York: SUNY Press. Journal of Student Affairs in Africa, 9(1), 243-245. DOI: 10.24085/jsaa.v9i1.1444 


\section{Thank you to our reviewers}

The $J S A A$ Editorial Executive wishes to thank the peer reviewers of Volume 8 of the Journal of Student Affairs in Africa for their time and expertise in evaluating and helping to select and improve the submissions received:

Chrissie Boughey

Graham Dampier

Liezl Dick

Nupur Goyal

Johan Groenewald

Mlamuli Hlatshwayo

Marcia Lyner-Cleophas

Matete Madiba

Alude Mahali

Livingstone Makondo

Martin Mandew

Sioux McKenna

Emmanuel Mgqwashu

Thandeka Mkhize

Keamogetse Morwe

Thabi Mtombeni

Ibrahim Oanda

Vianna Renaud

Robert Shea

Christopher Stipeck

Rupert Taylor

Pierre Viviers 


\section{Publications by AFRICAN SUN MeDIA}

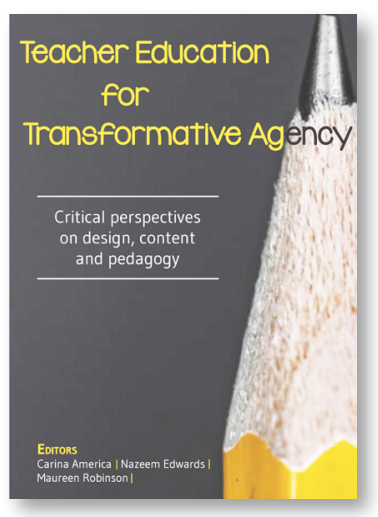

Teacher Education for Transformative Agency: Critical perspectives on design, content and pedagogy by Carina America, Nazeem Edwards \& Maureen Robinson (Eds.) (2020)

Many teacher education programmes globally are undergoing significant changes in response to government policy, imperatives driven by global competitiveness, as well as local conditions. In the South African context, teacher education seeks to address the developmental needs of the majority of its citizens. This book records and explores efforts by academic staff members in the Faculty of Education at Stellenbosch University, seeking to present a coherent programme in the Postgraduate Certificate in Education. It examines how curriculum design unfolds across disciplines in the programme, and crucially, the commonalities in the presentation of course material. Lecturers examine the purpose, structure and content of their teaching as they engage with putting democratic policy goals into practice in the core as well as subject-specific modules of the programme.

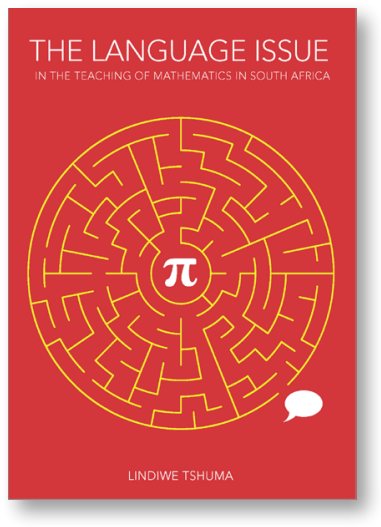

The Language Issue in the Teaching of Mathematics in South Africa: Intermediate Phase research from one province by Lindiwe Tshuma (2020)

This book is a platform for further dialogue towards better serving learners in under-resourced multilingual settings. Material is specifically intended for specialist Intermediate Phase Mathematics lecturers tasked to educate mathematics teachers who must deliver content in English or through translanguaging/code switching/code mixing. It has a clear and straightforward writing style that pre- and in-service teachers will find extremely useful. It includes practical cases that should be helpful in illustrating applicable learning points as support for academics. The book draws on a broad international perspective and at the same time refers to examples from the Eastern Cape, one of the South African provinces. The book highlights language and mathematics as pivotal parts of one whole.

AFRICAN SUN MeDIA is an integrated content manager and specialist supplier of publishing and printing services for the higher education market and the private sector. We publish under the imprints SUN PReSS, SUN MeDIA, SUN OA (Open Access) and SUNLiT. Most of our publications are available in electronic and print formats at: 


\section{Submissions}

Please register as an author and read the Author Guidelines at https://upjournals.up.ac.za/index. php/jsaa. Submissions must be made on the online system at https://upjournals.up.ac.za/index.php/ jsaa. For information and help, please contact the Journal Manager, Ms Maretha Joyce, at mjoyce@ sun.ac.za.

The JSAA typically has themed issues. However, submissions that fall within the general scope and focus of the Journal can be made at any time and may be published irrespective of the overall theme of the Journal. Particularly encouraged are open-theme manuscripts that address the following:

- Case studies of innovative practices in student affairs in the context of African higher education (e.g. student lifecycle, orientation, residence management, student governance, student counselling).

- High-level reflective practitioner accounts.

- Explorations of the nexus of student affairs theory, policy and practice in the African context and beyond.

- Conceptual discussions of student development, and key enablers and inhibitors of student development in Africa.

- Explorations of authoritative literature, theory and professional trends related to student affairs in Africa.

Please note that there are different requirements for different types of manuscripts:

- Research articles: Contributors are encouraged to submit research-based manuscripts. Research articles must include an extensive consideration of recent literature and relevant theory. Researchbased articles must be original and research-based and must make a significant conceptual (or empirical or normative) contribution relevant to the scope and focus of the JSAA.The length must be approximately 5000 words, including all references, notes, tables and figures. Manuscripts should be accompanied by an abstract of approximately 150-300 words.

- Reflective practitioner accounts: High-quality reports on professional campus practice are screened and reviewed according to the same criteria as for research articles, albeit with a different emphasis. Unlike a research article, they do not need to include an extensive consideration of recent literature and theory, but they must nonetheless comply with standard academic convention and scholarly practice. Reflective practitioner articles must be original, must make a significant empirical contribution, and must significantly enhance our understanding of student affairs practice within their respective scope and focus. Typical length should be 2500-5000 words. Manuscripts should be accompanied by an abstract of approximately 150-300 words.

- Book reviews should be between 800 and 1000 words in length. Competent reviews of key student affairs books are published at the discretion of the Editorial Executive.

- Comments and critique, of no more than 2500 words, are also welcome.

- Proposal for the Journal's Dialogue/Interview section and Calls and Notices should be emailed directly to the Journal Manager. The publication of calls and notices (for conferences, vacancies, etc.) may incur a nominal fee.

Authors are required to check their submission's compliance with all of the following items, and submissions that do not adhere to these guidelines may be returned to authors.

1. The ethical requirements of social research have been considered and fully complied with.

2. The submission has not been previously published, nor is it before another journal for consideration (or an explanation has been provided in Comments to the Editor).

3. The submission file is in MS Word, OpenOffice, or RTF document file format.

4. The text is double-spaced; uses a 12-point font; employs italics rather than underlining (except with URL addresses); and all illustrations, figures and tables are placed within the text at the appropriate points, rather than at the end.

5. The text adheres to the stylistic and bibliographic requirements outlined on the Journal's website.

6. The Journal uses the APA author-date referencing system.

7. If submitting to a peer-reviewed section of the Journal, i.e. as a research article or reflective practioner account, the instructions in Ensuring a Blind Peer Review must have been followed.

8. If submitting a proposal for the Dialogue section, a Call/Notice, or a Comment/Critique, this should be emailed directly to the Journal Manager. 
9. The final text of the article has been professionally edited and proofread prior to submission.

10. The front page of the manuscript indicates the Section under which it is proposed that the article be published, i.e. Research Article (peer-reviewed); Reflective Practice (peer-reviewed); or Book Reviews/Dialogues/other contributions.

11. Permission to reproduce any copyrighted material has been obtained and can be produced should this be requested by the Editorial Excecutive.

\section{Section review policy and process}

The $J S A A$ publishes research articles (peer-reviewed); high-quality reflective practitioner accounts (peer-reviewed); dialogues/interviews (non-reviewed); and book reviews (non-reviewed). The Journal is committed to assisting emerging scholars and professionals in developing promising manuscripts to the point of publication.

\begin{tabular}{|c|c|c|}
\hline \multicolumn{3}{|l|}{ Editorial commentary } \\
\hline$\square$ Open submissions & $\square$ Indexed & $\square$ Peer reviewed \\
\hline \multicolumn{3}{|c|}{ Research articles and professional practitioner accounts } \\
\hline$\square$ Open submissions & $\nabla$ Indexed & $\square$ Peer reviewed \\
\hline \multicolumn{3}{|c|}{ Campus dialogue/interview section } \\
\hline$\square$ Open submissions & $\square$ Indexed & $\square$ Peer reviewed \\
\hline \multicolumn{3}{|l|}{ Book reviews } \\
\hline$\square$ Open submissions & $\square$ Indexed & $\square$ Peer reviewe \\
\hline
\end{tabular}

The editorial and peer-review policy adheres to the ASSAf National Code of Best Practice in Editorial Discretion and Peer Review for South African Scholarly Journals (ASSAf Council, 2008). All submitted manuscripts undergo an initial careful examination by the Editorial Executive to ensure that authors' submissions fall within the mission, scope and focus of the JSAA and conform to scholarly best practice. Qualifying scholarly research-based articles and high-quality, relevant reflective practitioner accounts are blind-reviewed by at least two peer reviewers, who would typically be members of the International Editorial Advisory Board of the JSAA. Peer reviewers have proven scholarly and/ or professional expertise in the subject matter of a manuscript. Reviewer reports are assessed by a member of the Editorial Executive and form the basis of any decision by the Editorial Executive on how to proceed with a manuscript. The suitability of a manuscript is evaluated in terms of originality, significance, scholarship and adherence to the requirements of ethical social research, scope and interest, and accessibility.

\section{Publishing and dissemination policies}

\section{Cost of publishing}

There are no processing fees or page fees. No costs accrue to authors of articles accepted for publication.

\section{Licensing notice}

Authors who publish with this Journal agree to the following terms:

Authors retain copyright and grant the Journal right of first publication with the work simultaneously licensed under a Creative Commons Attribution License that allows others to share the work with an acknowledgement of the work's authorship and initial publication in this Journal.

Authors are able to enter into separate, additional contractual arrangements for the non-exclusive distribution of the Journal's published version of the work (e.g. post it to an institutional repository or publish it in a book), with an acknowledgement of its initial publication in this Journal.

Authors are permitted and encouraged to post their work online (e.g. in online research repositories or on their website), as it can lead to productive exchanges, as well as earlier and greater citation of published work.

Open access policy

This Journal provides open access to its e-journal content. Free copies can be downloaded from the Journal website at https://upjournals.up.ac.za/index.php/jsaa and at http://www.jsaa.ac.za, and from co-hosting sites e.g. http://ajol.info. Authors are encouraged to place copies of their final articles in their institution's research repository. 
Print copies/subscription

- Online subscriptions to the e-journal are free of charge. Please register at https://upjournals. up.ac.za/index.php/jsaa.

- Printed copies of past issues of the Journal (Vol. 1 to Vol. 4(1)) can be ordered from the following online bookstores: African Books Collective http://www.africanbookscollective.com/; Amazon Books http://www.amazon.com or directly from African Minds http://www.africanminds.co.za.

- Printed copies from Vol. 4(2) and following can be ordered directly from African Sun Media at orders@africansunmedia.co.za. 